Sergio Damas · Oscar Cordón Oscar Ibáñez

Handbook on

Craniofacial

Superimposition

The MEPROCS Project 
Handbook on Craniofacial Superimposition 
Sergio Damas • Oscar Cordón • Oscar Ibáñez

\section{Handbook on Craniofacial Superimposition}

The MEPROCS Project 
Sergio Damas

Edificio de Investigación

European Centre for Soft Computing

Mieres, Asturias, Spain

Oscar Ibáñez

Department of Computer Science \&

Artificial Intelligence (DECSAI)

University of Granada

Granada, Spain

\author{
Oscar Cordón \\ Edificio de Investigación \\ European Centre for Soft Computing \\ Mieres, Asturias, Spain
}

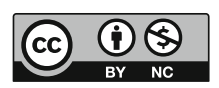

ISBN 978-3-319-11136-0

ISBN 978-3-319-11137-7 (eBook)

https://doi.org/10.1007/978-3-319-11137-7

Library of Congress Control Number: 2018953787

(C) The Editor(s) (if applicable) and the Author(s) 2020. This book is an open access publication.

Open Access This book is licensed under the terms of the Creative Commons AttributionNonCommercial 2.5 International License (http://creativecommons.org/licenses/by-nc/2.5/), which permits any noncommercial use, sharing, adaptation, distribution and reproduction in any medium or format, as long as you give appropriate credit to the original author(s) and the source, provide a link to the Creative Commons license and indicate if changes were made.

The images or other third party material in this book are included in the book's Creative Commons license, unless indicated otherwise in a credit line to the material. If material is not included in the book's Creative Commons license and your intended use is not permitted by statutory regulation or exceeds the permitted use, you will need to obtain permission directly from the copyright holder.

This work is subject to copyright. All commercial rights are reserved by the author(s), whether the whole or part of the material is concerned, specifically the rights of translation, reprinting, reuse of illustrations, recitation, broadcasting, reproduction on microfilms or in any other physical way, and transmission or information storage and retrieval, electronic adaptation, computer software, or by similar or dissimilar methodology now known or hereafter developed. Regarding these commercial rights a non-exclusive license has been granted to the publisher.

The use of general descriptive names, registered names, trademarks, service marks, etc. in this publication does not imply, even in the absence of a specific statement, that such names are exempt from the relevant protective laws and regulations and therefore free for general use.

The publisher, the authors, and the editors are safe to assume that the advice and information in this book are believed to be true and accurate at the date of publication. Neither the publisher nor the authors or the editors give a warranty, express or implied, with respect to the material contained herein or for any errors or omissions that may have been made. The publisher remains neutral with regard to jurisdictional claims in published maps and institutional affiliations.

This Springer imprint is published by the registered company Springer Nature Switzerland AG. The registered company address is: Gewerbestrasse 11, 6330 Cham, Switzerland 


\section{Foreword}

Personal identification represents a central goal of forensic anthropology and associated disciplines that are involved in the study of human remains. Craniofacial superimposition comprises one of the tools that can facilitate identification, or exclusion. Methodology in craniofacial superimposition has evolved with technological advances but remains at the nexus of scholarly activity in anthropology, anatomy, image analysis, art, photography, and computer science. Given the diversity of the academic fields involved and the variety of case applications, it is not surprising that techniques and procedures for interpretation vary widely, historically and globally. Such variation complicates comparison and understanding of research and case results. Clearly the need has existed for many years for a comprehensive examination of ideal technological approaches, the science relating to the interpretation of the key anatomical structures, and the probabilities involved in interpretation.

This volume represents a comprehensive examination of the key issues relating to craniofacial superimposition. The information presented results from many months of discussions by numerous researchers and practitioners experienced in this field. Recommendations relate to all areas of this complex process and provide a template for future advancement. Colleagues involved in applications will find thoughtful guidelines on technology, anatomical interpretation, and probabilities related to the identification process. Researchers will encounter a useful synthesis of the current state of the art and elucidation of the areas that remain in need of further investigation. All readers should appreciate the tremendous scholarly effort represented in this volume. It represents a comprehensive statement on the current status of craniofacial superimposition. The book also clearly signals the direction of future research by clarifying many of the issues that need further scholarly attention.

Smithsonian Institution

Douglas H. Ubelaker

Washington, DC, USA

May 2017 


\section{Preface}

As a researcher in the fields of computer science and artificial intelligence, I knew about craniofacial superimposition (CFS) in 2005, thanks to the outstanding achievements of Drs. Miguel Botella and Inmaculada Alemán who lead the Physical Anthropology Laboratory at the University of Granada (Spain). At that time, I had recently defended my $\mathrm{PhD}$, supervised by Dr. Oscar Cordón, who is one of my best friends and one of the most brilliant scientists I have known. We both soon recognized the potential utility of soft computing and computer vision to assist CFS practitioners in many time-consuming and tedious tasks. However, we also identified important shortcomings related to the lack of a standardized methodology to face such a challenging goal. Unlike other well-established forensic techniques, we certainly found a wide diversity of approaches to CFS in terms of the technological means employed, the procedures applied, and the protocols considered. Together with a PhD student - now Dr. Oscar Ibáñez - we three decided we should make an effort to propose an international initiative that could lead to a first international agreement on the basics for the appropriate application of CFS.

This handbook was supported by the European Union's Seventh Framework Programme for research, technological development and demonstration under the MEPROCS Project, Grant Agreement No. 285624. It is the main result of the European Project "New Methodologies and Protocols of Forensic Identification by Craniofacial Superimposition (MEPROCS)," granted by the European Commission in 2011. The project started in February 2012 and finished in July 2014. MEPROCS aimed to propose a common EU framework to allow the extensive application of the CFS technique in practical forensic identification scenarios commonly tackled by European law enforcement agencies.

Furthermore, the inclusion of the most recognized CFS practitioners and labs from the five continents made MEPROCS a global initiative beyond the EU borders. Even though the initial seed of the project included just 7 institutions from $5 \mathrm{EU}$ countries, the MEPROCS network finally involved 31 institutions from 17 different countries that actively participated and contributed to the success of the project (Table 1). 
Table 1 Organizations that contributed to the MEPROCS EU project (the European Centre for Soft Computing was the coordinating institution)

\begin{tabular}{|c|c|c|}
\hline $\begin{array}{l}\text { Participant } \\
\text { no. }\end{array}$ & Organization & Country \\
\hline 1 & $\begin{array}{l}\text { Fuzzy-Evolutionary Applications Research Unit, European } \\
\text { Centre for Soft Computing }\end{array}$ & Spain \\
\hline 2 & $\begin{array}{l}\text { Physical Anthropology Lab (PAL) and Department of Computer } \\
\text { Science and Artificial Intelligence (DECSAI), University of } \\
\text { Granada }\end{array}$ & Spain \\
\hline 3 & European Council of Legal Medicine & Germany \\
\hline 4 & $\begin{array}{l}\text { Consorzio Ricerca Sistemi ad Agenti (CORISA), University of } \\
\text { Salermo }\end{array}$ & Italy \\
\hline 5 & $\begin{array}{l}\text { Division of Identification and Forensic Science, Israel National } \\
\text { Police, Israel Ministry of Public Security }\end{array}$ & Israel \\
\hline 6 & Forensic Science Centre, University of Coimbra & Portugal \\
\hline 7 & Guardia Civil, Spanish Ministry of the Interior & Spain \\
\hline 8 & Policía Judiciária, Portuguese Ministry of the Interior & Portugal \\
\hline 9 & Council of Forensic Medicine & Turkey \\
\hline 10 & $\begin{array}{l}\text { Centre for Anatomy and Human Identification (CAHID), } \\
\text { University of Dundee }\end{array}$ & UK \\
\hline 11 & $\begin{array}{l}\text { Laboratory of Forensic Anthropology and Odontology } \\
\text { (LABANOF), University of Milan }\end{array}$ & Italy \\
\hline 10 & Moscow Regional Bureau of Forensic Medicine (MRBFM) & Russia \\
\hline 11 & Vilnius University (VU) & Lithuania \\
\hline 12 & Complutense University of Madrid (CUM) & Spain \\
\hline 13 & $\begin{array}{l}\text { Azienda Ospedaliero-Universitaria di Trieste. } \\
\text { Unita' di Ricerca Paleoradiologia e Scienze Affini (AOUT) }\end{array}$ & Italy \\
\hline 14 & Forensic Anthropology Society of Europe & \begin{tabular}{|l} 
International \\
Institution
\end{tabular} \\
\hline 15 & International Academy of Legal Medicine & $\begin{array}{l}\text { International } \\
\text { Institution }\end{array}$ \\
\hline 16 & International Association of Forensic Sciences & $\begin{array}{l}\text { International } \\
\text { Institution }\end{array}$ \\
\hline 17 & World Police Medical Officer & $\begin{array}{l}\text { International } \\
\text { Institution }\end{array}$ \\
\hline 18 & Department of Forensic Medicine, University of Copenhagen & Denmark \\
\hline 19 & Forensic Science Programme, Universiti Sains Malaysia & Malaysia \\
\hline 20 & University of Melbourne & Australia \\
\hline 21 & University Wiener-INML and Public Ministry & Peru \\
\hline 22 & North Carolina State University & USA \\
\hline 23 & University of Pretoria & South Africa \\
\hline 24 & National Research Institute of Police Science & Japan \\
\hline 25 & $\begin{array}{l}\text { Institute of Ethnology and Anthropology of the Russian } \\
\text { Academy of Sciences }\end{array}$ & Russia \\
\hline 26 & University of Health Sciences, Rohtak, Haryana & India \\
\hline 27 & South African Police Service & South Africa \\
\hline
\end{tabular}


Table 1 (continued)

\begin{tabular}{l|l|l}
\hline $\begin{array}{l}\text { Participant } \\
\text { no. }\end{array}$ & Organization & Country \\
\hline 28 & Department of Health, City of Moscow & Russia \\
\hline 29 & Moscow State Forensic Bureau & Russia \\
\hline 30 & Moscow Regional State Forensic Bureau & Russia \\
\hline 31 & BARS International & Russia \\
\hline
\end{tabular}

This handbook includes the tireless efforts of different representatives at these institutions. Even though they are not formally considered book coauthors and they are not included on the handbook's front cover - due to the publisher's rules - we consider them coauthors of this nonprofit publication. They are listed as follows (including their affiliation at the time they joined the MEPROCS project):

- S. Damas (European Centre for Soft Computing, Spain)

- O. Ibáñez (University of Granada, Spain)

- M. I. Huete (University of Granada, Spain)

- T. Kahana (Israel National Police, Israel)

- C. Wilkinson (University of Dundee, UK)

- E. Ferguson (University of Dundee, UK)

- C. Erolin (University of Dundee, UK)

- P.T. Jayaprakash (Universiti Sains Malaysia, Malaysia)

- R. Jankauskas (Vilnius University, Lithuania)

- F. Cavalli (Azienda Ospedaliero-Universitaria di Trieste, Italy)

- K. Imaizumi (National Research Institute of Police Science, Japan)

- R. Vicente (University of Coimbra, Portugal)

- D. Navega (University of Coimbra, Portugal)

- E. Cunha (University of Coimbra, Portugal)

- A.H. Ross (North Carolina State University, USA)

- E. Veselovskaya (Russian Academy of Sciences, Russia)

- A. Abramov (Moscow Regional Bureau of Forensic Medicine, Russia)

- P. Lestón (Guardia Civil, Spain)

- F. Molinero (Guardia Civil, Spain)

- E. Ruiz (Complutense University, Spain)

- F. Navarro (University of Granada, Spain)

- J. Cardoso (Policía Judiciaria, Portugal)

- F. Viegas (Policía Judiciaria, Portugal)

- D. Humpire (University Wiener-INML and Public Ministry, Peru)

- R. Hardiman (University of Melbourne, Australia)

- J. Clement (University of Melbourne, Australia)

- A. Valsecchi (European Centre for Soft Computing, Spain)

- B.R. Campomanes-Alvarez (European Centre for Soft Computing, Spain)

- C. Campomanes-Alvarez (European Centre for Soft Computing, Spain)

- A.S. Çağdır (Council of Forensic Medicine, Turkey) 
- T. Briers (South African Police Service, South Africa)

- M. Steyn (University of Pretoria, South Africa)

- M. Viniero (Consorzio Ricerca Sistemi ad Agenti, Italy)

- D.N. Vieira (European Council of Legal Medicine, Germany)

- O. Cordón (University of Granada, Spain)

In my role of MEPROCS coordinator, I'm also taking this opportunity to express my sincere gratitude to my good friend Dr. Oscar Ibáñez, who was my "right-hand man" since we made the decision to apply for the EU grant. This handbook together with most of the numerous MEPROCS tasks was successfully accomplished thanks to him and his passionate dedication to the project.

Likewise, the contribution of the administrative staff of the European Centre for Soft Computing was really significant. In alphabetic order, my acknowledgments go to:

- N. Bueno, Economist

- J.R. Gonzalez, Accountant

- C. Jiménez, Dissemination and Knowledge Manager

- C. Peña, Project Manager

- L.A. Roces, Secretary

- M.J. Santano, Secretary

Given the importance of this handbook for its authors, it is provided under an open-access license in order to facilitate its widest dissemination among all CFS practitioners, researchers, and stakeholders.

Mieres

Sergio Damas

May 2015 


\section{Project Overview}

The "New Methodologies and Protocols of Forensic Identification by Craniofacial Superimposition (MEPROCS)" project was a Coordination and Support Action granted by the European Commission that started in February 2011. In principle, the duration of the project was 24 months. However, an extension of 6 months was approved by the European authorities given the evolution of the tasks, the considerable number of participants that joined the project, and the expected outcomes.

This handbook is the final result and more important deliverable of the MEPROCS project. According to the description of work, the particular objectives of the project are focused on supporting the development of a trustable craniofacial superimposition (CFS) methodological framework by fulfilling requirements covering educational, technical, economic, social, and security aspects. According to the documents included in the Grant Agreement of the project, this would be achieved by:

1. Definition of standard protocols for the application of CFS to different forensic scenarios: During its century and a half of development, the CFS forensic identification technique has been successfully applied to a huge number of case studies all around the world. The establishment of specific forensic protocols for the application of CFS to different scenarios (crime scenes, missing persons, mass disasters, mass graves, terrorism, etc.) is a real need.

2. Specification of objective and semiautomatic validation techniques for CFS identification results: The defined protocols should depend on a reliable technique. Clear and objective evidence evaluation criteria must be established to measure the quality of CFS outcomes, avoiding subjectivity and removing potential biases.

3. Definition of the CFS-based forensic identification framework: The combination of protocols and validation methods defined in the preceding two objectives and of the previously defined semiautomatic CFS system will result in an easy-to-use framework, which will speed up the correct identification of deceased people in the different forensic scenarios mentioned. 
4. Dissemination and awareness raising: The MEPROCS project will focus specially on the dissemination of its results and on creating ample awareness in European stakeholders. 


\section{MEPROCS Work Packages}

The workload of the MEPROCS project was detailed in the document "Description of work (DoW)" approved by the European Commission. It was split into a number of work packages shown in Fig. 1 and described as follows:

WP1. Analysis of the Existing Methods and Procedures in the Field of CFSBased Forensic Identification

Review the state of the art in forensic identification from skeletal remains by CFS:

- Review forensic anthropology literature looking for applications of the CFS technique to identification cases. We will study the specialized scientific literature to identify all the reported applications of the CFS technique, including materials, methods, and tools used.

- Report internal procedures, protocols, and tools used to apply the CFS technique as well as previous implementations and experiences with the application of the CFS technique in different scenarios.

- Identify and create a list of users, researchers, and laboratories working on the CFS technique all over the world.

\section{WP2. Consolidation of the Network}

Engage new stakeholders and refine and focus the project agenda.

- Contact the most representative forensic anthropology labs and researchers to let them know about MEPROCS and try to incorporate them into the network.

- Correct possible deviations in the planned agenda and adapt the work plan after new stakeholders and/or new possible collaborations or interactions with other projects have been made.

\section{WP3. Standard Protocols Definition}

Establishment of specific protocols for the application of CFS to different scenarios:

- Identify and discuss the advantages and disadvantages of the different SC methods found in the literature. 


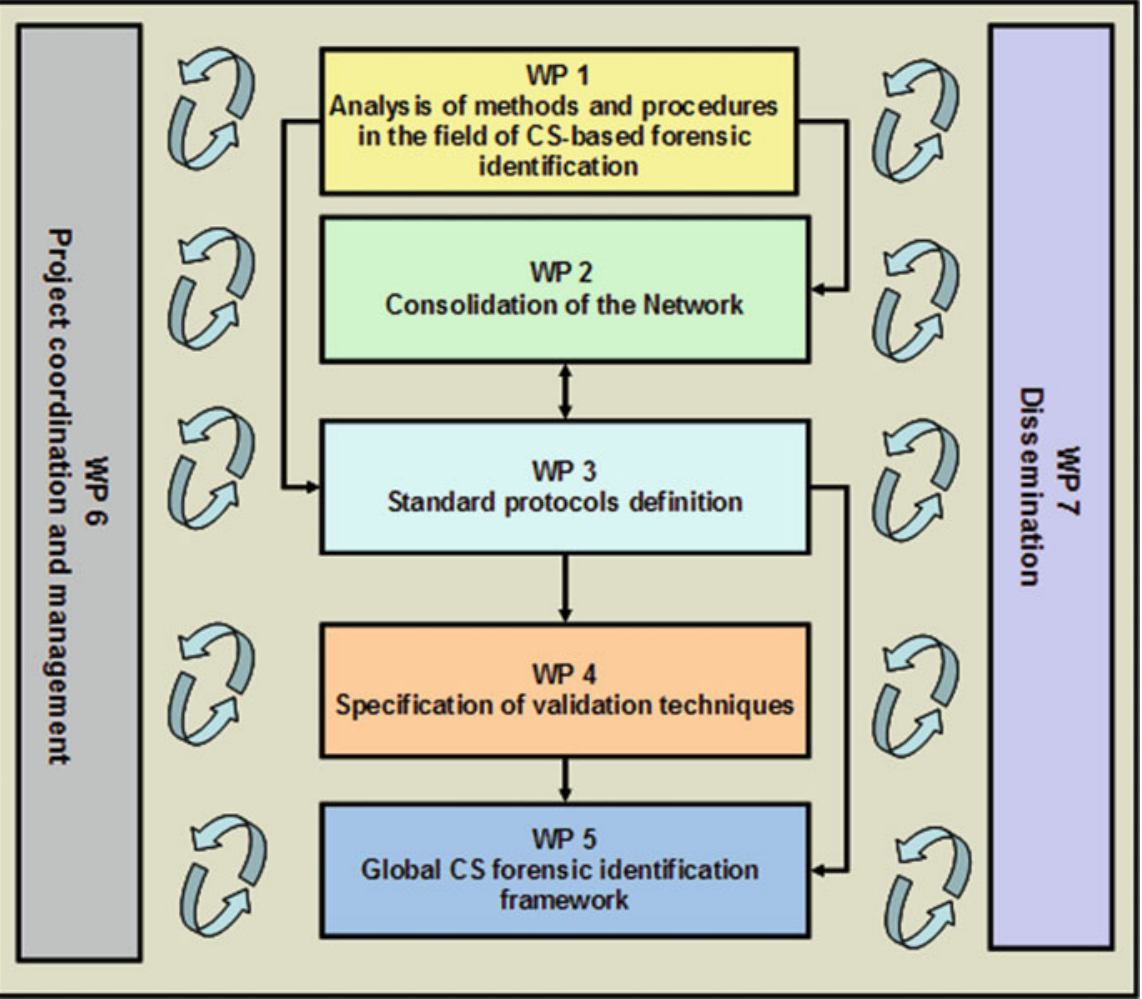

Fig. 1 Scheme of MEPROCS work packages and the relationships among them

- Identify the different scenarios (including their description) where CFS has been applied, reporting common problems, the number of tackled and solved cases, as well as predominant scenarios and reliability.

- Identify and discuss advantages and disadvantages of the different procedures and/or protocols followed by the end users in the network.

- Define standard protocols for each kind of considered scenario: missing people, mass disasters, common graves, etc.

\section{WP4. Specification of Validation Techniques}

Identification of objective and automatic CFS validation techniques and validation of the proposed CFS method:

- Review previous approaches related to manual or semiautomatic assessment of the CFS results.

- Report and analyze the different validation approaches followed by the end users in the consortium.

- Propose semiautomatic methods to assess CFS results.

- Study ethical and legal issues concerning scientific use of identification cases. 
- Compilation of solved and unsolved identification cases.

- Preparation of the materials involved in the identification cases.

- Objective assessment of the robustness and accuracy of the automatic CFS method.

\section{WP5. Global CFS Identification Framework Definition}

Design a set of protocols, techniques, and methods that can be easily distributed and accessed by stakeholders:

- Define an easy-to-use automatic CFS framework.

- Establish a validation procedure for the defined CFS framework to be followed by the end users.

- CFS framework validation over different (simulated) scenarios.

\section{WP6. Project Coordination and Management}

Address the project management and coordination tasks and those related with ethical issues:

- Address the project management and coordination tasks.

- Coordinating stakeholder involvement and obtaining broad support from the users' community.

- An Ethical Issues Committee will be created to supervise the ethical issues that arise during its development.

\section{WP7. Dissemination and Training}

Improve communication between the different communities involved, disseminate among the end users in the proposed automatic CFS framework, increase the visibility of the network, produce and publish a handbook on CFS, and organize public events to disseminate the network results:

- General dissemination activities.

- Create a distribution list, work groups, and a wikiportal.

- Carry out a training workshop on the proposed automatic CFS framework.

- Produce and publish a handbook on CFS.

- Organize public event(s) to present the results of the network collected in a handbook. 


\section{MEPROCS Consortium}

The MEPROCS consortium consists of partners, associated partners, supporting institutions, and committees of different countries. The countries with at least one institution involved in this initiative are represented in Fig. 2. We detail below the list of participants in the MEPROCS network:

\section{Partners}

European Centre for Soft Computing (ECSC), Spain Consorci di Recerca Sistemi ad Agenti (CORISA), Italy European Council of Legal Medicine (ECLM), Germany

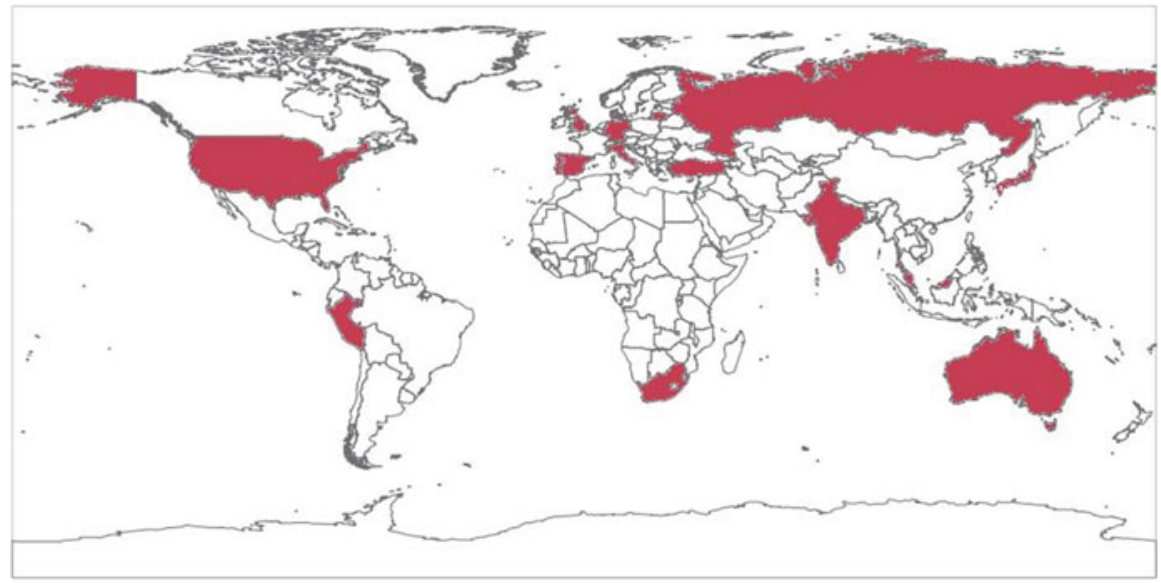

Fig. 2 Countries involved in the MEPROCS project 
Universidad de Granada (UGR), Spain

Ministry of Public Security-Israel National Police (INP), Israel

Forensic Sciences Centre (FSC)-University of Coimbra, Portugal

Ministry of Interior-Guardia Civil (GC), Spain

\section{Associated Partners}

Policía Judiciaria (PJ), Portugal

Council of Forensic Medicine (CFM), Turkey

Centre for Anatomy and Human Identification (CAHID), UK

Laboratorio di Antropología e Odontología Forense (LABANOF), Italy

Moscow Regional Bureau of Forensic Medicine (MRBFM), Russia

Vilnius University (VU), Lithuania

Universidad Complutense de Madrid (UCM), Spain

Azienda Ospedaliero-Universitaria di Trieste, Italy

\section{Supporting Institutions}

Dr. Niels Morling (University of Copenhagen, Denmark)

Dr. P.T. Jayaprakash (Universiti Sains Malaysia, Malaysia)

Dr. J.G. Clement (University of Melbourne, Australia)

Dr. D.J. Humpire (University Wiener-INML and Public Ministry, Peru)

Dr. A. Ross (North Carolina State University, USA)

Dr. M. Steyn (University of Pretoria, South Africa)

Dr. K. Imaizumi (National Research Institute of Police Science, Japan)

Dr. E. Veselovskaya (Institute of Ethnology and Anthropology of the Russian Academy of Sciences, Russia)

Dr. S. K. Dhattarwal (University of Health Sciences, Rohtak, Haryana, India)

Captain Teunis Briers (South African Police Service, South Africa)

\section{Committees}

\section{Management Committee}

One member for each full and associated partner. Chaired by ECSC as project coordinator.

Dr. Sergio Damas (European Centre for Soft Computing, ECSC) 
Dr. Oscar Cordón (Dept. Computer Science and Artificial Intelligence) and Dr. Miguel Botella (Forensic Anthropology Laboratory-University of Granada, PAL)

Dr. Vincenzo Loia (Consorzio Ricerca Sistemi ad Agenti, CORISA)

Dr. Tzipi Kahana (Israel National Police, INP)

Dr. Eugenia Cunha (Forensic Science Centre-University of Coimbra, FSC)

Mr. Francisco Molinero (Ministry of the Interior-Guardia Civil, GC)

Dr. Duarte Nuno Vieira (European Council of Legal Medicine, ECLM)

Mr. Fernando Viegas (Policía Judiciária Portugal, PJ)

Dr. Yalçin Büyük (Council of Forensic Medicine, CFM)

\section{Administrative Coordinator}

Dr. Carmen Peña (European Centre for Soft Computing)

\section{Dissemination Manager}

Ms. Carolina Jiménez (European Centre for Soft Computing)

\section{Ethical Committee}

Dr. Duarte Nuno Vieira (European Council of Legal Medicine, ECLM)

Dr. Cristina Cattaneo (Laboratorio di Antropología e Odontologia Forense)

Dr. Douglas Ubelaker (The George Washington University)

Dr. Margarida Silvestre (European Council of Legal Medicine)

\section{Security Committee}

Dr. Tzipi Kahana

Mr. Francisco Molinero

Dr. Miguel Botella

Dr. Eugenia Cunha 


\section{Advisory Board}

Forensic Anthropology Society Europe (FASE)

International Association of Forensic Sciences (IAFS)

World Police Medical Officers (WPMO)

Dr. P.T. Jayaprakash (Universiti Sains Malaysia)

Dr. Niels Morling (Director of the Department of Forensic Medicine of the University of Copenhagen)

Dr. Cristina Cattaneo (Laboratory of Forensic Anthropology and Odontology, University of Milan)

\section{Meetings}

In order to coordinate the evolution of the different activities of the project, the MEPROCS consortium attended different meetings with specific agendas. They are briefly described as follows.

\section{Mieres, Spain: March 12-13, 2012}

The goal of this first meeting was to present the general aspects of the project such as aim, partners, objectives, calendar, budget, etc.

All the full and associated partners, and the supporting institutions, made a short presentation about their expertise, research lines, and interests.

A brief description was made about the Research Executive Agency (REA) and of all the legal documents concerning MEPROCS: Grant Agreement, Consortium Agreement, and Certificate on financial statements. Eligible costs and payment modalities were detailed, as well as report procedures, audits, and causes for grant suspension.

The project management structure was also explained.

MEPROC's Committees composition was decided at this meeting. Then, a brief description of all the work packages, the tasks and deliverables involved in each of them, and the list of participants and leading institutions was introduced. Finally, the plan of next steps and an open discussion closed the event.

The meeting attendees were the following:

Dr. Sergio Damas (ECSC, Spain)

Dr. Oscar Cordón (ECSC, Spain)

Dr. Oscar Ibáñez (ECSC, Spain)

Dr. Raúl del Coso (ECSC, Spain)

Dr. Carmen Peña (ECSC, Spain)

Dr. Miguel Botella (PAL, Spain)

Dr. Inmaculada Alemán (OPAL, Spain)

Dr. Vincenzo Loia (Director CORISA, Conzozio Ricerca Sistemi ad Agenti, Italy) 
Dr. Mario Veniero (CORISA, Consorzio Ricerca Sistemi ad Agenti, Italy)

Dr. Tzipi Kahana (Ministry of Public Security-INP, Israel)

Dr. Eugenia Cunha (FSC-University of Coimbra, Portugal)

Dr. Sonia Codinha (FSC-Universidad Coimbra, Portugal)

Mr. Francisco Molinero (Ministry of the Interior-GC, Spain)

Mr. Patricio Lestón (Ministry of the Interior-GC, Spain)

Ms. Ascenção Rebelo (ECLM, Portugal)

Mr. Fernando Viegas (PL, Portugal)

Dr. Yalçin Büyük (CFM, Turkey)

Dr. A. Cadgir (CFM, Turkey)

Dr. Niels Lynnerup (University of Copenhagen, Denmark)

Dr. P.T. Jayaprakash (Universiti Sains Malaysia, Malaysia)

Dr. Pasquale Poppa (LABANOF, Italy)

\section{Coimbra, Portugal: May 31, 2012}

The general aspects of the project such as aim, partners, objectives, calendar, and the budget were summarized in this meeting. The coordinator also informed about the application of two different institutions to become associated partners. Then, the management committee voted and approved their inclusion. The financial rules of the project were discussed and planned, as well as the work plan and the ethical issues about data protection. The project logo and website (www.meprocs.eu) were also presented (Fig. 3):

The meeting attendees were:

Dr. Sergio Damas (ECSC, Spain)

Dr. Oscar Ibáñez (ECSC, Spain)

Dr. Raúl del Coso (ECSC, Spain)

Dr. Miguel Botella (PAL, Spain)

Dr. Inmaculada Alemán (PAL, Spain)

Dr. Vincenzo Loia (CORISA, Consorzio Ricerca Sistemi ad Agenti, Italy)

Dr. Mario Veniero (CORISA, Consorzio Ricerca Sistemi ad Agenti, Italy)

Dr. Tzipi Kahana (Ministry of Public Security-INP, Israel)

Dr. Eugenia Cunha (FSC-University of Coimbra, Portugal)

Dr. Sonia Codinha (FSC-Universidad Coimbra, Portugal)

Mr. Ricardo Vicente (FSC-Universidad Coimbra, Portugal)

Mr. David Navega (FSC-Universidad Coimbra, Portugal)

Mr. Francisco Molinero (Ministry of Interior-GC, Spain)

Mr. Patricio Lestón (Ministry of Interior-GC, Spain)

Dr. Vieira Nuno Viera (ECLM, Portugal)

Mr. Fernando Viegas (PL, Portugal)

Ms. Angela Azinheira (PL, Portugal)

Dr. Yalçin Büyük (CFM, Turkey)

Dr. Danilo de Angelis (LABANOF, Italy) 


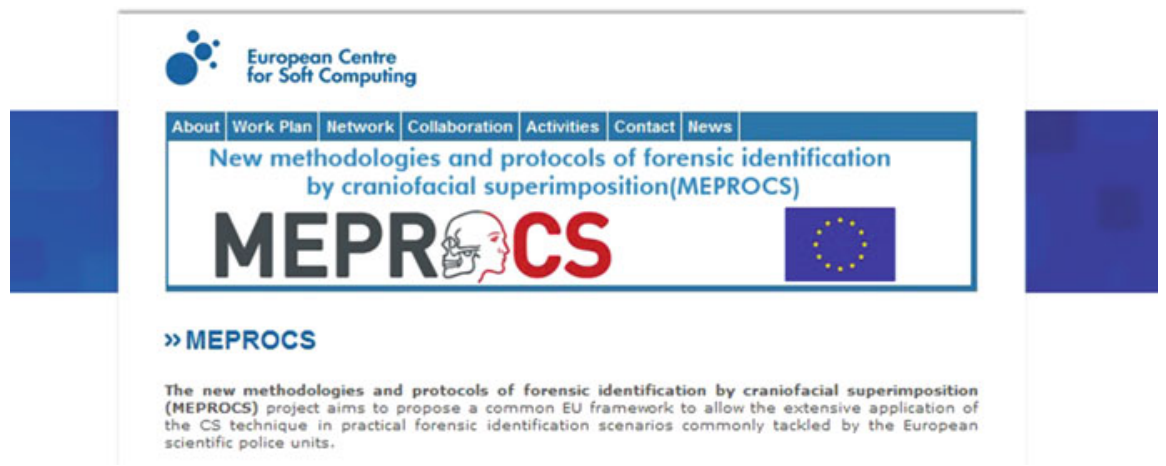

Fig. 3 MEPROCS website (www.meprocs.eu) with the MEPROCS logo

\section{The Hague, Netherlands: August 22-23, 2012}

In this meeting, new associated partners were introduced. After a brief summary of the MEPROCS project, the deadlines established in the previous meeting were extended. Then, the work packages and the deliverables were discussed, task by task.

The composition of the ethical committee was definitively approved, and all the partners started a discussion regarding ethical issues for sharing cases. The copyleft license to publish a final handbook was also proposed in this meeting. To facilitate the dissemination of the MEPROCS activities, this event took place together with the "6th European Academy of Forensic Science Conference" (EAFS 2012). MEPROCS was presented with its own booth (Fig. 4), and different oral presentations were accepted in the EAFS 2012 Program.

The participants were:

Dr. Sergio Damas (ECSC, Spain)

Dr. Oscar Ibáñez (ECSC, Spain)

Dr. Raúl del Coso (ECSC, Spain)

Dr. Mario Veniero (CORISA, Consorzio Ricerca Sistemi ad Agenti, Italy)

Dr. Tzipi Kahana (Ministry of Public Security-INP, Israel)

Dr. Sonia Codinha (FSC-University of Coimbra, Portugal)

Mr. Francisco Molinero (Ministry of Interior-GC, Spain)

Mr. Patricio Lestón (Ministry of Interior-GC, Spain)

Dr. Duarte Nuno Vieira (ECLM, Portugal)

Mr. Fernando Viegas (PL, Portugal)

Dr. YalÇin Büyük (CFM, Turkey)

Dr. Caroline Wilkinson (University of Dundee, UK)

Mr. Carlos Alberto Jiménez (Procuraduría General de la República, Mexico) 


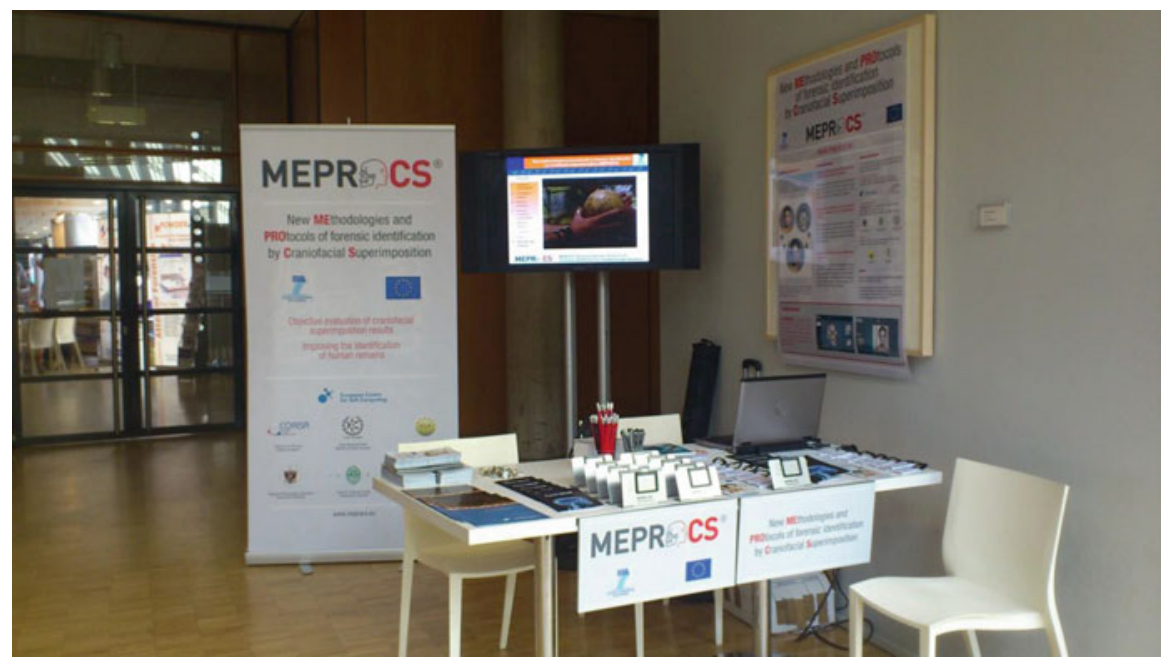

Fig. 4 MEPROCS booth at the EAFS 2012 Conference

\section{Madrid, Spain: February 3-5, 2013}

A detailed review of deliverables was presented in this event. All the partners had agreed on the need to do a first reliability study in order to determine which CFS methods performed better. Then, an open discussion about ethical issues related to the project took place. Finally, the partners accepted to publish in journals or conferences part of the results included in the handbook.

Meeting attendees (Fig. 5):

Dr. Sergio Damas (ECSC, Spain)

Dr. Oscar Ibáñez (ECSC, Spain)

Dr. Raúl del Coso (ECSC, Spain)

Dr. Fernando Navarro (UGR, Spain)

Ms. María Isabel Huete (UGR, Spain)

Dr. Mario Veniero (CORISA, Italy)

Dr. Tzipi Kahana (INP, Israel)

Dr. Eugenia Cunha (FSC, Portugal)

Mr. Francisco Molinero (GC, Spain)

Mr. Patricio Lestón (GC, Spain)

Dr. Duarte Nuno Vieira (ECLM, Portugal)

Dr. Margarida Silvestre (ECLM, Portugal)

Mr. Fernando Viegas (PJ, Portugal)

Mr. Joao Paulo Cardoso (PJ, Portugal)

Dr. Yalçin Büyük (CFM, Turkey)

Dr. Caroline Wilkinson (CAHID, UK)

Dr. Alexey Abramos (MRBFM, Russia)

Dr. Rimantas Jankauskas (VU, Lithuania) 


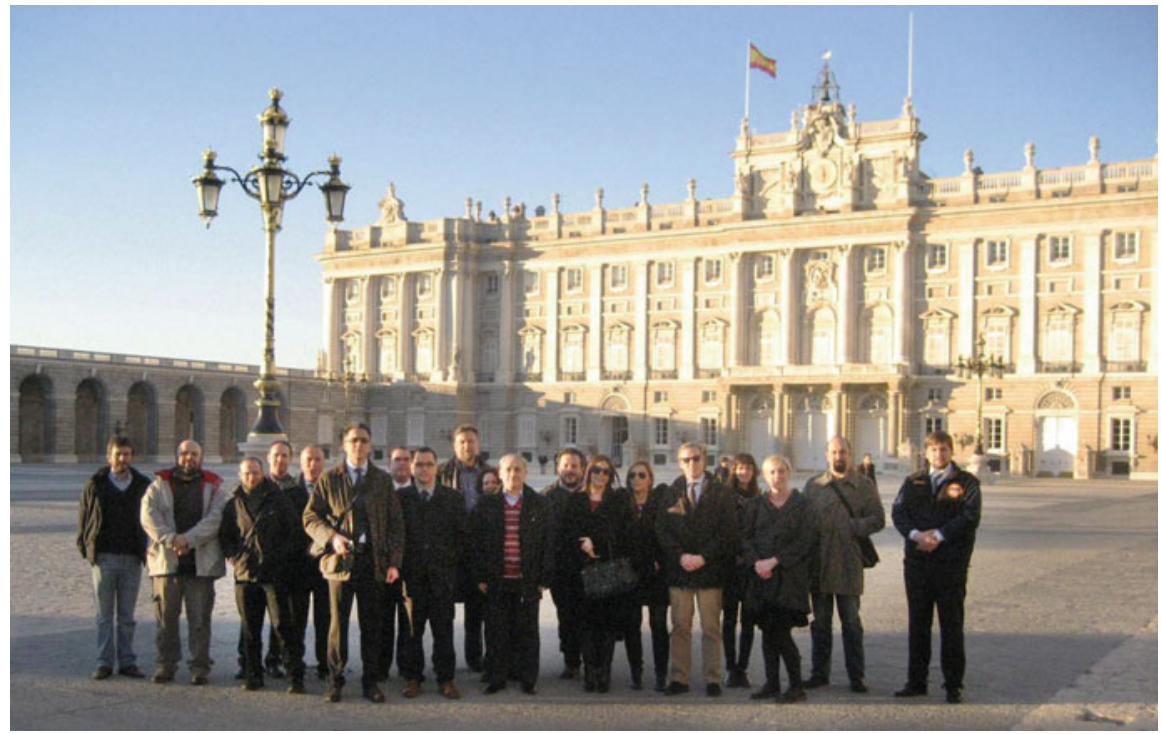

Fig. 5 Participants of the MEPROCS meeting in Madrid, Spain

Dr. José Antonio Sanchez (UCM, Spain)

Dr. Elena Ruíz Mediavilla (UCM, Spain)

Granada, Spain, International Workshop: May 27-29, 2013

Over 3 days, a workshop on CFS was held in Granada as part of the planned MEPROCS activities.

Among the participants from the beneficiaries and associated partners, supporting institutions and the invited speakers attended the workshop. International experts in CFS were invited to the workshop in order to discuss about CFS achievements and new challenges, according to the MEPROCS project objectives. Three different work panels were defined for the 3 days: CFS methods, assessing CFS results, and CFS reliability. A round table was organized where different issues within each work panel were discussed. Experts came to a draft agreement on different CFS issues. In particular, the recommended landmarks for the CFS orientation process and the skull-face consistency evaluation, and concerning degrees of confidence and requirements for each of them were discussed in the final identification decision. Documents with these agreements were included in the first draft of the handbook.

After the last activity of the workshop, a new meeting of the MEPROCS Management Committee took place.

Meeting attendees (Fig. 6): 


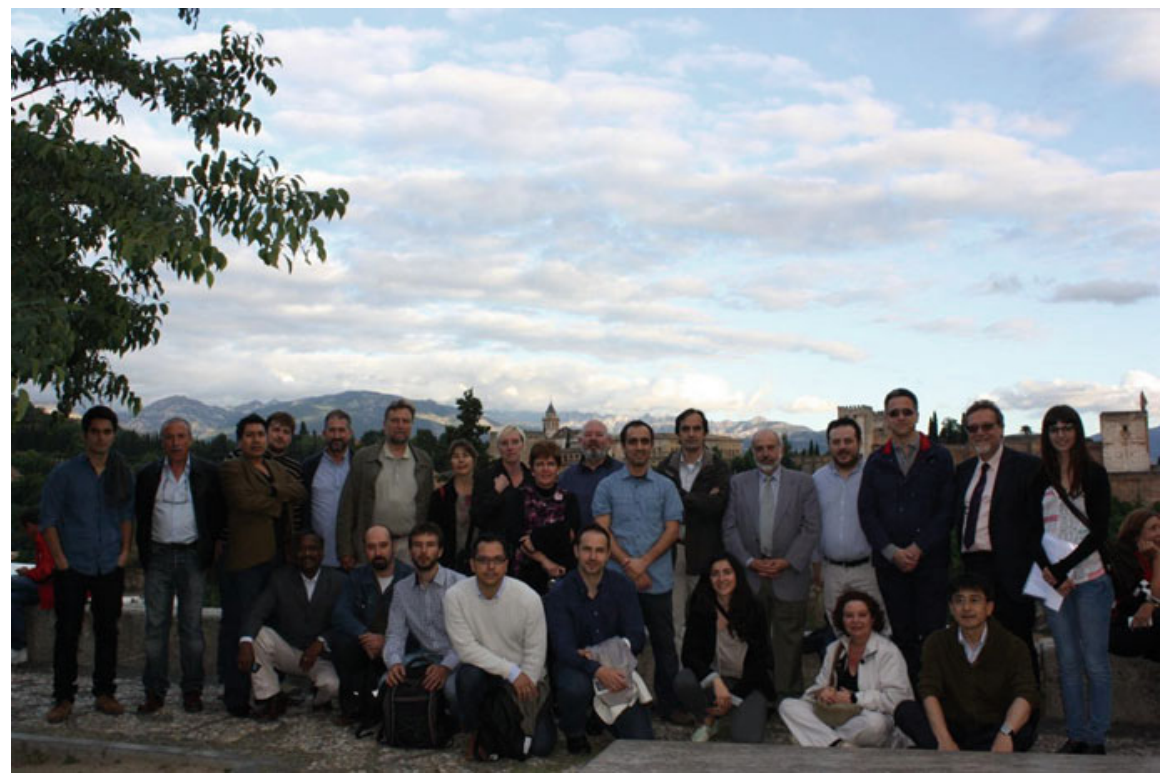

Fig. 6 Attendees of the MEPROCS meeting in Granada, Spain

\section{Partners}

Sergio Damas (ECSC, Spain)

Oscar Ibáñez (ECSC, Spain)

Luis Magdalena (ECSC, Spain)

Carmen Campomanes (ECSC, Spain)

Carolina Jiménez (ECSC, Spain)

Charo Campomanes (ECSC, Spain)

Oscar Cordón (UGR, Spain)

Fernando Navarro (UGR, Spain)

María Isabel Huete (UGR, Spain)

David Navega (FSC, Portugal)

Eugenia Cunha (FSC, Portugal)

Ricardo Vicente (FSC, Portugal)

Albertina Ortega (FSC, Portugal)

Kamal Rajaguru (FSC, Portugal)

Francisco Molinero (GC, Spain)

Patricio Lestón (GC, Spain)

Margarida Silvestre (ECLM, Portugal)

María Inés Gama (ECLM, Portugal)

Nuno Duarte Vieira (ECLM, Portugal)

Gonçalo Carnim (ECLM, Portugal)

Mario Veniero (CORISA, Italy)

Tzipi Kahana (INP, Israel) 


\section{Associated Partners}

Caroline Wilkinson (CAHID, UK)

Alexey Abramos (MRBFM, Russia)

Rimantas Jankauskas (VU, Lithuania)

José Antonio Sanchez (UCM, Spain)

Elena Ruíz Mediavilla (UCM, Spain)

Cristina Cattaneo (LABAOF, Italy)

Daniel Gaudio (LABAOF, Italy)

Pasquale Popa (LABAOF, Italy)

Fabio Cavalli (AOTS, Italy)

João Paulo Seguro Cardoso (PJ, Portugal)

Miguel da Torre Pinto da Silva (PJ, Portugal)

\section{External Experts}

John G. Clement. University of Melbourne, Australia

Elizaveta Veselovskaya. Laboratory of Anthropological Reconstruction of the Institute of Ethnology and Anthropology, Russian Academy of Sciences, Russia

Paul Thomas Jayaprakash. Universiti Sains Malaysia, Malaysia

Ann Helen Ross. North Carolina State University, USA

Danny J. Humpire. Instituto de Medicina Legal y Ciencias forenses de Lima, Peru Maryna Blignaut Steyn. University of Pretoria, South Africa

Eduardo Espejel S. Instituto Nacional de Antropología e Historia, México

Anja Petaros. University of Rijeka. Forensic Anthropology Society of Europe (FASE)

Kazuhiko Imaizumi. National Research Institute of Police Science, Japan

\section{Jerusalem, Israel: October 2-3, 2013}

In this meeting, the participants confirmed the appropriate progress made in the project. This initial positive feedback was confirmed with three particular decisions:

- A detailed and positive review of the project officer to allow the project to continue with minor modifications only.

- A 6-month project extension to recover from the start-up delay and complete the tasks of WP4 andWP5.

- The inclusion of the MEPROCS Project in the new edition of the Security Research Catalogue 2013 as one of the leading projects.

The meeting attendees were the following (Fig. 7): 


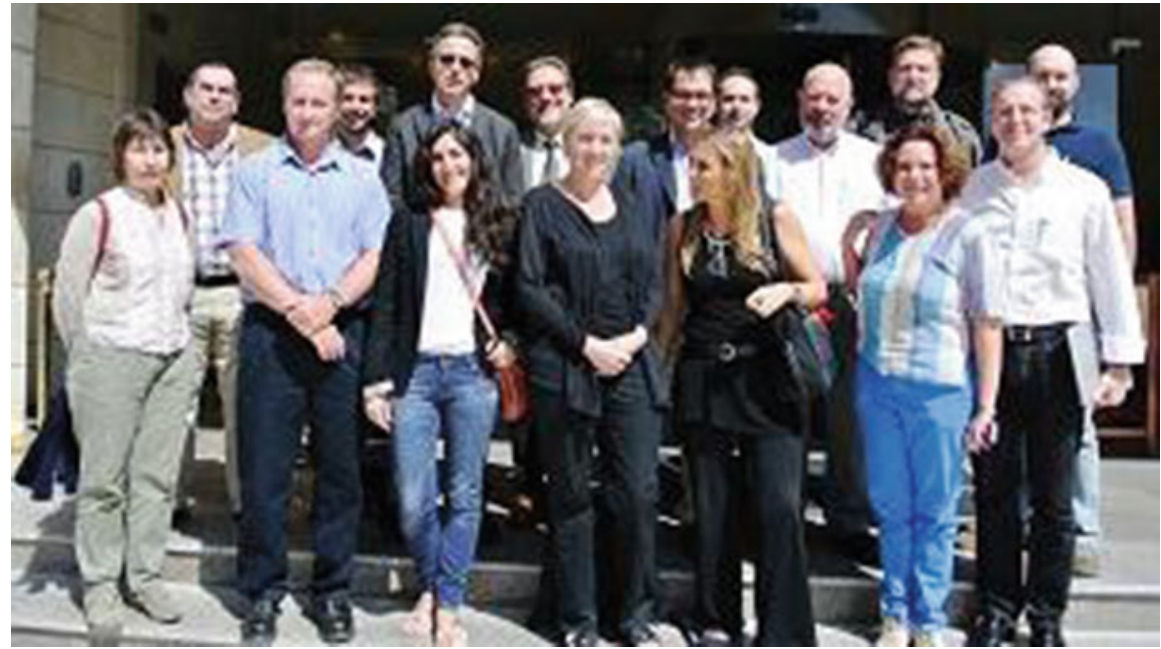

Fig. 7 MEPROCS representatives during the meeting in Jerusalem

\section{Partners}

Sergio Damas (ECSC, Spain)

Oscar Ibáñez (ECSC, Spain)

Raúl del Coso (ECSC, Spain)

Fernando Navarro (UGR, Spain)

Eugenia Cunha (FSC, Portugal)

Francisco Molinero (GC, Spain)

Patricio Lestón (GC, Spain)

Nuno Duarte Vieira (ECLM, Portugal)

Tzipi Kahana (INP, Israel)

Miryam Azoury (INP, Israel)

Tibby Roth (INP, Israel)

Shay Bchiry (INP, Israel)

\section{Associated Partners}

Caroline Wilkinson (CAHID, UK)

Rimantas Jankauskas (VU, Lithuania)

Elena Ruíz Mediavilla (UCM, Spain)

Fabio Cavalli (AOTS, Italy)

Fernando Viegas (PJ, Portugal) 


\section{External Experts from Supporting Institutions}

John Gerald Clement (University of Melbourne, Australia)

Elizaveta Veselovskaya (Russian Academy of Sciences, Russia)

Daniel Jesus Humpire Molina (Universidad Wiener-INML and Public Ministry, Peru)

Teunis Briers (South African Police Service, South Africa)

\section{Salerno, Italy: March 3-7, 2014}

After the welcome by the mayor of Salerno and the rector's representative at the University of Salerno (Fig. 8), the project coordinator briefly reviewed the work done so far and the remaining tasks and deliverables. The last news concerning the final conference, the current state of several upcoming publications, and financial issues were also summarized.

Participants discussed about CFS technical aspects and analyzed in depth the CFS study performed. They also discussed about best practices in video superimposition. Finally, they analyzed the relationship between the face and the skull in order to propose some criteria to study the correspondence between them.

A new website for the final conference registration was presented (https:// iccfs2014.wonference.com), shown in Fig. 9:

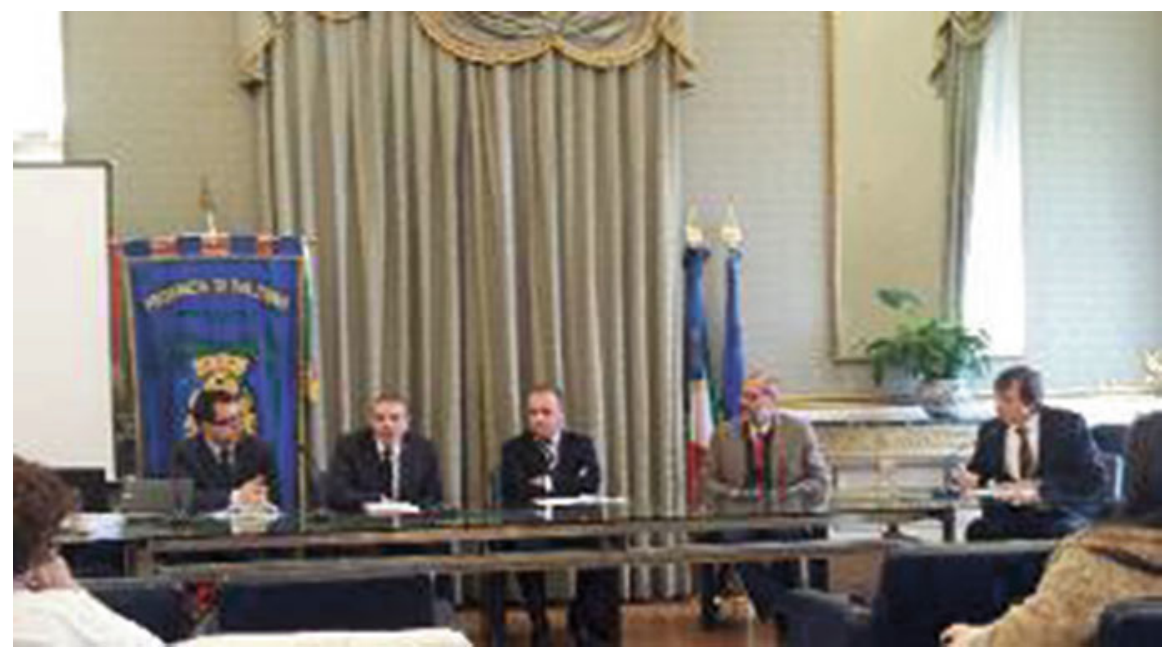

Fig. 8 Presentation of the MEPROCS meeting by the coordinator and different authorities of Salerno 


\section{MEPRR CS ICCFS2014}

International Conference On Craniofacial Superimposition 2014

\section{Home Program Activities Submit Abstract Workshop application Registration}

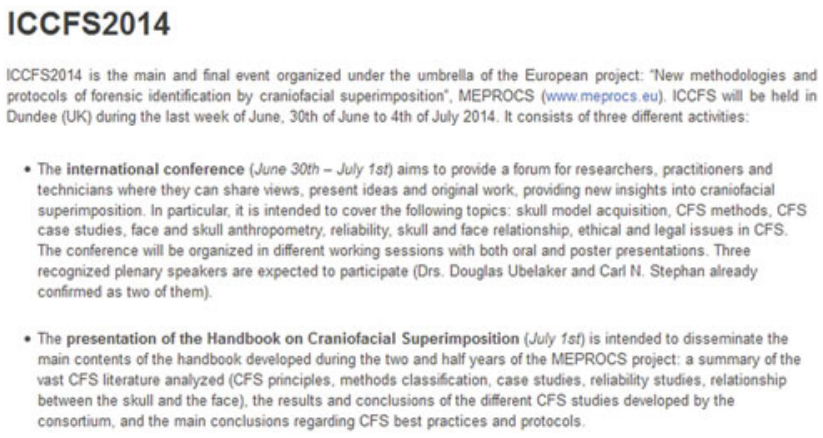

- The international conference (June $30 t h$ - July $19 t$ ) aims to provide a forum for researchers, practitioners and technicians where they can share views, present ideas and original work, providing new insights into craniofacial superimposition. In particular, it is intended to cover the following topics: skull model acquisition, CFS methods, CFS case studies, face and skull anthropometry, reliability, skull and face relationship, ethical and legal issues in CFS. The conference will be organized in different working sessions with both oral and poster presentations. Three recognized plenary speakers are expected to participate (Drs. Douglas Ubelaker and Carl N. Stephan already confirmed as two of them).

- The presentation of the Handbook on Craniofacial Superimposition (July $1 \mathrm{sf}$ ) is intended to disseminate the main contents of the handbook developed during the two and half years of the MEPROCS project: a summary of the vast CFS literature analyzed (CFS principles, methods classification, case studies, reliability studies, relationship between the skull and the face), the results and conclusions of the different CFS studies developed by the consortium, and the main conclusions regarding CFS best practices and protocols

Fig. 9 International Conference on Craniofacial Superimposition web: https://iccfs2014. wonference.com

Meeting attendees:

\section{Partners}

Sergio Damas (ECSC, Spain)

Oscar Ibáñez (ECSC, Spain)

Carmen Peña (ECSC, Spain)

Maribel Huete (UGR, Spain)

Eugenia Cunha (FSC, Portugal)

Ricardo Vicente (FSC, Portugal)

Francisco Molinero (GC, Spain)

Patricio Lestón (GC, Spain)

Tzipi Kahana (INP, Israel)

Mario Veniero (CORISA, Italy)

Vincenzo Loia (CORISA, Italy)

\section{Associated Partners}

Caroline Wilkinson (CAHID, UK)

Elena Ruíz Mediavilla (UCM, Spain)

Fabio Cavalli (AOTS, Italy) 
Helder Pedro de Oliveira Figueredo (PJ, Portugal)

Cristina Cattaneo (LABANOF, Italy)

Alexey Abramov (MRBFM, Russia)

\section{External Experts from Supporting Institutions}

Paul Thomas Jayaprakash (Universiti Sains Malaysia, Malaysia)

Elizaveta Veselovskaya (Russian Academy of Sciences, Russia)

Kazuhiko Imaizumi (National Research Institute of Police Science, Japan)

\section{Dundee, Scotland: June 30-July 4, 2014}

The meeting coincided with the "International Conference on Craniofacial Superimposition," which was the final MEPROCS event (Fig. 10). The main conclusions of the project were presented to all the delegates who also had the chance to experience different approaches to CFS by various international labs (Spain, Japan, UK, Malaysia, and Lithuania). More than 100 delegates attended the conference.

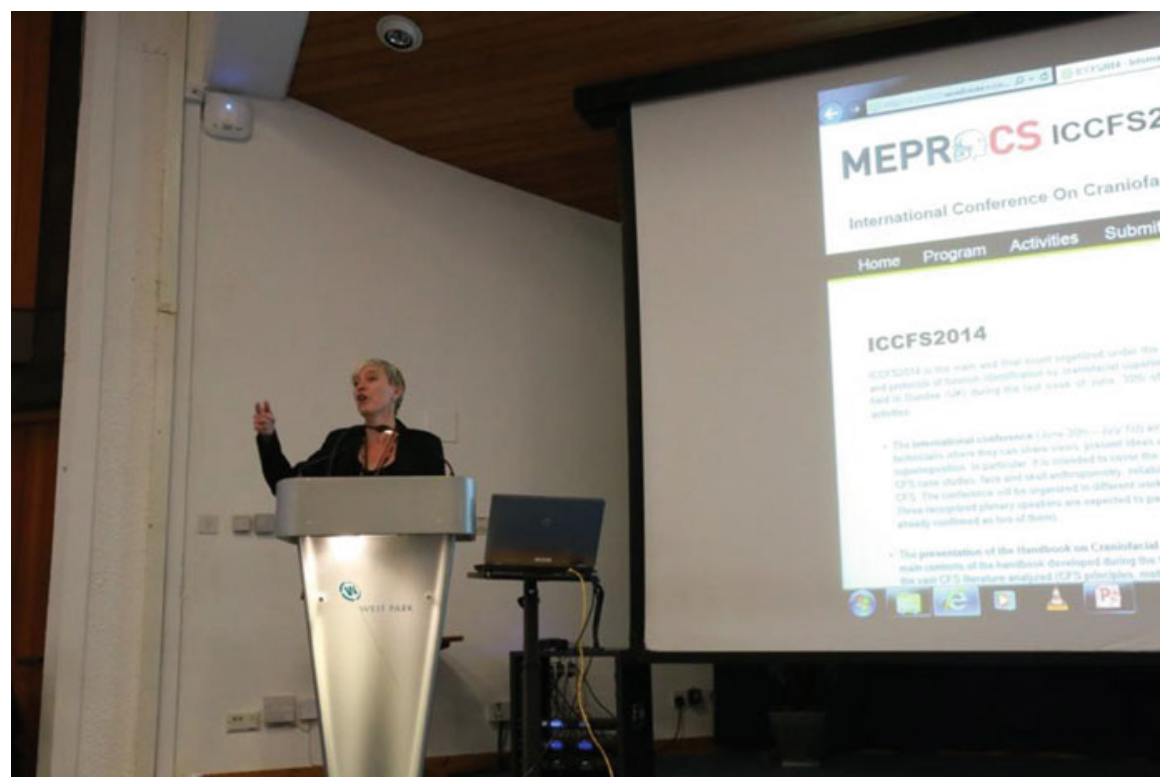

Fig. 10 Welcome to the delegates of the MEPROCS International Conference on CFS (ICCFS 2014) 
During the meeting, the coordinator informed the MEPROCS participants about the final review of the project by European authorities. According to the instructions of the project officer, he congratulated all the members of the MEPROCS consortium for their excellent contribution to the project success. The participants also analyzed the state of the pending tasks, mainly related to the dissemination of results. Finally, they discussed the potential use of data after the project and possible collaboration and common initiatives for the future.

\section{Partners}

Sergio Damas (ECSC, Spain)

Oscar Ibáñez (ECSC, Spain)

Carmen Peña (ECSC, Spain)

Maribel Huete (UGR, Spain)

Fernando Navarro (UGR, Spain)

Eugenia Cunha (FSC, Portugal)

Ricardo Vicente (FSC, Portugal)

Francisco Molinero (GC, Spain)

Patricio Lestón (GC, Spain)

Tzipi Kahana (INP, Israel)

Mario Veniero (CORISA, Italy)

Nuno Duarte Vieira (ECLM, Portugal)

\section{Associated Partners}

Caroline Wilkinson (CAHID, UK)

Elena Ruíz Mediavilla (UCM, Spain)

Rimantas Jankauskas (VU, Lithuania)

Fabio Cavalli (AOTS, Italy)

Helder Pedro de Oliveira Figueredo (PJ, Portugal)

Cristina Cattaneo (LABANOF, Italy)

\section{External Experts from Supporting Institutions}

Paul Thomas Jayaprakash (Universiti Sains Malaysia, Malaysia)

Elizaveta Veselovskaya (Russian Academy of Sciences, Russia)

Kazuhiko Imaizumi (National Research Institute of Police Science, Japan) 


\section{Contents}

1 Introduction to Craniofacial Superimposition . . . . . . . . . . . 1

2 Importance of Craniofacial Superimposition in Forensic

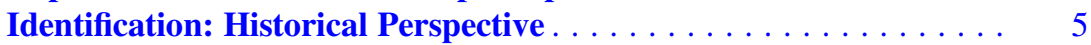

3 Relationships Between the Skull and the Face for Forensic Craniofacial Superimposition . . . . . . . . . . . . . . . . 11

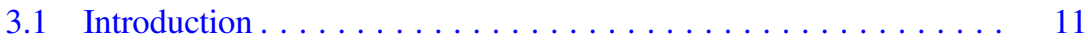

3.2 Anthropometrical Relationships . . . . . . . . . . . . . . . . . . . . . 12

3.3 Anatomical Relationships . . . . . . . . . . . . . . . 23

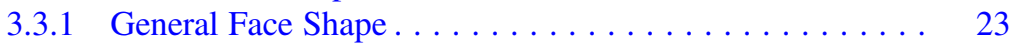

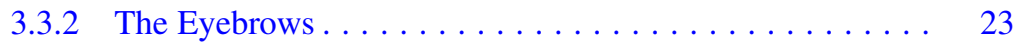

3.3 .3 The Eyes . . . . . . . . . . . . . . . . . . . . 26

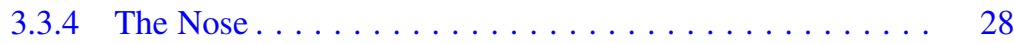

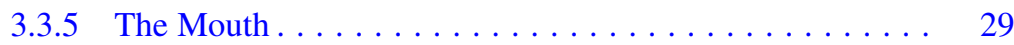

3.3 .6 The Cheeks . . . . . . . . . . . . . . . . . . . . . . 29

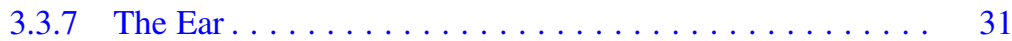

3.3 .8 The Chin . . . . . . . . . . . . . . . . 34

3.4 Examination Criteria for Craniofacial Superimposition . . . . . . . . 34

3.4.1 Helmer $(1984,2012) \ldots \ldots \ldots \ldots \ldots \ldots$

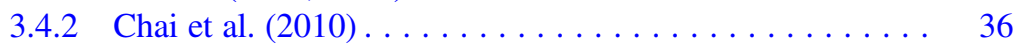

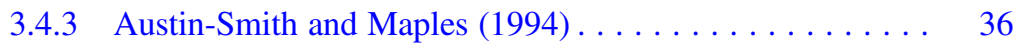

3.4 .4 Yoshino et al. $(1995,2012) \ldots \ldots \ldots \ldots \ldots$

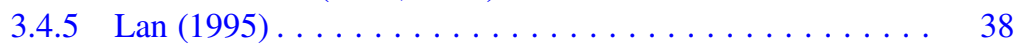

3.4 .6 Jayaprakash et al. $(2001) \ldots \ldots \ldots \ldots \ldots$

3.4 .7 Ricci et al. (2006) . . . . . . . . . . . . . . 40

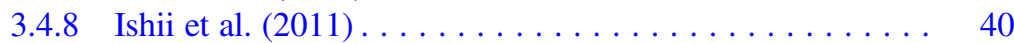

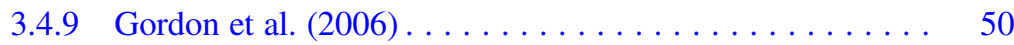

4 Craniofacial Superimposition Techniques . . . . . . . . . . . 51

4.1 Introduction . . . . . . . . . . . . . . . . . 51

4.2 Photographic Craniofacial Superimposition . . . . . . . . . 52 
4.2.1 Face Enhancement and Skull Modeling . . . . . . . . . . 53

4.2 .2 Skull-Face Overlay . . . . . . . . . . . . . . . . 57

4.2 .3 Decision Making . . . . . . . . . . . . . . . . 60

4.3 Video Craniofacial Superimposition . . . . . . . . . . . . . . 62

4.3.1 Face Enhancement and Skull Modeling . . . . . . . . . . 63

4.3 .2 Skull-Face Overlay . . . . . . . . . . . . . . . . . . . 64

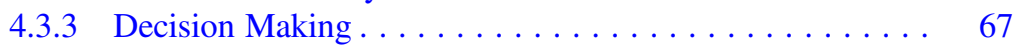

4.4 Computer-Aided Craniofacial Superimposition . . . . . . . . . . . 68

4.4.1 Discussion of Existing Works . . . . . . . . . . . 71

4.4.2 Face Enhancement and Skull Modeling . . . . . . . . 72

4.4 .3 Skull-Face Overlay . . . . . . . . . . . . . . . . . 76

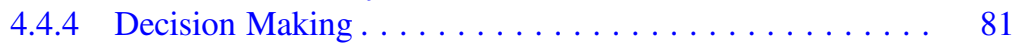

5 Craniofacial Superimposition: State of the Art . . . . . . . . . 85

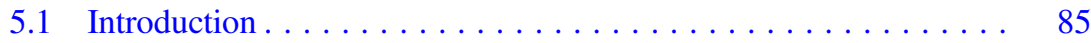

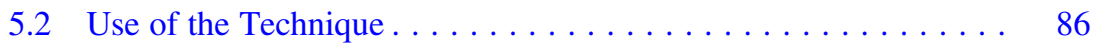

5.2.1 Identification Scenarios and Nature of the Investigation . . . 86

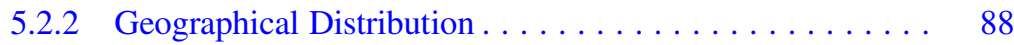

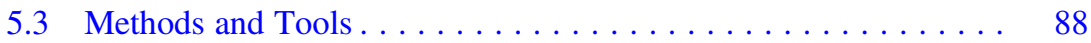

5.3 .1 Landmarks . . . . . . . . . . . . . . . . . . . . . . 89

5.3 .2 Literature Review . . . . . . . . . . . . . . . . . . . . . . . . . . . . . . . . . . 90

5.3 .3 Conclusions ................... 92

6 Ethical and Legal Issues in Craniofacial Superimposition . . . . . . . 93

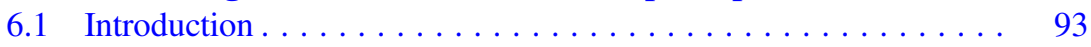

6.1.1 What Is Craniofacial Superimposition? . . . . . . . . . . . 94

6.2 The Importance of Craniofacial Superimposition in Human Identification . . . . . . . . . . . . . . . . . 95

6.3 Ethical Issues in Craniofacial Superimposition Methods

Research . . . . . . . . . . . . . . . . . . . . . 95

6.3.1 The Groups Involved (Victims, Families, Professionals,

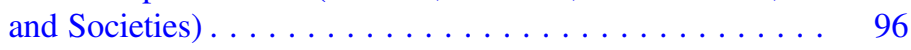

6.3.2 Databases for Craniofacial Superimposition Methods Research and Data Protection . . . . . . . . . . . . . . 98

6.4 The Problems of European and National Legislation and the Implications of Conventions and Declarations . . . . . . . . . . . . . . 101

6.5 Proposed Guidelines for Craniofacial Research . . . . . . . . . . . . . 101

6.6 Consent Forms for Craniofacial Superimposition Methods Research ........................... 102

7 Experimental Study of Craniofacial Superimposition Methodologies, Tools, and Criteria . . . . . . . . . . . . . . . . . . . . 105

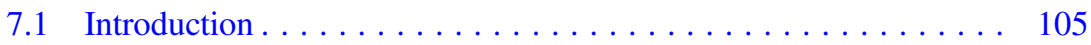

7.2 Study on the Performance of Different Craniofacial

Superimposition Approaches . . . . . . . . . . . . . . . . . . 105

7.2 .1 Experimental Study . . . . . . . . . . . . . . . . . . . . . . . . . . . . . . 105

7.2 .2 Results..................... 107 
7.3 Study on the Criteria Assessing Skull-Face Correspondence in Craniofacial Superimposition . . . . . . . . . . . . . . . . 118

7.3 .1 Experimental Study . . . . . . . . . . . . . . . . 118

7.3 .2 Results . . . . . . . . . . . . . . . . . . 127

8 MEPROCS Craniofacial Superimposition Framework . . . . . . . . . . 139

8.1 Introduction . . . . . . . . . . . . . . . . . . . . . 139

8.2 Study of the Most Important Issues for a Proper Implementation of the Craniofacial Superimposition Technique . . . . . . . . . . . . 140

8.2.1 Main Sources of Error in Craniofacial Superimposition . . . 141

8.2.2 Main Sources of Uncertainty in Craniofacial

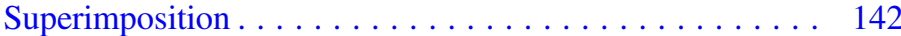

8.2.3 Best Practices in Craniofacial Superimposition . . . . . . . . . 143

8.2.4 Practices in Craniofacial Superimposition That Should Be Avoided. . . . . . . . . . . . . . . . . . . . . . 144

8.2.5 Recommended Landmarks to Guide Skull-Face Overlay . . . . . . . . . . . . . . . . . . . . . . . . . 144

8.2.6 Protocol for Evaluation of Anatomical Consistency in Craniofacial Superimposition . . . . . . . . . . . . . 145

8.2.7 Final Decision Making . . . . . . . . . . . . . . . . . . . 151

8.3 Conclusions . . . . . . . . . . . . . . . . . . . . 152

9 MEPROCS Framework Validation . . . . . . . . . . . . . . . . . 153

9.1 Introduction . . . . . . . . . . . . . . . . . . . . . . . 153

9.2 Results . . . . . . . . . . . . . . . . . . . . . . . . 163

9.3 Discussion and Conclusions . . . . . . . . . . . . . . . 168

9.3.1 Framework Understanding and Fulfillment . . . . . . . . . . . 168

9.3.2 Participants' Performance. . . . . . . . . . . . . . . 171

9.3 .3 Correlation..................... 171

10 Conclusions . . . . . . . . . . . . . . . . . . . . . . . . . . . . . . 173

10.1 Introduction . . . . . . . . . . . . . . . . . . . . . 173

10.2 Main Achievements . . . . . . . . . . . . . . . . . . . . 173

10.3 Problems Encountered . . . . . . . . . . . . . . . . . . . . . . . 177

10.4 Future Trends and Research Propositions . . . . . . . . . . . . . . 179

10.5 Concluding Remarks . . . . . . . . . . . . . . . . . . . 180

Appendix A. Informed Consent Template Relating to Human Remains . . . . . . . . . . . . . . . . . . . . . . . . . . . . . . 183

Appendix B. Informed Consent Template Regarding Data Collection from Living Individuals . . . . . . . . . . . . . . . . . . . . . . . . . . . . . . . 189

Appendix C. Informed Consent Form for Scientific

Material Sharing . . . . . . . . . . . . . . . . . . . . . . . . . 193

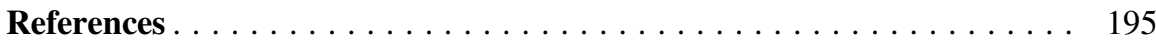




\section{List of Figures}

Fig. 3.1 Craniometric points in lateral view. Taken from Knußmann (1988) ....

Fig. 3.2 Craniometric point in vertical view (left) and in occipital view (right). Taken from Knußmann (1988)

Fig. 3.3 Craniometric points in basilar view. Taken from Knußmann (1988)

Fig. 3.4 Craniometric points in frontal view. Taken from Knußmann (1988)

Fig. 3.5 Somatometric points in frontal view ........................ 16

Fig. 3.6 Somatometric points in lateral view ......................... 17

Fig. 4.1 Case examples. On the left, the Ruxton case photograph showing the tiara used as a measurable reference object (Grüner 1993). In the center, a snapshot of deceased Michael Wolkersdorfer in which the tie was used as a scale (the image was taken from Gordon and Drennan (1948). On the right, a superimposition of transparencies and tracing of skull Z6 with photograph of victim 3 giving a possible elimination (the image was taken from McKenna et al. (1984)

Fig. 4.2 From left to right: (a) enlargement of the deceased's face and head (actual size); (b) the skull positioned to correspond with the points marked on the camera; (c) final result of the superimposition of the first two images (the image was taken from Webster 1955)

Fig. 4.3 Three different views of a skull and the reconstructed model..... 74

Fig. 4.4 Nonautomatic skull-face overlay based on Photoshop ${ }^{\mathrm{TM}} \ldots \ldots \ldots \ldots .78$

Fig. 4.5 From left to right, manual and computer-aided CFS ............ 80

Fig. 7.1 Overview of the ground-truth data creation process ............ 124 
Fig. 7.2 Statistical representation of the expert's assessment for each (negative and positive) SFO case. Expert decisions (between -3 and +3 ) on the $y$-axis and SFO cases on the $\mathrm{x}$-axis. F and L, in brackets after the number of the case, indicate frontal and lateral view cases, respectively

Fig. 7.3 Scatter plot including all the criteria under study spatially distributed according to their subjectivity (x-axis) and discriminative power (y-axis) .

Fig. 7.4 Criterion according to the frontal pose of the person's face in the photograph

Fig. 7.5 Criteria according to the lateral pose of the person's face in the photograph .

Fig. 8.1 In different colors, set of recommended craniometric landmarks for SFO (more reliable and effective) and set of still useful craniometric landmarks for guiding SFO, in frontal and lateral view

Fig. 8.2 In different colors, set of recommended cephalometric landmarks for SFO (more reliable and effective) and set of still useful cephalometric landmarks for guiding SFO, in frontal and lateral view

Fig. 8.3 Vertical and horizontal lines to analyze anatomical consistency in frontal photographs

Fig. 9.1 Skull 3D model without texture information (on the left) and with texture information (on the right).... 


\section{List of Tables}

Table 3.1 Craniometric points from Martin (1914) study

(neurocranium)

Table 3.2 Craniometric points from Martin (1914) study

(splanchnocranium) ................................. 12

Table 3.3 Somatometric points from Martin (1914) study ............. 12

Table 3.4 Landmarks used by authors, sample, and methodology ........ 18

Table 3.5 Comparison of the commonly used measuring techniques for calculating soft-tissue depth ....................... 21

Table 3.6 Systematic bias of soft-tissue measurement according to method of measurements .............................. 22

Table 3.7 Shape relationships of head and cranium ................... 24

Table $3.8 \quad$ Related face and skull measurements ...................... 25

Table 3.9 Eyebrow pattern standards .............................. 26

Table 3.10 Relationship between the eyeball and the orbit .............. 26

Table 3.11 Position of the inner (endocanthus) and outer (exocanthus) corners of the eye .................................... 27

Table 3.12 Eyelid pattern ......................................... 28

Table 3.13 Standards for nose shape prediction .................... 30

Table 3.14 Anatomical standards relating to mouth shape ............... 32

Table 3.15 Relationship between the zygomatic bones, the canine fossa, and the soft cheeks .................................... 33

Table 3.16 Relationship between ear morphology and skeletal structure .... 34

Table 3.17 Relationship between the mental region of the mandible and chin shape

Table 3.18 Landmarks, lines, and profile curves suggested by Chai et al. (1984) .......................................... 36

Table 3.19 Examination criteria for the assessment of anatomical consistency between the skull and the face ................. 39

Table 3.20 Criteria for assessing anatomical consistency between skull and face in frontal view

Table 3.21 Criteria for assessing anatomical consistency between skull and face in lateral/oblique view 
Table 3.22 Lines, landmarks and index from Lan (1995) .............. 41

Table 3.23 Facial and skull measurements and indices (a) .............. 43

Table 3.24 Facial and skull measurements and indices (b) .............. 46

Table 3.25 The criteria used for assessing the fit the skull with the face photograph during superimposition are the following ......... 48

Table 3.26 Anatomical points of the face .......................... 49

Table 3.27 Points of the skull X-rays ................................. 49

Table 3.28 Anthro-pometrical points used for each individual ............ 49

Table 3.29 Orientation, primary, and secondary landmarks .............. 50

Table 4.1 Review of the literature on photographic superimposition methods ............................................ 54

Table 4.2 Review of the literature on video superimposition methods .... 55

Table 4.3 Overview of computer-aided photo superimposition systems ... 69

Table 4.4 Overview of computer-aided video superimposition systems ... 70

Table 4.5 Overview of computer-aided 3D-2D approaches ............. 71

Table 5.1 Use of CFS reported by 45 investigators ................... 87

Table 5.2 Classification results obtained in the survey according to the nature of the investigation .............................. 87

Table $5.3 \quad$ CFS cases grouped by country .......................... 88

Table 5.4 Distribution of reported techniques ......................... 89

Table 5.5 Tools implemented in technique ......................... 89

Table $5.6 \quad$ Landmarks used ..................................... 90

Table $5.7 \quad$ Classification of case studies ............................. 91

Table 7.1 Summary of the characteristics of the datasets employed for the study ........................................... 106

Table 7.2 Participants of the study, their experience related to CFS, and datasets tackled .................................. 108

Table 7.3 Summarization of computer-aided semiautomatic 3D-2D superimposition (CAs3DS) approaches that participated in the study ..........................................

Table 7.4 Summarization of computer-aided manual 3D-2D superimposition (CAm3DS) approaches that participated in the study

Table 7.5 Summarization of computer-aided manual video superimposition (CAmVS) approaches that participated in the study

Table 7.6 Summarization of computer-aided manual photo superimposition (CAm3PS) approaches that participated in the study

Table 7.7 Performance of CFS methodologies on male dataset ......... 115

Table 7.8 Performance of CFS methodologies on female dataset........ 116

Table 7.9 Performance of CFS methodologies on male and female dataset 
Table 7.10 Overall accuracy of CFS grouped by level of experience of the participant

Table 7.11 Overall accuracy of CFS grouped by technological approach employed ........................................... 118

Table 7.12 Marking lines used to analyze anatomical consistency ........ 119

Table 7.13 Landmarks used to evaluate soft tissue thickness ............. 120

Table 7.14 Consistency of the bony and facial outlines/morphological curves

Table 7.15 Positional relationship analyzed to assess anatomical consistency ......................................... 123

Table 7.16 Cases with decision and simple expert proficiency ........... 128

Table 7.17 Spearman tests, correlation-based expert proficiency, cases

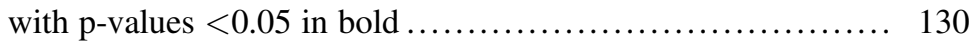

Table 7.18 Criterion usage .................................... 131

Table 7.19 Spearman test, correlation statistically significant between criterion and the status of the case ....................... 133

Table 7.20 Linear regression test, influence statistically significant between criterion and the status of the case ................. 134

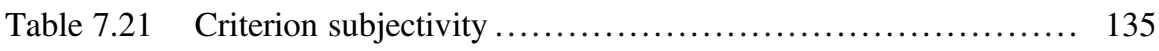

Table 8.1 Recommended homologous landmarks for guiding SFO ....... 145

Table 8.2 Other homologous landmarks still useful for guiding SFO ..... 145

Table 8.3 CFS requirements and desirable features for computer-aided equipment.

Table 8.4 CFS requirements and desirable features for video superimposition equipment ............................ 147

Table 8.5 Recommended criteria for frontal view photographs ........... 148

Table 8.6 Recommended criteria for lateral view photographs .......... 149

Table 8.7 Criteria not recommended due to low discriminative power and subjectivity .................................... 149

Table $8.8 \quad$ Examination notes ........................................ 149

Table 8.9 Decision degrees in CFS. Requirements to be fulfilled in each degree ..................................... 150

Table 9.1 Summary of the materials forming the dataset for the study . . . 154

Table 9.2 Summary of the materials forming the dataset employed for the study and ground-truth data ....................... 156

Table 9.3 Summary of the materials forming the dataset employed for the study and ground truth data ...................... 157

Table 9.4 Summary of the materials forming the dataset employed for the study and ground-truth data ..........................

Table 9.5 Summary of the materials forming the dataset employed for the study and ground-truth data ........................

Table 9.6 Participants of the study, their experience related to CFS, and number of CFS cases addressed ...................... 161

Table 9.7 Best practices fulfillment by the participants ............... 162 
Table 9.8 Fulfillment of the requirements and desirable features of the computer-aided tools employed by the participants ........... 163

Table 9.9 Identification performance of all the participants according to the number of CFS cases they addressed

Table 9.10 Identification performance of different groups of participants according to the degree of fulfillment of the framework ....

Table 9.11 Identification performance of different groups of participants according to the participants' CFS experience ............... 165

Table 9.12 Participants' performance comparison according to the results of the current study (MEPROCS methodology) and a previous one where the practitioners followed their own methodology ... 167

Table 9.13 Average standard deviation of criteria values $(\sigma)$, Pearson correlation between criteria values and GT.I $\left(\rho_{2}\right) \ldots \ldots \ldots \ldots \ldots . . \ldots 9$ 


\section{Chapter 1 \\ Introduction to Craniofacial \\ Superimposition}

The main focus of forensic anthropology lies in the determination of the identity of human remains when skeletal information becomes the last resort for forensic assessment (Burns 2007; Yoshino and Seta 2000; Alemán et al. 1997). In the last few decades, anthropologists have focused their attention on improving the techniques that help us in make the most accurate identification.

Before making an identification decision, anthropologists follow different processes to assign ancestry, sex, age, and height to human remains from the study of ante-mortem information (which can be retraced from visual material and interviews with relatives or witnesses) and post-mortem data (the skeletal remains found, i.e., bones). Different methodologies have been proposed for this purpose, with each implemented according to the features of the population group from which the method was derived (Alemán et al. 1997; İşcan 2005; Gonzalez-Colmenares et al. 2007; Urquiza et al. 2005; Landa et al. 2009). As these methods are population specific, they require the pre-determination of ancestry. The aforementioned anthropological studies are usually taken as the first step in the identification process, prior to the application of any other technique, as the determination of the main biological parameters (sex, age, stature, build, teeth, possible pathologies, etc.) reduces the number of individuals for comparison. Nevertheless, there are several other identification procedures that are more reliable than skeleton-based identification and can be applied either with the forensic anthropology evaluation or without it, such as (Stratmann 1998):

1. Comparison of fingerprints and foot and hand prints.

2. Comparison of data from the jaw and teeth (dental information).

3. External and internal autopsy. In the former, the location, size, and significance of scars, moles, tattoos, and even callous spots on the hands and feet are compared, whereas the internal autopsy looks for correspondence with regard to diseases and operations of the "disappeared person," which are retraceable in the recovered body, e.g., hysterectomy or prosthetic joint replacements. 
4. Deoxyribonucleic acid (DNA) research demonstrating a blood relation with known family members.

The application of these methods can be problematic, as on some occasions there is not enough information (ante- or post-mortem) available in order to conduct them. With regard to post-mortem data, the state of preservation of a corpse can vary considerably as a result of several chemical and mechanical factors. While the skeleton usually survives both natural and non-natural decomposition processes (fire, salt, water, etc.), the soft tissues (skin, muscles, hair, etc.) progressively degrade and are lost. The main disadvantage of DNA testing is the relatively large amount of high-quality tissue material required, which is not common in remains that were buried a long time ago. On the other hand, with regard to ante-mortem information, the first method requires the existence of a print database, the second is dependent on the availability of dental records (although in comparison to bones and skin, the teeth are more resistant to the effects of fire and salt water), the third requires previous X-ray images (among other information), and the last method depends upon a second DNA sample, either from the same person or from a relative.

Hence, anthropological identification based only on skeletal information can be considered as a final option for forensic identification when none of the previous methods can be applied. If the soft tissue or DNA methods cannot be applied but the skeletal studies provide positive results, then more specific skeleton-based identification techniques can alternatively be applied. These can include craniofacial superimposition (CFS) (İşcan 1993; Rathbun 1984; Taylor and Brown 1998).

Craniofacial superimposition is a forensic process in which photographs or still frame images taken from video recordings of a missing person are compared with the skull that is found. By projecting both photographs on top of each other (or, even better, matching a scanned three-dimensional skull model against the face photo/ series of video shots), the forensic anthropologist can try to establish whether they belong to the same person (Krogman and İscan 1986) based on the similarity of morphological features common to both.

Therefore, in every system, for skull identification by craniofacial superimposition, two objects are involved: a skull and an image of a face. The latter is typically a photograph although it can be sometimes replaced by a series of video shots or, more rarely, a portrait of the missing person. The final goal, common to every system, is to assess the anatomical consistency between the skull and the face.

Before reviewing the literature of this forensic identification technique, one should note that different terms have been used to refer to CFS over more than a century of its development. This has been mainly due to the use of close synonyms and also because of the coining of new, more specific terms depending on the supporting technical devices used throughout the developmental history of the overall technique. The following points justify our choice of "craniofacial superimposition" as the most general and currently appropriate name for this forensic identification method. 
- Craniofacial superimposition is the term widely found in the literature, which refers to all the tasks related to this forensic identification technique (Ubelaker et al. 1992; Yoshino et al. 1995; Cattaneo 2007). In particular, the most recent studies confirm the suitability of this terminology (Ranson 2009; Ibáñez et al. 2009a, 2011; Pickering and Bachman 2012; Stephan 2009).

- The term arises as a means to differentiate between the forensic technique itself and the technical devices used to tackle the identification problem. Indeed, craniofacial superimpositions were initially conducted using tracings made from photographs (Sen 1962; Webster 1955) and authors referred to the procedure as "photographic superimposition" (Dorion 1983; Brocklebank and Holmgren 1989; Maat 1989).

As a result of the rapid developments in video technology, the term "video superimposition" was then used when this tool became common in forensic identification (Seta and Yoshino 1993; Pesce Delfino et al. 1993; Shahrom et al. 1996; Yoshino et al. 1997). Finally, the use of computers to assist anthropologists in the identification process has evolved the next generation of CFS systems. ${ }^{1}$ The latter approach is usually referred to as "computer-aided" or "computer-assisted CFS", (Pesce Delfino et al. 1986; Ubelaker et al. 1992; Aulsebrook et al. 1995; Yoshino et al. 1997).

Hence, when using the generic term CFS, we are assuming neither a particular acquisition device nor a given data format for the input of our problem. We simply consider that any CFS method will deal with a 2D image of the disappeared person (typically a photograph) and corresponding images derived from the 3D skull recovered (possibly alongside other skeletal remains).

We are aware there are some authors who prefer to use the term "photographic supra-projection" (Bronkhorst 2006; Stratmann 1998). We avoid its use because it does not explicitly indicate the matching of a skull with a face.

Finally, CFS should not be confused with craniofacial identification either. It is important to recognize that the latter is used as an umbrella term, which includes both CFS and the very different technique of facial approximation ${ }^{3}$ (Clement

\footnotetext{
${ }^{1}$ Attempts to achieve high identification accuracy through the utilization of advanced computer technology have been a monumental task for experts in the field in the last two decades (Lan1992).

${ }^{2}$ Notice that the terms "skull-face superimposition," "skull-photo superimposition," "photographic superimposition," and "video superimposition" have also been used in combination with the "computer-aided/assisted" adjective.

${ }^{3}$ In the past, facial approximation methods have been known by many other names. The most popular of these is facial reconstruction. This name is highly misleading as it creates the erroneous impression that the methods are exact, reliable, and scientific. STEPHAN, C. N. 2009. Craniofacial identification: techniques of facial approximation and craniofacial superimposition. In: BLAU, S. and UBELAKER, D. H. (eds.) Handbook of Forensic Anthropogy and Archeaology. Walnut Creek, CA, USA: Left Coast Press.
} 
and Ranson 1998; Wilkinson 2009; Stephan 2009). Both methods are underpinned by the knowledge of human craniofacial anatomy. It is this principle that ties these two techniques together despite the use of different technical protocols for each of them.

Open Access This chapter is licensed under the terms of the Creative Commons AttributionNonCommercial 2.5 International License (http://creativecommons.org/licenses/by-nc/2.5/), which permits any noncommercial use, sharing, adaptation, distribution and reproduction in any medium or format, as long as you give appropriate credit to the original author(s) and the source, provide a link to the Creative Commons license and indicate if changes were made.

The images or other third party material in this chapter are included in the chapter's Creative Commons license, unless indicated otherwise in a credit line to the material. If material is not included in the chapter's Creative Commons license and your intended use is not permitted by statutory regulation or exceeds the permitted use, you will need to obtain permission directly from the copyright holder.

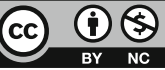




\section{Chapter 2 \\ Importance of Craniofacial \\ Superimposition in Forensic Identification: \\ Historical Perspective}

The successful comparison of human skeletal remains with artistic or photographic replicas has been achieved many times using CFS. From the identification of wellknown criminals, such as Adolf Hitler's chief medical officer Dr. Josef Mengele (Teixeira 1985; Helmer 1987), to the identification of victims of the recent Indian Ocean tsunami (Al-Amad et al. 2006) and in the identification of terrorists (Indriati 2009), this technique has been under continued development since its first application in 1935 (Glaister and Brash 1937). Craniofacial superimposition has become increasingly relevant in forensic scenarios worldwide.

Case studies are ideal for providing information regarding the evolution of the CSF technique and its application in various forensic situations. The most relevant identification works based on CFS throughout history are reviewed below.

The first documented cases, in which ante-mortem images were compared to cranial remains, date to the early twentieth century. In these instances, CFS served as supporting evidence to be presented in court rather than the principal means of identification of the victim.

Perhaps the most prominent case of this early period is the Ruxton case in 1937, in which two female skulls were compared to photographs of missing women using the superimposition technique (Glaister and Brash 1937). The comparison served as supporting evidence in the identification of the two skulls. However, the CFS evidence was not accepted by the court as a means for confirming a positive identification.

After Ruxton, the second case recorded in the literature is the Baptist Church Cellar Murder. In this case, the Photography Department of Guy's Hospital in London was able to superimpose a full-face portrait of a woman onto a full-face X-ray of a skull. The resulting superimposition contributed to the identification of the woman (Simpson 1943).

Three years later, Gordon conducted the identification of a severely burnt body found in an incinerated car near Durban, South Africa. Once again, based on the methodology followed in the Ruxton case, the investigators obtained three photographs of the suspected victim in order to make a comparison with the skull. The 
photographs were used to draw an outline of the head of the victim, which was superimposed onto a machine-made projection drawing of the skull in approximately the same orientation as the head in the photograph. Based on good anatomical correspondence, the investigators established the identification with a considerable degree of probability (Gordon and Drennan 1948).

Other cases in which photographic superimposition was accepted as part of the evidence for identification have been reported in South Africa, (Prinsloo 1953) and Sri Lanka. The latter case, known as the Plumbago Pit case in 1947, aroused public interest, when a putrefied body was found floating in a pit. One and a half months later, without solid evidence as to the identity of the body, Professor G. S. W. Saram explored the possibility of applying the CFS technique. Once again, the methodology was based on the Ruxton case. Neither the identity of the body nor the accuracy of the technique employed was questioned during the trial (Webster 1955).

Although the CFS technique has proved to be helpful in the identification process, the first positive identification accepted in court, based solely on CFS, took place in 1962 in a case reported by Sen (1962). Sen's paper does not offer many details on the methodology implemented, but it does mention that the investigators performed control experiments on collections from the Anatomy Department of the Calcutta Medical College to validate their findings. The Supreme Court of India accepted the comparison of the photo and the skull as evidence for a positive identification (Ubelaker et al. 1992).

In 1973, a prominent case was reported in India. Dismembered parts of a human body, including a human skull, were found over a period of 5 days and an analysis was conducted in order to obtain a positive identification. Captain K. Nagaraju, a doctor in the Indian army, was suspected of murdering his wife and child on a train during their journey from Delhi to Secunderabad. In a hotel bathroom in Secunderabad, he dismembered his wife's body into portions convenient for transport and dumped them at various places in a nearby tank to cover up the crime. The skull was identified by superimposing its photograph over a negative of an ante-mortem photograph of the suspected victim using the negative placed under the ground glass of the camera and marking the salient features of the face on the glass. The skull was mounted on an appropriate skull rest, placed in front of the camera and positioned so as to align it as accurately as possible with the outlines on the ground glass, making due allowance for the soft tissues covering the bone. In this position, a negative of the skull was prepared. The negatives of the photograph and the skull were superimposed by aligning the characteristic points in the negatives. In the report, the following cranial and facial landmarks were noted: (1) the eyes within the orbital plates, with the two pairs of canthii properly aligned; (2) the nasion; (3) the prosthion in the central line; (4) the nasal spine in the centre, which is a little above the tip of the nose; (5) the lower border of the nose; (6) the lower border of the upper jaw, that is, below the tip of the nose; and (7) the zygomas below the eyes. This case resulted in a positive identification and with the suicide of Doctor Nagaraju (Reddy 1973).

One of the most famous identification cases resolved by the use of CFS is that of Dr. Josef Mengele in Sao Paulo, Brazil, in 1985, the infamous physician of the 
concentration camp in Auschwitz. Following a request made by the Brazilian authorities, a team of Brazilian, German, and American Scientists exhumed the remains of a cadaver suspected to belong to Dr. Josef Mengele, based on the information that he died in Brazil on February 7, 1979, and was buried in the cemetery of Embu/São Paulo. Comparative data for the identification of the skeleton was recovered from a medical examination sheet from the SS main office for Race and Settlement in 1938. Data collected included date of birth, height, weight, cranial circumference, cranial form, type of body structure, two photographs of Dr. Josef Mengele in frontal and lateral views at the age of 27 and three at the age of 60. The authors concluded, based on various techniques, including CFS, that "there is no room for doubt that the exhumed skeletal parts are the remains of the corpse of Doctor Joseph Mengele" (Helmer 1987).

Some years later, the presumed skull of W. A. Mozart was examined by a team of French scientists (Puech et al. 1989). The skull was measured exhaustively and it was found to have a very distinctive form (vertical forehead, reduced orbits, and alveolar prognathism). The cranium was superimposed onto wax portraits of Mozart, available from 1778 (The André Meyer collection) and from 1788 by L. Posch. The superimpositions showed good correspondence in the forehead contour, nasal profile, orbit shape, and cheek position. An analysis of the investigation indicated that there was complete conformity concerning all side proportions of the head. This "positive match" put an end to the stories about the remains of Mozart being lost among the mixed bones of St. Marx's cemetery in Vienna (Helmer et al. 1989).

The first 50 years of development of the CFS technique is defined largely by case reports (Sen 1962; Reddy 1973; McKenna et al. 1984; Bastiaan et al. 1986; Basauri 1967; Vogel 1968; Sekharan 1971; Gejvall 1974; Sivaram and Wadhera 1975; Janssens et al. 1978; Brown 1982; Webster et al. 1986). These identification cases, solved using only photographs of both the skull and the face, belong to the first generation of CFS methods called photographic CFS. In the ensuing years, a new modality of CFS techniques based on video technology made their way into the scientific realm. Helmer and Grüner (1977a, b) were the first researchers to introduce the video superimposition technique. They took advantage of the "live images" of the object (skull and photograph) instead of taking photographs, or making tracings or drawings of the skull and face to superimpose them. These systems present an enormous advantage over the former photographic superimposition technique (Helmer and Grüner 1977a; Shahrom et al. 1996; McKenna et al. 1984; AustinSmith and Maples 1994; Yoshino et al. 1995; Solla and Iscan 2001; Fenton et al. 2008) and video superimposition is probably the most broadly employed method in terms of the number of cases solved to date.

One of the first reports in the literature, regarding the use of CFS in a mass casualty incident, belongs to the video CFS modality. In February 2003, commingled human bones were recovered from the Sonora desert in Arizona. Among the numerous human postcranial skeletal elements, five skulls were found (three females and two males). The presumed identity of the victims was known; thus, the incident was considered a closed disaster. The two male victims and the youngest of the three female victims were identified through the analysis of their 
biological profiles, conducted by a forensic anthropologist. The biological profiles of the final two females were very similar, requiring the use of other identification methods to discriminate between them. During the investigation, a photograph of one of the females was found and used to apply the CFS technique by a team of investigators from the Michigan State University Forensic Anthropology Laboratory. The use of the following equipment was reported for the implementation of the technique: two video cameras, a video mixer, a TV monitor, a video cassette recorder, and a desktop computer with image-capturing software. Through this analysis, the investigating team was able to exclude one skull and include the other skull as a possible match. During an in-depth analysis of the technique, the authors concluded that CFS should only be used to exclude or fail to exclude an individual as a potential match, rather than to explicitly identify cadaveric remains (Fenton et al. 2008).

Despite the high number of cases positively identified using video superimposition techniques, the popularization, dramatic development, and endless possibilities offered by computers have turned them into the next-generation CFS systems.

The first documented case of a superimposition performed using a "computerenhanced" method was developed by a team of experts from the FBI, led by Prof. Ubelaker, in 1992. In 1991, a cranium and a mandible discovered in 1978 by a hunter in Putnam County, Ohio, were forwarded to the FBI alongside a facial photograph of the presumed victim. The investigators compared the photograph of the presumed victim and the articulated cranium and mandible with the help of a personal computer and proclaimed this approach "a new, rapid and highly effective method to demonstrate consistency between skeletal features of the head and facial photographs" (Ubelaker et al. 1992). Another well-known computer-assisted CFS case involved the identification of Dr. Eugénio Antonio Berríos Sagredo, the physician accused of making nerve gas during the dictatorial regime of former Chilean President General Augusto Pinochet and whose remains were found in Uruguay in 1995 (Solla and Iscan 2001).

A variety of software packages are used to perform CFS, the most common one is Adobe Photoshop ${ }^{\mathrm{TM}}$. Bilge et al. (2003) described their use of this software together with Corel Draw ${ }^{\mathrm{TM}}$ in order to identify a decapitated body found in a suburban area of Ankara (Turkey). Cadaveric remains were found buried nearby an area where a skull exhibiting two gunshot wounds was found. In order to determine if the skull could be associated to the decapitated body, which had been identified by the wife of the deceased, the authors superimposed a photograph of the victim onto the disassociated skull and reported an "excellent adaptation." The positive match achieved by CFS was confirmed by a DNA analysis performed on the bones, dental pulp, and muscle tissue of the victim (Bilge et al. 2003).

As expected, CFS systems based on the use of computers have become consistently more popular among practitioners. The final example of the use of such a system was recently reported by Pushparani et al. (2012). In this case, an approximately 25 -year-old male skeleton was found with a photograph next to it. The photo and the cranium were examined by the Anthropology Division of the Forensic Sciences Department in India. They employed computer-aided video 
superimposition to perform a match between the photo and the cranium, concluding a likely identification. This was later confirmed by the radiographic comparison of a surgical plate found on the femur of the skeleton and the corresponding ante-mortem plate collected by the authorities (Pushparani et al. 2012).

Furthermore, in the last 5-10 years, the superimposition technique has been greatly simplified by automating the overlay process through computer-aided methods (Nickerson et al. 1991; Ghosh and Sinha 2001; Ibáñez et al. 2009a). These are proposed to be the next-generation CFS systems. However, their use in identification cases is still very limited. Only one case has been reported in the literature that makes use of the Ghosh and Sinha (2001) CFS identification system (Ghosh and Sinha 2005). In this instance, an unidentified skeleton was found in a bush. The remains were photographed in situ and then collected by the authorities. As the body was never claimed, following the post-mortem examination, the skeleton was cremated as is customary in India. A month later, the police found new evidence in the identification of the remains, but as they were no longer available, the investigators employed a novel CFS technique involving the preprocessing of the images from the scene for subsequent analysis by using artificial intelligence techniques. The proposed algorithm compared frontal views of the cranial and facial images and analyzed their hidden symmetry. During this process, the robust system suitably takes care of any ambiguities caused by soft tissue thickness in facial feature selection. The authors successfully superimposed one of the photos taken by the authorities onto one of the ante-mortem photographs of the deceased individual, achieving a positive match between the two pictures (Ghosh and Sinha 2005).

This last case is, most probably, the forerunner of the next-generation CFS techniques. As the steps for achieving the superimposition itself are simplified by the use of computer techniques, this forensic method of identification will gain more acceptance among the scientific community.

Open Access This chapter is licensed under the terms of the Creative Commons AttributionNonCommercial 2.5 International License (http://creativecommons.org/licenses/by-nc/2.5/), which permits any noncommercial use, sharing, adaptation, distribution and reproduction in any medium or format, as long as you give appropriate credit to the original author(s) and the source, provide a link to the Creative Commons license and indicate if changes were made.

The images or other third party material in this chapter are included in the chapter's Creative Commons license, unless indicated otherwise in a credit line to the material. If material is not included in the chapter's Creative Commons license and your intended use is not permitted by statutory regulation or exceeds the permitted use, you will need to obtain permission directly from the copyright holder. 


\section{Chapter 3 \\ Relationships Between the Skull and the Face for Forensic Craniofacial Superimposition}

\subsection{Introduction}

The evaluation of any superimposition is a significant issue that is dependent on the consistency of the anatomical link between the location of the soft tissue surfaces relative to the underlying bone (Taylor and Brown 1998).

In order to evaluate this consistency, a full comprehension of the anatomy of the skull and the relationship between the skull and the face are required. In biological organisms, structure and function are closely related. The human head, in terms of function, is related to four of the five senses: stereoscopic vision (eyes), audition (ears), gustation (tongue/mouth), and olfaction (nose), along with the protection of the brain. These functions are responsible for the structure of the head, and therefore the form of the face and the skull will be directly related to the position of the brain, eyes, ears, mouth, and nose.

From an anthropological perspective, the reliability of CFS and an identification based on this technique are evaluated mainly on the basis of the consistency between the anatomical structures of the face and skull.

The forensic expert usually relies on the analysis of anatomical criteria such as the soft tissue thickness, outlines, and positional relationships between the skull and the face. In the scientific literature, there are several studies conducted to assess the quality/degree of matching in CFS as well as to examine the criteria used to conduct this assessment. Before reviewing the different studies, Martin and Saller's studies (1957) must be considered. They created a treatise in which the fundamental pillars of this discipline were established. They defined an important set of craniometric and somatometric points (Tables 3.1, 3.2, and 3.3) that are crucial for all anthropological studies (Figs. 3.1, 3.2, 3.3, 3.4, 3.5, and 3.6).

A correct evaluation of anatomical consistency between facial and cranial structures is of paramount importance for reliable CFS. Generating accurate data on soft tissue thickness and the positioning of facial structures are important steps to improve current practices in craniofacial identification. At the moment, there is a 
Table 3.1 Craniometric points from Martin (1914) study (neurocranium)

Craniometric points: neurocranium

\begin{tabular}{l|l|l|l|l|l}
\hline ast & asterion & $\mathrm{ft}$ & frontotemporale & $\mathrm{ms}$ & mastoideale \\
\hline $\mathrm{au}$ & auriculare & $\mathrm{g}$ & glabella & o & opisthion \\
\hline $\mathrm{b}$ & bregma & $\mathrm{i}$ & inion & op & opisthocranion \\
\hline $\mathrm{ba}$ & basion & 1 & lambda & po & porion \\
\hline eu & euryon & $\mathrm{m}$ & metopion & so & supraorbitale \\
\hline
\end{tabular}

Taken from Martin and Saller (1957)

Table 3.2 Craniometric points from Martin (1914) study (splanchnocranium)

\begin{tabular}{l|l|l|l|l|l}
\hline \multicolumn{6}{l}{ Craniometric points: splanchnocranium } \\
\hline $\mathrm{d}$ & dacryon & $\mathrm{n}$ & nasion & rhi & rhinion \\
\hline gn & gnathion & $\mathrm{ns}$ & nasospinale & zo & zygoorbitale \\
\hline go & gonion & or & orbitale & zm & zygomaxillare \\
\hline $\mathrm{ml}$ & mentale & $\mathrm{pg}$ & pogonion & zy & zygion \\
\hline $\mathrm{mf}$ & maxillo-frontale & $\mathrm{pr}$ & prosthion & & \\
\hline
\end{tabular}

Taken from Knußmann (1988)

Table 3.3 Somatometric points from Martin (1914) study

\begin{tabular}{|c|c|c|c|c|c|c|c|}
\hline al & alare & $\mathrm{g}$ & glabellare & ma & mastoidale & $\mathrm{pr}$ & prosthion \\
\hline cdl & $\begin{array}{l}\text { condylion } \\
\text { laterale }\end{array}$ & go & gonion & $\mathrm{n}$ & nasion & prn & pronasale \\
\hline $\mathrm{ch}$ & cheilion & I & inion & or & orbitale & ps & $\begin{array}{l}\text { palpebrale } \\
\text { superius }\end{array}$ \\
\hline en & endocanthion & labm & labiomentale & os & \begin{tabular}{|l|} 
orbitale \\
superius
\end{tabular} & $\mathrm{sa}$ & superaulare \\
\hline eu & euryon & li & labrale inferius & pg & pogonion & sba & subaurale \\
\hline ex & exocanthion & 1s & $\begin{array}{l}\text { labrale } \\
\text { superius }\end{array}$ & pi & $\begin{array}{l}\text { palpebral } \\
\text { inferius }\end{array}$ & sci & superciliare \\
\hline $\mathrm{ft}$ & frontotemporale & $\mathrm{m}$ & metopion & po & porion & $\mathrm{se}$ & sellion \\
\hline gn & gnathion & op & opisthocranion & $\mathrm{pu}$ & pupilare & sn & subnasale \\
\hline sto & stomion & $\mathrm{t}$ & tragion & $\operatorname{tr}$ & trichion & $\mathrm{v}$ & vertex \\
\hline zy & zygion & & & & & & \\
\hline
\end{tabular}

Taken from Knußmann (1988)

clear lack of consensus in methodological approaches for CFS. The development of standard protocols is necessary to enhance the credibility of the technique, making it more readily admissible in judicial processes.

\subsection{Anthropometrical Relationships}

Understanding the relationship between the skull and the facial soft tissue has major relevance for forensic identification. Facial soft tissue thickness, measured as the distance from the skin surface to the most superficial surface of the underlying 


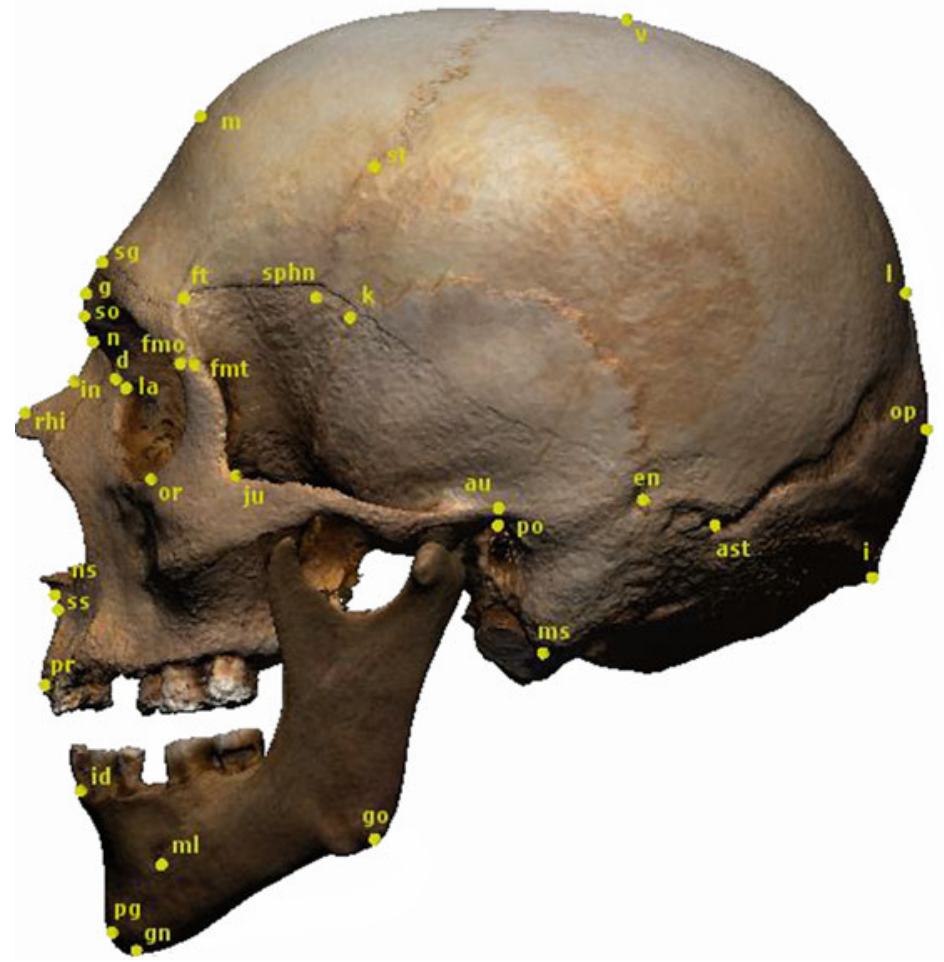

Fig. 3.1 Craniometric points in lateral view. Taken from Knußmann (1988)
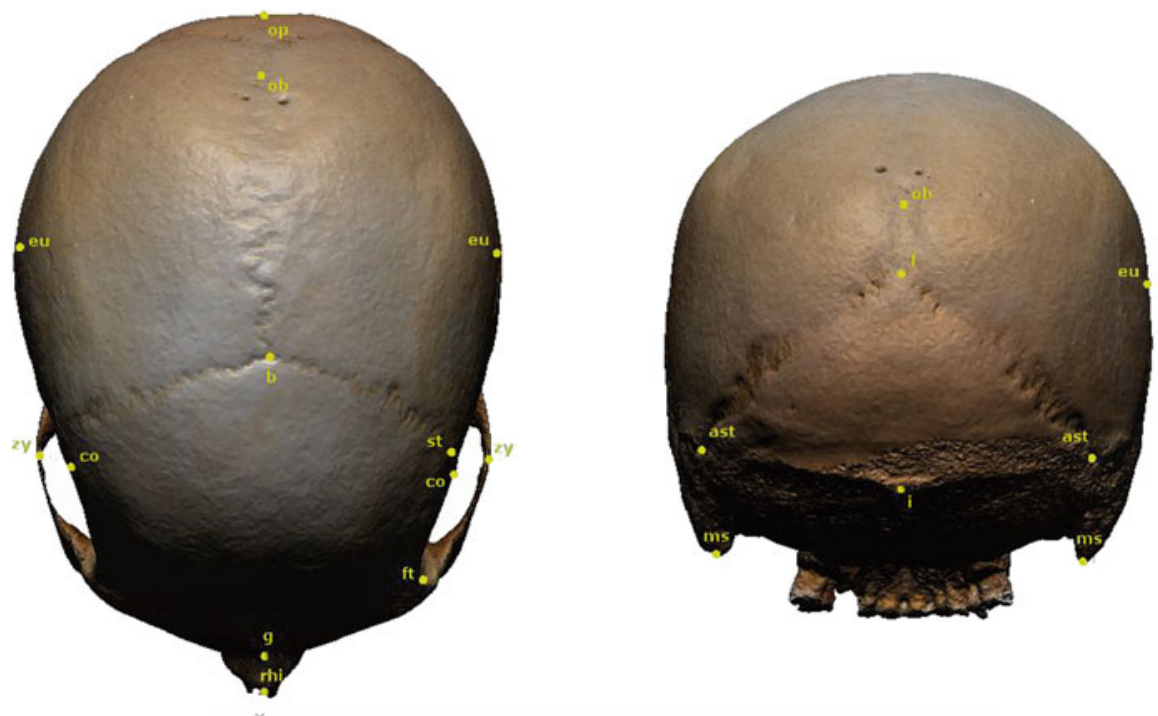

Fig. 3.2 Craniometric point in vertical view (left) and in occipital view (right). Taken from Knußmann (1988) 


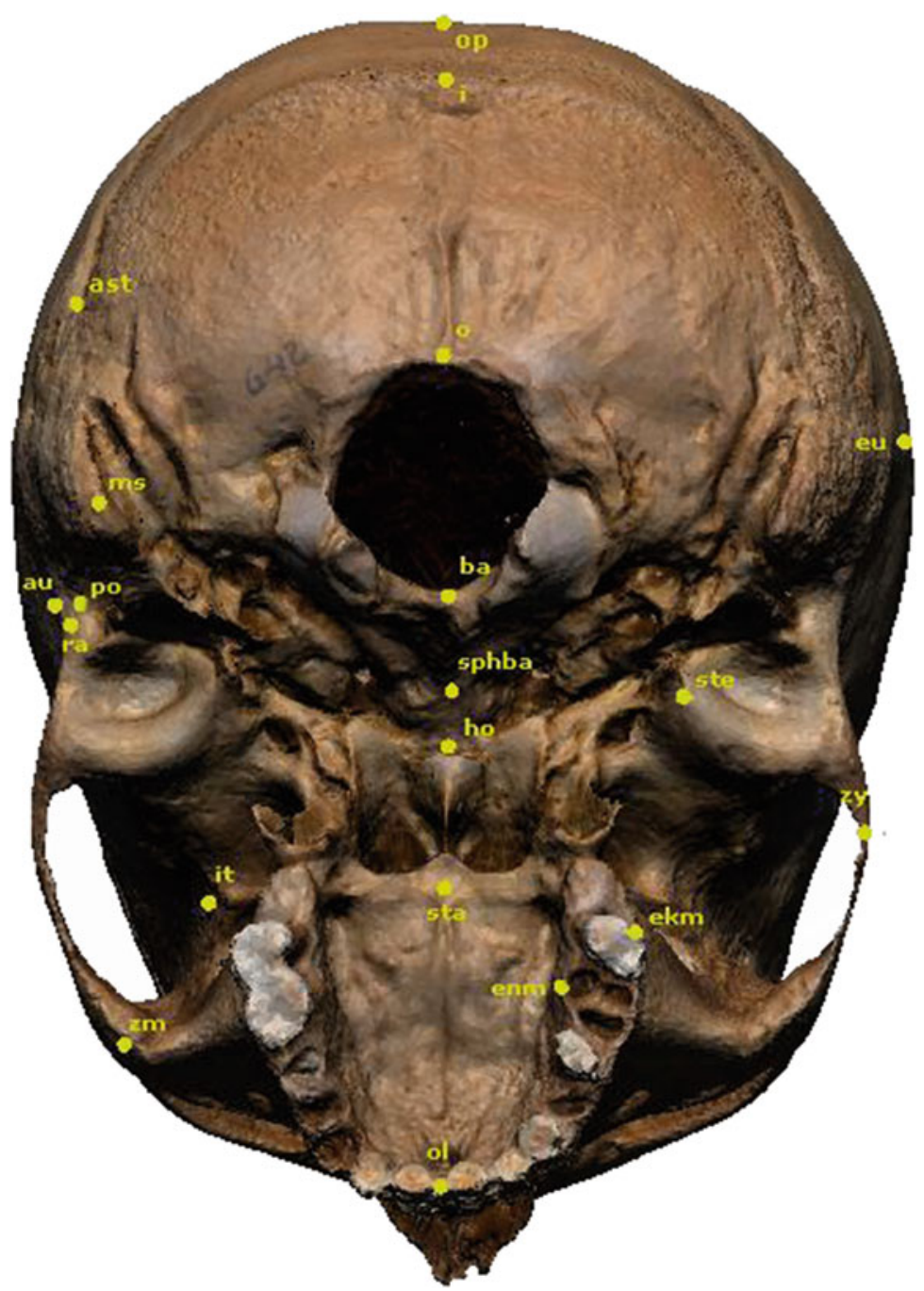

Fig. 3.3 Craniometric points in basilar view. Taken from Knußmann (1988)

skeletal tissue at specific landmarks, provides an important criterion for the evaluation of anatomical consistency. This kind of measurement provides general information on the match between the face and the skull, using facial soft tissue thickness as a means to control the outer contour of the face during the superimposition (Codinha and Fialho 2010; Stephan and Simpson 2008).

Due to the scientific value of facial soft tissue thickness in craniofacial identification, numerous studies have been conducted since 1883, with a great variation in measuring techniques, sample size, population ancestry, anatomical landmarks, and variables analyzed (e.g., sex, age, and body composition) (Codinha and Fialho 2010; Stephan and Simpson 2008). 


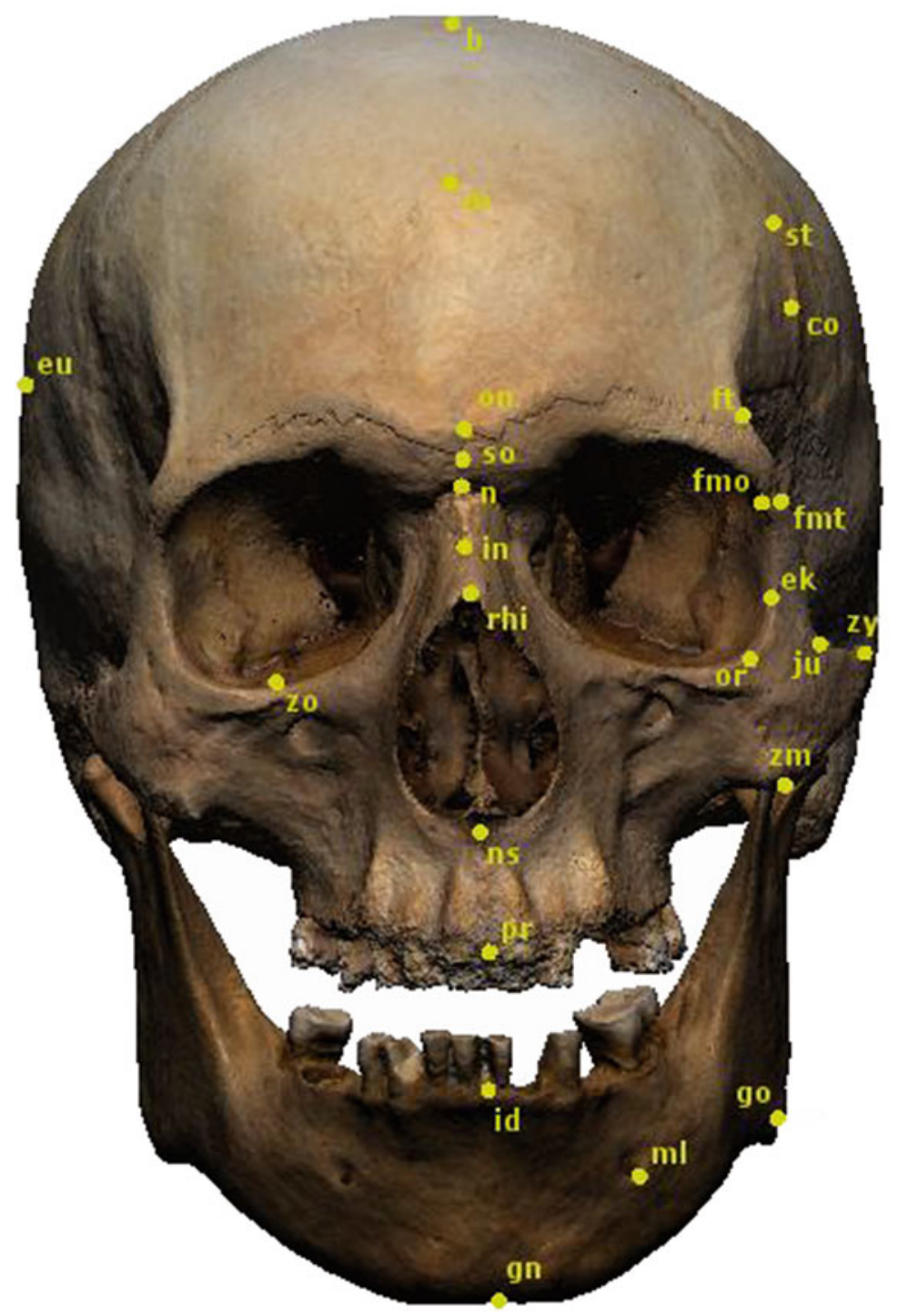

Fig. 3.4 Craniometric points in frontal view. Taken from Knußmann (1988)

Some of the main modalities for soft tissue thickness acquisition mentioned in the literature include:

- Needle puncture (Codinha and Fialho 2010; Simpson and Henneberg 2002; Domaracki and Stephan 2006; Rhine and Campbell 1980; Suzuki 1948; Birkner 1905; Stadtmuller 1925; Rhine et al. 1982; Galdames et al. 2008; His 1895; von Eggeling 1909) 


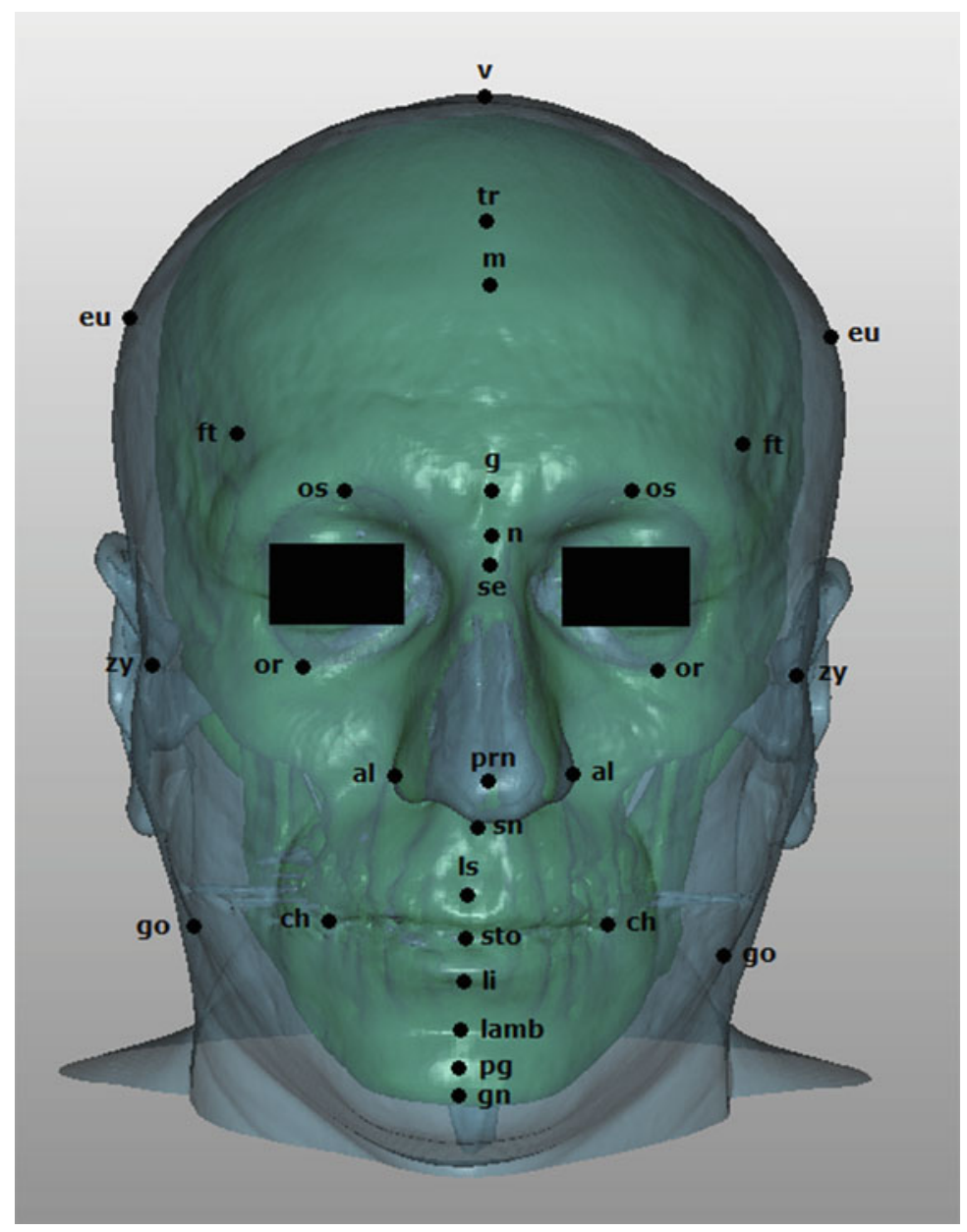

Fig. 3.5 Somatometric points in frontal view

- Cephaloradiography (George 1987; Leopold 1968; Weinig 1958; Bankowski 1958)

- Ultrasound imaging (Aulsebrook et al. 1996; Wilkinson 2002)

- Computer-assisted tomography (CT) (Phillips and Smuts 1996)

- Cone-beam CT (Bankowski 1958)

- Magnetic resonance imaging (Sahni 2002)

A summary of the most important soft tissue thickness studies and their main characteristics are listed in Table 3.4. None of these methodologies offer a perfect solution, as each technique has advantages and disadvantages. For example, needle puncture methods are inexpensive, but cadaveric material is not wholly 


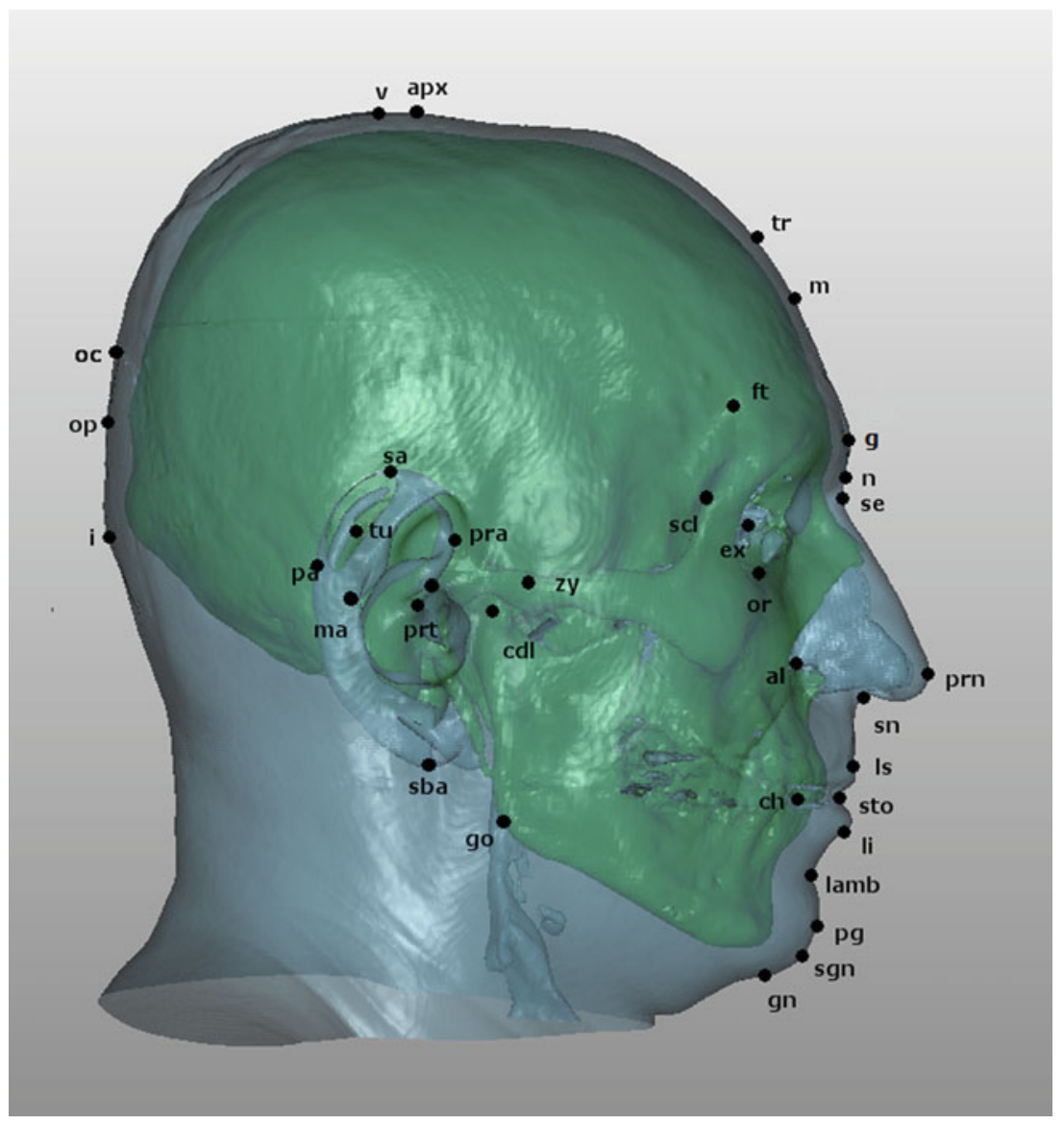

Fig. 3.6 Somatometric points in lateral view

representative of living subjects; CT scans are accurate and reproducible but may present gravity effects on the supine face, artifacts, and radiation damage; craniographs are inexpensive and the subject is upright, but the images can suffer from magnification and planar issues; ultrasound can be used on upright living subjects but involves contact and pressure issues. A more extensive list of advantages and disadvantages of the different methodologies used in soft tissue data collection was analyzed in Stephan and Simpson (2008) and in Preedy (2012). The latter is summarized in Tables 3.5 and 3.6.

The soft tissue thickness depth measurements are applied in facial depiction, but if they are used in CFS, changes due to facial expression must also be considered when determining identity. These measurements are usually, but not always, perpendicular to the bony structures, and are most useful if the image shows the soft tissue directly to the point of measurement (Clement and Ranson 1998). 
Table 3.4 Landmarks used by authors, sample, and methodology

\begin{tabular}{|c|c|c|c|c|c|c|c|}
\hline Reference & Date & $\begin{array}{l}\begin{array}{l}\text { Number } \\
\text { of points }\end{array} \\
\end{array}$ & Male & Female & Total & Population $^{\mathrm{a}}$ & Methods \\
\hline Welcker & 1883 & 7 & 13 & & 13 & $\begin{array}{l}\text { White } \\
\text { (Cadavers) }\end{array}$ & $\begin{array}{l}\text { Tissue punc- } \\
\text { ture by using } \\
\text { needle }\end{array}$ \\
\hline His & 1895 & 15 & 24 & 4 & 28 & $\begin{array}{l}\text { White } \\
\text { (Cadavers) }\end{array}$ & $\begin{array}{l}\text { Tissue punc- } \\
\text { ture by using } \\
\text { needle }\end{array}$ \\
\hline $\begin{array}{l}\text { Kollmann } \\
\text { and Buchly }\end{array}$ & 1898 & 18 & 21 & 4 & 25 & $\begin{array}{l}\text { White European } \\
\text { (Cadavers) }\end{array}$ & $\begin{array}{l}\text { Tissue punc- } \\
\text { ture by using } \\
\text { needle }\end{array}$ \\
\hline Fischer & 1905 & 18 & 2 & & 2 & $\begin{array}{l}\text { Mongoloid } \\
\text { (Papuans) }\end{array}$ & $\begin{array}{l}\text { Tissue punc- } \\
\text { ture by using } \\
\text { needle }\end{array}$ \\
\hline Birkner & 1905 & 18 & 9 & & 6 & $\begin{array}{l}\text { Mongoloid } \\
\text { (Chinese) }\end{array}$ & $\begin{array}{l}\text { Tissue punc- } \\
\text { ture by using } \\
\text { needle }\end{array}$ \\
\hline Czekanowski & 1907 & 6 & 64 & 51 & 112 & $\begin{array}{l}\text { White Cauca- } \\
\text { sian (Cadavers) }\end{array}$ & $\begin{array}{l}\text { Tissue punc- } \\
\text { ture by using } \\
\text { needle }\end{array}$ \\
\hline $\begin{array}{l}\text { Von } \\
\text { Eggeling }\end{array}$ & 1909 & 18 & 3 & & 3 & $\begin{array}{l}\text { Black } \\
\text { (Hererons) }\end{array}$ & $\begin{array}{l}\text { Tissue punc- } \\
\text { ture by using } \\
\text { needle }\end{array}$ \\
\hline Stadtmuller & $\begin{array}{l}1923- \\
1925\end{array}$ & 20 & 15 & 3 & 18 & $\begin{array}{l}\text { Mongoloid, } \\
\text { White }\end{array}$ & $\begin{array}{l}\text { Tissue punc- } \\
\text { ture by using } \\
\text { needle }\end{array}$ \\
\hline Suzuki & 1948 & 18 & 7 & 48 & 55 & $\begin{array}{l}\text { Mongoloid } \\
\text { (Japanese) }\end{array}$ & $\begin{array}{l}\text { Tissue punc- } \\
\text { ture by using } \\
\text { needle }\end{array}$ \\
\hline Weinig & 1958 & 10 & 99 & 21 & 120 & $\begin{array}{l}\text { White Ameri- } \\
\text { cans (Living) }\end{array}$ & Craniographs \\
\hline Bankowski & 1958 & 13 & 15 & 9 & 24 & $\begin{array}{l}\text { White } \\
\text { Europeans } \\
\text { (Living) }\end{array}$ & Craniographs \\
\hline Berger & 1965 & 14 & 26 & 102 & 128 & $\begin{array}{l}\text { White Cauca- } \\
\text { sian (Cadavers) }\end{array}$ & $\begin{array}{l}\text { Tissue punc- } \\
\text { ture by using } \\
\text { needle }\end{array}$ \\
\hline Leopold & 1968 & 13 & 102 & 52 & 154 & $\begin{array}{l}\text { White } \\
\text { Europeans } \\
\text { (Cadavers) }\end{array}$ & Craniographs \\
\hline Sutton & 1969 & & & & 104 & $\begin{array}{l}\text { White Cauca- } \\
\text { sian (Cadavers) }\end{array}$ & $\begin{array}{l}\text { Tissue punc- } \\
\text { ture by using } \\
\text { needle }\end{array}$ \\
\hline $\begin{array}{l}\text { Rhine and } \\
\text { Campbell }\end{array}$ & 1980 & 21 & 44 & 15 & 59 & $\begin{array}{l}\text { American Black } \\
\text { (Unembalmed } \\
\text { cadavers) }\end{array}$ & $\begin{array}{l}\text { Needle and } \\
\text { rubber-stopper } \\
\text { technique }\end{array}$ \\
\hline
\end{tabular}


Table 3.4 (continued)

\begin{tabular}{|c|c|c|c|c|c|c|c|}
\hline Reference & Date & \begin{tabular}{|l|}
$\begin{array}{l}\text { Number } \\
\text { of points }\end{array}$ \\
\end{tabular} & Male & Female & Total & Population $^{\mathrm{a}}$ & Methods \\
\hline Farkas & 1981 & 132 & & & & $\begin{array}{l}\text { White (Cauca- } \\
\text { sian North } \\
\text { American } \\
\text { population) }\end{array}$ & \\
\hline Rhine et al. & 1982 & 21 & 37 & 19 & 56 & $\begin{array}{l}\text { American White } \\
\text { Caucasian } \\
\text { (Unembalmed } \\
\text { cadavers) }\end{array}$ & $\begin{array}{l}\text { Tissue punc- } \\
\text { ture by using } \\
\text { needle }\end{array}$ \\
\hline Rhine & 1983 & 21 & 9 & 2 & 11 & $\begin{array}{l}\text { South-western } \\
\text { Indians } \\
\text { (Cadavers) }\end{array}$ & $\begin{array}{l}\text { Tissue punc- } \\
\text { ture by using } \\
\text { needle }\end{array}$ \\
\hline Helmer & 1984 & 34 & 61 & 62 & 123 & $\begin{array}{l}\text { White European } \\
\text { (Living) }\end{array}$ & Ultrasound \\
\hline Hodson et al. & 1985 & 20 & & & 50 & $\begin{array}{l}\text { American } \\
\text { Caucasians }\end{array}$ & Ultrasound \\
\hline Dumont & 1986 & 9 & 93 & 101 & 194 & Caucasian & X-Ray \\
\hline George & 1987 & 10 & 17 & 37 & 54 & $\begin{array}{l}\text { Whites Ameri- } \\
\text { can (Living) }\end{array}$ & $\begin{array}{l}\text { Lateral } \\
\text { craniographs }\end{array}$ \\
\hline $\begin{array}{l}\text { Nanda and } \\
\text { Meng }\end{array}$ & 1990 & 4 & 17 & 23 & 40 & Caucasian & X-Ray \\
\hline $\begin{array}{l}\text { Aulsebrook } \\
\text { et al. }\end{array}$ & 1996 & - & 55 & & 55 & $\begin{array}{l}\text { Zulu (Living) } \\
\text { Negroids }\end{array}$ & $\begin{array}{l}\text { Lateral, } \\
\text { oblique cepha- } \\
\text { lometry } \\
\text { ultrasound }\end{array}$ \\
\hline $\begin{array}{l}\text { Phillips and } \\
\text { Smuts }\end{array}$ & 1996 & 21 & 16 & 16 & 32 & $\begin{array}{l}\text { Mixed raced } \\
\text { South Africans } \\
\text { (Living) }\end{array}$ & $\begin{array}{l}\text { Computerized } \\
\text { tomography }\end{array}$ \\
\hline $\begin{array}{l}\text { Manhein and } \\
\text { Listi }\end{array}$ & 2000 & 19 & & & 712 & American & Ultrasound \\
\hline $\begin{array}{l}\text { El- } \\
\text { Mehallawi } \\
\text { and Soliman }\end{array}$ & 2001 & 17 & 120 & 84 & 204 & $\begin{array}{l}\text { Egyptian } \\
\text { (Living) }\end{array}$ & Ultrasound \\
\hline $\begin{array}{l}\text { El- } \\
\text { Mehallawi } \\
\text { and Soliman }\end{array}$ & 2001 & 17 & 120 & 84 & 204 & Egyptian & Ultrasound \\
\hline Sahni & 2002 & 19 & 30 & 30 & 60 & Indians (Living) & MRI scans \\
\hline $\begin{array}{l}\text { Simpson and } \\
\text { Henneberg }\end{array}$ & 2002 & 20 & 17 & 23 & 40 & Australian & $\begin{array}{l}\text { Tissue punc- } \\
\text { ture by using } \\
\text { needle }\end{array}$ \\
\hline Wilkinson & 2002 & 21 & 99 & 101 & 200 & $\begin{array}{l}\text { British } \\
\text { Juveniles }\end{array}$ & $\begin{array}{l}\text { Ultrasonic } \\
\text { echo-location }\end{array}$ \\
\hline $\begin{array}{l}\text { Williamson } \\
\text { and } \\
\text { Nawrocki }\end{array}$ & 2002 & 15 & 77 & 147 & 224 & $\begin{array}{l}\text { African } \\
\text { American }\end{array}$ & X-Ray \\
\hline $\begin{array}{l}\text { Utsuno and } \\
\text { Kageyama }\end{array}$ & 2005 & 12 & 0 & 112 & 112 & Japanese & X-Ray \\
\hline
\end{tabular}


Table 3.4 (continued)

\begin{tabular}{|c|c|c|c|c|c|c|c|}
\hline Reference & Date & $\begin{array}{l}\text { Number } \\
\text { of points }\end{array}$ & Male & Female & Total & Population $^{\mathrm{a}}$ & Methods \\
\hline $\begin{array}{l}\text { De Greef } \\
\text { et al. }\end{array}$ & 2006 & 52 & 510 & 457 & 967 & $\begin{array}{l}\text { White Cauca- } \\
\text { sian (Living) }\end{array}$ & Ultrasound \\
\hline $\begin{array}{l}\text { Domaracki } \\
\text { and Stephan }\end{array}$ & 2006 & 13 & 19 & 14 & 33 & Australian & $\begin{array}{l}\text { Tissue punc- } \\
\text { ture by using } \\
\text { needle }\end{array}$ \\
\hline $\begin{array}{l}\text { Vander } \\
\text { Pluym et al. }\end{array}$ & 2007 & - & 5 & 5 & 10 & $\begin{array}{l}\text { American (mul- } \\
\text { tiple ancestries) }\end{array}$ & MRI \\
\hline Panenková & 2007 & 14 & 80 & 80 & 160 & Slovak & CT Scan \\
\hline $\begin{array}{l}\text { Galdames } \\
\text { et al. }\end{array}$ & 2008 & 14 & 30 & & 30 & Cadavers & $\begin{array}{l}\text { Tissue punc- } \\
\text { ture by using } \\
\text { needle }\end{array}$ \\
\hline Sahni et al. & 2008 & 29 & 173 & 127 & 300 & Indian & MRI \\
\hline Inada et al. & 2009 & & 40 & 40 & 80 & $\begin{array}{l}\text { Mongoloid } \\
\text { (Japanese) } \\
\text { (Living) }\end{array}$ & Cephalograms \\
\hline $\begin{array}{l}\text { Codinha and } \\
\text { Fialho }\end{array}$ & 2010 & 20 & 103 & 48 & 151 & Portuguese & $\begin{array}{l}\text { Tissue punc- } \\
\text { ture by using } \\
\text { needle }\end{array}$ \\
\hline $\begin{array}{l}\text { Menezes } \\
\text { et al. }\end{array}$ & 2009 & 50 & 531 & 357 & 888 & & $\begin{array}{l}\text { Electronic } \\
\text { digitizer }\end{array}$ \\
\hline $\begin{array}{l}\text { Tedeschi- } \\
\text { Oliveira et al. }\end{array}$ & 2009 & 11 & 26 & 14 & 40 & Brazilian & $\begin{array}{l}\text { Tissue punc- } \\
\text { ture by using } \\
\text { needle }\end{array}$ \\
\hline $\begin{array}{l}\text { Cavanagh } \\
\text { and Steyn }\end{array}$ & 2011 & 28 & 0 & 154 & 154 & South African & CT Scan \\
\hline Saxena et al. & 2012 & 7 & 19 & 21 & 40 & Indian & CT Scan \\
\hline Hwang et al. & 2012 & 31 & 50 & 50 & 100 & Korean & CT Scan \\
\hline
\end{tabular}

${ }^{a}$ Population as described by the authors

Other factors that must be taken into account when utilizing soft tissue data are growth, weight change, and age-related changes. For this purpose, many authors place emphasis on facial features with minimal soft tissue depth. The middle third of the face (eyes, nose, and teeth) is less influenced by any photographic distortion and could be considered more accurate (Taylor and Brown 1998).

Currently, there is no agreement among practitioners as to the number of landmarks, their name, or their correct position; thus, comparison between the results of several papers is extremely difficult (Panenková 2007). Furthermore, some papers use the vernacular rather than anatomical terminology, that is, "end of nasal" (Phillips and Smuts 1996), "middle of the bony nose" (Helmer 1984), and "angle of mouth" (Aulsebrook et al. 1996; Panenková 2007).

There seems to be one major difference of opinion with regard to the thicknesses of facial tissues (Wilkinson 2002). The results obtained by the needle puncture method in cadavers are relative to the process of dehydration of the soft tissue (10-18 g/day/weight), resulting in considerable variations depending on the 
Table 3.5 Comparison of the commonly used measuring techniques for calculating soft-tissue depth

\begin{tabular}{|c|c|c|}
\hline $\begin{array}{l}\text { Method of } \\
\text { measurement }\end{array}$ & Advantage & Disadvantage \\
\hline Needle puncture & $\begin{array}{l}\text { Low cost. } \\
\text { Operating characteristics well } \\
\text { defined. Measurements can be made } \\
\text { in Frankfort. Horizontal plane. }\end{array}$ & $\begin{array}{l}\text { Invasive. } \\
\text { Most information from cadavers, } \\
\text { soft tissue may not accurately } \\
\text { reflect living tissue. } \\
\text { Compression of soft tissue inevita- } \\
\text { ble during measurement. } \\
\text { No visualization of the skeletal } \\
\text { surface. }\end{array}$ \\
\hline $\begin{array}{l}\text { Plain film } \\
\text { radiography }\end{array}$ & $\begin{array}{l}\text { Standard cephalograms widely used } \\
\text { in dentistry and medicine. } \\
\text { Films generally taken in Frankfort } \\
\text { horizontal plane. Relatively inex- } \\
\text { pensive. } \\
\text { No compression of tissue while tak- } \\
\text { ing measurement. }\end{array}$ & $\begin{array}{l}\text { Exposure to ionizing radiation, } \\
\text { patient selection may bias results. } \\
\text { Only useful where surface land- } \\
\text { mark and bony landmark are par- } \\
\text { allel to the film plate. } \\
\text { Metallic implants (braces and fill- } \\
\text { ings) may interfere with measure- } \\
\text { ments. Magnification issues. }\end{array}$ \\
\hline $\begin{array}{l}\text { Computerized } \\
\text { tomography }\end{array}$ & $\begin{array}{l}\text { Widely used in medicine and den- } \\
\text { tistry. } \\
\text { Images are digital and easy to } \\
\text { manipulate (e.g., absorption charac- } \\
\text { teristic of soft and hard tissue rela- } \\
\text { tively easy to distinguish). } \\
\text { Accuracy of surface landmark } \\
\text { placement relative to bony landmark } \\
\text { can be verified. } \\
\text { Paired landmarks easily measured. } \\
\text { Known accuracy and } \\
\text { reproducibility. }\end{array}$ & $\begin{array}{l}\text { Expensive. } \\
\text { Requires exposure to ionizing } \\
\text { radiation, patient selection may } \\
\text { introduce bias. } \\
\text { Patient motion artifact (voluntary } \\
\text { or involuntary) may interfere with } \\
\text { measurements. } \\
\text { Radio-opaque objects (e.g., filling, } \\
\text { braces) may distort images and } \\
\text { measurements. } \\
\text { Images are not in Frankfort hori- } \\
\text { zontal plane. } \\
\text { Gravity effects on soft tissue due to } \\
\text { supine position. } \\
\text { Translation to 3D shape may } \\
\text { involve manual intervention. }\end{array}$ \\
\hline $\begin{array}{l}\text { Magnetic } \\
\text { Resonance Imaging }\end{array}$ & $\begin{array}{l}\text { No exposure to ionizing radiation, } \\
\text { ethically acceptable to image sub- } \\
\text { jects for tissue depth estimation. } \\
\text { Can be repeated on same subjects to } \\
\text { obtain longitudinal data. } \\
\text { No soft-tissue compression during } \\
\text { measurement } \\
\text { Images are digital and easy to } \\
\text { manipulate (e.g. absorption charac- } \\
\text { teristics of soft and hard tissue rela- } \\
\text { tively easy to distinguish). } \\
\text { Accuracy of surface landmark } \\
\text { placement relative to bony landmark } \\
\text { can be verified. } \\
\text { Paired landmarks easily measured. }\end{array}$ & $\begin{array}{l}\text { Very expensive. } \\
\text { Images generally not acquired in } \\
\text { Frankfort horizontal plane. } \\
\text { Requires exposure to high-intensity } \\
\text { magnetic field, subjects with } \\
\text { metallic exposure not eligible. } \\
\text { Subject motion artifact distorts } \\
\text { images. } \\
\text { May not visualize bone well. } \\
\text { Gravity effects due to supine posi- } \\
\text { tion. } \\
\text { Translation to 3D shape may } \\
\text { involve manual intervention. }\end{array}$ \\
\hline
\end{tabular}


Table 3.5 (continued)

\begin{tabular}{|c|c|c|}
\hline $\begin{array}{l}\text { Method of } \\
\text { measurement }\end{array}$ & Advantage & Disadvantage \\
\hline Ultrasound & $\begin{array}{l}\text { No exposure to ionizing radiation; } \\
\text { can be used repeatedly in the same } \\
\text { subject. } \\
\text { Portable, can be used in the field. } \\
\text { Measurements made in Frankfort } \\
\text { horizontal plane. }\end{array}$ & $\begin{array}{l}\text { Probe must touch skin surface, tis- } \\
\text { sue compression possible with } \\
\text { inexperienced operator. } \\
\text { Operating characteristics of porta- } \\
\text { ble equipment differ according to } \\
\text { manufacturer and must be defined } \\
\text { before use. } \\
\text { Difficult to scan parallel to skeletal } \\
\text { surface and this can make visuali- } \\
\text { zation of the surface more } \\
\text { challenging. }\end{array}$ \\
\hline
\end{tabular}

Taken from Taylor and Brown (1998)

Table 3.6 Systematic bias of soft-tissue measurement according to method of measurements

\begin{tabular}{l|l|l|l}
\hline $\begin{array}{l}\text { Measurement } \\
\text { technique }\end{array}$ & $\begin{array}{l}\text { Landmarks at which tissue } \\
\text { depths are consistently } \\
\text { higher than with other } \\
\text { techniques }\end{array}$ & $\begin{array}{l}\text { Landmarks at which tissue } \\
\text { depths are consistently } \\
\text { lower than with other } \\
\text { techniques }\end{array}$ & $\begin{array}{l}\text { Measurements } \\
\text { technique that } \\
\text { most closely } \\
\text { correlates }\end{array}$ \\
\hline $\begin{array}{l}\text { Needle } \\
\text { puncture }\end{array}$ & - & - & - \\
\hline $\begin{array}{l}\text { Plain } \\
\text { radiology }\end{array}$ & All midline landmarks & $\begin{array}{l}\text { Lateral landmarks: gonion } \\
\text { and zygion }\end{array}$ & - \\
\hline CT scan & All midline landmarks & All midline points & MRI \\
\hline MRI scan & - & All midline points & CT \\
\hline Ultrasound & $\begin{array}{l}\text { Supra M2, infra M2, gonion, } \\
\text { mid-infraorbital, anterior } \\
\text { masseter border }\end{array}$ & - & $\begin{array}{l}\text { Needle puncture } \\
\text { (except for supra } \\
\text { M2) }\end{array}$ \\
\hline
\end{tabular}

Taken from Preedy (2012)

different methods used for conservation, alongside the development of rigor mortis, which affects the muscle fibers (Galdames et al. 2008; de Greef et al. 2006).

Various investigators have compared the soft facial tissue thicknesses measured in fresh cadavers with embalmed cadavers. Simpson and Henneberg (2002) reported an increase in soft tissue thickness of all landmarks, due to embalming processes. Galdames et al. (2008) indicated that the embalmed cadavers presented larger thicknesses of tissue in all sites, with the exception of the right exocanthion and right and left gonion points. The most significant differences between fresh and embalmed tissue were observed at the trichion, glabella, nasion, pogonion, superciliary, supraorbital, infraorbital, and gonion points (Galdames et al. 2008; Simpson and Henneberg 2002).

Postmortem data and the use of the different methods of cadaver conservation must be considered when comparing measurements with those obtained from living subjects by means of radiograph, ultrasound, computerized tomography, or nuclear magnetic resonance (Clement and Ranson 1998; Galdames et al. 2008). 


\subsection{Anatomical Relationships}

The face is one of the most individualistic and unique parts of the human body. It is important to establish the most commonly utilized morphological features when carrying out an assessment of face and skull correspondence. There are many standards for the prediction of the soft tissue features from skeletal assessment, and these standards were established through human dissection, palpation, medical imaging modalities, and direct anthropometry of living subjects. The relative limitations of each method when evaluating the reliability of the standards produced should be noted. Human dissection studies offer a unique opportunity to visualize the face and the related skeletal structures, but are limited by the effects of embalming, deformation associated with a cadaver face, and dehydration. Palpation studies employ living faces but are limited by the inability to accurately locate bony landmarks, especially in the areas of the face with the greatest soft tissues. Clinical imaging of living faces enables the visualization of soft and hard tissues simultaneously, but different imaging modalities suffer from gravitational problems (the subject is supine), artifacts (dental flare), bone visibility (MRI), and pressure effects (ultrasound). Direct anthropometry from a living subject is probably the most reliable form of data collection, but although multiple measurements can be collected from the soft tissues, direct measurements of the skull are limited to the teeth.

This report will attempt to highlight the published anatomical standards feature by feature.

\subsubsection{General Face Shape}

The relationship between the shape of the head and the shape of the cranium is well established. Several classifications of this relationship have been published (Clement and Ranson 1998; Fedosyutkin and Nainys 1993; Balueva et al. 2009), Table 3.7 summarizes the standards.

The relationship between facial measurements and related skull measurements has also been studied (Balueva et al. 2009). Table 3.8 summarizes the standards.

\subsubsection{The Eyebrows}

Eyebrow pattern standards (Table 3.9) have been developed from a combination of palpation (Balueva et al. 2009) and craniograph studies (Fedosyutkin and Nainys 1993). 
Table 3.7 Shape relationships of head and cranium

\begin{tabular}{|c|c|}
\hline $\begin{array}{l}\text { Morphological and } \\
\text { facial traits }\end{array}$ & Correspondence with facial structures \\
\hline \multicolumn{2}{|c|}{ The general head shape } \\
\hline Shape of face & Transverse arc of the cranium \\
\hline Rounded & Semisphere \\
\hline Square & Pentagonoid \\
\hline Oval & Oval \\
\hline \multirow[t]{2}{*}{ Triangular } & Rectangular \\
\hline & $\begin{array}{l}\text { The shape of the temporal lines provides information about the forehead } \\
\text { width }\end{array}$ \\
\hline Shape of the face & Mandible \\
\hline Oval & $\begin{array}{l}\text { If the gonial angle is over } 125^{\circ} \text { and the coronoid process is high, the } \\
\text { lowest part of the head is likely to be narrow }\end{array}$ \\
\hline Triangular & $\begin{array}{l}\text { If the gonial angle is over } 125^{\circ} \text { and the coronoid process is high, the } \\
\text { lowest part of the head is likely to be narrow }\end{array}$ \\
\hline Rounded & $\begin{array}{l}\text { If the gonial angle is less than } 125^{\circ} \text {, then the face shape is likely to be } \\
\text { wide }\end{array}$ \\
\hline Rectangular & $\begin{array}{l}\text { If the gonial angle is less than } 125^{\circ} \text {, then the face shape is likely to be } \\
\text { wide }\end{array}$ \\
\hline \multicolumn{2}{|l|}{ General face shape } \\
\hline Rounded & $\begin{array}{l}\text { Parietal part gently curved in frontal view; occiput rounded in lateral } \\
\text { view }\end{array}$ \\
\hline Dome shaped & Parietal part protruding; occiput flattened in lateral view \\
\hline Egg shaped & Parietal part gently curved in frontal view; occiput protruding \\
\hline Keel shaped & $\begin{array}{l}\text { Parietal part narrow, laterally compressed and "sharpened" in frontal } \\
\text { view; gently curved or protruding in lateral view; occiput rounded, } \\
\text { flattened, or protruding }\end{array}$ \\
\hline Flattened & $\begin{array}{l}\text { Parietal part flattened in frontal view, flattened in lateral view; occiput } \\
\text { rounded or protruding in lateral view }\end{array}$ \\
\hline Saddle shape & $\begin{array}{l}\text { Parietal part gently curved or flattened, saddle shaped in lateral view; } \\
\text { occiput rounded, flattened, or protruding in lateral view }\end{array}$ \\
\hline \multicolumn{2}{|l|}{ Face in frontal view } \\
\hline Rounded & As in cranial contour; malar bones prominent; general contour rounded \\
\hline Oval & As in cranial contour; facial outline smooth; general contour elliptical \\
\hline Triangular & $\begin{array}{l}\text { As in cranial contour; frontal part wide, mandible narrow; general } \\
\text { contour triangular }\end{array}$ \\
\hline Square & $\begin{array}{l}\text { As in cranial contour; transverse dimensions large; general contour } \\
\text { square }\end{array}$ \\
\hline Rectangular & $\begin{array}{l}\text { As in cranial contour; frontal and mandibular widths roughly equal; face } \\
\text { high, outline angular; general contour rectangular }\end{array}$ \\
\hline Diamond-shaped & $\begin{array}{l}\text { As in cranial contour; frontal and mandibular breadth small, face broad } \\
\text { and high; general contour diamond shaped }\end{array}$ \\
\hline \multicolumn{2}{|l|}{ Vertical facial profile } \\
\hline Sharp & Nasal saddle high; malar bones not prominent \\
\hline Flattened & Nasal saddle low; malar bones prominent \\
\hline
\end{tabular}


Table 3.7 (continued)

\begin{tabular}{|c|c|}
\hline $\begin{array}{l}\text { Morphological and } \\
\text { facial traits }\end{array}$ & Correspondence with facial structures \\
\hline \multicolumn{2}{|c|}{ Frontal curvature in profile } \\
\hline Flat & Frontal outline nearly straight \\
\hline Convex & Frontal outline convex arc \\
\hline Concave & $\begin{array}{l}\text { Both glabella and frontal tubers developed, creating the impression of } \\
\text { concavity in the middle part }\end{array}$ \\
\hline Wavy & $\begin{array}{l}\text { Glabella developed, well-expressed flexure between it and the upper } \\
\text { part of the frontal bone }\end{array}$ \\
\hline \multicolumn{2}{|c|}{ Frontal angle in profile } \\
\hline Vertical & $\begin{array}{l}\text { Perpendicular to Frankfort horizontal plane tangent to glabella nearly } \\
\text { vertical }\end{array}$ \\
\hline Inclined backward & $\begin{array}{l}\text { Perpendicular to Frankfort horizontal plane tangent to glabella inclined } \\
\text { backward }\end{array}$ \\
\hline Inclined forward & $\begin{array}{l}\text { Perpendicular to Frankfort horizontal plane tangent to glabella inclined } \\
\text { forward }\end{array}$ \\
\hline \multicolumn{2}{|l|}{ Brow ridges } \\
\hline Medium & $\begin{array}{l}\text { Brow ridges markedly prominent, but without a depression between } \\
\text { them }\end{array}$ \\
\hline Large & Brow ridges markedly prominent and separated by depression \\
\hline Small & Brow ridges barely distinguishable \\
\hline \multicolumn{2}{|l|}{ Brow ridges } \\
\hline Medium & Moderately prominent from side view \\
\hline Large & Markedly prominent from side view \\
\hline Small & Barely distinguishable from side view \\
\hline \multicolumn{2}{|c|}{ Length of brow ridges } \\
\hline Large & Extend beyond midpoint of supraorbital margin \\
\hline Small & Do not reach midpoint of supraorbital margin \\
\hline
\end{tabular}

Table 3.8 Related face and skull measurements

\begin{tabular}{|c|c|}
\hline \multicolumn{2}{|c|}{ Relative facial breadth } \\
\hline Medium & $($ Bizygomatic $(45)+10 \mathrm{~mm}) /($ supraorbitale to gnathion $(47 \mathrm{~b})+6 \mathrm{~mm})=1.10 \pm 0.04$ \\
\hline Large & $($ Bizygomatic $(45)+10 \mathrm{~mm}) /($ supraorbitale to gnathion $(47 \mathrm{~b})+6 \mathrm{~mm})>1.14$ \\
\hline Small & $($ Bizygomatic $(45)+10 \mathrm{~mm}) /($ supraorbitale to gnathion $(47 \mathrm{~b})+6 \mathrm{~mm})<1.06$ \\
\hline \multicolumn{2}{|c|}{ Frontal height } \\
\hline Medium & $($ Trichion to supraorbitale)/(supraorbitale to gnathion $(47 \mathrm{~b})+6 \mathrm{~mm})=0.45 \pm 0.03$ \\
\hline Large & (Trichion to supraorbitale)/(supraorbitale to gnathion $(47 \mathrm{~b})+6 \mathrm{~mm})>0.48$ \\
\hline Small & (Trichion to supraorbitale)/(supraorbitale to gnathion $(47 \mathrm{~b})+6 \mathrm{~mm})<0.42$ \\
\hline \multicolumn{2}{|c|}{ Frontal breadth } \\
\hline Medium & $($ Bicoronal $(10)+10 \mathrm{~mm}) /($ bizygomatic $(45)+10 \mathrm{~mm})=0.90 \pm 0.02$ \\
\hline Large & $($ Bicoronal $(10)+10 \mathrm{~mm}) /($ bizygomatic $(45)+10 \mathrm{~mm})>0.92$ \\
\hline Small & $($ Bicoronal $(10)+10 \mathrm{~mm}) /($ bizygomatic $(45)+10 \mathrm{~mm})<0.88$ \\
\hline
\end{tabular}


Table 3.9 Eyebrow pattern standards

\begin{tabular}{l|l}
\hline Eyebrow pattern \\
\hline Overhanging & $\begin{array}{l}\text { There is a strong development of the supraorbital margin and brow ridge, the } \\
\text { eyebrows are shifted downward, 1-2 mm lower than the supraorbital rim }\end{array}$ \\
\hline Arched & $\begin{array}{l}\text { This is related to a smooth forehead and high orbit, with the eyebrow following } \\
\text { the curve of the supraorbital margin }\end{array}$ \\
\hline Triangular & $\begin{array}{l}\text { There is thickening of the outer part of the supraorbital rim and a strong brow } \\
\text { ridge, the eyebrow is arranged over the supraorbital margin forming an angle }\end{array}$ \\
\hline Outline of eyebrows \\
\hline Straight & Supraorbital margin straight; superciliary arch horizontal \\
\hline Arched & Supraorbital margin arcuate; lateral end of superciliary arch directed upward \\
\hline Broken & Supraorbital margin wavy; lateral end of superciliary arch directed upward \\
\hline
\end{tabular}

Table 3.10 Relationship between the eyeball and the orbit

\begin{tabular}{l|l}
\hline Eyes & \\
\hline Protrusion of the eyeballs \\
\hline Deep-set eye & $\begin{array}{l}\text { This is related to the depth of the orbital cavity, vertical inclination of the orbit, } \\
\text { and the thickness and degree of overhang of its upper rim }\end{array}$ \\
\hline $\begin{array}{l}\text { The supraorbital rim is greatly thickened and protrudes relative to the } \\
\text { infraorbital rim } \\
\text { Supraorbital margin projects inferiorly (“closed orbit") } \\
\text { (orbital height }(52)) /(\text { exocanthion to endocanthion) }<0.81\end{array}$ \\
\hline Prominent eye & $\begin{array}{l}\text { Supraorbital margin does not project inferiorly } \\
\text { (orbital height }(52)) /(\text { exocanthion to endocanthion) })\end{array}$ \\
\hline $\begin{array}{l}\text { Eyeball } \\
\text { prominence }\end{array}$ & $\begin{array}{l}\text { Normal prominence is when the iris touches a tangent across the } \\
\text { mid-supraorbital to mid-infraorbital bone } \\
\text { eyeball protrusion }=18.3-(0.4 \times \text { orbit depth) }\end{array}$ \\
\hline
\end{tabular}

\subsubsection{The Eyes}

A number of studies assessing the relationship between the eyeball and the orbit in relation to prominence and frontal position have been conducted.

Prominence studies utilizing MRI (Wilkinson and Mautner 2003) exophthalmometry (Stephan 2002), and palpation (Fedosyutkin and Nainys 1993; Balueva et al. 2009) all present results indicating a general agreement between current published standards (see Table 3.10).

Studies on the position of the eyeball in the orbit from a frontal view seem to report different results depending on the method of assessment. Dissection studies (Whitnall 1921; Stephan and Davidson 2008; Stephan et al. 2003) suggest that the eyeball sits slightly superior $(1-2 \mathrm{~mm})$ and lateral to the centre in the orbit, but palpation studies (Balueva and Veselovskaya 2004) suggest that the eyeball sits $2 \mathrm{~mm}$ closer to the medial wall than the lateral wall; other dissection studies (Krogman and İşcan 1986) suggest the eyeball sits centrally in the orbit. 
The positions of the inner (endocanthus) and outer (exocanthus) corners of the eye have been studied in detail, but there is no clear agreement between standards. There is a general agreement concerning the malar (or Whitnall's) tubercle in relation to the outer canthus. Human dissection has shown that the tendons that fix the eyelids to the orbit are inserted at this tubercle (Whitnall 1921). Although it has been established that the outer canthus is located at the same height as the malar tubercle, there is no consensus as to the distance of the outer canthus from the orbital wall. The distance has been published as $1 \mathrm{~mm}$ (Sills 2004), 3-5 mm (Balueva et al. 2009; Angel 1978; Krogman and İşcan 1986; Stephan 2009), 5-7 mm (Wolff 1976; Rosenstein et al. 2000), 8-10 mm (Couly et al. 1976), and $13 \mathrm{~mm}$ (Anastassov and van Damme 1996). Where the malar tubercle is absent, the outer canthus can be positioned 8-11 mm below the line of the frontozygomatic suture (Stewart 1983; Krogman and İscan 1986; Wolff 1976).

There is an agreement that the medial canthus is positioned approximately 2-5 mm lateral to the anterior lacrimal crest (Yoshino and Seta 1989; Angel 1978; Sills 2004; Krogman and İşcan 1986; Stephan 2009), but where exactly on the anterior lacrimal crest this measurement is taken from is unclear. Different studies suggest the top (Balueva and Veselovskaya 2004), middle (Angel 1978), and base (Fedosyutkin and Nainys 1993) as the measurement point, while other studies suggest that the point can be found 4-5 mm (Angel 1978) or $10 \mathrm{~mm}$ (Stewart 1983) below the dacryon. Table 3.11 presents the standards related to dissection and anthropometrical studies (Whitnall 1921; Merkel 1886).

Table 3.11 Position of the inner (endocanthus) and outer (exocanthus) corners of the eye

\begin{tabular}{l|l}
\hline Eyes & $\begin{array}{l}\text { The slope of the fissure is defined by a straight line that connects the malar (Whitnall's) } \\
\text { tubercle on the lateral border of the orbit with the anterior lacrimal crest on the medial } \\
\text { border of the orbit }\end{array}$ \\
\cline { 2 - 3 } & $\begin{array}{l}\text { The curves of the eyelid margins are not symmetrical and the upper lid is more } \\
\text { pronounced than the lower, its height being greatest nearer the medial angle, whereas } \\
\text { that of the lower lid is nearer the lateral angle } \\
\text { The lateral canthal angle is more acute than the medial and lies in close contact with the } \\
\text { globe, whereas the medial canthus extends toward the nose } 5-7 \text { mm away from the } \\
\text { globe, being separated by the caruncula and the plica semilunaris } \\
\text { The radius of the upper eyelid curve is } 16.5 \text { mm and that of the lower eyelid is } 22 \text { mm } \\
\text { The outer canthus (exocanthus) is positioned at the same height as the malar } \\
\text { (Whitnall's tubercle) and medial to it } \\
\text { Where the malar tubercle is absent, the outer canthus can be positioned } 8-11 \text { mm } \\
\text { below the line of the frontozygomatic suture } \\
\text { The inner canthus (endocanthus) is situated } 2-5 \text { mm lateral to the anterior lacrimal } \\
\text { crest }\end{array}$ \\
\hline Eye fissure & The length of the eye fissure is $60-80 \%$ of the width of the orbit \\
\hline Medium & $\begin{array}{l}\text { (Exocanthion to endocanthion }-14 \mathrm{~mm}) /(\text { upper facial breadth }(43) \\
+10 \text { mm) }=0.25 \pm 0.01\end{array}$ \\
\hline (Exocanthion to endocanthion $-14 \mathrm{~mm}) /($ upper facial breadth $(43)+10$ mm) $>0.26$ \\
\hline (Exocanthion to endocanthion $-14 \mathrm{~mm}) /($ upper facial breadth $(43)+10$ mm) $<0.24$ \\
\hline
\end{tabular}


Table 3.12 Eyelid pattern

\begin{tabular}{l|l}
\hline Eyelid patterns \\
\hline Lateral & There is an overhang in the lateral part of the supraorbital rim \\
\hline Central & There is an overhang in the central part of the supraorbital rim \\
\hline Upper eyelid fold \\
\hline Moderate & Supraorbital margins straight or slightly rounded \\
\hline Defined & Supraorbital margins arched and sharp \\
\hline Absent & Supraorbital margins arched, supraorbital overhang markedly shifted medially \\
\hline Irregular & Supraorbital margin wave shaped or oblique in distal part \\
\hline Epicanthic fold \\
\hline Present & $\begin{array}{l}\text { Crest descending from medial supraorbital margin directed toward anterior lacrimal } \\
\text { crest } \\
\text { This is characteristic of a high orbit, a low-or medium-height nasal bridge, and a long } \\
\text { lacrimal fossa }\end{array}$ \\
\hline Absent & Crest descending from medial supraorbital margin directed inside orbit \\
\hline
\end{tabular}

The eyelid pattern has been studied using palpation and anthropometry studies (comparison of skulls with ante-mortem images) (Balueva et al. 2009; Rynn et al. 2012). These standards are presented in Table 3.12.

\subsubsection{The Nose}

The nose is the most studied feature on the face; studies on the relationship between the configuration of the nasal tissue and the bones surrounding the nasal aperture are abundant (Gerasimov 1955; Macho 1986; McClintock Robinson et al. 1986; George 1993; Schultz 2005; Tandler 1909; Virchow 1912; Glanville 1969; Prokopec and Ubelaker 2002; Stephan et al. 2003). Studies conducted by Gerasimov (1955) show that the soft nose is wider than the bony aperture, as a narrower soft nose would have no supporting structure. Furthermore, he suggested that the bony nasal aperture at its widest point is three-fifths of the overall width of the soft nose. This assertion has been confirmed by a CT study on living subjects of various ethnic groups (Rynn 2006).

Gerasimov (1955) also suggested that the nasal base angle (the angle between the upper lip and the columella) is determined by the direction of the nasal spine. In his study, he stated that the axis of the nasal spine serves as a base for the soft nose and the determination of the nasal spine direction follows the point of the spine, as if it were an arrowhead. He also suggested that the end of the soft nose could be predicted as the point where a line following the projection of the last part of the nasal bones (at the rhinion) crosses a line following the direction of the nasal spine, and he confirmed these standards with a blind study of 50 cadaver heads. This standard has been widely debated in the literature; Ullrich, a former student of Gerasimov, claimed that Gerasimov did not follow the direction of the nasal spine, but rather the general direction of the floor of the anterior part of the nasal aperture (maxillary 
bone) laterally adjacent to the anterior nasal spine and vomer bone (Ullrich and Stephan 2011). However, this is disputed by the academic group who worked for many years alongside Gerasimov and Lebedinskaya, and continue their work at the Russian Academy of Sciences in Moscow (Balueva et al. 2009; Rynn et al. 2012) and they confirm that the nasal spine was indeed the feature used by Gerasimov to determine the nasal base angle. Rynn and Wilkinson (2006) tested six different methods of nose prominence prediction (Gerasimov 1955; Prokopec and Ubelaker 2002; Macho 1986; Stephan et al. 2003; George 1987; Krogman and İşcan 1986) in order to understand which method was the most accurate. This study found that the Gerasimov (1955) method performed with the most accuracy, while the Krogman and İşcan (1986) method performed poorly.

Rynn (2006) produced guidelines for nasal shape prediction, utilizing three cranial measurements that can be used to predict six soft nose measurements. These guidelines were tested in a blind study showing a high level of accuracy (Rynn et al. 2010).

Gerasimov (1955) also suggested that the height of the upper border of the alae is in line with the crista conchalis and the profile of the nose is a nonscaled mirror of the nasal aperture in profile. These standards have been confirmed using CT data of living subjects (Rynn 2006); this study additionally confirmed previous papers' suggestions that deviation of the nasal tip from the midline is associated with opposing nasal septum deviation (Selzter 1944; Gray 1965) and that nasal tip bifurcation is associated with a bifid nasal spine (Weaver and Bellinger 1946).

A recent dissection study suggested that the shape of the nasal aperture when viewed from posterior-anterior aspect is mirrored in the shape of the nasal tip (Davy-Jow et al. 2012). Standards for nose shape prediction are given in Table 3.13.

\subsubsection{The Mouth}

There are some anatomical standards relating to mouth shape, which have been confirmed in different populations and by a variety of methods of study (Stephan et al. 2003; Balueva et al. 2009; Stephan and Murphy 2008; Angel 1978; Krogman and İscan 1986). These are presented in Table 3.14.

Scientific literature from orthodontic and anatomical disciplines suggests that the form of the mouth is related to the occlusion of the teeth (Roos 1977; Rudee 1964; Koch et al. 1979; Waldman 1982; Holdaway 1983; Denis and Speidel 1987; Talass et al. 1987), the dental pattern (Subtelny 1959), and the facial profile (Gerasimov 1955). These are presented in Table 3.14.

\subsubsection{The Cheeks}

Studies demonstrating the relationship between the zygomatic bones, the canine fossa, and the soft cheeks are presented in Table 3.15 (Fedosyutkin and Nainys 1993; Balueva et al. 2009). 
Table 3.13 Standards for nose shape prediction

\begin{tabular}{|c|c|}
\hline \multicolumn{2}{|l|}{ Nose } \\
\hline \multicolumn{2}{|c|}{ Height of the nose } \\
\hline & This equals the distance from nasion to $1-2 \mathrm{~mm}$ below the nasal spine \\
\hline Medium & (Supraorbitale to subspinale)/(trichion to gnathion $+6 \mathrm{~mm})=0.32 \pm 0.015$ \\
\hline Large & (Supraorbitale to subspinale)/(trichion to gnathion $+6 \mathrm{~mm})>0.335$ \\
\hline Small & (Supraorbitale to subspinale)/(trichion to gnathion $+6 \mathrm{~mm}$ ) $<0.305$ \\
\hline $\begin{array}{l}\text { Nasal } \\
\text { length }\end{array}$ & Europeans: nasion to prosthion $=0.74$ (bony nasion to subspinale) +3.5 \\
\hline $\begin{array}{l}\text { Nasal } \\
\text { length }\end{array}$ & $\begin{array}{l}\text { Nasion to pronasale }(\mathrm{mm}) \text { in nasion-prosthion plane }=0.9 \text { (bony nasion to } \\
\text { acanthion) }-2\end{array}$ \\
\hline $\begin{array}{l}\text { Nasal } \\
\text { height }\end{array}$ & $\begin{array}{l}\text { European females: nasion to subspinale }=0.63 \text { (bony nasion to subspinale })+17 \\
\text { European males: nasion to subspinale }=0.78 \text { (bony nasion to subspinale })+9.5\end{array}$ \\
\hline \multicolumn{2}{|c|}{ Width of the nose } \\
\hline & $\begin{array}{l}\text { This is defined between the midpoints of the canines or their alveoli } \\
\text { The maximum width of the nasal aperture is three-fifths }(3 / 5) \text { of the maximum width } \\
\text { of the soft nose }\end{array}$ \\
\hline Medium & Nasal breadth/(bizygomatic breadth $(45)+10 \mathrm{~mm})=0.25 \pm 0.01$ \\
\hline Large & Nasal breadth/(bizygomatic breadth $(45)+10 \mathrm{~mm})>0.26$ \\
\hline Small & Nasal breadth/(bizygomatic breadth $(45)+10 \mathrm{~mm})<0.24$ \\
\hline \multicolumn{2}{|c|}{ The base of the nose } \\
\hline Horizontal & Horizontal nasal spine \\
\hline Elevated & Up-turned nasal spine \\
\hline Prolapsed & Down-turned nasal spine \\
\hline \multicolumn{2}{|c|}{ The tip of the nose } \\
\hline Bifid & Bifurcated nasal spine \\
\hline $\begin{array}{l}\text { Nasal } \\
\text { depth }\end{array}$ & $\begin{array}{l}\text { Female; subspinale to pronasale }=0.5 \text { (bony rhinion to subspinale })+1.5 \text { male; } \\
\text { subspinale to pronasale }=0.4 \text { (bony rhinion to subspinale })+5\end{array}$ \\
\hline Pronasale & Anterior projection $(\mathrm{mm})$ perpendicular to nasion-prosthion plane $=0.83 \mathrm{Y}-3.5$ \\
\hline Pronasale & $\begin{array}{l}\text { Projection from subspinale in Frankfort horizontal plane }=0.93 \text { (bony rhinion to } \\
\text { subspinale) }-6\end{array}$ \\
\hline Deviated & $\begin{array}{l}\text { Deviation of nose is opposite to the deviation of the nasal septum and in the same } \\
\text { direction as the nasal spine (right or left) }\end{array}$ \\
\hline Wide & $\begin{array}{l}\text { Wider than the nose ridge. It is correlated with a short, wide, groovy, nasal spine and } \\
\text { low, wide nasal foramen }\end{array}$ \\
\hline Moderate & Equal to the width of the nose ridge \\
\hline Narrow & $\begin{array}{l}\text { It is correlated with a long, narrow, pronounced nasal spine and long, narrow nasal } \\
\text { foramen }\end{array}$ \\
\hline Rounded & $\begin{array}{l}\text { Length of anterior nasal spine equal to or smaller than width of its base; tip of spine } \\
\text { forming an obtuse angle }\end{array}$ \\
\hline Pointed & Length of anterior nasal spine larger than width of its base; tip of spine pointed \\
\hline \multicolumn{2}{|c|}{ Wing of the nose } \\
\hline & $\begin{array}{l}\text { The wing of the nose begins at the lateral edge of the piriform foramen at the level of } \\
\text { nasal spine } \\
\text { The height of the upper border of the alae is in line with the crista conchalis } \\
\text { An exposed nasal septum is characteristic of a crest-shaped base of the nose }\end{array}$ \\
\hline Medium & $($ Conchale to subspinale $) /($ supraorbitale to subspinale $)=0.21 \pm 0.02$ \\
\hline
\end{tabular}


Table 3.13 (continued)

\begin{tabular}{|c|c|}
\hline \multicolumn{2}{|l|}{ Nose } \\
\hline High & (Conchale to subspinale)/(supraorbitale to subspinale) $>0.23$ \\
\hline Low & (Conchale to subspinale)/(supraorbitale to subspinale) $<0.19$ \\
\hline Level & $\begin{array}{l}\text { Left and right conchale and left and right lower points of the piriform aperture } \\
\text { situated on the same level }\end{array}$ \\
\hline $\begin{array}{l}\text { Right } \\
\text { higher }\end{array}$ & Right conchale or right lower point of the piriform aperture higher than left \\
\hline $\begin{array}{l}\text { Left } \\
\text { higher }\end{array}$ & Left conchale or left lower point of the piriform aperture higher than right \\
\hline \multicolumn{2}{|c|}{ Nasal bridge depth } \\
\hline Medium & Sellion not much deeper than glabella to rhinion line \\
\hline Large & Sellion much deeper than glabella to rhinion line \\
\hline Small & Sellion on glabella to rhinion line \\
\hline \multicolumn{2}{|c|}{ Nasal bridge breadth } \\
\hline Medium & $\begin{array}{l}\text { (Minimal breadth of nasal bones at nasal saddle level }(57)+6 \mathrm{~mm}) /(\text { naso-gnathic } \\
\text { left to naso-gnathic right }+6 \mathrm{~mm})=0.85 \pm 0.04\end{array}$ \\
\hline Large & $\begin{array}{l}\text { (Minimal breadth of nasal bones at nasal saddle level }(57)+6 \mathrm{~mm}) /(\text { naso-gnathic } \\
\text { left to naso-gnathic right }+6 \mathrm{~mm})>0.89\end{array}$ \\
\hline Small & $\begin{array}{l}\text { (Minimal breadth of nasal bones at nasal saddle level }(57)+6 \mathrm{~mm}) /(\text { naso-gnathic } \\
\text { left to naso-gnathic right }+6 \mathrm{~mm})<0.81\end{array}$ \\
\hline \multicolumn{2}{|c|}{ Nasal saddle width } \\
\hline Medium & $\begin{array}{l}\text { (Naso-gnathic left to naso-gnathic right }+6 \mathrm{~mm}) /(\text { canine left to canine right) } \\
=0.38 \pm 0.03\end{array}$ \\
\hline Large & (Naso-gnathic left to naso-gnathic right $+6 \mathrm{~mm}$ )/(canine left to canine right) $>0.41$ \\
\hline \multirow[t]{2}{*}{ Small } & (Naso-gnathic left to naso-gnathic right $+6 \mathrm{~mm}$ )/(canine left to canine right) $<0.35$ \\
\hline & $\begin{array}{l}\text { Nasal ridge index }=\text { minimal breadth of nasal bone } \times 100 / \text { anterior length of nasal } \\
\text { bone } \\
10-30=\text { narrow; } 30-45=\text { medium; } 45-75=\text { broad }\end{array}$ \\
\hline
\end{tabular}

\subsubsection{The Ear}

Although there have been some studies relating ear morphology to skeletal structure, this facial feature is understudied. Gerasimov (1955) considered the angle of ear to be parallel to the jaw line and stated that when the mastoid processes are directed downward (in the Frankfort Horizontal Plane), the earlobe will be attached (adherent to the soft tissue of the cheek), whereas, where the mastoid processes point forward, the ear lobe will be free. However, recent dissection studies disagree as to the reliability of these standards; Renwick (2012) confirmed that adherent ear lobes relate to downward pointing mastoid processes, while studies using CT data showed no relationship between these features (Guyomarc'h and Stephan 2012). The confirmed standards are presented in Table 3.16. 
Table 3.14 Anatomical standards relating to mouth shape

\begin{tabular}{|c|c|}
\hline \multicolumn{2}{|l|}{ Mouth } \\
\hline \multicolumn{2}{|l|}{ Width of the mouth } \\
\hline & $\begin{array}{l}\text { Equal to the distance between the mandibular second molars } \\
\text { Mouth corners positioned on radiating lines (perpendicular to the } \\
\text { palate arc) from the first premolar-canine junction } \\
\text { Intercanine distance }=75 \% \text { of overall mouth width } \\
\text { The distance between the first premolars equal to mouth width } \\
\text { Mouth corners positioned vertically below the infraorbital foramina }\end{array}$ \\
\hline Medium & $\begin{array}{l}\text { Estimated on regression equation mouth width/(bigonial } \\
\text { breadth }+20 \mathrm{~mm})=0.52 \pm 0.02\end{array}$ \\
\hline Large & $\begin{array}{l}\text { Estimated on regression equation mouth width/(bigonial } \\
\text { breadth }+20 \mathrm{~mm})>0.54\end{array}$ \\
\hline Small & $\begin{array}{l}\text { Estimated on regression equation mouth width/(bigonial } \\
\text { breadth }+20 \mathrm{~mm})<0.50\end{array}$ \\
\hline \multicolumn{2}{|l|}{ Position of the fissure } \\
\hline & $\begin{array}{l}\text { The closed fissure is positioned at the level of the upper edge of the } \\
\text { anterior teeth of the mandible } \\
\text { The open fissure is positioned at the mid-line of the maxillary } \\
\text { incisors }\end{array}$ \\
\hline \multicolumn{2}{|l|}{ Height of the lips } \\
\hline & $\begin{array}{l}\text { Approximately equal to the height of the enamel of the upper and } \\
\text { lower incisors } \\
\text { European: maximum upper lip height }(\mathrm{mm})=0.4+(0.6 \times \text { max. } \\
\text { maxillary tooth enamel height }) \\
\text { European: maximum lower lip height }(\mathrm{mm})=5.5+(0.4 \times \text { max. } \\
\text { mandibular tooth enamel height }) \\
\text { Indian subcontinent: maximum upper lip height } \\
(\mathrm{mm})=3.4+(0.4 \times \text { max. maxillary tooth enamel height }) \\
\text { Indian subcontinent: maximum lower lip height } \\
(\mathrm{mm})=6+(0.5 \times \text { max. mandibular tooth enamel height })\end{array}$ \\
\hline Medium & $\begin{array}{l}\text { (Subspinale to supradentale)/(supraorbitale to gnathion }(2)+6 \mathrm{~mm} \text { ) } \\
=0.12 \pm 0.011\end{array}$ \\
\hline High & $\begin{array}{l}\text { (Subspinale to supradentale)/(supraorbitale to gnathion }(2)+6 \mathrm{~mm}) \\
>0.131\end{array}$ \\
\hline Low & $\begin{array}{l}\text { (Subspinale to supradentale)/(supraorbitale to gnathion }(2)+6 \mathrm{~mm} \text { ) } \\
<0.109\end{array}$ \\
\hline \multicolumn{2}{|l|}{ Width of the philtrum } \\
\hline & $\begin{array}{l}\text { The width of the philtrum corresponds to the distance between the } \\
\text { midpoints of the upper central incisors }\end{array}$ \\
\hline \multicolumn{2}{|l|}{ Prognathism } \\
\hline $\begin{array}{l}\text { Overbite or maxillary } \\
\text { prognathism }\end{array}$ & The upper lip projects more anteriorly than the lower lip \\
\hline $\begin{array}{l}\text { An underbite or edge-to- } \\
\text { edge occlusion }\end{array}$ & The lower lip protrudes more anteriorly than the upper lip \\
\hline
\end{tabular}


Table 3.14 (continued)

\begin{tabular}{l|l}
\hline \multicolumn{2}{l}{ Mouth } \\
$\begin{array}{l}\text { Line between closed lips } \\
\begin{array}{l}\text { Arched (upward or } \\
\text { downward) }\end{array}\end{array}$ & $\begin{array}{l}\text { The direction of these lines generally coincides with the line } \\
\text { formed when the teeth are closed }\end{array}$ \\
\hline $\begin{array}{l}\text { Straight (upward or } \\
\text { downward) }\end{array}$ & \\
\hline \multicolumn{2}{l}{ Occlusion and malocclusion } \\
\hline Edge-to-edge bite & Upper and lower anterior teeth fitting together edge-to-edge \\
\hline Moderate overbite & Anterior upper teeth slightly projecting over lower ones \\
\hline Roof-shaped & Marked overbite \\
\hline Cornice-shaped bite & Marked maxillary and mandibular alveolar prognathism \\
\hline Stepwise & $\begin{array}{l}\text { Anterior mandibular teeth projecting anteriorly relative to anterior } \\
\text { maxillary teeth }\end{array}$ \\
\hline Gaping & $\begin{array}{l}\text { Anterior maxillary and mandibular teeth curved and not fitting } \\
\text { together }\end{array}$ \\
\hline Oblique & Some teeth fit together normally, others show malocclusion \\
\hline
\end{tabular}

Table 3.15 Relationship between the zygomatic bones, the canine fossa, and the soft cheeks

Horizontal profile of the face

\begin{tabular}{|c|c|}
\hline & The cheekbones define the width of the face and its horizontal profile \\
\hline & $\begin{array}{l}\text { The horizontal profile of the face depends on the width and height of the } \\
\text { curvature of the cheekbones, the depth of the canine fossae, and the } \\
\text { nasomalar and zygomaxillary angles }\end{array}$ \\
\hline \multicolumn{2}{|c|}{ Size of malar bones } \\
\hline Medium & $\begin{array}{l}\text { Malar bones medium width and gently inclined backward; (bizygomatic } \\
\text { breadth }(45)+10 \mathrm{~mm}) /(\text { minimal frontal breadth }(9)+10 \mathrm{~mm}) \\
=1.37 \pm 0.03\end{array}$ \\
\hline Large & $\begin{array}{l}\text { Malar bones wide and frontally positioned; (bizygomatic breadth } \\
(45)+10 \mathrm{~mm}) /(\text { minimal frontal breadth }(9)+10 \mathrm{~mm})>1.40\end{array}$ \\
\hline Small & $\begin{array}{l}\text { Malar bones narrow and inclined backward; (bizygomatic breadth } \\
(45)+10 \mathrm{~mm}) /(\text { minimal frontal breadth }(9)+10 \mathrm{~mm})<1.34\end{array}$ \\
\hline \multicolumn{2}{|l|}{ Smile line } \\
\hline & $\begin{array}{l}\text { The nose-cheek (nasolabial) fold extends from the upper edge of the } \\
\text { nostril toward the upper first molar }\end{array}$ \\
\hline \multicolumn{2}{|c|}{ Protrusion of the smile line } \\
\hline & $\begin{array}{l}\text { It depends on the depth of the following parts: } \\
\text { - The canine fossa } \\
\text { - The degree of horizontal face profiling } \\
\text { - The projection of the frontal surface of the cheekbones } \\
\text { - The presence or absence of teeth }\end{array}$ \\
\hline $\begin{array}{l}\text { Nose-cheek folds } \\
\text { pronounced }\end{array}$ & The canine fossae are deep, and profiling of the face is strong \\
\hline \multicolumn{2}{|c|}{ Depth of the canine fossa } \\
\hline Shallow & Up to $3 \mathrm{~mm}$ \\
\hline Moderate & Between 4 and $6 \mathrm{~mm}$ \\
\hline Deep & Over $6 \mathrm{~mm}$ \\
\hline
\end{tabular}


Table 3.16 Relationship between ear morphology and skeletal structure

\begin{tabular}{l|l}
\hline Ear & \multicolumn{2}{l}{ The tragus of the ear corresponds to the upper rim of the external auditory meatus } \\
\cline { 2 - 2 } & The height of the ear approximates the length of the nose \\
\hline Protrusion of the ear \\
\hline Upper & The supramastoid crest on the temporal bone is strongly developed and protrudes \\
\hline Lower & The outer surface of the mastoid process is rough \\
\hline Total & All these features are present \\
\hline Lobe of the ear \\
\hline $\begin{array}{l}\text { Lobe } \\
\text { attached }\end{array}$ & $\begin{array}{l}\text { The mastoid processes are directed downward when the skull is in the Frankfort } \\
\text { horizontal plane }\end{array}$ \\
\hline Lobe free & The mastoid points forward when the skull is in the Frankfort horizontal plane \\
\hline
\end{tabular}

\subsubsection{The Chin}

There are some standards relating the mental region of the mandible to chin shape (Balueva et al. 2009). These are presented in Table 3.17.

The facial proportions are an important element to understanding facial geometry. The aim of the facial proportion assessment is to establish the variation from the ideal dimensions of the human form. This, combined with anthropometric norms, gives information about facial features as a symmetrical and balanced pattern, based on statistical means taking into account variations in age, sex, and ancestry. In this way, George (1993) described facial proportions based on the studies of Farkas and Munro (1987), Powell and Humphreys (1984).

\subsection{Examination Criteria for Craniofacial Superimposition}

Assessment of the quality of the matching and anatomical consistency between the face and skeletal structures for CFS has been carried out following a number of different criteria. These include the works of Helmer (1987), Helmer et al. (1989), Powell and Humphreys (1984), Chai et al. (1989), Austin-Smith and Maples (1994), Yoshino et al. (1995), Yoshino (2012), Lan (1995), Jayaprakash et al. (2001), Ricci et al. (2006), Ishii et al. (2011), and Gordon and Steyn (2012). These criteria are presented in detail below.

\subsubsection{Helmer $(1984,2012)$}

This method of assessment includes the use of several soft tissue thickness markers, attached to the skull along a vertical central line. Helmer employed average German 
Table 3.17 Relationship between the mental region of the mandible and chin shape

\begin{tabular}{l|l}
\hline & $\begin{array}{l}\text { The presence of convexities in the lower part of the mandibular body is a notable } \\
\text { feature both of the skull and of the face. }\end{array}$ \\
\hline Width of the chin & $\begin{array}{l}\text { This is defined by the degree of elevation in the mental region of the mandible and } \\
\text { the width its base. }\end{array}$ \\
\hline \multicolumn{2}{|l}{ Shape of the chin } \\
\hline High & The height of the mandibular body diminishes from the chin triangle to the rami. \\
\hline Wide & $\begin{array}{l}\text { Everted gonial regions of the mandible are associated with the wider variants of the } \\
\text { lower face and more developed masseter muscles. }\end{array}$ \\
\hline Height of the chin \\
\hline Medium & $\begin{array}{l}\text { (Supramentale to gnathion }+6 \text { mm }) /(\text { supraorbitale to } \\
\text { gnathion }+6 \text { mm) }=0.215 \pm 0.015\end{array}$ \\
\hline Large & (Supramentale to gnathion +6 mm)/(supraorbitale to gnathion $+6 \mathrm{~mm})>0.23$ \\
\hline Small & (Supramentale to gnathion +6 mm)/(supraorbitale to gnathion $+6 \mathrm{~mm})<0.20$ \\
\hline & $\begin{array}{l}\text { Chin height index }=\text { Height of the chin triangle } \times 100 / \text { Height of the ramus along the } \\
\text { second premolar } \\
100-110=\text { normal; } 110-115=\text { high; } 115-120=\text { very high }\end{array}$ \\
\hline Chin prominence \\
\hline Straight & Most projecting point of chin slightly anterior to vertical line \\
\hline Prominent & Most projecting point of chin markedly anterior to vertical line \\
\hline Receding & Most projecting point of chin on vertical line or behind it \\
\hline Width of the chin \\
\hline Medium & (Mentale left to mentale right)/(bigonial width +20 mm) $=0.35 \pm 0.02$ \\
\hline Large & (Mentale left to mentale right)/(bigonial width $+20 \mathrm{~mm})>0.37$ \\
\hline Small & (Mentale left to mentale right)/(bigonial width $+20 \mathrm{~mm})<0.33$ \\
\hline Shape of the chin in frontal view \\
\hline Rounded & Outline rounded, genial tubercles unexpressed \\
\hline Triangular & Outline pointed, genial tubercles close together \\
\hline Square & Outline square, genial tubercles wide apart \\
\hline
\end{tabular}

soft tissue data (Helmer 1984) collected by ultrasound. These cephalometric landmarks (nasion, rhinion, gonion, gnathion) are then matched to the profile on the antemortem photograph. The alignment of these landmarks indicates a positive identification. Variations on this methodology have been employed. Bajnóczky and Királyfalvi (1995) suggested a digital method to mark the superimposed antemortem photograph and skull image. The coordinate values of these points were then recorded and expressed as pixel units. Birngruber et al. (2010) glued 53 markers to the skull to mark the tissue depth at each anthropological landmark (Helmer 1984). The skull and the ante-mortem photograph were then superimposed in order to assess whether or not the tissue markers matched with the contours of the face. 
Table 3.18 Landmarks, lines, and profile curves suggested by Chai et al. (1984)

\begin{tabular}{l|l|l|l}
\hline Landmarks on face and skull & Facial lines & Skeletal lines & Profile outlines \\
\hline g: glabella & ex-ex & ec-ec & Cranial vault \\
\hline tr: trichion & g-gn & g-gn & Brow ridge \\
\hline v: vertex & se-se & se-se & Nasal \\
\hline n: nasion & ch-ch & -gn- & Gonial angle \\
\hline sn: subnasal & en-eh & & Lower jaw \\
\hline gn: gnathion & en-eh & & Occipital \\
\hline pg: pogonion & -gn- & & Forehead \\
\hline rhi: rhinion & & & Chin \\
\hline ns: nasospinale & & & Zygomatic \\
\hline pr: prosthion & & & \\
\hline inf: infradentale anterior & & & \\
\hline t: tragion & & & \\
\hline eu: euryon & & & \\
\hline al: alare & & & \\
\hline che: cheilion & & & \\
\hline en: endocanthion & & & \\
\hline ex: exocanthion & & & \\
\hline zy: zygion & & & \\
\hline go: gonion & & & \\
\hline ca: caninion & & & \\
\hline se: superciliary & & & \\
\hline ec: ectoconchion & & & \\
\hline
\end{tabular}

\subsubsection{Chai et al. (2010)}

This method is based on a study of 224 Chinese subjects (100 males and 124 females) aged between 18 and 55 years, from X-ray images. The protocol relies on the analysis of positional relationships between homologous facial and skull landmarks, the thickness of soft tissue at specific points, and the fit of facial outlines with the cranial structures. Fifty-two indices were established as a standard for CFS and identification (Table 3.18).

\subsubsection{Austin-Smith and Maples (1994)}

Two sets of 12 criteria are employed in this method to analyze skull-face consistency using lateral and frontal view photographs. Relevant soft tissue thickness data is also utilized along with the anatomical criteria. The authors suggest that with anterior dentition, skull/photograph superimposition is reliable when two or more photographs are used in the identification. The following features were used for a consistent fit between skull and face: 


\section{Lateral View}

1. The vault of the skull and the head height must be similar.

2. The glabellar outline of both the bone and the soft tissue must have a similar slope, although the line of the face does not always follow the line of the skull exactly. There may be slight differences in soft tissue thicknesses that do not relate to nuances in the contour of the bone.

3. The lateral angle of the eye lies within the bony lateral wall of the orbit.

4. The glabella, nasal bridge, and nasal bone area is perhaps the most distinctive. The prominence of the glabella and the depth of the nasal bridge are closely approximated by the soft tissue covering this area. The nasal bones fall within the structure of the nose and the imaginary continued line, composed of the lateral nasal cartilages in life, will conform to the shape of the nose except in cases of noticeable deformity.

5. The outline of the frontal process of the zygomatic bones can normally be seen in the flesh of the face. The skeletal process can be aligned with the process seen in the face.

6. The outline of the zygomatic arch can be seen and aligned in those individuals with minimal soft tissue thickness.

7. The anterior nasal spine lies posterior to the base of the nose near the most posterior portion of the lateral septal cartilage.

8. The porion aligns posterior to the tragus and inferior to the crus of the helix.

9. The prosthion lies posterior to the anterior edge of the upper lip.

10. The pogonion lies posterior to the indentation observable in the chin where the orbicularis oris muscle crosses the mentalis muscle.

11. The mental protuberance of the mandible lies posterior to the point of the chin. The shape of the bone (pointed or rounded) corresponds to the shape of the chin.

12. The occipital curve lies within the outline of the back of the head. This area is usually covered with hair and the exact location may be difficult to judge.

\section{Frontal View}

1. The length of the skull from bregma to menton fits within the face. Bregma is usually covered with hair.

2. The width of the cranium fills the forehead area of the face.

3. The temporal line can sometimes be distinguished on the photograph. If so, the line of the skull corresponds to the line seen on the face.

4. The eyebrow generally follows the upper edge of the orbit over the medial two-thirds. At the lateral superior one-third of the orbit, the eyebrow continues horizontally as the orbital rim begins to curve inferiorly.

5. The orbits completely encase the eyes including the medial and lateral folds. The point of attachment of the medial and lateral palpebral ligaments can usually be found on the skull. These areas align with the folds of the eye.

6. The lacrimal groove can sometimes be distinguished on the photograph. If so, the groove observable on the bone aligns with the groove seen on the face. 
7. The breadth of the nasal bridge on the cranium and surrounding soft tissue is similar. In the skull, the bridge extends from one orbital opening to the other. In the face, the bridge spreads between the medial palpebral ligament attachments.

8. The external auditory meatus opening lies medial to the tragus of the ear. The best way to judge this area is to place a projecting marker in the ear canal. On superimposition, the marker will appear to exit the ear behind the tragus.

9. The width and length of the nasal aperture falls inside the borders of the nose.

10. The anterior nasal spine lies superior to the inferior border of the medial crus of the nose. With advanced age, the crus of the nose begins to sag and the anterior nasal spine is located more superiorly.

11. The oblique line of the mandible (between the buccinator and the masseter muscles) is sometimes visible in the face. The line of the mandible corresponds to the line of the face.

12. The curve of the mandible is similar to that of the facial jaw. At no point does the bone appear to project from the flesh. Rounded, pointed, or notched chins will be evident in the mandible.

\subsubsection{Yoshino et al. $(1995,2012)$}

This method evaluates the anatomical consistency between skull and face by means of video superimposition. The anatomical relationships and soft tissue thickness data is based on Ogawa's data (Ogawa 1960). The exact thicknesses of soft tissue at the anthropometrical points of the skull are measured on the superimposed transparent films by using a sliding caliper. Eighteen assessment criteria are used for the evaluation of the anatomical consistency between the face and the skull. The criteria used are divided into three types: outlines, soft-tissue thickness, and positional relationships (Tables 3.19, 3.20, and 3.21). The authors suggest a positive identification can be achieved if 13 or more criteria demonstrate concordance between the skull and the face.

\subsubsection{Lan (1995)}

This method is based on a study of 3123 subjects from 15 nationalities (1554 males and 1569 females), with one front view and one profile photograph of each subject. The method includes anthropometry from photographs and X-rays. A total of 69 indices are established for identification (Table 3.22). The authors noted that some indices showed significant differences between different nationalities: the distance between the vertical line of ectocanthion and gonion; the distance between gonions; and the thickness of the soft tissue at the trichion, opisthocranion, and sellion. 
Table 3.19 Examination criteria for the assessment of anatomical consistency between the skull and the face

\begin{tabular}{|c|c|c|}
\hline Outline & $\begin{array}{l}\text { Soft tissue } \\
\text { thickness }\end{array}$ & Positional relationships \\
\hline $\begin{array}{l}\text { 1. Forehead } \\
\text { line }\end{array}$ & 1. Zygion & $\begin{array}{l}\text { 1. Distance from the supraorbital margin to the midline of } \\
\text { eyebrow }\end{array}$ \\
\hline 2. Buccal line & 2. Gnathion & 2. Distance from the medial orbital margin to the endocanthion \\
\hline $\begin{array}{l}\text { 3. Mandibu- } \\
\text { lar line }\end{array}$ & 3. Pogonion & 3. Distance from the lateral orbital margin to the ectocanthion \\
\hline $\begin{array}{l}\text { 4. Nasal dor- } \\
\text { sum line }\end{array}$ & 4. Gonion & $\begin{array}{l}\text { 4. Eye-slit standard ratio (eye-slit height from the lower orbital } \\
\text { margin/orbital height) }\end{array}$ \\
\hline- & 5. Nasion & 5. Distance from the lateral margin of nasal aperture to the ala \\
\hline- & 6. Rhinion & $\begin{array}{l}\text { 6. Distance from the lower margin of nasal aperture to the lowest } \\
\text { portion of external nasal tip }\end{array}$ \\
\hline- & 7. Subnasale & 7. Placement of the cheilion to upper teeth \\
\hline
\end{tabular}

Taken from Yoshino et al. (1995)

Table 3.20 Criteria for assessing anatomical consistency between skull and face in frontal view

\begin{tabular}{|c|c|c|c|c|c|}
\hline \multicolumn{2}{|l|}{ Outline } & \multicolumn{2}{|c|}{ Soft-tissue thickness } & \multicolumn{2}{|l|}{ Positional relationship } \\
\hline Skull & Face & Skull & Face & Skull & Face \\
\hline Temporal line & Forehead & Zygion & Zygion & Supraorbital margin & Eyebrow \\
\hline $\begin{array}{l}\text { Lateral line of } \\
\text { zygomatic } \\
\text { bone }\end{array}$ & $\begin{array}{l}\text { Cheek } \\
\text { outline }\end{array}$ & Gonion & Gonion & Medial orbital margin & Endocanthion \\
\hline $\begin{array}{l}\text { Mandibular } \\
\text { line }\end{array}$ & $\begin{array}{l}\text { Lower } \\
\text { jaw } \\
\text { outline }\end{array}$ & Gnathion & Gnathion & $\begin{array}{l}\text { Lateral orbital margin } \\
\text { (Whitnall's malar } \\
\text { tubercle) }\end{array}$ & Ectocanthion \\
\hline- & - & - & - & Orbit & Eye-slit \\
\hline- & - & - & - & $\begin{array}{l}\text { Lateral margin of } \\
\text { piriform aperture }\end{array}$ & Alare \\
\hline- & - & - & - & $\begin{array}{l}\text { Cutting edge of upper } \\
\text { central incisor }\end{array}$ & Stomion \\
\hline- & - & - & - & Teeth (premolar) & Cheilion \\
\hline- & - & - & - & Occlusal line & Oral slit \\
\hline
\end{tabular}

Taken from Yoshino (2012)

\subsubsection{Jayaprakash et al. (2001)}

This is a craniofacial morpho-analytical approach, based on the shape correlation between the skull and face photograph. This approach relies on previous work developed by Lan (1995), İşcan (1993), Farkas (1981), and George (1987, 1993) and special attention is placed on the nasal region. The facial and skull traits and attributes, and the measurements employed for this study are detailed in Tables 3.23, 3.24 , and 3.25. 
Table 3.21 Criteria for assessing anatomical consistency between skull and face in lateral/ oblique view

\begin{tabular}{l|l|l|l|l|l}
\hline Outline & \multicolumn{3}{l|}{ Soft-tissue thickness } & Positional relationship & \\
\hline Skull & Face & Skull & Face & Skull & Face \\
\hline $\begin{array}{l}\text { Frontal bone } \\
\text { contour }\end{array}$ & $\begin{array}{l}\text { Forehead } \\
\text { outline }\end{array}$ & Trichion & Trichion & Supraorbital margin & Eyebrow \\
\hline $\begin{array}{l}\text { Outline from } \\
\text { nasion to } \\
\text { rhinion }\end{array}$ & $\begin{array}{l}\text { Nasal } \\
\text { dorsum } \\
\text { line }\end{array}$ & Glabella & Glabella & $\begin{array}{l}\text { Lateral orbital margin } \\
\text { (Whitnall's malar } \\
\text { tubercle) }\end{array}$ & Ectocanthion \\
\hline $\begin{array}{l}\text { Mental } \\
\text { outline }\end{array}$ & $\begin{array}{l}\text { Chin } \\
\text { outline }\end{array}$ & Nasion & Nasion & Nasion & $\begin{array}{l}\text { Higher than } \\
\text { nasal root }\end{array}$ \\
\hline $\begin{array}{l}\text { Gonial } \\
\text { outline }\end{array}$ & $\begin{array}{l}\text { Jaw angle } \\
\text { outline }\end{array}$ & Rhinion & Rhinion & $\begin{array}{l}\text { Lateral margin of } \\
\text { piriform aperture }\end{array}$ & Alare \\
\hline- & - & $\begin{array}{l}\text { Slightly infe- } \\
\text { rior to } \\
\text { nasospinale }\end{array}$ & Subnasale & $\begin{array}{l}\text { Lower margin of } \\
\text { piriform aperture }\end{array}$ & Subnasale \\
\hline- & - & Pogonion & Pogonion & Incisor & Stomion \\
\hline- & Gnathion & Gnathion & $\begin{array}{l}\text { Teeth (canine } \\
\text { premolar) }\end{array}$ & Cheilion \\
\hline
\end{tabular}

Taken from (Yoshino et al. 1995)

\subsubsection{Ricci et al. (2006)}

The authors presented an algorithm for identification using CFS. Fourteen subjects and their matching facial photographs and skull radiographs were selected. The algorithm calculated the distance of each transferred cross (anatomical points) and the corresponding average. Their results indicate that the smaller the mean value, the greater the index of similarity between the face and the skull. A total of 196 crosscomparisons were carried out. The following tables present the anatomical points that were located and marked with a cross on each facial image (Tables 3.26 and 3.27).

\subsubsection{Ishii et al. (2011)}

This method was based on a study of three subjects, a young man (23 years old), a man with an edentulous upper jaw (36 years old), and a woman (40 years old), using 3D CT data for CFS. Miyasaka (1987), Suzuki (1948), and Ichikawa (1975) studies were used for the morphological assessment technique (Table 3.28). 
Table 3.22 Lines, landmarks and index from Lan (1995)

\begin{tabular}{|c|c|c|c|}
\hline Determining lines & $\begin{array}{l}\text { Landmarks } \\
\text { index }\end{array}$ & $\begin{array}{l}\text { Index of soft } \\
\text { tissue } \\
\text { thickness }\end{array}$ & Index number of index \\
\hline $\begin{array}{l}\text { 1. Ectocanthion line. } \\
\text { Between two ectocanthions, } \\
\text { used as a horizontal base } \\
\text { line to mark the horizontal } \\
\text { relationship of the } \\
\text { superimposition. }\end{array}$ & $\begin{array}{l}\text { Superciliary and } \\
\text { supraorbital line }\end{array}$ & Vertex & $\begin{array}{l}\text { Endocanthion: Distance } \\
\text { between endocanthion and } \\
\text { supraorbital/orbital height }\end{array}$ \\
\hline $\begin{array}{l}\text { 2. Front central line. From } \\
\text { glabella to gnathion, vertical } \\
\text { to the ectocanthion line, } \\
\text { used to mark the vertical } \\
\text { relationship of the } \\
\text { superimposition. }\end{array}$ & Orbital height & Euryon & $\begin{array}{l}\text { Ectocanthion: Distance } \\
\text { between ectocanthion and } \\
\text { supraorbital/Orbital height }\end{array}$ \\
\hline $\begin{array}{l}\text { 3. Superciliary line. } \\
\text { Between two superciliaries, } \\
\text { parallel with the } \\
\text { ectocanthion line, and verti- } \\
\text { cal to the front central line. }\end{array}$ & $\begin{array}{l}\text { Ectocanthion } \\
\text { and supraorbital } \\
\text { line }\end{array}$ & Zygion & $\begin{array}{l}\text { Distance between } \\
\text { Endocanthions: Distance } \\
\text { between bi-endocanthions/ } \\
\text { Distance between junctures } \\
\text { of external orbit }\end{array}$ \\
\hline $\begin{array}{l}\text { 4. Subnasal line. At the } \\
\text { subnasale, vertical to the } \\
\text { front central line, used to } \\
\text { mark the superimposition of } \\
\text { subnasale and infra-apertura } \\
\text { piriformis. }\end{array}$ & $\begin{array}{l}\text { Endocanthion } \\
\text { and supraorbital } \\
\text { line }\end{array}$ & Tragion & $\begin{array}{l}\text { Distance between } \\
\text { Ectocanthions: Distance } \\
\text { between bi-ectocanthions/ } \\
\text { Distance between junctures } \\
\text { of external orbit }\end{array}$ \\
\hline $\begin{array}{l}\text { 5. Cheilion line. Between } \\
\text { two cheilions, vertical to } \\
\text { front central line, used to } \\
\text { mark the superimposition of } \\
\text { cheilion and maxillary teeth. }\end{array}$ & $\begin{array}{l}\text { Subnasale and } \\
\text { infra-apertura } \\
\text { piriformis }\end{array}$ & Gonion & $\begin{array}{l}\text { Stomion line: Distance } \\
\text { between supradental alveo- } \\
\text { lus and stomion line/Dis- } \\
\text { tance between infradental } \\
\text { alveoli and stomion line }\end{array}$ \\
\hline $\begin{array}{l}\text { 6. Gnathion line. At } \\
\text { gnathion, vertical to the } \\
\text { front central line, used to } \\
\text { mark the superimposition of } \\
\text { soft tissue of gnathion and } \\
\text { pogonion. }\end{array}$ & $\begin{array}{l}\text { Cheilion line and } \\
\text { infra-apertura } \\
\text { piriformis }\end{array}$ & Gnathion & $\begin{array}{l}\text { Distance between gonions: } \\
\text { Distance between gonions } \\
\text { on skull/Distance between } \\
\text { gonions on human image }\end{array}$ \\
\hline $\begin{array}{l}\text { 7, 8. Endocanthion vertical } \\
\text { lines (left and right). From } \\
\text { the endocanthion line to the } \\
\text { cheilion line, parallelwith } \\
\text { the front central line, used to } \\
\text { mark the relationship of } \\
\text { endocanthion and maxillary } \\
\text { teeth. }\end{array}$ & $\begin{array}{l}\text { Endocanthion } \\
\text { vertical line to } \\
\text { maxillary tooth } \\
\text { (left) }\end{array}$ & Opisthocranion & $\begin{array}{l}\text { Distance between } \\
\text { cheilions: Distance } \\
\text { between cheilions/ } \\
\text { Distancebetween gonions } \\
\text { on skull }\end{array}$ \\
\hline $\begin{array}{l}9,10 . \text { Ectocanthion vertical } \\
\text { lines (left-right). From the } \\
\text { ectocanthion line to the } \\
\text { gonion line, parallel with the } \\
\text { front central line, and are }\end{array}$ & $\begin{array}{l}\text { Endocanthion } \\
\text { vertical line to } \\
\text { maxillary tooth } \\
\text { (right) }\end{array}$ & Trichion & - \\
\hline
\end{tabular}


Table 3.22 (continued)

\begin{tabular}{|c|c|c|c|}
\hline Determining lines & $\begin{array}{l}\text { Landmarks } \\
\text { index }\end{array}$ & $\begin{array}{l}\text { Index of soft } \\
\text { tissue } \\
\text { thickness }\end{array}$ & Index number of index \\
\hline \multicolumn{4}{|l|}{$\begin{array}{l}\text { used to mark the horizontal } \\
\text { superimposition of } \\
\text { ectocanthion and gonion. }\end{array}$} \\
\hline $\begin{array}{l}\text { Morphological curves } \\
\text { include the following: } \\
\text { (1) head vault curve, } \\
\text { (2) arcus superciliary curve, } \\
\text { (3) nose curve, (4) lower jaw } \\
\text { curve,(5) gonion curve, } \\
\text { (6) head back curve, } \\
\text { (7) forehead curve, } \\
\text { (8) pogonion curve, and } \\
\text { (9) zygomatic curve. }\end{array}$ & $\begin{array}{l}\text { Distance } \\
\text { between two } \\
\text { junctures of } \\
\text { external orbit }\end{array}$ & Glabella & - \\
\hline- & $\begin{array}{l}\text { Distance } \\
\text { between } \\
\text { bi-endocanthions } \\
\end{array}$ & Nasion & - \\
\hline- & $\begin{array}{l}\text { Cheilion to man- } \\
\text { dibular tooth }\end{array}$ & Sellion & - \\
\hline- & $\begin{array}{l}\text { Ectocanthion } \\
\text { and } \\
\text { endoconchion }\end{array}$ & Subnasale & - \\
\hline- & $\begin{array}{l}\text { Prosthion and } \\
\text { cheilion line }\end{array}$ & Pogonion & - \\
\hline- & $\begin{array}{l}\text { Infradentale } \\
\text { anterius and } \\
\text { cheilion }\end{array}$ & - & - \\
\hline- & $\begin{array}{l}\text { Distance } \\
\text { between gonions }\end{array}$ & - & - \\
\hline- & $\begin{array}{l}\text { Distance } \\
\text { between gonions } \\
\text { on the skull }\end{array}$ & - & - \\
\hline- & $\begin{array}{l}\text { Distance } \\
\text { between zygions }\end{array}$ & - & - \\
\hline- & $\begin{array}{l}\text { Distance } \\
\text { between } \\
\text { cheilions }\end{array}$ & - & - \\
\hline- & $\begin{array}{l}\text { Gonion and } \\
\text { tragion on the } \\
\text { skull }\end{array}$ & - & - \\
\hline- & $\begin{array}{l}\text { Gonion and } \\
\text { ectocanthion } \\
\text { vertical line on } \\
\text { the skull }\end{array}$ & - & - \\
\hline
\end{tabular}




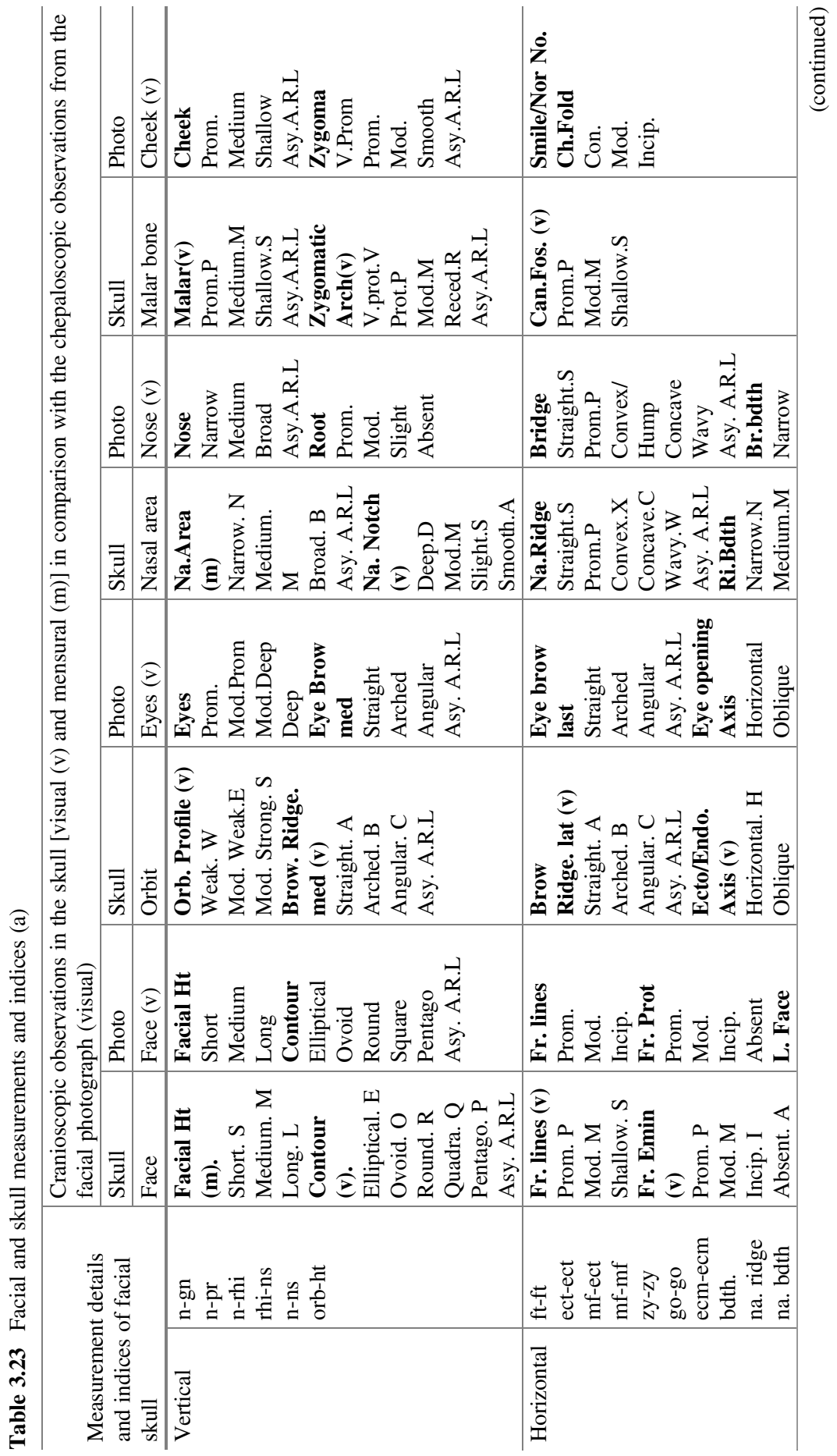




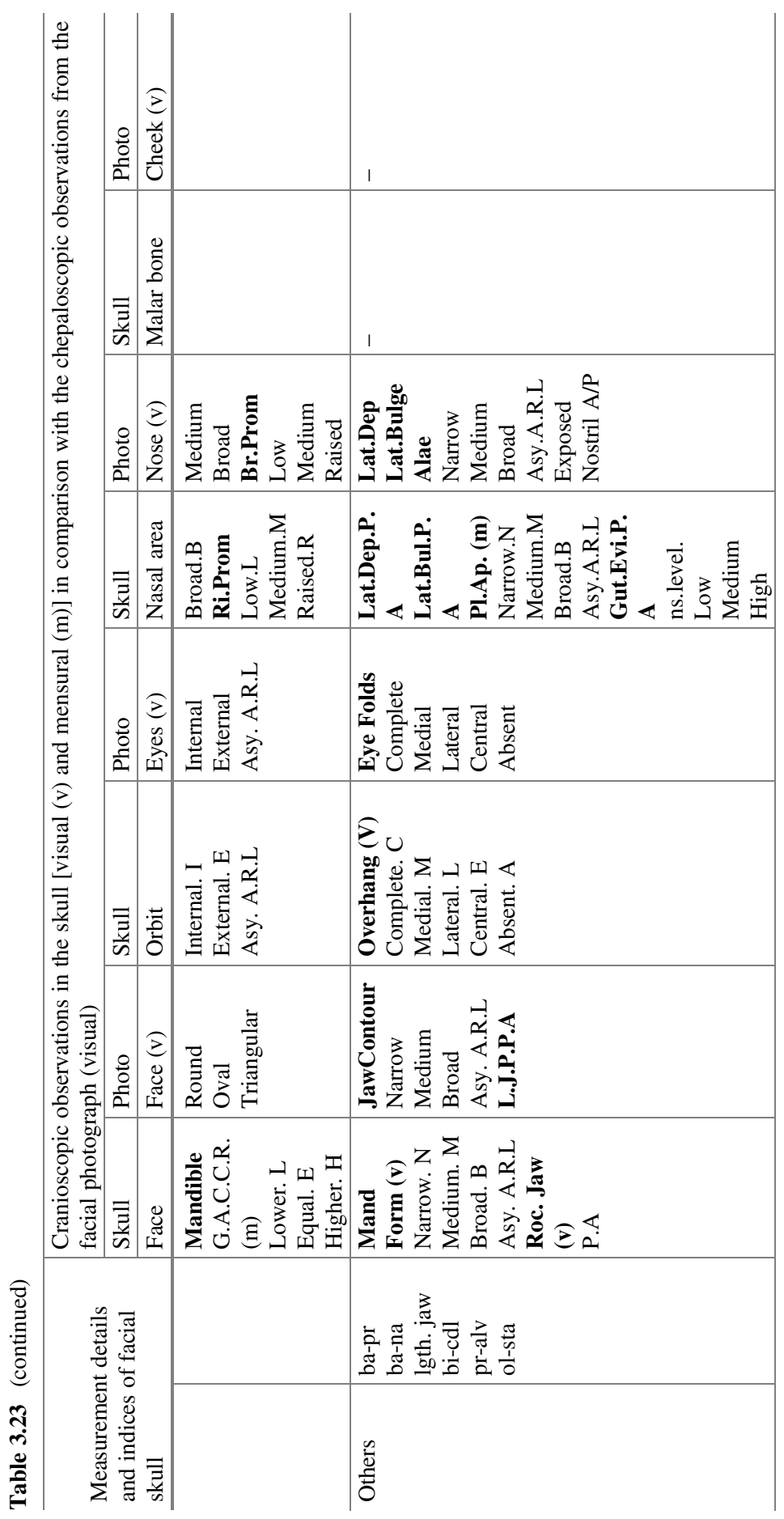




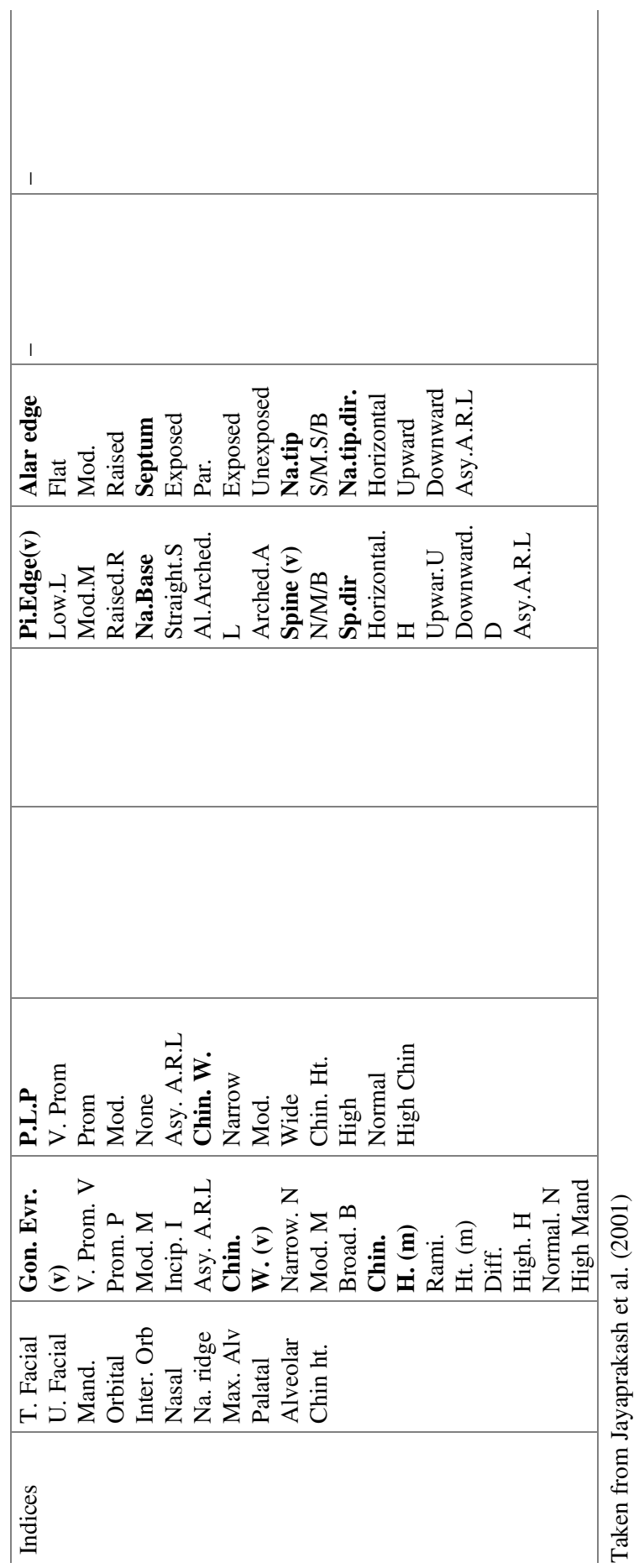




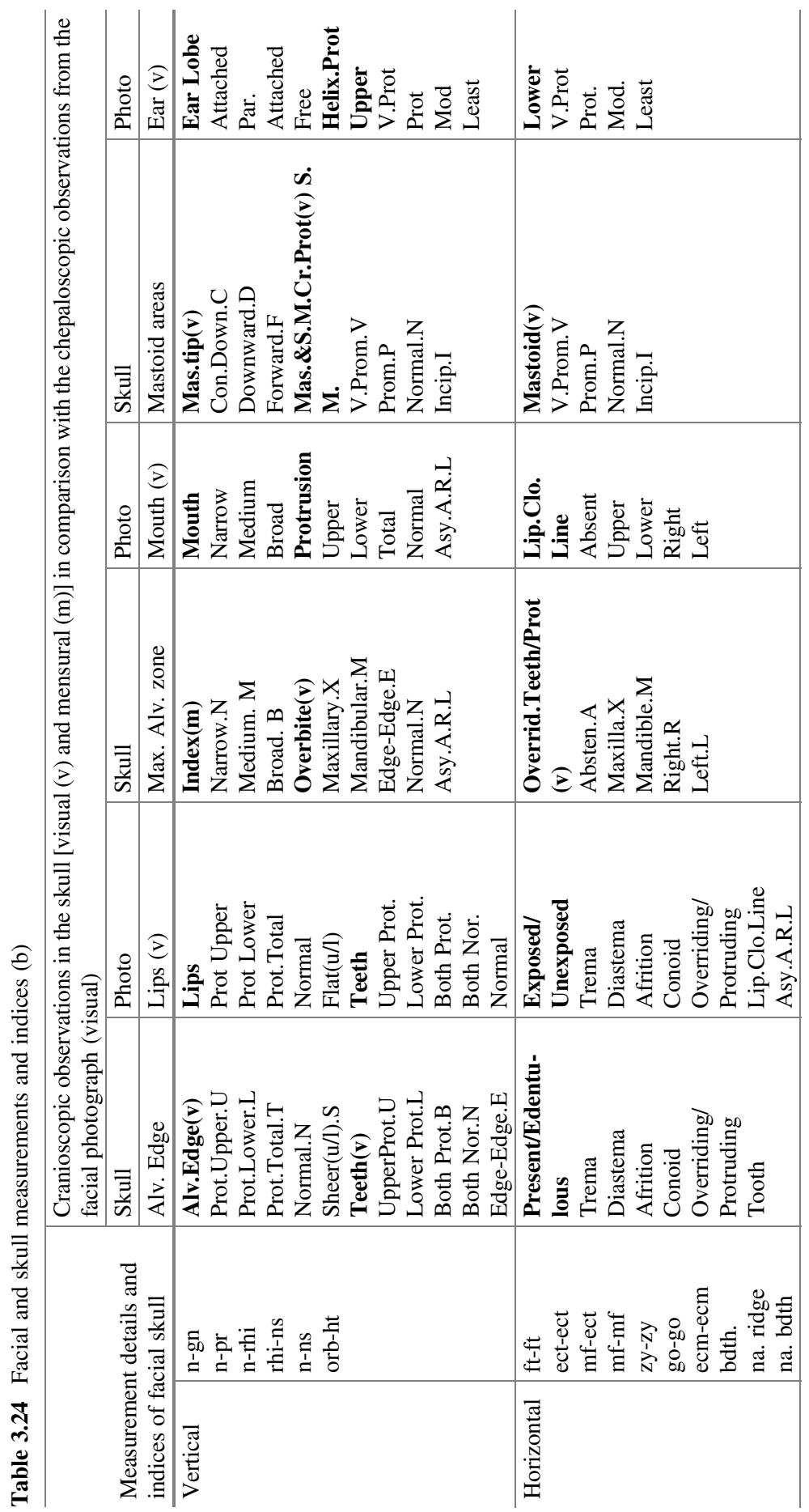




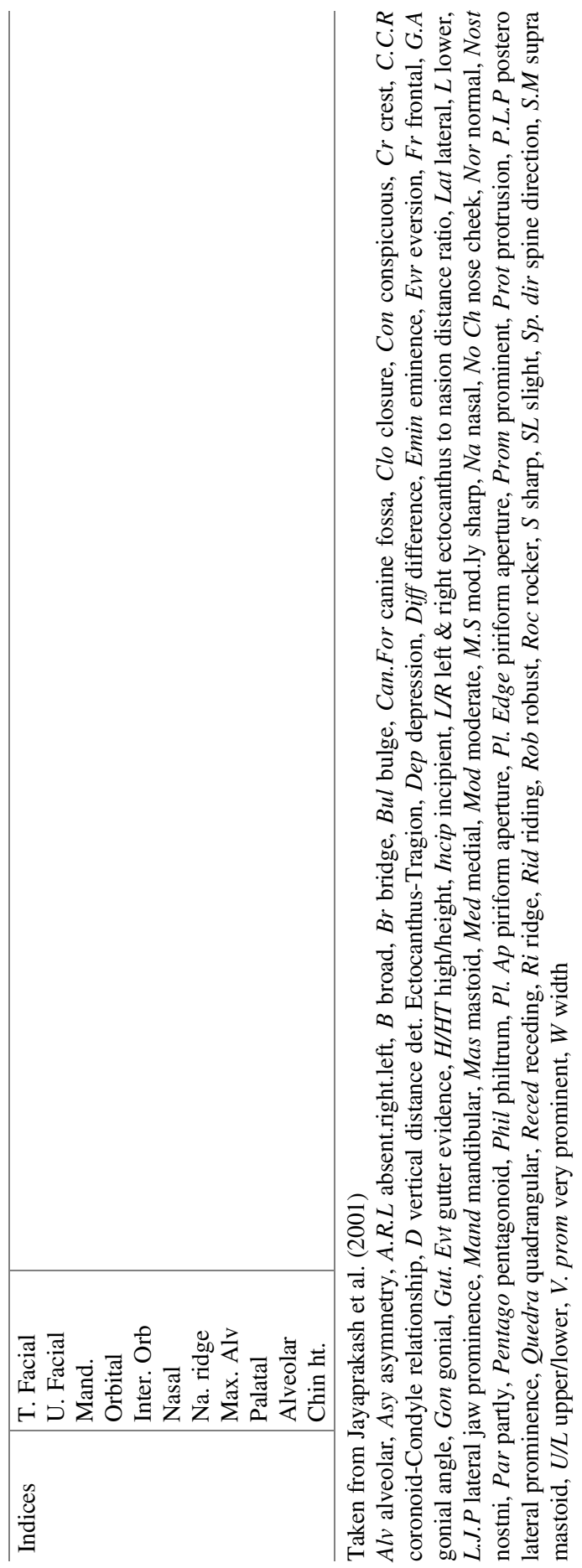




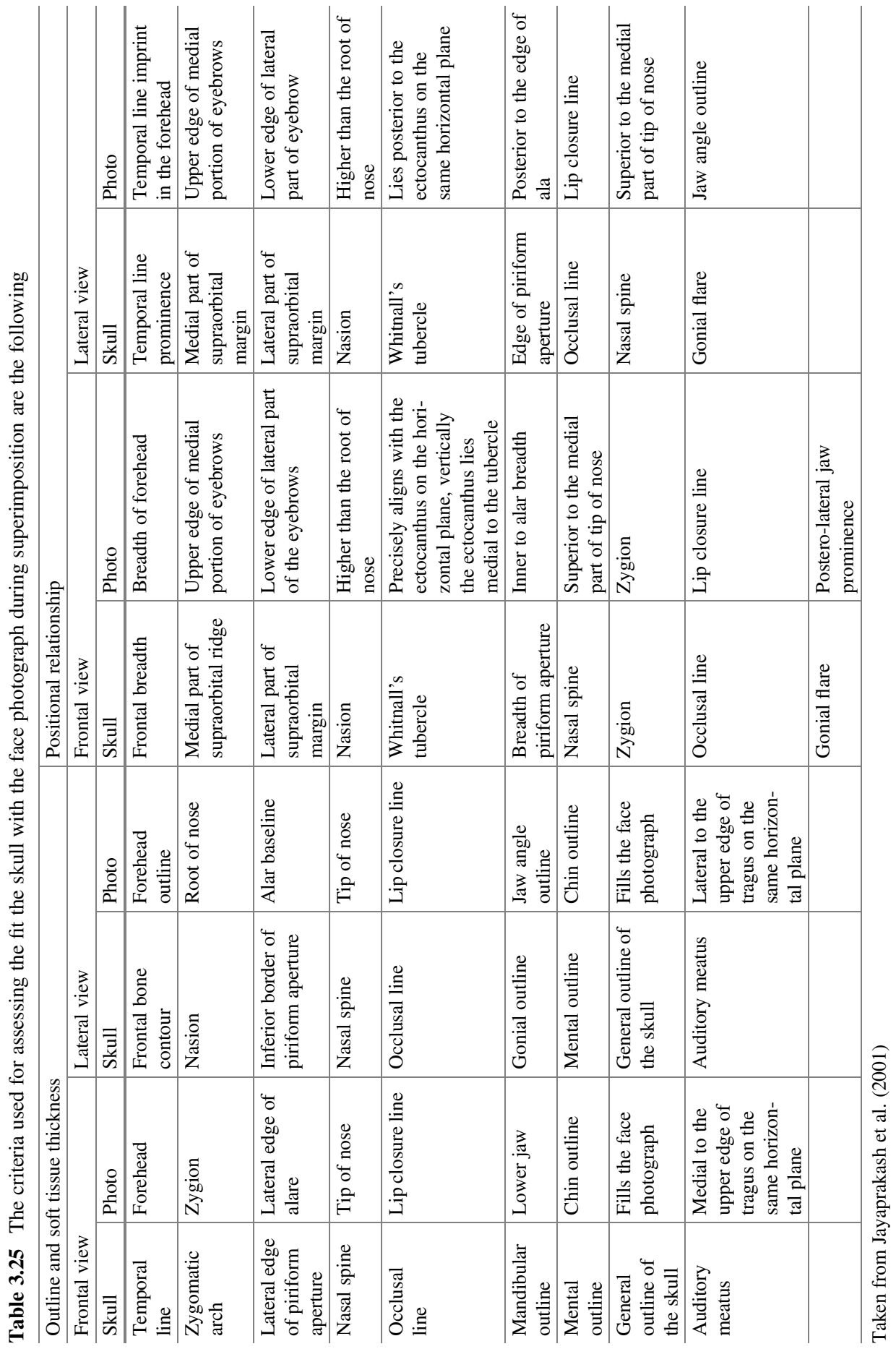


Table 3.26 Anatomical points of the face

Anatomical points of the face

Eyebrow midpoint

Midpoint of the inferior margin of the palpebra inferior (lower eyelid)

Inner canthus

Outer canthus

The most forward point of the midsagittal plane (located between the two eyebrows)

Point below the inferior margin of the cartilaginous septum of the nose

Superior margin of the upper lip midpoint

Inferior margin of the lower lip midpoint

Zygoma

Table 3.27 Points of the skull X-rays

Points of the skull X-rays

Arcus superciliaris midpoint (superciliary arch)

Inferior orbital rim midpoint

Inner canthus, placed $3 \mathrm{~mm}$ medially to the medial wall of the orbit1 or against the medial wall of the orbit 2 or 2-3 mm laterally to the lacrimal crest and $4-5 \mathrm{~mm}$ below the dacryon (junction of the lacromaxillary suture and the frontal bone) 3

Outer canthus, placed $5 \mathrm{~mm}$ laterally to the orbit margin 1 or 3-4 mm medially to the "Whitnall's malar tubercle"3; the "Whitnall's malar tubercle," placed on the orbital surface of the zygomatic bone $11 \mathrm{~mm}$ below the frontozygomatic suture, is the site of attachment of the rectus lateralis bulbi muscle, suspensory ligament, and levator palpebrae superioris muscle 4

Glabella

Inferior margin of the nasal spine

Upper infradental point (between the two medial upper incisors)

Lower infradental point (between the two medial lower incisors)

Zygomatic process of the maxilla

Table 3.28 Anthropometrical points used for each individual

\begin{tabular}{l|l}
\hline Landmarks & \\
\hline $\mathrm{n}$ & R-ex \\
\hline R-zy & L-ex \\
\hline L-zy & sn-ns \\
\hline gn & R-al \\
\hline R-go & L-al \\
\hline L-go & R-ch \\
\hline R-en & L-ch \\
\hline L-en & - \\
\hline
\end{tabular}

$n$ nasion, $R$-zy right zygion, $L$-zy left zygion, $g n$ gnathion, $R$ - $g o$ right gonion, $L$-go left gonion, $R$-en right endocanthion, $L$-en left endocanthion, $R$-ex right exocanthion, $L$-ex left exocanthion, $s n$-sn subnasal-subnasal, $R$-al right alare, $L$-al left alare, $R$-ch cheilion, $L$-che left cheilion 
Table 3.29 Orientation, primary, and secondary landmarks

\begin{tabular}{|c|c|}
\hline Methods & Description \\
\hline \multicolumn{2}{|l|}{ Orientation landmarks } \\
\hline Ectocanthion (ec) & \multirow[t]{3}{*}{ Should overlap: used to define the orientation } \\
\hline Subnasal point (ns) & \\
\hline Nasion (n) & \\
\hline \multicolumn{2}{|l|}{ Primary landmarks } \\
\hline Glabella (g) & \multirow{3}{*}{$\begin{array}{l}\text { Expected to be very close on skull and face, landmarks should touch or } \\
\text { overlap }\end{array}$} \\
\hline Dacryon (d) & \\
\hline Frontotemporale (ft) & \\
\hline \multicolumn{2}{|l|}{ Secondarylandmarks } \\
\hline Gonial angle (go) & \multirow{4}{*}{$\begin{array}{l}\text { Bone and soft tissue landmarks not expected to overlap exactly but } \\
\text { bony landmarks should be inside soft tissue landmarks }\end{array}$} \\
\hline Gnathion (gn) & \\
\hline Zygion (zy) & \\
\hline $\begin{array}{l}\text { Nasal aperture width/ } \\
\text { alare (al) }\end{array}$ & \\
\hline
\end{tabular}

The description of the landmark on the skull (bony landmark) and the corresponding soft tissue landmark is given. Taken from Gordon and Steyn (2012)

\subsubsection{Gordon et al. (2006)}

The authors studied three methods: basic morphological matching (Austin-Smith and Maples 1994), landmark matching, and a combination of both approaches. The bony and soft tissue landmarks used were based on Martin and Saller (1957) and Farkas (1981). They proposed three different sets of landmarks for orientation and evaluation purposes for CFS (see Table 3.29).

Open Access This chapter is licensed under the terms of the Creative Commons AttributionNonCommercial 2.5 International License (http://creativecommons.org/licenses/by-nc/2.5/), which permits any noncommercial use, sharing, adaptation, distribution and reproduction in any medium or format, as long as you give appropriate credit to the original author(s) and the source, provide a link to the Creative Commons license and indicate if changes were made.

The images or other third party material in this chapter are included in the chapter's Creative Commons license, unless indicated otherwise in a credit line to the material. If material is not included in the chapter's Creative Commons license and your intended use is not permitted by statutory regulation or exceeds the permitted use, you will need to obtain permission directly from the copyright holder. 


\section{Chapter 4 \\ Craniofacial Superimposition Techniques}

\subsection{Introduction}

The technological support for craniofacial superimposition (CFS) techniques used in the initial identifications found in the literature involved a large number of very diverse approaches. This could also be the reason for the current diversity of CFS methods and their terminology, as mentioned before. Rather than following a uniform methodology, every expert tends to apply his/her own approach to the problem, based on the available technology and his/her own knowledge of human craniofacial anatomy, soft tissues, and their relationships. Therefore, CFS approaches have evolved as new technology has become available, although their foundations were previously laid. Some of these approaches were classified in a review by Aulsebrook et al. (1995) according to the technology used to acquire the data and to support the skull-face overlay (SFO) and identification processes, that is, static photographic transparency, video technology, and computer graphics.

Similar classification schemes have been reported by other authors, which describe how CFS has passed through three phases: photographic superimposition (developed in the mid-1930s), video superimposition (widely used since the second half of the 1970s), and computer-aided superimposition (introduced in the second half of the 1980s) (Nickerson et al. 1991; Aulsebrook et al. 1995; Yoshino and Seta 2000). Moreover, Yoshino et al. (1997) classified some of the computer-aided CFS methods into two categories from the viewpoint of the identification strategy. The first strategy is to digitize the skull and face photographs and then morphologically compare the two images by image processing. The second is to evaluate the fit between the skull and facial images by morphometric examination. Notice that the latter contributions are prior to the image-processing boom of the last decade. Indeed, important issues like 3D modeling and machine learning are neglected. In the case it was used, the computer was usually considered just as a secondary support for the technique even when authors claim they followed a "computer-aided" approach (Ubelaker et al. 1992; Ricci et al. 2006). 
Recently, Damas et al. (2011) surveyed existing methods considering a new computing-based classification criterion. This criterion is more related to the use of computers during the different stages of the CFS process itself. They defined the different stages involved in the craniofacial process to properly characterize any CFS system (and specifically computer-aided ones). These stages: face enhancement and skull modeling, SFO, and decision making:

- The first stage involves achieving a digital model of the skull and the enhancement of the image of the face. This stage is not present in all the systems. Indeed, the oldest systems and most of the recent ones still acquire a photograph and/or a series of video shots of the skull, instead of building a 3D model of it. ${ }^{1}$ Concerning the image of the face, most recent systems use a $2 \mathrm{D}$ digital image. This stage also involves the application of image-processing techniques (Gonzalez and Woods 2008) to enhance the quality of the image of the face that was typically provided when the person disappeared.

- The second stage is the SFO. It consists of searching for the best overlay of either, a 2D image of the skull and face or the 3D model of the skull and 2D image of the face acquired during the first stage.

- Finally, the third stage of the CFS process corresponds to the decision making. Based on the SFO achieved, the identification decision is made by investigating the outline and soft-tissue thickness at various anthropometric landmarks and positional relationships of the skull to face parts based on anatomical data.

This categorization of the superimposition process will be taken into account throughout the current document when reviewing all work carried out in the field.

\subsection{Photographic Craniofacial Superimposition}

Identification by photographic superimposition is a technique that began to be developed in the middle of the 1930s. The first superimposition was probably made in 1885 by Welcker and His, who used an outline drawing of the skull in relation to drawings of the deceased's death mask. From the beginning, their studies of the relationship between soft and bony tissues were taken as a basis for developing new studies and different methodologies in this forensic area. Following this, many authors performed different measurements of the soft and hard tissues in order to make reconstructions of their subject's face for sculptures and paintings. In some cases, these studies were focused on making a comparison between the reconstruction and the actual face represented in paintings. The appearance of the photographic CFS technique allowed for the first time the comparison of an unknown skull with facial images of the presumed deceased. Its evolution has resulted in a variety of

\footnotetext{
${ }^{1}$ In this case, the first stage would be better named "face and skull data acquisition."
} 
techniques and tools depending on several factors, ranging from the skull conservation, to the quality of the images and the knowledge of the expert who proposed it.

We can consider the acquisition of a painting, contour, or photograph of both the skull and face, the replication of the skull size and its orientation with respect to the facial photograph of the presumed victim, and the assessment of the anatomical consistency between the face and the skull as common tasks in photographic CFS. A clear relation with the three stages identified before can be seen with the most common tasks to be carried out in each of them as follows:

- Face enhancement and skull modeling: In this first stage, one or more photographs of the skull have to be taken. The quality of the employed photographs will be related to the quality of the photographic equipment used in the acquisition. In particular, the type of lens, the focal length and the distance, and position of the subject together with other factors are responsible for producing deformations. Many authors have drawn tracings of the face and/or skull to facilitate the superimposition process.

- Skull-face overlay: Almost every author has created their own methodology to project both images, using craneoforos, images with transparencies, or other mechanisms that allow placing the skull and facial photographs in the same position. In addition, some authors made use of anatomical landmarks to make the overlay process easier.

- Decision making: In most of the cases, the decision was based on subjective features due to the lack of soft tissue studies and the difficulty to perform measurements on photographs.

The scientific literature on the implementation of photographic CFS is presented in Table 4.1. Only the methodology followed within the stages of face enhancement and skull modeling and skull face overlay is summarized, as no significant contributions were made on the decision-making stage of the process.

In the following subsections, the different photographic CFS proposals and their contribution to each of the CFS stages are reviewed.

\subsubsection{Face Enhancement and Skull Modeling}

In this first stage, the initial steps are intended to select and/or obtain clear and measurable images. The most important factors affecting the quality of the portrait to be superimposed that have been taken into account are the selection of the antemortem image, the knowledge of all the technical details of the photographic equipment, the focal length, the distance to the camera, etc. (see Table 4.2). In the case of the skull, this could sometimes include working with fragmented remains. In particular, Cocks (1971) developed a photographic CFS methodology, which was also applied to fragmented skulls. Moreover, in order to obtain measurable images, a few workers have followed the example of Glaister and Brash (1937) in using objects of known size, external to the person, to establish a magnification factor 
Table 4.1 Review of the literature on photographic superimposition methods

\begin{tabular}{|c|c|}
\hline Stage & Authors \\
\hline \multicolumn{2}{|l|}{ Face enhancement and skull modeling } \\
\hline Location of anthropometric measurements & $\begin{array}{l}\text { Simpson (1943), Sekharan (1971), Reddy } \\
\text { (1973), Sognnaes (1980), McKenna et al. } \\
\text { (1984), Brocklebank and Holmgren (1989), } \\
\text { Lan (1992) }\end{array}$ \\
\hline Location of measurable objects & $\begin{array}{l}\text { Glaister and Brash (1937), Gordon and } \\
\text { Drennan (1948), Gruner and Reinhard (1959), } \\
\text { Sekharan (1971), Janssens et al. (1978) } \\
\end{array}$ \\
\hline Location of anatomical landmarks & Webster (1955), Dorion (1983), Maat (1989) \\
\hline Location of special characteristics & Brocklebank and Holmgren (1989) \\
\hline Draw tracings or outlines of the face and skull & $\begin{array}{l}\text { Peason and Morant (1934), Glaister and Brash } \\
\text { (1937), Gordon and Drennan (1948), Prinsloo } \\
\text { (1953), Reddy (1973) }\end{array}$ \\
\hline Reconstruct fragmented skulls & Cocks (1971) \\
\hline Replicate the exact photographic conditions & Scully and Nambiar (2002) \\
\hline \multicolumn{2}{|l|}{ Skull face overlay } \\
\hline Size replication using measurable objects & $\begin{array}{l}\text { Glaister and Brash (1937), Gordon and } \\
\text { Drennan (1948), Sekharan (1971), Janssens } \\
\text { et al. (1978) }\end{array}$ \\
\hline $\begin{array}{l}\text { Size replication using anthropometric } \\
\text { measurements }\end{array}$ & $\begin{array}{l}\text { Simpson (1943), Sekharan (1971), Reddy } \\
\text { (1973), Sognnaes (1980), Brocklebank and } \\
\text { Holmgren (1989) }\end{array}$ \\
\hline Size replication using anatomical landmarks & Dorion (1983) \\
\hline $\begin{array}{l}\text { Use of pivoting head, skull holding, phantom- } \\
\text { head, or pan-and-tilt device }\end{array}$ & $\begin{array}{l}\text { Sekharan (1971), Dorion (1983), Mackenna } \\
\text { et al. (1984), Brocklebank and Holmgren } \\
\text { (1989) }\end{array}$ \\
\hline $\begin{array}{l}\text { Geometrical method to calculate projections of } \\
\text { anthropometric distances, angles of rotation, } \\
\text { and inclination of the head }\end{array}$ & Maat(1989) \\
\hline Distance calculation between skull and camera & Gruner and Reinhard (1959), Dorion (1983) \\
\hline $\begin{array}{l}\text { Use of asymmetrical features of the facial } \\
\text { skeleton to assess the matching }\end{array}$ & Prinsloo (1953) \\
\hline Landmark matching & Glaister and Brash (1937), Reddy (1973) \\
\hline $\begin{array}{l}\text { Match of the tracings, outlines, negatives, } \\
\text { transparencies or X-ray of the face and skull }\end{array}$ & $\begin{array}{l}\text { Peason and Morant (1934), Glaister and Brash } \\
\text { (1937), Gordon and Drennan (1948), Webster } \\
\text { (1955), Gruner and Reinhard (1959), Reddy } \\
\text { (1973), Mackenna et al. (1984), Brocklebank } \\
\text { and Holmgren (1989) }\end{array}$ \\
\hline Triangulation system based on landmarks & Cocks (1971) \\
\hline Importance of photographic perspective & Klonaris and Furue (1980) \\
\hline Furue's methodology validation & Scully and Nambiar (2002) \\
\hline
\end{tabular}

for photographic enlargement, presumably because such objects are not always present or clear in ante-mortem photographs (see Fig. 4.1). When present, features of articles of clothing that lie in roughly the same focal plane as the face have been used. Enlargements of snapshots or photographic portraits based on the dimensions 
Table 4.2 Review of the literature on video superimposition methods

\begin{tabular}{|c|c|}
\hline Stage & Author \\
\hline \multicolumn{2}{|l|}{ Face enhancement and skull modeling } \\
\hline $\begin{array}{l}\text { Location of anthropometric } \\
\text { measurements }\end{array}$ & Bastiaan et al. (1986), Jayaprakash et al. $(2001,2010)$ \\
\hline Location of anatomical landmarks & $\begin{array}{l}\text { Koelmeyer (1982), Dorion (1983), Bastiaan et al. } \\
\text { (1986), Mackenna (1988), Austin-Smith and Maples } \\
\text { (1994), Fenton et al. (2008) }\end{array}$ \\
\hline $\begin{array}{l}\text { Location of useful morphological } \\
\text { characteristics }\end{array}$ & Austin (1999) \\
\hline Location of tissue thickness markers & $\begin{array}{l}\text { Austin-Smith and Maples (1994), Fenton et al. } \\
\text { (2008) }\end{array}$ \\
\hline \multicolumn{2}{|l|}{ Skull face overlay } \\
\hline $\begin{array}{l}\text { Replication of the exact photographic } \\
\text { conditions }\end{array}$ & Iten (1987) \\
\hline $\begin{array}{l}\text { Size replication using anthropometric } \\
\text { measurements }\end{array}$ & Bastiaan et al. (1986), Jayaprakash et al. $(2001,2010)$ \\
\hline $\begin{array}{l}\text { Size replication using tissue thickness } \\
\text { markers }\end{array}$ & Austin-Smith and Maples (1994) \\
\hline $\begin{array}{l}\text { Size replication using anatomical } \\
\text { landmarks }\end{array}$ & $\begin{array}{l}\text { Koelmeyer (1982), Bastiaan et al. (1986), Mackenna } \\
\text { (1988) }\end{array}$ \\
\hline Size replication using zoom & Iten (1987), Solla and İşcan (2001) \\
\hline $\begin{array}{l}\text { Size replication using focal length and } \\
\text { the focusing of the video camera }\end{array}$ & Shahrom et al. (1996) \\
\hline Orientation using landmarks & Solla and İşcan (2001) \\
\hline $\begin{array}{l}\text { Orientation by trial and error } \\
\text { manipulation }\end{array}$ & Austin-Smith and Maples (1994) \\
\hline Dynamic orientation process & Fenton et al. (2008) \\
\hline $\begin{array}{l}\text { Use of pivoting head, skull holding, } \\
\text { phantom-head, or pan-and-tilt device }\end{array}$ & $\begin{array}{l}\text { Sekharan }(1988,1993) \text {, Jayaprakash et al. (2001, } \\
\text { 2010) }\end{array}$ \\
\hline $\begin{array}{l}\text { Distance calculation between skull and } \\
\text { camera }\end{array}$ & Dorion (1983) \\
\hline $\begin{array}{l}\text { Tracings, outlines, negatives, or trans- } \\
\text { parencies matching }\end{array}$ & $\begin{array}{l}\text { Helmer and Grüner (1977a, b), Koelmeyer (1982), } \\
\text { Dorion (1983), Iten (1987), Shahromet al. (1996) }\end{array}$ \\
\hline Landmark matching & $\begin{array}{l}\text { Bastiaan et al. (1986), Iten (1987), Mackenna (1988), } \\
\text { Shahromet al. (1996) }\end{array}$ \\
\hline Morphological matching & $\begin{array}{l}\text { Austin-Smith and Maples (1994), Austin (1999), } \\
\text { Fenton et al. (2008), Jayaprakash et al. (2001, 2010) }\end{array}$ \\
\hline \multicolumn{2}{|l|}{ Decision making } \\
\hline Fade-in/fade-out and sweep & $\begin{array}{l}\text { Helmer and Grüner (1977a, b), Koelmeyer (1982), } \\
\text { Bastiaan et al. (1986) }\end{array}$ \\
\hline Video mixing unit device & $\begin{array}{l}\text { Helmer and Grüner (1977a, b), Bastiaan et al. (1986), } \\
\text { Iten (1987), Austin-Smith and Maples (1994), } \\
\text { Shahromet al. (1996), Austin (1999), Solla and İşcan } \\
\text { (2001), Jayaprakash et al. (2001, 2010) }\end{array}$ \\
\hline Special effects generator & Mackenna (1988), Sekharan $(1988,1993)$ \\
\hline
\end{tabular}



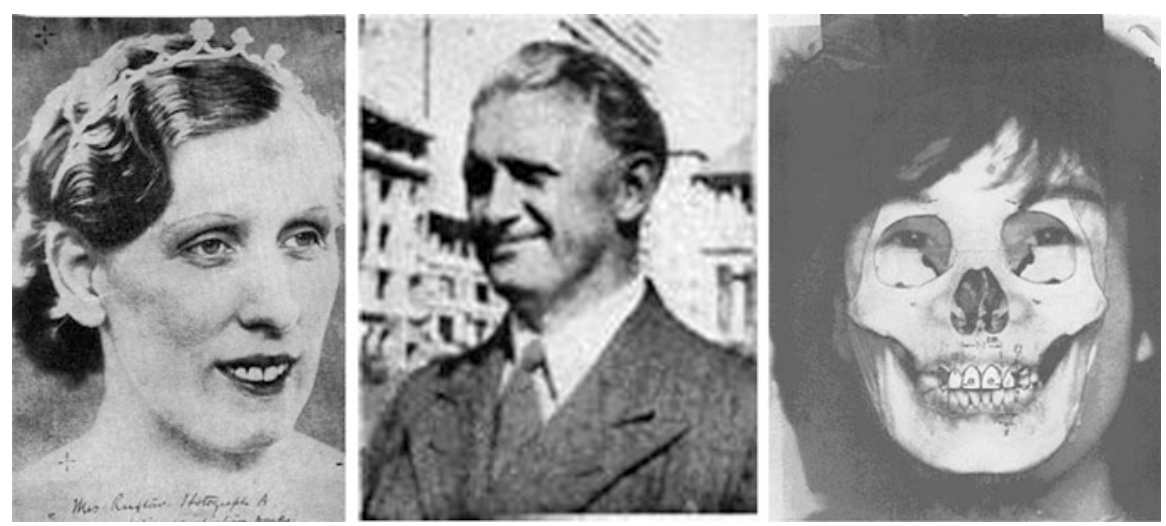

Fig. 4.1 Case examples. On the left, the Ruxton case photograph showing the tiara used as a measurable reference object (Grüner 1993). In the center, a snapshot of deceased Michael Wolkersdorfer in which the tie was used as a scale (the image was taken from Gordon and Drennan (1948). On the right, a superimposition of transparencies and tracing of skull Z6 with photograph of victim 3 giving a possible elimination (the image was taken from McKenna et al. (1984)

of the linear pattern of a tie (Gordon and Drennan 1948), the pattern on the border of a sari (Sekharan 1971), and the diameter of a button on a sweater (Janssens et al. 1978) have yielded successful superimpositions and positive identifications. Measurements of a wooden chair present in a photographic portrait also yielded a magnification factor from which an accurate enlargement was made (Sekharan 1971). In the absence of objects of known size in ante-mortem photographs, several workers have combined the use of anatomical landmarks and anthropometric measurements of the facial skeleton with so-called established values for thicknesses of soft tissues to estimate a magnification factor and, thus, obtain a superimposition by best fit. Among anthropometric measurements, the most common references were the interpupillary distance (Simpson 1943; Reddy 1973; Sekharan 1971) and the features of the anterior dentition (McKenna et al. 1984; Sognnaes 1980).

Figure 4.1(right) shows an example of the latter reference feature. The use of landmarks became more important at the end of the century.

Once the photographs have been selected/obtained and any measurable references have been marked, there are still some tasks to be developed in order to facilitate the SFO stage, for example, trace drawings of the head outline have been quite helpful in many of the solved cases. Pearson and Morant (1934) took a photograph of an Egyptian criminal before his execution to be compared with the skull subsequently prepared after his death. The authors made tracings of the face and skull photographs so that they could superimpose them. This work is considered as the first superimposition using a photograph of the skull and tracings of the face. Glaister and Brash (1937) used a full-size transparent portrait outline on the viewing screen of the camera. They transferred the head outline of both the face and skull photographs to tracing paper. Gordon and Drennan (1948), Cocks (1971), and Reddy (1973) also made use of tracings before performing SFO. In this way, 
Scully and Nambiar (2002) identified a number of factors, which, in their opinion, directly influenced a positive superimposition. He said that the selection of a good quality ante-mortem photograph is of primary importance to get the most reliable result. Poor quality images can result in poor definition, because the ante-mortem photograph usually has to be enlarged, making the determination of certain features difficult. The expert must choose photographs in which the face under study appears as near as possible to the center of the picture. Use of the outer extremities of the frame should be avoided due to barrel or pin cushion distortion, as the proportions of the face will be considerably distorted. Therefore, the author advised that the face should be in good focus, well lit, and not in partial shadow. Scully and Nambiar (2002) advised that the exact photographic conditions under which the ante-mortem photograph was taken should be discovered: the distance at which it was taken, the focal length of the lens used to record the image, even the settings used on the darkroom enlarger to produce the final print may be of value. The surface to which the ante-mortem photograph is attached should also be exactly parallel to the image plane of the camera. The author affirmed that if these factors are unknown, the final result is negatively affected.

\subsubsection{Skull-Face Overlay}

There is no common procedure used to carry out SFO and each author tries to do this depending on the equipment they have and their knowledge of the technique. Identification through photographic superimposition usually shares the following two steps: (1) determination of the correct life-size; (2) replication of the same orientation of the face in the photograph when photographing the skull. To perform these tasks, a diverse set of elements (X-ray, negative and positive photographs, outlines, and transparencies), apparatus (light stand, optical bench), and methodologies (measurable objects, distance between landmarks or anthropometric measures, triangulation based on the landmarks and transparencies, asymmetrical features of the facial skeleton) are employed (a summary is presented in Table 4.2).

Glaister and Brash (1937), while addressing the Ruxton Case, adjusted the skull orientation to a similar head position as the one the face showed in a portrait. They used tracings of the head outline in both the face and skull photographs and then superimposed them. The tracing paper with the superimposed outlines was positioned onto the positive print photograph and the paper skull negative. The transparency was then superimposed using different landmarks (prosthion and nasion)and the headoutlines. The positive portrait and the negative skull print were photographed again on x-ray. A positive skull portrait and a negative face portrait, each one with the registration marks photographed, were obtained as a result. Finally, two transparencies were superimposed using the central marks and were photographed again on the x-ray film. This methodology was the basis for later modification by numerous authors. 


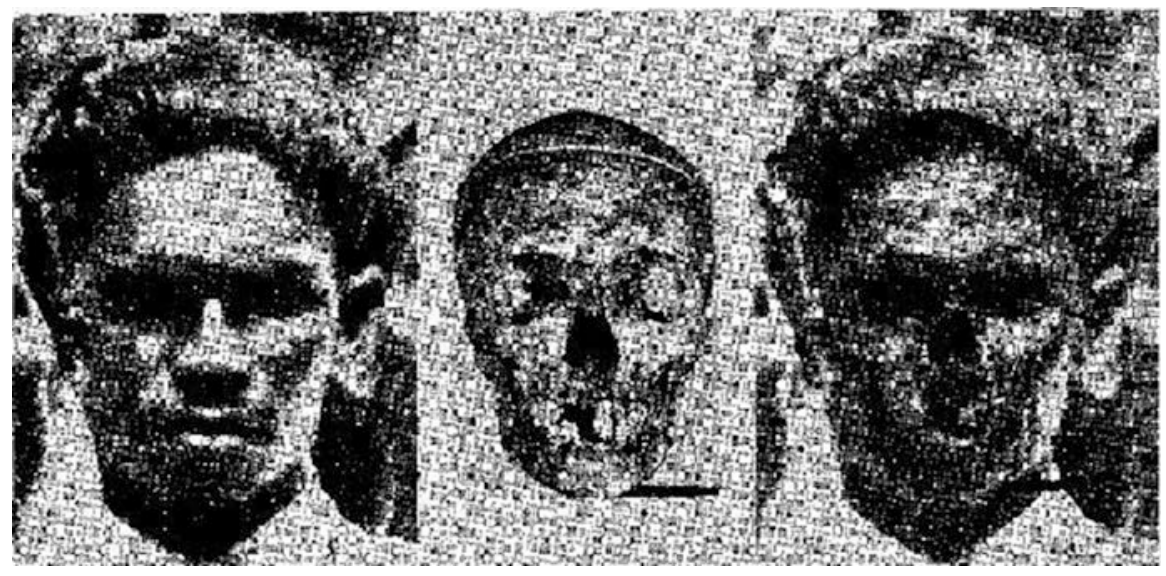

Fig. 4.2 From left to right: (a) enlargement of the deceased's face and head (actual size); (b) the skull positioned to correspond with the points marked on the camera; (c) final result of the superimposition of the first two images (the image was taken from Webster 1955)

Simpson (1943) executed a superimposition with an x-ray portrait. The width was standardized between the eye sockets and the full portrait was then superimposed onto the X-ray skull photograph.

The first step in the Wolkersdorfer case, Gordon and Drennan (1948), was to obtain the skull and face images in life-size. They used the natural tie size as a scale. The head outline was drawn and a machine was used to superimpose the skull drawing over the life-size head drawing. This superimposition showed a good anatomical correspondence.

In Webster (1955), the author obtained a $12^{\prime \prime} \times 10^{\prime \prime}$ photograph of 90 people, within which the victim was present. The equipment was composed of a Ross halfplate camera equipped with a 5-in. Xpres f.4 wide angle lens. They created the deceased's face negative from the photograph, which was enlarged approximately eight times the size of the original picture. The skull was then oriented in the same position as the face. The negative was placed on the ground glass ${ }^{2}$ and three points (center of nasal bone, extreme prominence of the left malar bone, and the inner end of the left supra-orbital ridge) were marked to obtain the correct alignment of the two images (see Fig. 4.2).

Gruner and Reinhard (1959) designed a light stand and an optical bench for positioning the skull and adjusting the photographic angle, with the aim of making an accurate superimposition, taking the soft tissue thickness into consideration. They stipulated that the correct distance between skull and camera was $1.75 \mathrm{~m}$. The author

\footnotetext{
${ }^{2}$ Ground glass is a glass whose surface has been ground to produce a flat but rough (matte) finish. In photography, a sheet of ground glass is used for manual focusing in some still and motion picture cameras. The ground-glass viewer is inserted in the back of the camera, and the lens opened to its widest aperture. This projects the scene onto the ground glass upside down.
} 
took a negative of the skull, which was then enlarged. Finally, he printed it as a single image to be used in the overlay.

Cooks (1971)'s methodology takes a photograph of the skull and compares it with a passport picture of the suspected victim. To obtain a good correspondence between the skull and the portrait, the author developed a system of triangulation based on landmarks (nasion, anterior nasal spine, gnathion, orbit points, and mandible) marked in both images. The triangle patterns were drawn onto the transparency looking for correspondence between the superimposed images.

In Reddy's method (Reddy 1973), the outlines of the salient features of the face are drawn onto the ground glass and the skull is then positioned equally to the face in the portrait thanks to a skull-rest. Those outlines are then matched with the skull, making allowance for the soft tissue covering the bone.

Furue's method (Klonaris and Furue 1980) represented a breakthrough in craniofacial photographic superimposition. In this study, the authors give importance to photographic perspective. They developed a system taking into account the distance between camera and subject, and they try to replicate conditions similar to those of the ante-mortem photograph. In the first step, the skull was positioned on an adjustable stand in front of a backdrop sheet of contrasting colored cardboard at one end of a bench and a 30-cm grid of $9 \mathrm{~mm}$ was positioned in front of skull. A single lens reflex camera was set at the opposite end of the bench and, on the other side, a life-size enlargement of the ante-mortem photograph was positioned behind a grid of $10 \mathrm{~mm}^{2}$. Two mirrors were placed such that the full mirror reflected the image of the photograph upon the half-silvered mirror along the central axis of the camera. Two lamps were positioned between the skull and the camera. The images reflected in both mirrors were transmitted to the cameras, and the images of both the skull and the portrait could be seen through the camera viewfinder. The skull is aligned taking into account the perspective incorporated in the ante-mortem image, and the skull image was recorded on the camera film following removal of the half mirror. Finally, they obtained a victim image negative print and skull positive print, which were superimposed.

Meanwhile, Dorion (1983) used a Graflex camera $4 \times 5$ with a $135 \mathrm{~mm}$ lens atf-4.5, and a pivoting head that permitted placement of the skull in the same orientation as the photographic transparency. Both are positioned in front of the camera at a distance of $95.25 \mathrm{~cm}$. A beam splitter was used for varying the intensity of the mounted quartz lights in front of the skull to get a superimposed image viewing through the camera. He made a correct image magnification considering factors such as the distance of the subject from the camera, which was $95 \mathrm{~cm}$ with the lens. Then, he enlarged the photograph to a 1:1 ratio using reference landmarks on the skull.

McKenna et al. (1984) selected a photograph in which the maxillary anterior teeth are shown. He used a "phantom-head" device that permits skull movements in different planes. The negative of the photograph was enlarged until the dentition coincided with the dentition of the skull image. Skull features and facial contours traced in the negative portrait were superimposed on a radiographic viewing box. A 
similar methodology was used by Brocklebank and Holmgren (1989) who developed new equipment with minor advantages.

Maat (1989) explained that an optimal result is possible if the distance between camera and the skull is the same as the distance from which the original photograph was taken; however, this is difficult to achieve. Some authors have established that portraits are taken at a safe distance, if they are taken at a distance of $1.5 \mathrm{~m}$ or more (Gruner and Reinhard 1959). On the basis of the above, Maat enlarged a skull image taking into account that all visible landmarks of the superimposed image must cover, in the best possible way, their equivalent points on the original portrait. In particular, he used a geometrical method to calculate projections of anthropometric distances, angles of rotation, and inclination to define the posture of the head or skull with respect to the anatomical frontal plane. He proposed to use a set of anthropometrical landmarks, along with relative reference lines, to calculate the three components of head rotation ("bending forward," "turning sideways," and "rolling sideways") to position the skull. The principle of central projection and a minimum photographic distance of $1.5 \mathrm{~m}$ are important preconditions.

Lan (1990) used the distance between ectoconchions to determine the natural head size in the photograph. He had considered differences in the deflection angle with a mechanism that examined eight lines capable of determining the image proportions. In contrast, in some other cases, asymmetrical features of the facial skeleton (Prinsloo 1953; Sivaram and Wadhera 1975) or the presence of a supernumerary anterior tooth (mesiodens) (Asananer 1972) has facilitated identification by superimposition.

Scully and Nambiar (2002) determined the validity of Furue's methodology. They photographed the skull following similar conditions to those indicated by Furue. Despite Scully et al. using digital images, the result was similar to the conventional direct photography print used in Furue's methodology.

\subsubsection{Decision Making}

This phase consists of the systematic evaluation of the correspondence of morphological features between the face and skull. However, most authors have described anatomical landmarks and anthropometric measurements, which, in their opinion, were more significant than others in the determination of a positive identification.

Before the use of photographic superimposition in the identification of victims, several attempts were made to fit tracings or photographs of skulls to painted or photographic portraits of famous or infamous people from history (Glaister and Brash 1937; Krogman and İşcan 1986). Lander compared the skull of an individual of known age, race, and sex with a photograph of the individual, but concluded that "It seems improbable that any one examining the skull would postulate a type of face similar to that seen in the photograph"(Prinsloo 1953).

Some years later, the superimposition of a photograph of the skull and tracings of the face, achieved by Pearson and Morant (1934), were considered to be satisfactory. 
However, they recognized that such a positive result would not be possible when comparing a skull with an artist's portrait.

In the Wolkersdorfer Case (Gordon and Drennan 1948), the identity of the victim was established by overlapping a drawing of the available parts of the face with the outline of the head obtaining a positive anatomical correspondence. In the Plumbago Pit Case (Webster 1955), the correspondence between the skull and portrait was positive, and the following points were establishing as being significant in determining the final result from the superimposition: (1) the length of the skull as measured from the nose to the chin; (2) the length of the skull from the top of the skull to the chin or nose; (3) the margin of the eye-sockets; (4) the width of the temple (bi-temporal width); (5) the width of the face as measured from one cheek bone to the other; (6) the position of the mastoid processes; (7) the position of the midpoint of the upper jaw between the sockets for the central incisor teeth, and its relation to the nose; (8) the position of the teeth in the upper jaw on the left side; and (9) the position of the angle of the jaws.

Reddy (1973) overlapped the negative of a photograph and skull by aligning the following characteristic points: the eyes within the two pairs of orbital plates, the nasion, the prosthion, the nasal spine in the center, which is a little above the tip of the nose, the lower border of the nose, the lower border of the upper jaw, and the zygomas below the eyes. The expert observed from the superimposed image that all these points properly matched, making it possible to establish the identity of the victim. He considered that superimposition may provide significant evidence in Court, affirming that it could solve medico-legal problems, such as the identification of an individual from the skull.

Dorion (1983) obtained a positive identification in two cases, comparing soft tissue outlines to bone and dental characteristics, although he considered that photographic superimposition does not serve as the only basis for a positive identification and it should be corroborated by other identification methods or circumstantial evidence.

McKenna et al. (1984) drew clearly defined features of the skull on matte acetate, from the transparency of the skull. The facial contours were traced from the transparency of the enlarged snapshot. The transparencies and tracings were superimposed, and the correspondence between dental landmarks of the skull and face were verified. The photographic superimpositions and composite tracings were presented in court and were accepted as a positive identification. Finally, the author indicated that photographic superimposition could be established not only as a complementary method of identification, but as a means of a positive identification in its own right.

Maat (1989) determined that only a limited number of cephalometric landmarks of the head lie close to the craniometric landmarks of the skull, such as nasionnasion, subnasale-nasospinale, gnathion-gnathion, gonion-gonion, a point on the lower border of the eyebrow-orbitale superius, and tragion-porion. He suggested that, taking individual variability into consideration, it is very unlikely that someone else other than the victim reflects all those features. 
Scully and Nambiar (2002) consider that photographic superimposition can be used as the only means of confirming the identity of an unknown skull, using the craniometric and somatometric landmarks, racial features, soft-tissue thickness, scars, or injuries as a basis. They affirmed that knowledge of craniofacial anatomy is a crucial factor for establishing the identity of the victim.

Krogman and İşcan (1986) recommended the use of photographic CFS whenever possible, arguing that it can provide important corroborative and possibly conclusive evidence for identification.

\subsection{Video Craniofacial Superimposition}

The common components of almost all video superimposition systems include two video cameras, an electronic mixing device, and a TV monitor. Instead of making photographs, tracings, or drawings in order to properly superimpose the skull and the face, the video cameras provide focused "live images" of the objects (skull and photograph). These systems present a great advantage over the former photographic superimposition procedures by minimizing several problems associated with the photographic systems. For example, the number of manual manipulations and the length of the time required in superimposition are dramatically decreased since an expert can control the matching of two different images on the TV monitor. Nevertheless, the processes of skull orientation and sizing of the ante-mortem photograph and the skull in video superimposition remain troublesome. The face enhancement and skull modeling stage in this modality is very similar to the one in the photographic superimposition technique. For example, Lan and Cai (1985) advocated the use of the same orientation procedure employed in photographic superimposition.

In this section, we will review the existing contributions of video CFS systems. They will be classified according to the stage of the process, which is addressed using a video system. Information about the method used for the remaining stages will be given shortly, along with a brief discussion. Unfortunately, in some of the existing video superimposition methods, these stages are not as clearly distinguished as we might expect. This fact can cause some confusion, as sometimes the authors themselves define their own method as photo, video, or computer-aided CFS when they are actually referring to one or part of one of the three general stages of CFS. In order to be consistent throughout this document, we decided to limit this section to the methods in which a video system is the core apparatus of the superimposition method and there is no use of computers. There are a set of methods (Lan and Cai 1985, 1993; Yoshino et al. 1997) that use video cameras to acquire images of the skull and the face photograph but also make use of computers to perform important tasks within the whole process. Thus, these "hybrid" methods will be reviewed in Sect. 4.4.

As in photographic superimposition, Table 4.2 presents a review of the papers describing video superimposition according to the different stages. 
In the following subsections, the different video CFS approaches and their contribution to each of the CFS stages are reviewed.

\subsubsection{Face Enhancement and Skull Modeling}

As in photographic superimposition, in this stage, the first steps are intended to select and/or obtain clear and measurable images. Therefore, a photograph, which is overexposed or underexposed, blurry, or noisy, will result in a low-quality superimposition (Nickerson et al. 1991). The objectives of image enhancement for video superimposition can be enumerated as follows: obtain measurable images; know the object-subject distance; select the correct ante-mortem photographs; choose the photograph nearest to the moment of disappearance; avoid photographs that show chiaroscuro; know all technical data of the equipment; and filter the image to produce as much useful image information as possible. In order to obtain measurable images, most of the authors used anatomical landmarks and anthropometrical measurements of the skull and the face. The procedure to mark them varies among authors. Some authors, such as Dorion (1983), placed the landmarks on the transparency using movable white cardboard, which blocks out the skull's characteristic for the same region. Others, for example Bastiaan et al. (1986), located anatomical landmarks on the skull by placing a white pointer in or around an area so that each point can be accurately viewed. Similarly, Fenton et al. (2008) placed tissue depth markers on the skull.

The knowledge of all the technical data of the equipment used is shown to be helpful for the superimposition process. All components can affect the final quality of the results achieved. For example, Brow (1983) replaced the video cameras by semiprofessional Ikegami cameras, considerably increasing the quality of the image.

Iten (1987) said that the first step in superimposition is to determine the correct height and location of the camera. This must coincide with the photographs that the skull is going to be compared with and is defined by a number of variable parameters such as the distance between the camera and object, camera height, and orientation of the skull.

Austin (1999) stated that the quality of the photographs is essential. He received mug shots, driver's licenses, and family photos to make an identification. Driver's license photographs are usually full face and benefit from the enlargement capabilities of the equipment. However, mug shots and family photographs often represent varying angles to the camera film plane. The author suggests using at least two photographs with an attempted difference of $90^{\circ}$ between them. He recommends avoiding images with obstructing factors (facial hair, long hair, hats, etc.). The facial photographs must show useful morphological characteristics of the person to be identified. Finally, he examined all photographs with a stereomicroscope to ascertain the amount of grain, clarity of features, and shadow details. 


\subsubsection{Skull-Face Overlay}

The next step consists of the comparison of both images. Skull orientation can be performed in the same manner as in photographic superimposition; however, the correct size of the skull is easier to achieve by adjusting the size of the skull using the zoom mechanism of the video camera (Yoshino 2012). The method of skull orientation has varied with the incorporation of new tools, apparatus, and mechanisms (see Table 4.2): Helmer and Grüner (1977a) were probably the first researchers to introduce the video superimposition technique. They substituted a photographic camera with a video camera in the CFS procedure. The equipment consisted of two video cameras, an electronic mixing unit, and two TV monitors. This allows for recording and displaying the skull and the face portrait at the same time. In addition, it also offers the possibility of mixing both images, thanks to the mixing unit. Consequently, this approach significantly reduced the time needed to enlarge the ante-mortem photograph and the skull to the same size. It also presented an outstanding mechanism to help in the proper orientation of the skull. Both were the most time-consuming tasks in the previous photographic-based approaches.

Koelmeyer (1982) used three video cameras to reproduce the facial images, the skull x-ray, and the partially reassembled skull to perform the superimposition between the images. In addition, he made use of the sweep fade-in/out mechanism to help guide the superimposition of the skull portrait and face photograph on both vertical and horizontal axes.

Dorion (1983) replaced a Graflex camera with a video camera. He placed it at a distance of $92.25 \mathrm{~cm}$ from the zygomatic process ${ }^{3}$ of the skull and a face transparency was put in front of the skull. Similarly, Chee and Cheng (1989) used a transparency of the face photograph positioned in front of the skull and recorded both images on the monitor. The face photograph was enlarged to natural size and photocopied onto the transparency.

Bastiaan et al.'s (1986) system incorporated an adjustable support to mount the skull. This allowed movement in three planes. Two video cameras (Hitachi GP-5 colour) were aligned with the ante-mortem portrait and the skull, respectively. Both cameras must be compatible with "Gen-Lock" (which consists of the ability of two video cameras to synchronize together in order to use the facility of video or vision mixing) to obtain synchronized vision mixing. The skull is oriented in the same angulation as the head of the subject in the ante-mortem portrait. They proposed to enlarge the ante-mortem photograph until the teeth in the superimposed video picture overlap. If the teeth are not visible in the face, an estimation of the enlargement factor must be employed. Finally, both photographs were superimposed taking into account different anatomical landmarks (the external auditory meatus, orbits, anterior nasal spine, chin point, angles of the mandible, and zygomatic processes).

\footnotetext{
${ }^{3}$ The zygomatic process is a protrusion from the rest of the skull, like the bumper of a car. Most of it belongs to the zygomatic bone, but there are other bones contributing to it too, namely, the frontal bone, maxilla, and temporal bone.
} 
These points were highlighted on the skull by placing a white pointer in or around the relevant area so that each point could be accurately viewed. A video mixing unit allowed a fade-in/out of both images in the vertical or horizontal plane.

The equipment employed by Iten (1987) consisted of two video tubes: an electronic mixer unit and three monitors. The skull is recorded with video tube 1 and reproduced on monitor 1 . Then, the photograph is recorded with video tube 2 and reproduced on monitor 2 . Both images are mixed on monitor 3 , to be appraised and recorded. Then, the zoom mechanism of the video camera is used to adjust the skull image to facial image size on the monitor, using soft-tissue thickness as reference points. Finally, the exact orientation of the skull image is accomplished by adjusting the outlines and anatomical landmarks between face and skull images. For this purpose, Iten used the ratio of the distance between the eyes and the distance between the eye and auditory canal as axes.

McKenna et al. (1984) used two video cameras and two monitors to record images of the skull and the ante-mortem photograph, respectively. They presented a method that aligned the skull through a distinctive anatomical point (e.g., the line between the central incisor teeth at their incisal tips) and clamped it into position. A video camera is focused through a transparent lens cap sight on this reference point and is secured in position. Then, it projects the image of the skull onto a television monitoring screen. A second video camera, focused on the ante-mortem photograph, also projects the corresponding image to the monitor screen. Finally, they made the superimposition using a special effects generator, which allowed the mixing of both images.

Brocklebank and Holmgren (1989) developed novel equipment consisting of a skull-holding jig and a "pan-and-tilt" device to position the skull by virtue of specifically calibrated scales and markings provided on the apparatus. A camera was positioned on an adjustable mount running on twin parallel rails, allowing the camera distance to be varied. The equipment allowed the correct replication of the skull position with the face in the photograph. Finally, the face and skull photographs could be evaluated to determine whether it was a positive or negative superimposition.

Sekharan (1993) determined antero-posterior tilt with a mechanical device, but she added two parallel wires which show the distance and the different landmark planes. She suggested using the vertical distance "d" between the ectocanthions and tragion as a measure for calculating the extent of flexion or extension of the head. The extent of the rotation of the face was calculated from the L/R ratio, where $\mathrm{L}$ and $\mathrm{R}$ denote the distances between the left and right ectocanthion from the midline of the face. Using these factors, the skull under examination was positioned on a tripod stand with the help of a remote control positioning device (Kumari and Chandra Sekharan 1992).

Shahrom et al. (1996) presented a method to superimpose a skull and a facial photograph, which was very similar to previous approaches. In order to determine the position of the skull, the facial photograph was rotated in the coronal plane to match the skull angulation. Manipulation of the skull position or angulation using the skull holder was only conducted in two planes (sagittal and horizontal). Then, 
two different video cameras captured the facial photograph and the skull. The video images were mixed into one on the television monitor, and then, the expert determined the relationship between landmarks on the skull and the face.

Iten (1987) developed three different methods of video superimposition for forensic case work: skull/photograph superimposition, radiographic comparison, and photograph/photograph superimposition. These procedures usually involve a still photograph of the skull, which is overlaid with the facial photograph, two video cameras, and a mixing device to superimpose the two images. The video superimposition set-up proved useful for ante-mortem and post-mortem radiograph comparisons. He used the video superimposition equipment to compare scene photographs with known photographs of a suspect. In Austin-Smith and Maples (1994), the superimposition process was presented as follows: A photograph was placed under one of the cameras and the face was focused so that it filled the monitor screen as fully as possible. Tissue thickness markers were positioned on the skull at the appropriate anatomical landmarks. The tissue thicknesses used were determined by ultrasound on living subjects and ranged from thin to obese individuals. The position of the head in the photograph was scrutinized, and the skull was placed on a cork ring to estimate that position. The distance between a horizontal projection from the lateral angle of the eye and another from the external auditory meatus was approximated. The skull was put under the second video camera, the size was adjusted so that the tissue thickness markers fell within the outline of the face, and the proportions of the anatomical features were maintained. Exact positioning was determined by trial and error manipulation of the skull.

Solla and İşcan (2001) modified the previous system. In this case, the facial image was reproduced and digitized in the video mixing unit. A plastic sheet with different landmarks traced was taped to the monitor. The orientation of the skull was adjusted based on these landmarks, taking soft tissue into account, and manipulated manually to get the same position as the face in the portrait. Then, they used a video camera zoom to adjust the size of both images. Both images were then reproduced on a TV monitor for detail comparison. The authors describe the video mixing unit as a device that allows any desired combination of photo-skull comparison, including removing the soft tissue to view the underlying skeletal structures such as the auditory canal, eye sockets, cheekbones, jaw bones, root of nose, teeth, chin, skull contours, and so forth.

Fenton et al. (2008) employed two video cameras, a video cassette recorder, a video mixer, TV monitor, and software similar to that recommended by AustinSmith and Maples (1994). Their video superimposition process began by placing appropriate tissue depth markers on the skulls. Once this was completed, the "dynamic orientation process" was used to arrive at the best fit possible in the alignment of the skull with the ante-mortem photo.

The dynamic orientation process involves positioning of the ante-mortem photograph under one of the two video cameras so that the image fills most of the TV monitor. Next, the skull is placed under the other camera. Using the mixer and monitor, the skull image is sized so that it can be superimposed onto the image of the face. Once the skull and ante-mortem photo are satisfactorily adjusted for size and 
basic orientation, the craniofacial proportions of the skull and the face can be evaluated and compared. This is accomplished by manually adjusting the skull so that the key skeletal landmarks align with corresponding landmarks on the face. The set of landmarks employed for this purpose are: porion, right and left Whitnall's tubercles (to be aligned with right and left ectocanthion points of the face), subnasal points, and gnathion.

In conclusion, the general procedure of video superimposition presents important similarities among the different approaches; however, the techniques or methodologies have varied with the development and incorporation of new tools, apparatus, and mechanisms, which have reduced the problems of the orientation and size of the skull with respect to the facial photograph.

\subsubsection{Decision Making}

Once SFO is fulfilled, the decision-making process is carried out. The main tools involved in the decision-making stage include fade-in/out, video mixing, or special effect generators (see Table 4.2). Nevertheless, the experience of the forensic anthropologist continues to be of paramount importance in the determination of identity.

Koelmeyer (1982) used three video cameras to reproduce the skull, the facial photographs, and a radiograph. Then, the use of a switcher joystick to fade-out, fadein, and sweep allows a progressive superimposition of the radiograph, and the skull image on the facial photograph, on both vertical and horizontal axes. As a result, the system creates a more pleasing image and makes a better comparison of bony landmarks possible.

Bastiaan et al. (1986) considered different anatomical landmarks for the decision stage: the external auditory meatus, orbits, anterior nasal spine, chin point, angles of the mandible, and zygomatic processes.

Helmer and Grüner (1977a)'s system allows the division of the superimposed image into various sections that show either the skull or the face. It also provides control over the transparency of both the skull and face images on the TV monitor. Both have resulted in being very helpful for the overall assessment of the anatomical correspondence between the skull and the face. Many authors employ this video equipment with similar configurations and procedures. In particular, Sekharan has carried out positive identifications in 140 cases since 1985 using this methodology (Sekharan 1988). Half of the skull image and half of the photograph can be displayed simultaneously using a special effects generator. Sekharan assured that observation, comparison time, and judgment error could be reduced by a significant rate.

Iten (1987) indicated that one can begin comparing the facial image with that of the skull, once the enlargement and orientation procedures are complete. The comparison is carried out on a monitor that allows the user to mix and produce picture sections in order to compare all anatomical landmarks and morphological features such as the auditory canal, eyes socket, cheekbones, jawbone, root of the 
nose, teeth, chin, and skull contour. The same procedure described above was performed by Shahrom et al. (1996).

McKenna (1988) used a special effects generator that enables the size of the images of the skull and photographs to be matched by superimposition of the respective dentitions. This allows the points to be easily placed. McKenna adds that the video camera can be replaced by a photographic camera at the same radial distance and the same angular axes. Therefore, overlay transparencies can be prepared from the photographic camera negatives for presentation in court, considering that it allows a static display of the final result of the overlap without the distortion created by the monitor screen.

Brocklebank and Holmgren (1989) marked the outlines of all relevant features of both transparencies on tracing film for an assessment of the degree of anatomical consistency. Suitable hard and soft tissue features included the following: all dental features; outlines of bone margins and corresponding soft tissue features; interpupillary line and midorbital line; and the midline of the face and skull. Then, superimposition of both transparencies took place in order to assess whether there was a positive match or not, and the level of confidence in the resulting identification.

Austin (1999) claimed that the experience of the analyst and the integrity of the equipment are very important. He affirmed that it is necessary to know the relationship of soft tissue with face bones, achieved through the study of known skulls with their own photographs.

Fenton et al. (2008) used the same 12 morphological features, in frontal view, as Austin-Smith and Maples (1994), for establishing a consistent fit between the face and skull. By evaluating facial proportionality and by comparing morphological features of the face and skulls, one skull was excluded as a possible match and one skull was not excluded as a match to the ante-mortem photo.

The most advanced video superimposition systems also make use of computer software that allows the user to quantitatively evaluate the adjustment between a skull and a facial photograph in two and three dimensions.

\subsection{Computer-Aided Craniofacial Superimposition}

The differentiation between methods that use computer technology and those that do not has already been proposed (Aulsebrook et al. 1995). In the literature, photographic and video superimpositions have been considered to belong to the former category. Meanwhile, methods defined as digital or computer-aided CFS have been considered to belong to the latter. Thus, the distinction between computer-aided and non-computer-aided methods has been clearly guided by the use of computer-based technology within the CFS process up to now. Nevertheless, the role of the computer in this process is presently very important and it has not been considered in previous reviews. Moreover, the analysis of previous contributions is especially difficult when some authors claim they propose a "computer-aided" or "computer-assisted" 
Table 4.3 Overview of computer-aided photo superimposition systems

\begin{tabular}{|c|c|}
\hline Stage & Author \\
\hline \multicolumn{2}{|l|}{ Face enhancement and skull modeling } \\
\hline $\begin{array}{l}\text { Acquisition of photographs of the skull at dif- } \\
\text { ferent angles }\end{array}$ & Al-Amad et al. (2006) \\
\hline Acquisition of frontal photographs of the skull & Ghosh and Sinha $(2001,2005)$ \\
\hline \multicolumn{2}{|l|}{ Skull face overlay } \\
\hline $\begin{array}{l}\text { Manual scaling with Adobe Photoshop" }{ }^{\mathrm{TM} \text { "ffree }} \\
\text { transform" tool }\end{array}$ & $\begin{array}{l}\text { Austin-Smith and Maples (1994), Bilge et al. } \\
\text { (2003), Ricci et al. (2006) }\end{array}$ \\
\hline $\begin{array}{l}\text { Face and skull visualization at the same time } \\
\text { with Adobe Photoshop }{ }^{\mathrm{TM}} \text { "Semitransparent" } \\
\text { utility }\end{array}$ & $\begin{array}{l}\text { Damas et al. (2011), Bilge et al. (2003), Ghosh } \\
\text { and Sinha (2005), Scully and Nambiar (2002) }\end{array}$ \\
\hline $\begin{array}{l}\text { Automatic overlay using artificial neural } \\
\text { networks (frontal images only) }\end{array}$ & Ghosh and Sinha $(2001,2005)$ \\
\hline \multicolumn{2}{|l|}{ Decision making } \\
\hline $\begin{array}{l}\text { Morphological validation with Adobe } \\
\text { Photoshop }\end{array}$ & $\begin{array}{l}\text { Scully and Nambiar (2002), Bilge et al. } \\
\text { (2003), Ricci et al. (2006), Takač and Pilija } \\
\text { (2012) }\end{array}$ \\
\hline $\begin{array}{l}\text { Automatic calculation of index of similarity } \\
\text { based on distances }\end{array}$ & Ghosh and Sinha (2001) \\
\hline Automatic objective assessment of symmetry & Ghosh and Sinha $(2001,2005)$ \\
\hline
\end{tabular}

system (Ricci et al. 2006) yet the computer mainly plays the role of a simple visualization tool.

Whenever a computer is employed as part of the CFS system, the method should be considered a computer-aided technique. The following classification better reflects the state of the art regarding the use of computers in one or all stages of the process and the interaction between various technological approaches: (a) computer-aided craniofacial photo superimposition, (b) computer-aided craniofacial video superimposition, and (c) computer-aided craniofacial 3D-2D superimposition.

Additionally, the classification should differentiate between nonautomatic and automatic methods (Damas et al. 2011). Computer-aided nonautomatic methods use some kind of digital infrastructure to support the CFS process, that is, computers are used for storing and/or visualizing the data. However, they are characterized by the fact that their computational capacity to automate human tasks is not considered. On the other hand, computer-aided automatic methods use computer programs to accomplish an identification subtask itself.

Tables 4.3, 4.4, and 4.5 give an overview of the papers describing computer-aided systems, classified into the three categories already detailed. Studies are listed in chronological order. Additional information about the degree of automation and the input data required is provided where available.

There are some remarks that should be pointed out concerning the three stages of the process:

- Regarding the first stage, automatic methods may deal with either the 2D image of the face or the skull. On the one hand, when dealing with the 2D image of the 
Table 4.4 Overview of computer-aided video superimposition systems

\begin{tabular}{|c|c|}
\hline Stage & Author \\
\hline \multicolumn{2}{|l|}{ Face enhancement and skull modeling } \\
\hline $\begin{array}{l}\text { Manual anatomical landmark location on a } \\
\text { plastic slide taped onto the monitor }\end{array}$ & Ubelaker et al. (1992) \\
\hline $\begin{array}{l}\text { Manual landmark location using specific } \\
\text { software }\end{array}$ & $\begin{array}{l}\text { Ricci et al. (2006), Takač and Pilija (2012), } \\
\text { Ghosh and Sinha (2001), Pesce Delfino et al. } \\
(1986,1993) \text {, Yoshino et al. (1995), Lan and } \\
\text { Cai (1988, 1993) }\end{array}$ \\
\hline Manual contouring using specific software & $\begin{array}{l}\text { Pesce Delfino et al. (1986, 1993), Yoshino et al. } \\
(1995)\end{array}$ \\
\hline $\begin{array}{l}\text { Automatic contrast enhancement, equalization, } \\
\text { and filtering using specific software }\end{array}$ & Pesce Delfino et al. $(1986,1993)$ \\
\hline Manual tissue marker location on the real skull & Pesce Delfino et al. (1986) \\
\hline $\begin{array}{l}\text { X-ray acquisition in seven pitch angles and ten } \\
\text { reflection angles (research method for living } \\
\text { individuals) }\end{array}$ & Pesce Delfino et al. (1993) \\
\hline \multicolumn{2}{|l|}{ Skull face overlay } \\
\hline $\begin{array}{l}\text { Manual manipulation of the skull for replica- } \\
\text { tion and orientation using landmarks }\end{array}$ & $\begin{array}{l}\text { Yoshino et al. (1995), Lan and Cai (1988), } \\
\text { Pesce Delfino et al. (1986, 1993), Ubelaker } \\
\text { et al. (1992) }\end{array}$ \\
\hline $\begin{array}{l}\text { Manual skull replication and orientation using } \\
\text { anthropometric measurements }\end{array}$ & Lan and Cai $(1985,1988,1993)$ \\
\hline $\begin{array}{l}\text { Face and skull visualization at the same time } \\
\text { using specific software }\end{array}$ & $\begin{array}{l}\text { Lan and Cai (1993), Yoshino et al. (1995), } \\
\text { Ubelaker et al. (1992) }\end{array}$ \\
\hline $\begin{array}{l}\text { Manual skull replication and orientation using } \\
\text { a pulse motor-driven mechanism, fade-out, and } \\
\text { wipe mode }\end{array}$ & Yoshino et al. (1995), Lan and Cai (1988) \\
\hline \multicolumn{2}{|l|}{ Decision making } \\
\hline Manual assessment using soft tissue markers & Lan and Cai (1993) \\
\hline Fade-in and fade-out & Yoshino et al. (1995), Ubelaker et al. (1992) \\
\hline $\begin{array}{l}\text { Semiautomatic landmark distance } \\
\text { measurement }\end{array}$ & $\begin{array}{l}\text { Yoshino et al. (1995, 1997), Birngruber et al. } \\
(2010)\end{array}$ \\
\hline $\begin{array}{l}\text { Semiautomatic measurement of } \\
\text { anthropometrical indexes using specific } \\
\text { software }\end{array}$ & $\begin{array}{l}\text { Yoshino et al. (1995), Lan and Cai (1988), } \\
\text { Ubelaker et al. (1992) }\end{array}$ \\
\hline $\begin{array}{l}\text { Automatic assessment of skull and face out- } \\
\text { lines using specific software }\end{array}$ & $\begin{array}{l}\text { Yoshino et al. }(1995,1997), \text { Pesce Delfino et al. } \\
(1986,1993)\end{array}$ \\
\hline
\end{tabular}

face, automatic systems accomplish the restoration of the photograph by means of digital image-processing techniques. On the other hand, the aim of automatic methods concerning the skull is the achievement of an accurate $3 \mathrm{D}$ model.

- Concerning the second stage, Damas et al. (2011) pointed out a clear division between computer-aided nonautomatic and automatic SFO methods. The former use computers to support the overlay procedure and/or to visualize the skull, the face, and the obtained superimposition. Nevertheless, the size and orientation of the skull are changed manually to correctly match that of the head in the 
Table 4.5 Overview of computer-aided 3D-2D approaches

\begin{tabular}{l|l}
\hline Stage & Author \\
\hline \multicolumn{2}{l}{ Face enhancement and skull modeling } \\
\hline Manual alignment of skull range images & $\begin{array}{l}\text { Shahrom et al. (1996), Lan and Cai (1993), } \\
\text { Yoshino et al. (1995) }\end{array}$ \\
\hline Automatic alignment of skull range images & $\begin{array}{l}\text { Santamaría et al. (2007a), Pesce Delfino et al. } \\
(1986,1993)\end{array}$ \\
\hline $\begin{array}{l}\text { Automatic and faster alignment of skull range } \\
\text { images }\end{array}$ & Shahrom et al. (1996), Fantini et al. (2008) \\
\hline $\begin{array}{l}\text { Holography for 3D recording of forensic } \\
\text { objects }\end{array}$ & Biwasaka et al. (2005) \\
\hline $\begin{array}{l}\text { Computed tomography vs. laser range scanner } \\
\text { Fuzzy location of cephalometric landmarks }\end{array}$ & $\begin{array}{l}\text { Senazzi et al. (2009) } \\
\text { 2011), Ballerini et al. (2009) }\end{array}$ \\
\hline \begin{tabular}{l} 
Skull face overlay \\
\hline $\begin{array}{l}\text { Automatic overlay by matching pairs of land- } \\
\text { marks and genetic algorithms }\end{array}$
\end{tabular} & $\begin{array}{l}\text { Nickerson et al. (1991), Galantucci et al. } \\
\text { (2006), Ibáñez et al. (2009a) }\end{array}$ \\
\hline
\end{tabular}

photograph. This is achieved by either physically moving the skull, while computers are simply used to visualize it on the monitor, or (with the help of some commercial software) by moving its digital image on the screen until a good match is found. The automatic SFO methods find the optimal superimposition between the 3D model of the skull and the 2D image of the face using computer programs.

- Finally, regarding the decision-making stage, automatic systems assist the forensic expert by applying decision support systems (Keen and Morton 1978). Moreover, these computer programs use objective and numerical data for evaluating the obtained matching between the skull and the face. Based on that evaluation, the system suggests an identification decision to the forensic expert. Thus, the decision support system is intended to help decision makers compile useful information from the analysis of the SFO outcomes. Of course, the final decision will be always made by the anthropologist according to both the support of the automatic system and his expertise. On the other hand, if the identification decision only relies on the human expert who visually evaluates the superimposition obtained in the previous stage, then the method will be considered as a nonautomatic system, although it might use digital data as a supporting means.

\subsubsection{Discussion of Existing Works}

In this section, we will review the existing contributions of computer-aided CFS systems. They have been classified according to the stage of the CFS process which is addressed using a computer-aided method. Information about the methods used for the remaining stages will be given together with a brief discussion. 
Unfortunately, in some of the existing CFS methods, the stages are not as clearly distinguished as we might expect. This causes some confusion as sometimes authors themselves define their own method as computer-aided CFS when they refer only to the decision-making stage and others refer to the identification method when they tackle the SFO stage.

\subsubsection{Face Enhancement and Skull Modeling}

Let us highlight the main differences between the image of the face and the model of the skull. The face image is typically a photograph that has been acquired under fixed conditions that are usually unknown at the time of the forensic analysis. With a digital image, the only possibility is to attempt to enhance its quality. If it is not in digital format, it can be scanned and transformed into a 2D digital image. Then, it can be enhanced using digital image filters and/or processing algorithms. However, the skull is an available physical object and a model of it needs to be obtained to allow for an automatic procedure.

We will detail both face enhancement and skull modeling procedures. Regarding the image of the face, good quality is needed (Nickerson et al. 1991); therefore, enhancement techniques should be applied (Gonzalez and Woods 2008). Such techniques depend on the available format (digital camera image or scanned photographic paper) and include frequency domain filters to fix artifacts due to aliasing and sampling problems present in scanned documents, as well as removal of nonuniform illumination effects and sharpening methods to deal with blurring and problems related to movement. Notice that the choice of a proper filter and its most suitable parameters must be performed by the expert, since they depend strongly on the acquisition conditions. As explained above, approaches that use human-operated commercial software for the 2D face image enhancement will be considered nonautomatic methods. Automatic methods perform such 2D image enhancement using computer programs with almost no human intervention.

Regarding the model of the skull, recent techniques for CFS need an accurate 3D model. In the biomedical field computed tomography, scanning images are used as the starting data for reconstructing the skull (Singare et al. 2009; Fantini et al. 2008). However, the possibility of recording 3D forensic objects is limited, considering the available resources of a typical forensic anthropology lab. Indeed, nowadays, many forensic labs are exploiting the capabilities of laser range scanners. That is due to the fact that these devices present a greater availability and a lower cost. Thus, we will consider the possibility of extending the study to other devices that have also been used for obtaining a 3D model of the skull in other application domains (Nakasima et al. 2005; Enciso et al. 2003). Laser range scanners are based on the optical principle of triangulation and acquire a dense set of three-dimensional point data in a very rapid, noncontact way (Bernardini and Rushmeier 2002). Some laser range scanners are equipped with an additional positioning device, such as a rotary table, and appropriate software that permits the $3 \mathrm{D}$ reconstruction. Nevertheless, there are 
situations where the software does not provide suitable 3D models. Moreover, there are scenarios where it is not even possible to use a rotary table.

Before continuing with the 3D modeling process, every 3D view of the skull acquired by the laser range scanner must be preprocessed. This task involves the cleaning, smoothing, and filling of the view. Cleaning aims to remove those artifacts that were acquired by the scanner as part of the scene but which do not correspond to the skull. Meanwhile, smoothing is mainly concerned with the removal of any artificial vertices that could have been wrongly included by the scanner on the borders of the surface because of perspective distortion. Fortunately, this task is not needed as often. Finally, filling is used to avoid small holes appearing in the parts of the skull that are not properly scanned, because they are too dark for the scanner capabilities or because they are located in shadow regions.

Some anthropologists are skilled enough to deal with the set of $3 \mathrm{D}$ views and supervise the creation of the 3D model using commercial software like RapidForm TM. Sometimes, this software does not provide the expected outcomes and the anthropologists have to stitch up every couple of adjacent views manually. Hence, $3 \mathrm{D}$ image reconstruction software is a real requirement in the construction of the $3 \mathrm{D}$ model, as it allows the views to be aligned in a common coordinate frame. This process is usually referred to as range image registration (Brown 1982; Ikeuchi and Sato 2001; Zitova and Flusser 2003). It consists of finding the best 3D rigid transformation (composed of a rotation and a translation) to align the acquired views of the object. An example of three different views of a skull and the reconstructed 3D model is shown in Fig. 4.3.

In this section, we will mainly focus on contributions that include an automatic3D modeling procedure, because the other methods do not consider this stage and directly acquire a $2 \mathrm{D}$ projection of the skull (i.e., a skull photo). As said, all the approaches that use computers but do not consider the 3D skull model will be considered as nonautomatic methods (Yoshino et al. 1995; Ghosh and Sinha 2001; Pesce Delfino et al. 1986; Ricci et al. 2006).

To our knowledge, Nickerson et al. (1991) were the first researchers to propose the use of a 3D model to tackle the CFS problem. In their work, a range scanner and a digital camera were used for 3D digitization of the skull surface mesh and the $2 \mathrm{D}$ ante-mortem facial photograph, respectively.

Well-known image-processing algorithms were used for image enhancement (median filtering, histogram equalization, Wiener filtering) (Gonzalez and Woods 2008). Rendering was completed through the use of computer graphics techniques. A feature-based algorithm to reduce the computational and memory complexities inherent in solid modeling was also described.

Shahrom et al. (1996) followed a similar approach based on the use of a 3D laser range scanner. The authors used a skull holder, which could be slowly rotated through $360^{\circ}$ in a horizontal plane under computer control. The 3D model was later used in facial approximation.

A completely different approach is presented in Biwasaka et al. (2005), in which the authors examined the applicability of holography in the 3D recording of forensic 


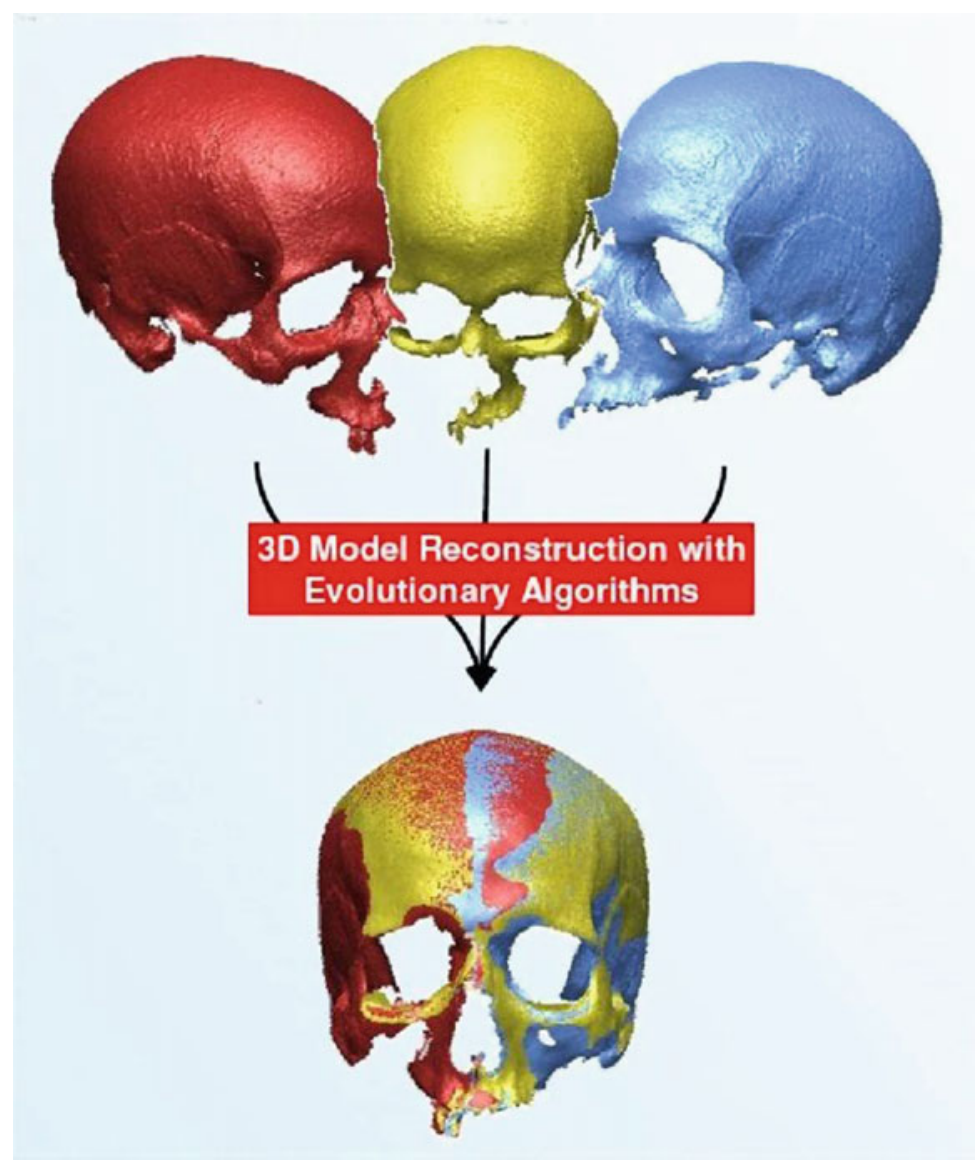

Fig. 4.3 Three different views of a skull and the reconstructed model

objects. Holography is an optical technique capable of recording the 3D data of an object. Two types of images, real and virtual, can be recorded in a holographically exposed film or hologram. Two superimposition systems using holographic images were examined in order to evaluate the potential use of this recording method. The authors claim that the performance of holography is comparable to that of the computer graphics system, which consists of an image scanner, software, and a display unit. Moreover, they argue that it can even be superior to the computer technique with respect to the $3 \mathrm{D}$ reconstruction of images. The suitability of this technique requires further study. In particular, the use of an automatic superimposition method and a comparison with a reconstructed 3D range image could objectively prove the utility of holography in this field.

Galantucci et al. (2006) compared two different acquisition techniques of images of a skull. In particular, computed tomography and laser range scanners performance were compared to ascertain which enabled more accurate reproductions of the 
original specimen. Comparison between the original and each model yielded satisfactory results for both techniques. However, computed tomography scanning demonstrated some advantages over the laser technique, as it provided a cleaner point cloud, enabling shorter preprocessing times, as well as data on the internal parts, which resulted in the reproduction of a more faithful model.

Santamaría et al. (2007a, 2007b, 2009a) proposed a method, based on evolutionary algorithms (Bäck et al. 1997), for the automatic alignment of skull range images. Different views of the skull to be modeled were acquired by using a laser range scanner. A two-step pair-wise range image registration technique was successfully applied to such images. The method includes a prealignment stage that uses a scattersearch based algorithm (Laguna and Martí 2003) and a refinement stage based on the classical iterative closest point algorithm (Besl and McKay 1992). The method is very robust since it reconstructs the $3 \mathrm{D}$ model of the skull even if there is no turntable and the views are scanned incorrectly.

Fantini et al. (2008) used a laser range scanner to create a 3D model of a damaged medieval skull. The large missing part of the skull allowed scanning of both the outer and inner surfaces of the object. Thirty-three partial views were needed to complete the acquisition of the whole surface by rotating the skull. Through postprocessing of the data collected from the 3D scans, a triangular mesh was finally obtained. The operations were performed by RapidForm 2006, $\mathrm{RE}^{\mathrm{TM}}$ commercial software.

A similar approach was followed in Benazzi et al. (2009) in order to tackle the 3D skull reconstruction of Dante Alighieri (1265-1321) as part of a project to achieve a facial approximation of the famous poet. Based on the data provided by a laser range scanner, the model of Dante's skull was constructed using the utilities provided by the Rapidform XOS2 ${ }^{\mathrm{TM}}$ commercial software. In particular, authors refer to operations such as registration and merging of the point clouds, as well as simplification and editing of the digital model.

Ballerini et al. (2009) presented a feature extraction algorithm, based on evolutionary computation (Bäck et al. 1997; Laguna and Martí 2003),to identify a subset of points that could improve the registration of multiple views and reconstruct an accurate 3D model of skull objects. They extracted a set of relevant features from point clouds acquired by a 3D range scanner. They overcame the trade-off between having a fully automatic method and using allow number of points located on meaningful features. The method detected regions close to boundaries and localized small and sharp features. The technique was robust when dealing with nonuniform sampled surfaces.

Ballerini et al. (2009) proposed the automatic reduction of data provided by the laser range scanner used in the skull 3D model reconstruction task. The dense point cloud corresponding to every skull view is synthesized by considering heuristic features that are based on the curvature values of the skull surface. Those features guide the automatic 3D skull model reconstruction by means of an evolutionary algorithm. 


\subsubsection{Skull-Face Overlay}

The success of the superimposition technique requires the positioning of the skull in the same pose as the face. The orientation process is a very challenging and timeconsuming part of the CFS technique (Fenton et al. 2008). Most of the existing CFS methods are guided by a number of landmarks on the skull and the face. Once these landmarks are available, the SFO procedure is based on searching for the skull orientation leading to the best matching of the set of landmarks. Scientific methods for positioning the skull had already been proposed before computers became largely available. As reviewed in Sect. 4.2, in some of the very early approaches (Glaister and Brash 1937), the enlargement factor is calculated based on linear measurements of items within the ante-mortem photograph, such as fabric patterns, buttons, ties, and other objects of known geometry (doors, chairs, etc.) (Sekharan 1993). Other scale correlation methodology has included measurement of the interpupillary distance and the size of the dentition (Austin-Smith and Maples 1994) used a geometrical method to calculate projections of anthropometric distances, angles of rotation, and inclination to define the posture of the head or skull with respect to the anatomical frontal plane. None of these methods are computer-aided, but they are somehow closer to such strategies than to the trial and error procedures. In these approaches, the skull is manually placed on a tripod; however, its pose is estimated using a mathematical procedure instead of a trial and error routine. The researchers calculated the head size and orientation in the photograph to position the skull in the same posture.

Within the group of computer-aided SFO contributions, we will differentiate between nonautomatic and automatic works as follows.

\subsubsection{Nonautomatic Skull-Face Overlay Methods}

Below, we describe SFO methods known as computer-aided methods in the literature. Nevertheless, following the Damas et al. (2011) proposal, we prefer to refer to them as computer-aided nonautomatic SFO methods. They are typical examples of the use of a digital infrastructure but without taking advantage of its potential utility as an automatic support tool for the forensic anthropologist. Notice that they depend on good visualization and overlay mechanisms to aid human operators. Hence, processes following this approach are prone to be time-consuming, hard to reproduce, and subjective.

Lan and Cai (1985) developed a CFS apparatus called TLGA-1, based on the principles of dual projection. During the following years, these authors further developed this system resulting in new subsequent versions, TLGA-2 and finally TLGA-213 (Lan and Cai 1988; Tao 1986; Lan 1990). The TLGA-213 system was composed of a TV camera, a computer, an A/D and D/A converter, a mouse, and the 213 system software library. The system calculated the pitch angle of the photograph of the face by measuring the ratio between distances in the vertical line segments 
glabella to nasion and gnathion to nasion. The natural head size was calculated from the distance between the ectocanthions and the deflection angle in the photograph. The latter parameters were iteratively computed and considered as a guide for the manually performed SFO.

Ubelaker et al. (1992) solved a huge number of cases submitted to the Smithsonian Institute by the FBI. Their software allows any desired combination of skeletal-photograph comparisons, including the chance to remove the soft tissue to view the underlying skeletal structure. It works on digitized images of both the face and skull and offers the possibility to assess the consistency between them. The identification procedure usually requires less than $1 \mathrm{~h}$. It is not specified if this time includes the acquisition and SFO steps or only the decision-making stage. However, for the acquisition of the digital images, the authors visualize the facial photograph and trace anatomical landmarks on a plastic slide taped onto the monitor. Then, they visualize the skull and manually manipulate it to match the marked landmarks. The quality of the photograph and the proper orientation of the skull are claimed to be highly influential to the success of the technique.

The superimposition method of Lan and Cai (1993) is based on the radiographic recognition and labeling of landmarks on the face and skull. First, they placed a drop of lead on 28 landmarks on the face of the person to be examined. Then, they had the subject sit facing the radiographic film box and took X-rays in seven pitch angles and ten reflection angles, using the two ectocanthions on the skull as objective points with a certain subject-to-film box and X-ray unit-to-film plate distances. After the radiographs had been developed, measurements were taken and the distances between landmarks on the skull and face were calculated, as well as indices, and corrections for radiographic distortion of the measurements were made to make them conform to their actual values. From the above test, they obtained projectional plane data and index relationships between landmarks in related parts of the skull image and soft tissue of the face. They also calculated the displacement formulae and projectional data of different superimposed marking points at different angles.

Yoshino et al.'s skull identification system (Yoshino et al. 1997) consists of two main units, namely, a video SFO system and a computer-aided decision-making system. In the former, a pulse motor-driven mechanism and a video image-mixing device (with fade-out or wipe mode) are used to estimate the orientation and size of the skull to reach the pose in the facial photograph. Then, the skull and facial images are digitized, stored in the computer, and superimposed on the monitor.

Ricci et al. (2006) presented an algorithm to compare a facial image with a skull radiograph. They worked with pairs of $2 \mathrm{D}$ images and the superimposition was carried out by the human operator who marked anatomical points and adjusted them to match. The algorithm only calculates distances and thresholds in an automatic way, while SFO is completed manually.

The use of commercial software such as Adobe Photoshop ${ }^{\mathrm{TM}}$ has been reported by Bilge et al. (2003) and Al-Amad et al. (2006). They used the "free transform" tool to adjust the scale of the photograph of the face, superimposed over the skull photograph. The "semitransparent" utility allows the operator to see both images while moving, rotating, and resizing the overlaid image (see Fig. 4.4). 


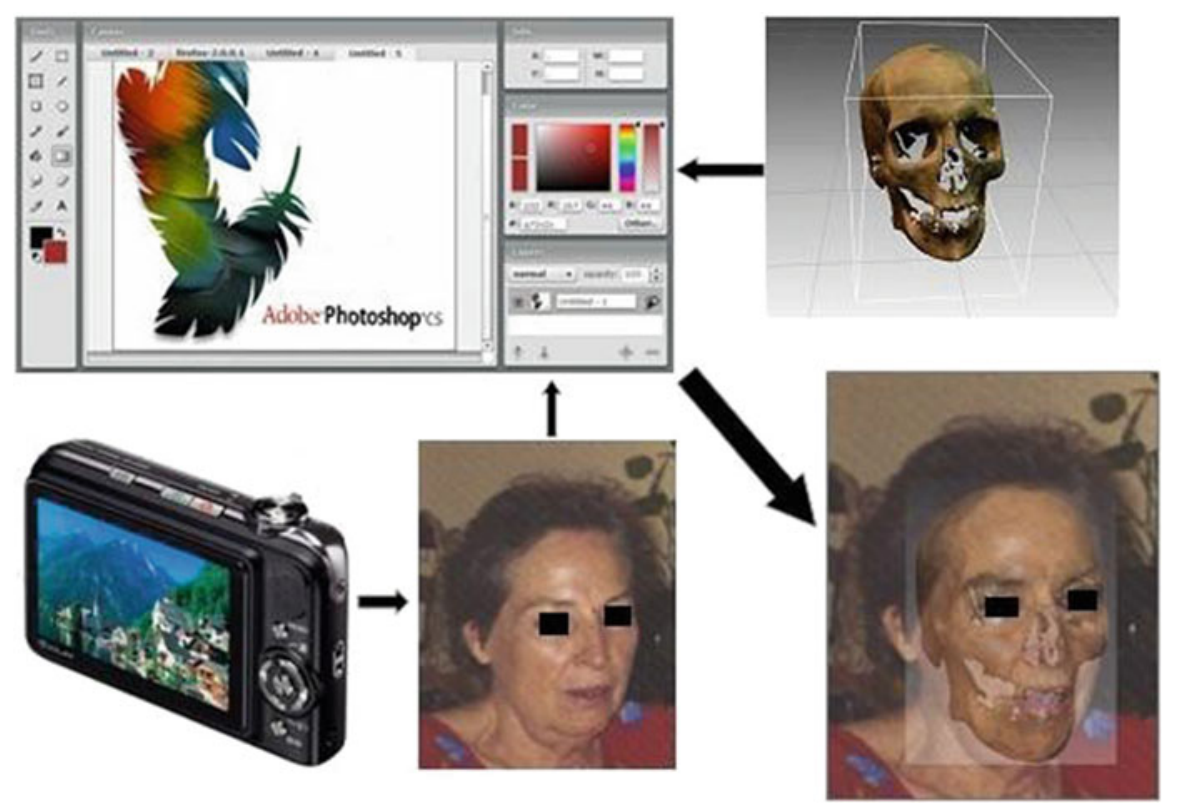

Fig. 4.4 Nonautomatic skull-face overlay based on Photoshop ${ }^{\mathrm{TM}}$

A similar approach was also used by both Scully and Nambiar (2002) and Ricci et al. (2006) to validate a classical method and to superimpose skull radiographs, respectively. The computer program Adobe Photoshop ${ }^{\circledR} 7.0$ was also used in Takač and Pilija's (2012) proposal. They reported a case of negative superimposition. Photographs of randomly selected young living woman were superimposed onto a previously discovered female skull. Digitized photographs of the skull and face were superimposed onto each other and displayed on a monitor in order to assess their possible similarities or differences. Special attention was paid to matching the same anthropometrical points of the skull and face, as well as following their contours. The process of fitting the skull and the photograph was usually started by setting the eyes in the correct position relative to the orbits. In this case, the gonions were positioned beyond the face contour and gnathion was highly placed. In positioning the chin, the mouth and nose could not be placed in their correct anatomical position. The authors detailed all the difficulties associated with the superimposition and recorded the negative superimposition results. The negative superimposition had a greater probative value (exclusion of identification) than a positive superimposition (possible identification).

Birngruber et al. (2010) presented a superimposition technique that uses a free software tool called Afloat ${ }^{\circledR}$. The skull is positioned at a distance of $2 \mathrm{~m}$ in front of a camera and the image is displayed in live view mode on the computer screen. The window with the digitized portrait image is then made semitransparent and floated 
over the live view window showing the skull with the Afloat ${ }^{\circledR}(\mathrm{v} .2 .1)$ software. In the windows, the skull with the tissue markers can then be aligned along the anatomical axes to match the orientation of the portrait in the overlying window. The skull is then photographed to obtain an aligned skull image for the superimposition technique.

\subsubsection{Automatic Skull-Face Overlay Methods}

We have found only a small number of really interesting works that perform SFO in a fully automatic way. A few of them are based on the use of machine learning algorithms (Mitchell 1997) from artificial intelligence, as artificial neural networks (Rumelhart and McClelland 1986). However, the majority use multimodal optimization methods, that is, evolutionary algorithms (Bäck et al. 1997) and fuzzy logic (Zadeh 1965). The automation provided by these approaches represents an added value, since they are typically faster than nonautomatic methods. Moreover, they rely on quantitative measures and they can be easily reproduced. However, this type of work often involves technical concepts that are usually unknown by most forensic anthropologists. Thus, a multidisciplinary research team is required. A brief description of the methods in this group is provided below.

The method proposed by Ghosh and Sinha (2001) is an adaptation of their previous work for face recognition problems (Sinha 1998), and it was recently applied to an unusual identification case (Ghosh and Sinha 2005). Their proposed Extended Symmetry Perceiving Adaptive Neuronet (ESPAN) consists of two neural networks, which are applied to two different parts of the overlaying process. It allows the selection of fuzzy facial features to account for ambiguities due to soft tissue thickness. The system can also implement an objective assessment of the symmetry between two nearly frontal $2 \mathrm{D}$ images: the cranial image and the facial image, which are input as the source and the target images, respectively. The output is the mapped cranial image suitable for superimposition. The two neural networks need to be trained separately, because each can correctly map only a part of the cranial image. Two limitations are pointed out by the authors: (1) a part of the cranial image will not be properly mapped, and (2) a front view image is needed. Moreover, this method is not fully applicable for two reasons. Firstly, an important drawback is its long computation time and secondly, the need to apply two different networks separately is also a relevant flaw. Each network must deal with the upper skull contour and the front view cranial features, respectively. The superimposition found by the first network can be disrupted by the one achieved by the second network.

On the other hand, Nickerson et al. (1991) proposed a novel methodology to find the optimal fit between a 3D skull model and a 2D digital facial photograph. The most important novelty of this technique was the automatic calculation of the overlay of the skull surface mesh on the digital facial photograph. This mapping was achieved by the matching of four landmarks previously identified in both the 

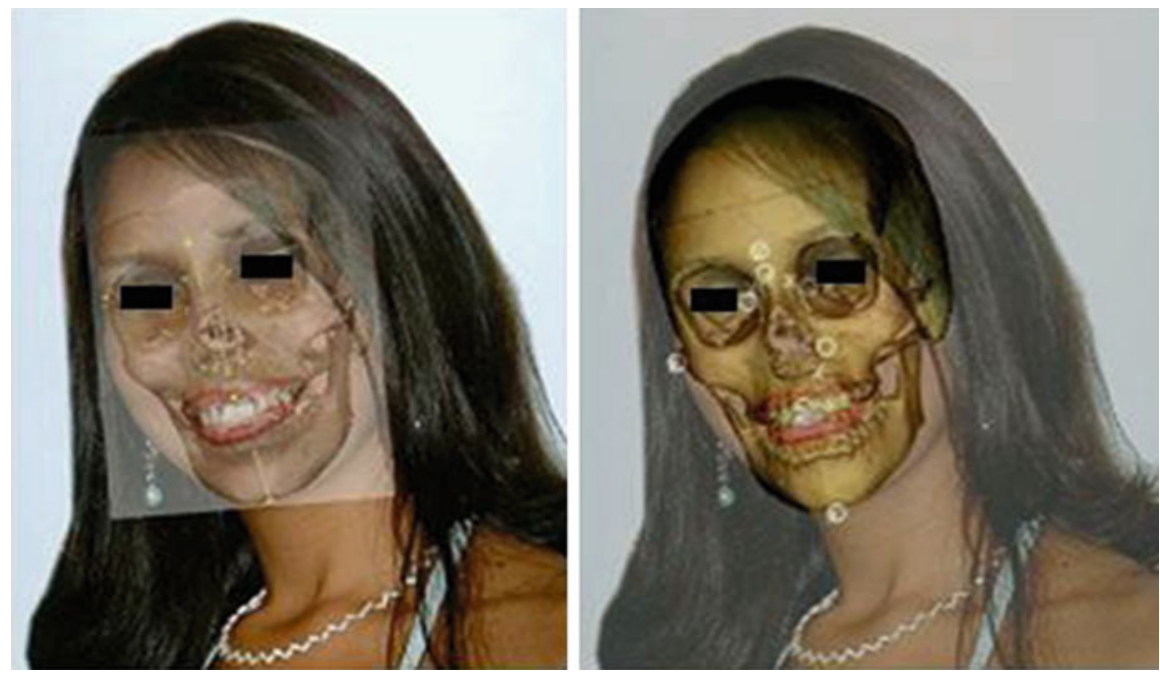

Fig. 4.5 From left to right, manual and computer-aided CFS

face and the skull. The landmarks used in their work were: glabellaor nasion, the two ectocanthion points, and an upper mandibular dentition point, if present, or the subnasal point. The mappings were developed from sets of similarity transformations and a perspective projection. The parameters of the transformations and the projection that overlay the $3 \mathrm{D}$ skull on the $2 \mathrm{D}$ photograph are optimized with three different methods: heuristic, classic nonlinear optimization, and a binary-coded genetic algorithm, with the latter achieving the best results.

Ballerini et al. (2007) proposed an improvement on Nickerson et al.'s approach. The forensic experts extracted different landmarks on the 3D skull model obtained in the first stage and on the face photograph. Then, a genetic algorithm was used to find the optimal transformation to match them. The main differences between this approach and the previous one are the use of a real coding scheme and a better design of the genetic algorithm components. The method for the superimposition of the $3 \mathrm{D}$ skull model on the 2D face photograph is fully automatic.

Ibáñez et al. (2009a) extended the initial results from Ballerini et al. (2007) to accomplish a broader study in order to demonstrate that real-coded evolutionary algorithms are suitable approaches for CFS. In particular, the authors highlighted the good performance and high robustness of the state-of-the-art covariance matrix adaptation evolution strategy (CMA-ES) (Hansen and Ostermeier 2001). Moreover, the CMA-ES computation time was less than $15 \mathrm{~s}$ in the six real-world identification cases considered. It is an impressive improvement with respect to the manual superimposition performed by a forensic expert, which took several hours. An example of an automatic superimposition achieved by this method is shown in Fig. 4.5. A new SFO method based on the scatter search evolutionary algorithm 
was proposed a few years later by Ibáñez et al. (2012a). It was a new 3D-2D image registration optimizer for the SFO task that facilitates the integration of prior knowledge. They incorporated a method to properly initialize the algorithm and to restrict the parameter ranges using problem-specific information (domain knowledge). The "intelligent" initialization is based on the orientation of the skull to a frontal pose and the corresponding limitation of the rotation angles, which results in a significant reduction of the solution space, thus easing the problem solving. This new design exploits problem-specific information in order to achieve faster and more robust solutions. The performance of this method outperformed their previous approach (Ibáñez et al. 2009a).

Ibáñez et al. (2011) extended their previous approach (Ibáñez et al. 2009a), considering the uncertainty involved in the location of the cephalometric landmarks. In particular, they made use of fuzzy logic to model the difficult task of locating the landmarks (Richtsmeier et al. 1995) in an invariable place, with the accuracy needed by CFS. By the location of a larger number of cephalometric landmarks (precise and imprecise), the automatic SFO method is able to overcome coplanarity problems (Santamaría et al. 2009b) and it achieves a more robust performance. Fuzzy landmarks are regions on the face image that are provided by the forensic anthropologists when it is not possible to determine an accurate location for the cephalometric landmarks. The main drawback is the increasing computational time needed to perform an automatic SFO. In order to reduce the runtime while improving the accuracy and robustness, the same group of authors presented a novel SFO approach (Ibáñez et al. 2012b). It was based on a cooperative coevolutionary algorithm (Paredis 1995), which is able to look for both the best projection parameters and the best landmark locations (inside a given imprecise region) at the same time. Promising results were achieved, dramatically reducing the runtime required by their previous work (Ibáñez et al. 2011).

\subsubsection{Decision Making}

Once SFO is achieved, the decision-making stage can be tackled. The straightforward approach would involve measuring the distances between every pair of landmarks on the face and on the skull. Nevertheless, this is not advisable, because errors are likely to be accumulated during the process of calibrating the size of the images. Instead, studies based on proportions between landmarks seem to be preferred. Geometric figures like triangles or squares are good choices. It is also important to consider as many landmarks as possible and different proportions among them (George 1993). Although the methods described in the following are usually called computer-aided CFS in the literature, we prefer to refer to them as decision-making methods, since we think that the authors fail to specify the correct CFS stage in which their works are included. Indeed, the proposed automatic techniques focus mainly on the decision-making strategy as they are actually 
decision support systems assisting the anthropologist in making the final identification decision. ${ }^{4}$

These algorithms are applied on the digitized images stored in the computer, after the determination of the orientation and size of the skull by "routine" SFO techniques.

Tao (1986) developed the first procedure in which a computer was used for the decision-making stage. That decision support system aimed to replace the previously used methods based on range estimation and subjective judgment. The system provided an identification conclusion by using distances between landmarks from the superimposed images. Later, Lan and Cai proposed the use of 52 different superimposition identification indexes in the TLGA-213 system, with the same aim (Lan and Cai 1988, 1993; Lan 1990). Those indices were based on anthropometrical measures of Chinese adults, male and females, and were used together with proportions and distances between superimposed landmark lines to automatically compute the final identification decision.

Pesce Delfino et al. $(1986,1993)$ applied $k$-th-order polynomial functions and Fourier harmonic analysis to assess the fit between the outline of the skull and the face. Ten cases including positive and negative identifications were investigated. The polynomial function was used to smooth the curve representing the investigated profile. The square root of the mean square error was taken to calculate the distance between polynomial function curves obtained for the skull and the face profiles. The Fourier analysis considered each profile as an irregular periodic function whose sinusoidal contributors are found. Low-order harmonics (the first three or four) represented the basic profile shape and the high-order harmonics corresponded to the details. The sum of the amplitude differences of the sinusoidal contributors between profiles of the skull and the face represented the second independent parameter for numerical comparison. A Janus procedure (so-called by the authors because of the double-headed Latin god Janus, the bi-front) was used to evaluate the symmetry differences between the two profiles. This procedure takes into account the relationship between the total arc and the chord length and the area they delimit in the two-faced profiles. All these parameters are calculated by a computer software package called Shape Analytic Morphometry. However, this method would be only applicable when lateral or oblique photographs are available. Furthermore, their contribution requires manual repositioning of the skull for the correct superimposition.

Bajnóczky and Királyfalvi (1995) used the difference between the coordinate values of pairs of anatomical and/or anthropometrical points in both skull and face for judging the match between the skull and facial image obtained by the superimposition technique. Eight to twelve pairs of points were recorded and expressed as

\footnotetext{
${ }^{4}$ Although the reviewed systems are labeled as automatic, in the sense that they are able to provide an identification decision without the intervention of the forensic expert, the supervision and final validation of the latter is always required as in any computer-aided medical diagnosis system BERNER, E. S. 2007. Clinical decision support systems: theory and practice, Springer.
} 
pixel units. Then, the final matrix, containing coordinates of measured points and calculated values, was established by computer-aided processing. Lacking the appropriate information, their model assumed that all data in that matrix was independent and followed a normal distribution with the same variance. A part of that variance was $\sigma^{2}$, which was the square of the measurement error and was itself assumed to be the same for all the data. The model of the authors was based on assumption that

The components of the error term are independent and distributed according to

$$
N\left(0,2 \sigma^{2}\right)
$$

The authors used a presupposed value of $\sigma$ as part of the model assumption. Under the assumption that the null hypothesis (Eq. 4.1) is valid, it was statistically tested using two values for $\sigma$. The authors claimed that, when a given case is evaluated, it is crucial to know what value can be considered as measurement error. One skull and two photographs were used to test the method. Both frontal and lateral face photographs were considered. They noted that their method is suitable for filtering out false-positive identifications. Although the results obtained from this method are objective and easily interpreted for lay people, the anatomical and anthropometrical consistency between the skull and the face should be assessed by forensic examiners who are well versed in the anatomy of the skull and face. The authors concluded that their method should be used only in combination with classic video superimposition and could be regarded as an independent check.

In Yoshino et al.'s skull identification system (Yoshino et al. 1997), the distance between the landmarks and the thickness of the soft tissue of the anthropometrical points are semiautomatically measured on the monitor for the assessment of the anatomical consistency between the digitized skull and face. The consistency is based on 13 criteria that they previously defined using 52 skulls (Yoshino et al. 1995). The software includes polynomial functions and Fourier harmonic analysis for evaluating the match of outlines such as the forehead and mandibular line in both digitized images. To extract the outline, gradient and threshold operations are used. Five case studies were carried out. However, they noted that this analysis could not always be applied because of the difficulties in extracting the facial contour from small and poor facial photographs offered by the victim's family.

Skull-face overlay was guided by different crosses that were manually marked by the human operator in both the face and the skull radiograph photographs in Ricci et al. (2006). Once that stage has been completed, the algorithm calculates the distance moved for each cross and the respective mean in pixels. The algorithm considers a 7-pixel distance a negligible move. The mean value of the total distance moved represents the index of similarity between the given face and skull: the smaller the index value, the greater the similarity. The algorithm suggests an 
identification decision based on that index of similarity. The authors claim 100\% correct identifications over 196 cross-comparisons and report that the minimal number of landmarks required is 4 .

In Birngruber et al. (2010), the portrait image and the image of the aligned skull are compared at the same scale and morphological matches are searched for, such as the general length and width of the face or the deviation of the bridge of the nose. The facial proportionality of the portrait and the aligned skull should be in accordance with horizontal lines drawn through the middle of the eyes, the spina nasalis, and the mouth.

Open Access This chapter is licensed under the terms of the Creative Commons AttributionNonCommercial 2.5 International License (http://creativecommons.org/licenses/by-nc/2.5/), which permits any noncommercial use, sharing, adaptation, distribution and reproduction in any medium or format, as long as you give appropriate credit to the original author(s) and the source, provide a link to the Creative Commons license and indicate if changes were made.

The images or other third party material in this chapter are included in the chapter's Creative Commons license, unless indicated otherwise in a credit line to the material. If material is not included in the chapter's Creative Commons license and your intended use is not permitted by statutory regulation or exceeds the permitted use, you will need to obtain permission directly from the copyright holder.

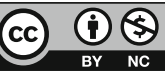




\section{Chapter 5 \\ Craniofacial Superimposition: State of the Art}

\subsection{Introduction}

A complete analysis of the scientific literature concerning cases resolved using CFS was conducted to ascertain the prevalence of CFS use among forensic scientists. However, since many experts working with CFS may not have published their activity in the field, a survey was launched among anthropologists by the "Methodologies and Protocols of Forensic Identification by Craniofacial Superimposition" (MEPROCS) project, a project which aimed to propose a common EU framework to allow the extensive application of the CFS technique in practical forensic identification scenarios, commonly tackled by the European scientific police units.

The questionnaire was prepared by the European Center for Soft Computing (Spain), based on the requirements and scientific experience of forensic investigators from the University of Granada (Spain), Coimbra University (Portugal), Guardia Civil (Spain), and Israel Police. This survey was sent to approximately 600 forensic scientists worldwide, over a period of 3 months. The data was provided by forensic investigators from universities and law enforcement agencies from 32 countries in North, Central, and South America; Europe; Asia; and Africa. A total of 97 responses were received. Of these, 45 investigators answered that they have used CFS as a method of identification in diverse investigations.

The survey was composed of 16 questions addressing issues related to the number of cases undertaken in the last 30 years; classified according to different identification scenarios (mass graves, terrorism, missing persons, and common graves); the number of hours employed conducting CFS; identification results; whether the results were presented in court; the materials, tools, and techniques used; and the main problems faced in the application of CFS.

Of the 97 responses, 56\% were positive, that is, the investigator reported using CFS on a regular basis or having used CFS in the past. The following report addresses only the positive responses. 


\subsection{Use of the Technique}

From the MEPROCS survey, a total of 3854 cases of CFS were reported: of these, $2744(71.2 \%)$ were presented in a court of law and $1246(32.3 \%)$ of them resulted in a positive identification. Most cases (2489) were not classified by the responders into any of the categories suggested in the survey. The following sections are devoted to an in-depth analysis of participant responses, according to the main issues asked. The data was provided by forensic investigators from universities and law enforcement agencies worldwide.

Over $50 \%$ of the investigators have implemented CFS in only a small number instances (1-10 cases over a period of 10 years) mostly in missing persons or homicide investigations, while the remaining respondents reported a larger caseload (more than 20 cases).

\subsubsection{Identification Scenarios and Nature of the Investigation}

According to the identification scenario, we have defined a classification system based on the number of candidates to be identified and the number of possible matches: one candidate, an open list, or a closed list of candidates. The open list is considered an event that results in the death of an undetermined number of unknown individuals, for whom no data or records are available. Closed lists, on the other hand, are those in which death has occurred to a known group of identifiable people. The first category of this classification is the presumed identity of only one candidate (PIOI). The second and third categories are either the presumed identity of an individual within a closed list of possible candidates, PICL, or the unknown identity of an individual within a closed list of possible candidates, UICL. The last category is the unknown identity of an individual within an open list (UIOL). Finally, CNC denotes those cases not classified by the responders.

Table 5.1 shows the classification of the total number of CFS cases reported by the participants in the survey according to the nature of the investigation. The most common scenario is the presumed identity of only one individual candidate (545 cases). The two different categories considering a closed list include 670 cases, while the open list was applied in at least 150 cases.

All cases were further classified based on the nature of the investigation addressed. We have distinguished the following four:

- Mass disasters are defined as natural or man-made events, which cause death or injuries to large numbers of individuals. These include natural disasters caused by floods, climate and geophysical phenomena and epidemics or pandemics, and man-made disasters, caused by man's actions, intentional or otherwise, such as, wars, civil disasters, or accidents.

- Terrorism can be defined as a human activity designed to cause harm, using premeditated violence with political or religious purposes. 
Table 5.1 Use of CFS reported by 45 investigators

\begin{tabular}{l|l|l|l|l|l}
\hline Scenario $^{\text {a }}$ & $\begin{array}{l}\text { Positive } \\
\text { identification }\end{array}$ & Exclusion & Undetermined & Not classified & Total \\
\hline PIOI & $451(11.7 \%)$ & $33(0.9 \%)$ & $61(1.6 \%)$ & - & $545(14.1 \%)$ \\
\hline PICL & $309(8.0 \%)$ & $4(0.1 \%)$ & $19(0.5 \%)$ & - & $332(8.6 \%)$ \\
\hline UICL & $336(8.7)$ & - & $2(0.1 \%)$ & - & $338(8.8 \%)$ \\
\hline UIOL & $150(3.9 \%)$ & - & - & - & $150(3.9 \%)$ \\
\hline CNC & - & - & - & $2489(64.6 \%)$ & $2489(64.6 \%)$ \\
\hline Total & $1246(32.3 \%)$ & $37(1.0 \%)$ & $82(2.1 \%)$ & $2489(64.6 \%)$ & $3854(100.0 \%)$ \\
\hline
\end{tabular}

${ }^{a}$ Scenario abbreviations: PIOI presumed identity of only one individual candidate, $P I C L$ presumed identity of an individual within a closed list of possible candidates, UICL unknown identity of an individual within a closed list of possible candidates, $U I O L$ unknown identity of an individual within an open list, $C N C$ cases not classified by the responders

Table 5.2 Classification results obtained in the survey according to the nature of the investigation

\begin{tabular}{l|l}
\hline Nature of the investigation & Cases \\
\hline Terrorist attack & $15(0.4 \%)$ \\
\hline Missing persons & $458(11.9 \%)$ \\
\hline Mass casualty & $130(3.4 \%)$ \\
\hline Mass grave & $87(2.2 \%)$ \\
\hline Other & $3164(82.1 \%)$ \\
\hline Total & $3854(100.0 \%)$ \\
\hline
\end{tabular}

- Missing persons, in accordance with the RCIC (Red Cross International Committee), are those persons about whom their families have no news of and/or who, on the basis of reliable information, have been reported missing as a result of an armed conflict, international or noninternational, cause of internal violence, internal disturbances, or any other situation that might require the intervention of a neutral and independent public authority or when bodies lack information for identification, pursuant a medico-legal investigation of deceased person.

- Mass graves are places where an undetermined number of individuals are buried as a consequence of war, guerrilla warfare, or as a result of mass disasters. Often, the exhumation and study of skeletal remains from mass graves involves a long and costly set of procedures. A number of protocols have been suggested; mostly modified from the UN Manual on the effective prevention and investigation of extralegal, arbitrary, and summary executions (Pesce Delfino et al.1993), in which five different phases for the study of skeletal remains are suggested: preliminary investigations, exhumation research, forensic study, final report, and final destination of skeletal remains (Ibáñez et al.2009b).

Table 5.2 summarizes the responses according to the scenario in which CFS was applied. Unfortunately, most of the survey participants $(82.1 \%)$ did not classify their cases. 
Table 5.3 CFS cases grouped by country

\begin{tabular}{l|r|r}
\hline Continent/country & Cases & Percentage \\
\hline Central and North America & 147 & 3.8 \\
\hline Mexico & 105 & 2.7 \\
\hline USA & 42 & 1.1 \\
\hline South America & 1164 & 30.3 \\
\hline Brazil & 6 & 0.2 \\
\hline Chile & 2 & 0.1 \\
\hline Peru & 980 & 25.4 \\
\hline Uruguay & 176 & 4.6 \\
\hline Asia & 2367 & 61.4 \\
\hline China & 600 & 15.6 \\
\hline Japan & 15 & 0.4 \\
\hline Jordan & 5 & 0.1 \\
\hline India & 1471 & 38.2 \\
\hline Russia & 217 & 5.6 \\
\hline Turkey & 58 & 1.5 \\
\hline United Arab Emirates & 1 & 0.0 \\
\hline Europe & 176 & 4.6 \\
\hline Spain & 31 & 0.8 \\
\hline Denmark & 10 & 0.3 \\
\hline Italy & 20 & 0.5 \\
\hline Lithuania & 80 & 2.1 \\
\hline Netherland & 8 & 0.2 \\
\hline UK & 7 & 0.2 \\
\hline Romania & 20 & 0.5 \\
\hline Total cases & 3854 & 100.1 \\
\hline & &
\end{tabular}

\subsubsection{Geographical Distribution}

The global distribution of CFS identification cases between the different continents and countries is summarized in Table 5.3. India is the country in which most cases have been reported (1471), followed by Peru (980).

\subsection{Methods and Tools}

The investigators were asked to report on the method (manual, semiautomatic, or fully automatic) and type of CFS technique used, as well as the source of material (photograph, video image, or digital) for superimposition. Table 5.4 presents the distribution of the various techniques reported.

The tools required during the implementation of the technique are presented in Table 5.5. 
Table 5.4 Distribution of reported techniques

\begin{tabular}{l|l|l|l|l}
\hline & $\begin{array}{l}\text { Photographic } \\
\text { superimposition }\end{array}$ & $\begin{array}{l}\text { Video } \\
\text { superimposition }\end{array}$ & $\begin{array}{l}\text { Computer assisted } \\
\text { superimposition }\end{array}$ & Total responses \\
\hline Manual & 20 & 3 & 8 & 31 \\
\hline Semiautomatic & 10 & 3 & 5 & 18 \\
\hline Automatic & 11 & 1 & 2 & 14 \\
\hline Total & 41 & 7 & 15 & 63 \\
\hline
\end{tabular}

Table 5.5 Tools implemented in technique

\begin{tabular}{l|l|l|c}
\hline Response & Chart & Percentage & Count \\
\hline X-rays & & 12 & 4 \\
\hline CTs & & 12 & 4 \\
\hline 3D Scanner & & 12 & 4 \\
\hline Video system & & 15 & 6 \\
\hline Skull bench & & 15 & 5 \\
\hline Photoshop & & 61 & 21 \\
\hline Others & & 39 & 13 \\
\hline & Total responses & & 34 \\
\hline
\end{tabular}

Other responses included software such as Photomodeler, Freeform Modeling System, Powerpoint, Geomagic, and 3Dmax. Hardware used included Phantom ${ }^{\mathbb{B}}$ haptic devices, photographic cameras, and various types of scanners.

Tables 5.4 and 5.5 appear to present some inconsistencies. These can be explained by the lack of proper differentiation between the three CFS methods (photo, video, and computer). While only 14 of the investigators answered that they used computer-assisted superimposition, at least 20 of them reported that they used computer software (Photoshop ${ }^{\mathrm{TM}}$ ) to perform the superimposition.

These types of responses are expected as the scientific literature on the subject does not make a clear differentiation between the three categories. Similarly, there is also an inconsistency regarding the modality (manual, semiautomatic, automatic). For instance, 11 investigators responded that they utilized automatic photographic superimposition, when in fact to our knowledge, there is not a single automatic method or system of photographic superimposition.

\subsubsection{Landmarks}

Finally, the anthropological landmarks were addressed. The investigator responses regarding the landmarks utilized are presented in Table 5.6.

Other landmarks included general shape of the skull, contour of the face and skull vault, orbital measurements, orbital shape, eye width, Whitnall's tubercle, chin lip fold, nasal outline (including asymmetry), tragus, position of auditory meatus, position of lips, dentition, chin, and mandibular angles. 
Table 5.6 Landmarks used

\begin{tabular}{l|l|c}
\hline Response & Frequency & Count \\
\hline Glabella & $38 \%$ & 11 \\
\hline Nasion & $38 \%$ & 11 \\
\hline Rhinion & $17 \%$ & 5 \\
\hline Nasospinale-Subnasale & $28 \%$ & 8 \\
\hline Alare-Alare & $31 \%$ & 9 \\
\hline Subspinale-Superior labial sulcus & $24 \%$ & 7 \\
\hline Prosthion-Upper lip border (Labiale superius) & $34 \%$ & 10 \\
\hline Infradentale superius-Lower lip border & $17 \%$ & 5 \\
\hline Incisor superius-Stomion & $10 \%$ & 3 \\
\hline Supramentale-Labiomentale & $14 \%$ & 4 \\
\hline Gonion & $38 \%$ & 11 \\
\hline Zygion & $31 \%$ & 9 \\
\hline Orbitale-Infraorbital & $17 \%$ & 5 \\
\hline Supraorbital & $10 \%$ & 3 \\
\hline Porion & $17 \%$ & 5 \\
\hline Supraglenoide & $10 \%$ & 3 \\
\hline Dacryon-Endocanthion & $34 \%$ & 10 \\
\hline Gnathion-Menton & $21 \%$ & 6 \\
\hline Gnathion & $38 \%$ & 11 \\
\hline Pogonion-Mental & $14 \%$ & 4 \\
\hline Pogonion & $14 \%$ & 4 \\
\hline Prosthion & $24 \%$ & 7 \\
\hline Menton & $7 \%$ & 2 \\
\hline Ectoconchion & $38 \%$ & 11 \\
\hline Frontozygomatic suture-Ectocanthion & $21 \%$ & 6 \\
\hline Other & $62 \%$ & 2 \\
\hline
\end{tabular}

\subsubsection{Literature Review}

The statistics obtained in the survey were similar to the data found in the literature.

Table 5.7 presents an analysis of the manuscripts reporting case studies solved using CFS. All of the papers reviewed were classified according to the nature of the investigation, identification scenarios, and results.

The literature reviewed for the project revealed that 26 articles had addressed the nature of the investigation in which CFS was implemented and, later on, had undergone judicial scrutiny. Of these, $8 \%$ relate to missing persons' identification (Ross 2004; İşcan et al. 2005), 4\% were terrorist attacks (Indriati 2009) and 4\% of the articles relate to mass casualty scenarios (Al-Amad et al. 2006). It can be observed that $68 \%$ of cases comprised of the identification of one individual (PIOI) (Birngruber et al. 2010; Gordon and Drennan 1948; Simpson 1943; Prinsloo 1953; Sen 1962; Bilge et al. 2003; Pushparani et al. 2012; Ghosh and Sinha 2005; Shahrom et al. 1996; Ubelaker et al. 1992; Bastiaan et al. 1986; Puech et al. 1989; 
Table 5.7 Classification of case studies

\begin{tabular}{|c|c|c|c|c|c|c|c|c|c|c|c|c|}
\hline \multirow[b]{2}{*}{ Author } & \multicolumn{5}{|c|}{ Nature of investigation } & \multicolumn{4}{|c|}{ Identification scenario } & \multicolumn{3}{|c|}{ Result } \\
\hline & TA & $\mathrm{MP}$ & MCI & MG & $\mathrm{O}$ & PIOC & PICL & UICL & UIOL & $\mathrm{PI}$ & $\mathrm{E}$ & $\mathrm{U}$ \\
\hline $\begin{array}{l}\text { Glaister and } \\
\text { Brash (1937) }\end{array}$ & & & & & $\mathrm{x}$ & & $\mathrm{x}$ & & & & $\mathrm{x}$ & \\
\hline Prinsloo (1953) & & & & & $\mathrm{x}$ & $\mathrm{x}$ & & & & $\mathrm{x}$ & & \\
\hline Simpson (1943) & & & & & $\mathrm{x}$ & $\mathrm{x}$ & & & & $\mathrm{x}$ & & \\
\hline $\begin{array}{l}\text { Gordon and } \\
\text { Drennan (1948) }\end{array}$ & & & & & $\mathrm{x}$ & $\mathrm{x}$ & & & & $\mathrm{x}$ & & \\
\hline Webster (1955) & & & & & $\mathrm{x}$ & $\mathrm{x}$ & & & & $\mathrm{x}$ & & \\
\hline Sen (1962) & & & & & $\mathrm{x}$ & $\mathrm{x}$ & & & & & & \\
\hline Reddy (1973) & & & & & $\mathrm{x}$ & & $\mathrm{x}$ & & & $\mathrm{x}$ & & \\
\hline $\begin{array}{l}\text { McKenna et al. } \\
\text { (1984) }\end{array}$ & & & & & $\mathrm{x}$ & & $\mathrm{x}$ & & & $\mathrm{x}$ & & \\
\hline Teixeira (1985) & & & & & $\mathrm{x}$ & $\mathrm{x}$ & & & & $\mathrm{x}$ & & \\
\hline $\begin{array}{l}\text { Bastiaan et al. } \\
\text { (1986) }\end{array}$ & & & & & $\mathrm{x}$ & $\mathrm{x}$ & & & & $\mathrm{x}$ & & \\
\hline Webster (1955) & & & & & $\mathrm{x}$ & $\mathrm{x}$ & & & & $\mathrm{x}$ & & \\
\hline Sen (1962) & & $\mathrm{x}$ & & & & & $\mathrm{x}$ & & & $\mathrm{x}$ & $\mathrm{x}$ & $\mathrm{x}$ \\
\hline $\begin{array}{l}\text { Puech et al. } \\
\text { (1989) }\end{array}$ & & & & & $\mathrm{x}$ & $\mathrm{x}$ & & & & $\mathrm{x}$ & & \\
\hline $\begin{array}{l}\text { Ubelaker et al. } \\
\text { (1992) }\end{array}$ & & & & & $\mathrm{x}$ & $\mathrm{x}$ & & & & $\mathrm{x}$ & & \\
\hline $\begin{array}{l}\text { Shahrom et al. } \\
\text { (1996) }\end{array}$ & & & & & $\mathrm{x}$ & $\mathrm{x}$ & & & & $\mathrm{x}$ & & \\
\hline Austin (1999) & & & & & $\mathrm{x}$ & $\mathrm{x}$ & & & & $\mathrm{x}$ & & \\
\hline $\begin{array}{l}\text { Solla and Iscan } \\
(2001)\end{array}$ & & & & & $\mathrm{x}$ & & $\mathrm{x}$ & & & $\mathrm{x}$ & & \\
\hline $\begin{array}{l}\text { Bilge et al. } \\
(2003)\end{array}$ & & & & & $\mathrm{x}$ & $\mathrm{x}$ & & & & $\mathrm{x}$ & & \\
\hline Chai et al. (1989) & & $\mathrm{x}$ & & & & $\mathrm{x}$ & & & & $\mathrm{x}$ & & \\
\hline $\begin{array}{l}\text { Puech et al. } \\
\text { (1989) }\end{array}$ & & $\mathrm{x}$ & & & & & & & $\mathrm{x}$ & & $\mathrm{x}$ & \\
\hline $\begin{array}{l}\text { Ghosh and Sinha } \\
(2005)\end{array}$ & & & & & $\mathrm{X}$ & $\mathrm{X}$ & & & & $\mathrm{x}$ & & \\
\hline $\begin{array}{l}\text { Al-Amad et al. } \\
(2006)\end{array}$ & & & $\mathrm{x}$ & & & & & & $\mathrm{X}$ & $\mathrm{x}$ & & \\
\hline $\begin{array}{l}\text { Fenton et al. } \\
(2008)\end{array}$ & & & & & $\mathrm{X}$ & & $\mathrm{X}$ & & & & $\mathrm{x}$ & \\
\hline $\begin{array}{l}\text { Shahrom et al. } \\
\text { (1996) }\end{array}$ & $\mathrm{x}$ & & & & & & $\mathrm{x}$ & & & $\mathrm{x}$ & & \\
\hline $\begin{array}{l}\text { Solla and Iscan } \\
(2001)\end{array}$ & & & & & $\mathrm{X}$ & $\mathrm{x}$ & & & & $\mathrm{x}$ & & \\
\hline $\begin{array}{l}\text { Pushparani et al. } \\
\text { (2012) }\end{array}$ & & & & & $\mathrm{X}$ & $\mathrm{x}$ & & & & $\mathrm{x}$ & & \\
\hline
\end{tabular}


Teixeira 1985; Webster 1955; Austin 1999; Helmer 1987), 16\% addressed CFS identification within a closed list of possible individuals (PICL) (Indriati 2009; Al-Amad et al. 2006; Glaister and Brash 1937; Gordon and Drennan 1948; Simpson 1943; Prinsloo 1953; Sen 1962; Reddy 1973; Solla and Iscan 2001; McKenna et al. 1984; Webster 1955), 8\% of the papers reported on the exclusion of a presumed identity within a closed list of possible individuals (UICL) (Glaister and Brash 1937; Gordon and Drennan 1948; Simpson 1943; Prinsloo 1953; Sen 1962; Reddy 1973; Bilge et al. 2003; Pushparani et al. 2012; Ghosh and Sinha 2005; Webster 1955; Fenton et al. 2008), and $8 \%$ of papers were related to the identification of individuals whose identity was not presumed, within an open list of possible candidates. Half of the latter cases resulted in identification, and half resulted in exclusion (UIOL) (Al-Amad et al. 2006).

It should be noted that a large number of the cases referred to judicial authorities included identification based on superimposition, corroborated by other identification techniques, that is, comparison of DNA profiles. When no corroboration could be obtained, the superimposition, together with the anthropological profile, was used as the method of identification. The majority of the articles were classified within a general category "others," which in most cases included single case identification of cadavers in diverse taphonomic conditions, or the identification of historical figures such as Mozart (Puech et al. 1989).

\subsubsection{Conclusions}

The international survey on the use of CFS as a method of identification among forensic investigators is a unique tool that has provided an important insight into this state of the art of the technique.

The results of the pertinent literature scrutiny and the survey conducted among forensic investigators seem to indicate that CFS is deemed as a reliable and efficient technique of identification, although implemented in conjunction with another method in many cases. From a total of 3854 cases reported worldwide, 32.3\% resulted in the positive identification of remains, with 2744 (71.2\%) cases submitted to judicial scrutiny.

Open Access This chapter is licensed under the terms of the Creative Commons AttributionNonCommercial 2.5 International License (http://creativecommons.org/licenses/by-nc/2.5/), which permits any noncommercial use, sharing, adaptation, distribution and reproduction in any medium or format, as long as you give appropriate credit to the original author(s) and the source, provide a link to the Creative Commons license and indicate if changes were made.

The images or other third party material in this chapter are included in the chapter's Creative Commons license, unless indicated otherwise in a credit line to the material. If material is not included in the chapter's Creative Commons license and your intended use is not permitted by statutory regulation or exceeds the permitted use, you will need to obtain permission directly from the copyright holder. 


\section{Chapter 6 \\ Ethical and Legal Issues in Craniofacial Superimposition}

\subsection{Introduction}

Methodology in craniofacial superimposition (CFS) relies on the knowledge of the anatomical relationship between the soft tissues of the head and the underlying skeletal and dental structures. This information is also critical to the closely related practice of facial approximation/reproduction. Craniofacial superimposition is usually employed when a skull has been recovered and thought to perhaps be related to a particular missing person for whom ante-mortem facial photographs are available. Facial approximation refers to the process utilized to estimate a person's facial appearance from a recovered skull (Bilge et al. 2003; Pushparani et al. 2012; Al-Amad et al. 2006). Although both techniques can prove to be important in the investigation of missing persons, recovered remains, and events producing mass fatalities, this document specifically addresses ethical issues relating to research in the development of methodology for craniofacial superimposition.

In recent years, as advances in forensic odontology, genetics, and anthropology have improved, so have the chances of identifying victims beyond recognition. According to the Interpol Disaster Victim Identification (DVI) Guide, fingerprints, dental examination, and deoxyribonucleic acid (DNA) are the primary identifiers (Schuliar and Knudsen 2012; Al-Amad et al. 2006). There are unmistakable reasons why these are the most reliable indicators of identity: fingerprints are unique, do not change, and can be classified, which enables them to be identified and registered systematically. Subsequently, the prints are then easily retrieved for purposes of comparison (Puech et al. 1989).

The unique structures and traits of human teeth, dental restorations, and jaws readily lend themselves to use in the identification of living and deceased victims. Dental data can be recovered and recorded at the time of the post-mortem examination and compared to ante-mortem data that is supplied by the generalist and/or 
specialist dentists who treated the victim during their lifetime (Fernándes et al. 2012). While an important and valuable identification method, dental identification is subject to the availability and quality of ante-mortem and post-mortem dental records (Al-Amad et al. 2006).

Deoxyribonucleic acid is a proven source of material for use in identification, as a significant portion of the genetic information contained in a cell is unique to a specific individual and thus differs - except in identical twins - from one person to the next. DNA testing can be performed even in cases involving partial, severely decomposed remains. Additionally, DNA matching is the best way to identify body parts and can be based on profiles from relatives, self-samples, or belongings (Al-Amad et al. 2006).

Secondary means of identification include personal description, medical findings, as well as evidence and clothing found on the body. These contributions serve to support identification by other means and are not ordinarily sufficient as a sole means of identification (Schuliar and Knudsen 2012), unless they have a rare identification potential, such as prosthetic devices, especially when they bear a serial number or an identification (ID) code. Face recognition is a natural human ability and a widely accepted identification and authentication method. In modern legal settings, considerable credence is placed on identifications made by eyewitnesses. However, these are based on human perception, which is often flawed and can lead to situations where identity is disputed.

The craniofacial superimposition technique can contribute to the process of identification especially when there is no reference sample for a forensic DNA analysis, when DNA typing from remaining tissue samples has failed, or when ante-mortem dental records and comparative fingerprints are not available (2012).

The aim of this chapter is to analyze ethical and legal issues involved in the use of craniofacial superimposition, considering the creation of a common multicentric framework that will allow the extensive application of the CFS technique in practical forensic identification scenarios.

\subsubsection{What Is Craniofacial Superimposition?}

This method consists of the superimposition of the image of the skull and a photograph of a missing person. It involves the comparison of specific landmarks on soft tissue and bone surfaces. The technique is employed in cases when human remains are found and are thought to possibly relate to a particular missing person. The method can be used when a photograph of the missing person taken during life is available, and molecular, odontological, and/or fingerprint data are not available to facilitate identification. 


\subsection{The Importance of Craniofacial Superimposition in Human Identification}

There are various situations in which craniofacial superimposition can be extremely useful. Examples include when a corpse is unrecognizable due to its state of decomposition, soft-tissue mutilation or incineration (2012), and in mass disasters, which are associated with a large number of fatalities, with victims being visually unidentifiable in most cases (Al-Amad et al. 2006).

The method is mostly useful for exclusion. In such cases, observations of hard tissue landmarks on the recovered remains are sufficiently inconsistent with those on the ante-mortem photograph to suggest that the individual in the photograph could not be the person represented by the skeletal remains.

In the application of this technique, an initial assessment involves comparison of all available features of the recovered remains with the superimposed ante-mortem photograph. If major differences are apparent, an exclusion can be concluded. If no significant differences are found, the examiner then must determine the uniqueness of the features compared. The extent to which a positive comparison contributes to the identification process depends upon the uniqueness of those features and the probabilities involved.

The supporters of this method report that up to $96 \%$ of positive correlations can represent correct identifications, when both frontal and lateral superimposition views are utilized. However, anthropologists have varied opinions regarding the reliability and probabilities involved in this type of investigation. In our opinion, this method is best used in conjunction with others for identification, as there are several problems to overcome in the comparison between a soft tissues structure (face) and a structure made of hard tissue (skull). The SWGANTH document for best practices in facial approximation (Al-Amad et al. 2006) provides valuable commentary on the strengths and weaknesses of facial approximation methodology in its current state. While limited in scope, it can be useful for excluding identity if gross incompatibilities are present.

\subsection{Ethical Issues in Craniofacial Superimposition Methods Research}

Ethical issues relate to proper consent for the acquisition of documented data from known individuals, protection and proper storage of data, and appropriate scientific utilization of the data.

The ethical issues in CFS methods vary according to their aim. First of all, it is necessary to find and develop the best method, which implies research using skulls (from both deceased and living individuals) to improve the technique and to create a 
database that will allow the future application of these methods. In fact, it is an altruistic contribution, without any benefits for those people who participate. In the future, CFS will be used to assist in identification when recognition by other resources has failed, and thus will benefit society as a whole.

\subsubsection{The Groups Involved (Victims, Families, Professionals, and Societies)}

The primary groups of ethical concern are living individuals who contribute data, and the families of the deceased whose remains and photographs are utilized. Other groups of ethical interest include professional researchers, scientific organizations, project organizers, administrators, and those involved with data entry and the computer programming of the database.

When we are analyzing the ethical issues of the CFS application, we must consider all the groups involved: the victims, their families, all the professionals, and, finally, society.

\subsubsection{The Victims}

The Universal Declaration on Bioethics and Human Rights aims "to promote respect for human dignity and protect human rights" (2012). According to the Convention on Human Rights and Biomedicine, "Parties to this Convention shall protect the dignity and identity of all human beings. .." (2012). Additional declarations suggest similar ethical approaches when working with human subjects (Smeets et al. 2010; Claes et al. 2010; Al-Amad et al. 2006). Given these issues, we can say that victims are to be treated with dignity and respect, as human dignity persists beyond death. Everyone, dead or alive, deserves to be identified.

\subsubsection{The Families}

The family is essential in this whole process, through the cooperation they can provide by making available photographs, personal details, and otherwise assisting in the identification process. It is undoubted that cooperation on the part of relatives in the collection of ante-mortem data enhances the quality and speed of identification measures. However, we must not forget that they may need psychological support, and we must be able to provide it in every situation. They also deserve to pay a last tribute to their dead, so we should do our best to enable it in every situation. 


\subsubsection{The Professionals}

All participants in this project should demonstrate a scientific competence and adhere to ethical guidelines. Participants shall not misrepresent themselves or their work products, inappropriately utilize tangible or intellectual property, or through their actions or words indicate disrespect to the deceased, their family members, or others contributing data to this project. Participants should refrain from conduct adverse to the best interests of the professional scientific community. Participants should properly and accurately present their education, training, experience, and expertise. Participants should comply with all relevant laws, regulations, and policies that relate to the acquisition, security, and use of data in this project, especially in relation to human remains. Participants should ensure that all scientific procedures meet professional standards. All professional activity should be carried out in a manner that inspires confidence in the project and the professional forensic science community.

The professionals working in this area have to bear in mind that the most important requirement for victim identification work is the application of International standards (The Scientific Working Group for Forensic Anthropology 2012c). In this context, it is indispensable that the highest possible quality standards will be applied, not only for procedures and equipment, but also with regards to human resources $(1997,2005)$. It means that everyone has to be well trained and has to strictly follow all the procedures. As the team is frequently the point of contact for relatives within the context of family assistance, they also have to be trained to provide this kind of support.

In the CFS research, the professionals involved must act according to the "four principles" approach, postulated by (1964):

- The respect for autonomy - by which the patient has the right to accept or refuse any procedure; in this particular case, no images can be used unless informed consent is provided.

- Beneficence-every practitioner should act in the best interest of those providing data. As discussed above, in the initial research phase, the benefits we can achieve are the reliability and accuracy of this technique, in order to be safely used in the future. When CFS is used as a tool to help identify nameless individuals, all the professionals should do their best, not only technically, but also by providing psychological support to the victims' families.

- Non-maleficence- the "first, do no harm" principle can be applied as a way to minimize the possibility of a misrecognition, which carries tough legal, social, and religious issues.

- Justice-it generally concerns the distribution of scarce health resources, and the decision of who gets what treatment (fairness and equality). In this particular field, efforts must include widely informing all concerned individuals about the MEPROCS framework, and in the last step, this technique should be equally available to every partner. 
Another value which is sometimes discussed includes the respect for personsthe individuals providing data have the right to be treated with dignity. In addition, families of the deceased have the basic human rights for the identification of their loved ones.

\subsubsection{Society}

Society increasingly wants to be up to date, seeking information about missing persons and requiring that every effort should be undertaken to find them. It is extremely important to know how to deal with media, and share only useful information, without risking the success of the investigation. When CFS is used to assist in the identification of criminals, it can also be considered an important matter of safety.

Another important point we have to consider is the cost-effectiveness of the project. The costs of building an image database can be high, and the proportionality issue facing the benefits of its use has to be considered. On the other hand, the method's limitations and the misidentification consequences make this technique itself an ethical issue.

\subsubsection{Databases for Craniofacial Superimposition Methods Research and Data Protection}

Databases raise ethical questions, and many reasons exist both for and against their creation. Two main advantages of their use are the possibility of accelerating the process of identification (in mass disaster situations), and of enhancing the efficacy of identification of a guilty or an innocent person. On the other hand, they risk violating the right to privacy, human dignity, the right to physical and moral integrity, the right to not testify, the innocence presumption, the right to health, and the right to freedom (Board 2012).

Databases must be constructed in a manner to facilitate the research that is expected to be performed. The primary ethics issues in such database construction and maintenance involve protection of the data from improper use and viewing, limiting access to only those approved individuals and institutions and defining research protocols that limit applications. These ethical issues apply not only to the construction and initial research use of the database but also to its maintenance when the primary research is complete.

A long-term goal should be the maintenance of the database, since scientific research represents an ongoing process as new problems and approaches are identified. When we consider the creation of a database for CFS research, protocols of registration, collection, storage, and sharing data are needed. It is crucial to define 
what images should be inserted, how they should be stored, how long they should be maintained in storage, as well as how and when this data should be shared.

Considering all these issues, the MEPROCS' database should be built after defining all previous issues. By using the principle of precaution, we have to prevent the slippery slope effect, as well as the risk of discrimination that the power of the organizations can exercise on the minor partners. It is essential to have a quality control system for this image database.

\subsubsection{Database Accessibility}

All the participants and partners in the proposal must obey national laws and European directives of privacy and data protection by ensuring that their employees and collaborators fulfill the appropriate procedures to handle sensitive electronic data.

The personal information used during the project should be coded and encrypted following the practices approved by their respective local/national ethical committees. The data will be accessible only for the participants involved in the project and a security policy should be generated and communicated to all the participants in the network. This security policy should also state the protected data transfer protocols, preferably by European secure network (as S-TESTA) that will be used to transmit confidential data. Such data will not be transferred to any person outside the network. The implementation of the security policy should be monitored by the ethics committee (EC). It is important to note that anonymous data is not considered personal data and the processing of this anonymous data requires less special safeguards. The data will be anonymous for the participants. Irreversible anonymization of data will be assured using a secured procedure to permanently delete the electronic data. Once data is anonymous, it does not require specific processing apart from the standard data protection procedures. Data will not be kept in an identifiable form in the resources of the partners.

\subsubsection{Privacy: Data Anonymity}

The Data Protection Act 1998 (the DPA) applies only to information, which falls within the definition of "personal data." European data protection authorities have been considering what is meant by "personal data" in Directive 95/46/EC on the protection of individuals with regard to the processing of personal data and on the free movement of such data (the European Data Protection Directive, or the Directive). This work has culminated in Opinion 4/2007 on the concept of personal data (01248/07/EN-WP136) adopted by the Article 29 Data Protection Working Party on June 20, 2007.

The Data Protection Act (DPA) is concerned with "personal data." Personal data means data that relates to a living individual who can be identified from the data or 
from the data and other information, which is in the possession of, or is likely to come into the possession of, the data controller.

In order to determine if the data under study is considered personal data, the following questions have to be answered (The Scientific Working Group for Forensic Anthropology 2012a):

- Can a living individual be identified from the data, or, from the data and other information in the possession of, or likely to come into the possession of, the data controller?

- Does the data "relate to" an identifiable living individual, whether in personal or family life, business, or profession?

If the answer to any of the previous questions is yes, the data can be considered personal data in most of the cases.

In the particular case of the data needed to perform CFS, neither the skull (the actual physical skull, photographs, or 3D models of it) nor the anthropological profile can be considered as personal data. Contrary to that, face photographs of living persons are considered personal data in the CFS scenario so they have to be treated as confidential data. Those photos will be processed to learn something about the individual. In addition, as mentioned before, face recognition is a natural human ability.

The partners will make available anonymous data together with a unique coding, which falls short of actually identifying the individual to the MEPROCS participants. By making data anonymous, the privacy of individuals will be maintained. Converting personal data into a form in which the individuals to whom it relates are no longer identifiable will be only possible in the case of the skull and anthropological profile. It is not possible to anonymize face photographs for CFS purposes since the task to be performed is exactly the contrary, individual identification. However, it is clearly legitimate to use personal data for particular purposes where the intention is to inform decisions about particular individuals, or to provide services to them, as is the goal of the current research study (2012).

The process of anonymization (The Scientific Working Group for Forensic Anthropology 2012b) starts once a relative of the deceased decides to allow the use of data in the study. At this moment, the responsible person designated by the MEPROCS EC to carry out this process has to access the database, in which he/she will add files containing the reference of the data that is going to be introduced. These references and the file name will be a random code obtained using certified and secured commercial anonymization software. Then, the MEPROCS EC will ensure that the privacy supervisor designated in each center has verified that the files have been codified properly and that they comply with privacy rights. At this time, files can be transferred to the rest of the partners. Organizations holding the data are the guardians and should exercise due diligence with its protection.

Finally, special attention will be given to the images that might be needed for dissemination outside the network (project reports, scientific papers, etc.). The research intending to use images in open dissemination publication and activities should seek explicit permission from the EC. A second check will be performed on 
the medical images to ensure that it remains impossible for the public to identify the deceased from the data.

\subsection{The Problems of European and National Legislation and the Implications of Conventions and Declarations}

Every effort should be made to acquire data in a manner that is consistent with existing European and national legislation and policies.

The MEPROCS international framework must respect international conventions and declarations, as well as the legal issues of all involved countries. It should be important that a legal expert from each country compiles his/her national legislations, and assure that all MEPROCS' documents comply with them.

Participants must abide by the national legislation and regulations of the countries in which the project will be carried out. Furthermore, each participant will seek the approval of the relevant local or national ethics committee to start the research activities.

Participants must conform to relevant EU legislation: Charter of Fundamental Rights, Decision $\mathrm{N}^{\circ} 1982 / 2006 / \mathrm{EC}$ of the European Parliament and of the Council of 18 December 2006 concerning the 7FP for research, technological and demonstration activities (2007-2013), the Directive 95/46/EC, and the Council of 24 October 1995 on the protection of individuals with regard to the processing of personal data and of free movement of such data.

Participants must abide by International conventions and declarations: Helsinki Declaration 1996/2000, UN Convention on the Rights of the Child, Convention of the Council of Europe on Human Rights and Biomedicine (1997), UNESCO Universal Declaration on Bioethics and Human Rights (2005), and W.H.O./C.IO. M.S. International Ethical for Biomedical Research Involving Human Subjects (1993, reviewed 2001).

In addition, each MEPROCS full partner shall provide the Research European Agreement (REA) with written confirmation that it has received favorable opinion (s) from the relevant ethics committee(s) and, if applicable, the regulatory approval (s) of the competent national or local authority (ies) in the country in which the research is to be carried out, before beginning any REA-approved research requiring such opinions or approvals. The copy of the official approval from the relevant national or local ethics committees must also be provided to the REA.

\subsection{Proposed Guidelines for Craniofacial Research}

During the research process, all the participants must adhere to the proposed guidelines: 
- In the acquisition of individual data, proper informed consent must be secured.

- Procedures for obtaining informed consent should follow the guidelines and regulations of the countries and institutions involved.

- Once properly obtained, individual data must be protected against inappropriate use. Such protection must include not only the usual computer firewalls but also clear procedures for screening access.

- Use of the data should follow guidelines regarding the type of research conducted as well as defining those individuals/institutions with access.

- Procedures should safeguard the identities of all individuals in the database.

Research methods resulting from utilization of the database should relate the appropriate probabilities involved, including appropriate and adequate statistical procedures.

\subsection{Consent Forms for Craniofacial Superimposition Methods Research}

Informed consent represents an essential ethical cornerstone of database construction. Protocols must be followed to ensure that data are properly acquired and that the necessary approvals are in place. As indicated above, the uses of CFS techniques vary according to particular project goals: research or real practice. In both cases, the use of official consent forms is mandatory.

Although there are various models internationally for consent forms and procedures, attached are consent forms that the ethics committee feels will meet the goals of this project (see Appendices A-C).

To authorize the acquisition of individual data, there are two different MEPROCS Informed Consent Forms: one to be provided to the relatives of the deceased person that we will include in the study (Appendix A) and a second one regarding data collection from living individuals (Appendix B). These forms have been evaluated and approved by the Ethical Committee, as they comply with the ethical values and individual rights. They include a clause with the right to cancel the authorization at any time and state that the proposer will then erase any previous data or images.

The process of obtaining informed consent is basic in the tasks of this project. First, a detailed explanation of how the project will be developed and what its objectives are has to be given to the victims' relatives, or the living individuals. With this aim, the persons in charge should show, in their respective center and using simple and a clear language, a PowerPoint presentation, explaining the details and the social benefits of the MEPROCS project. In order to help people in their understanding of the contents, they should also be provided with a short explanatory document. The next step should include personal interviews with each person to detail the most relevant aspects of MEPROCS.

The principles of this practice are universal: people need to be adequately informed and they must clearly understand the information. Finally, they have to 
make their own decision regarding the authorization to include their images in the database, freely and without coercion. In the case of children, incapable persons, or the deceased, the informed consent is usually given by a close relative or a procurator, always following the rules previously listed.

Once all this information has been transmitted, they should be provided with an informed consent form so that they can accept, freely and without any kind of constraint, to participate in the project.

In the event that data is imported, either from within the MEPROCS consortium, or from an external center/institution, the protocols must adhere to the general ethical guidelines provided in this document.

When there are remains from individuals deceased for more than 15 years, and the national laws allow their sharing and use, the MEPROCS EC approves their inclusion in this study, after the signing of the "Informed Consent form for scientific material sharing" (Appendix C).

Open Access This chapter is licensed under the terms of the Creative Commons AttributionNonCommercial 2.5 International License (http://creativecommons.org/licenses/by-nc/2.5/), which permits any noncommercial use, sharing, adaptation, distribution and reproduction in any medium or format, as long as you give appropriate credit to the original author(s) and the source, provide a link to the Creative Commons license and indicate if changes were made.

The images or other third party material in this chapter are included in the chapter's Creative Commons license, unless indicated otherwise in a credit line to the material. If material is not included in the chapter's Creative Commons license and your intended use is not permitted by statutory regulation or exceeds the permitted use, you will need to obtain permission directly from the copyright holder.

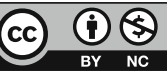




\section{Chapter 7 \\ Experimental Study of Craniofacial Superimposition Methodologies, Tools, and Criteria}

\subsection{Introduction}

The objective of this chapter is to analyze the reliability of different CFS methodologies and the corresponding technical approaches to the CFS identification technique. Moreover, we aim to examine the subjectivity and discriminative power of the different criteria (detailed in Sect. 7.2) for assessing the skull-face correspondence either proposed in the literature or by any of the MEPROCS partners.

This novel study is expected to provide important insights to better understand: (1) which are the most convenient characteristics of every method included in this study, (2) which are the most and less discriminative criteria; and (3) which criteria are dependent more on the expert and which criteria are more independent, that is, less subjective. The two latter points could give an idea of how many and which criteria are needed to reach a reliable conclusion. Those criteria that are determined to be more discriminatory could be later included as a recommended standard for CFS.

\subsection{Study on the Performance of Different Craniofacial Superimposition Approaches}

\subsubsection{Experimental Study}

Each participant was requested to tackle each of the provided cases using the typical protocol that they would follow at their institutions. The participants were requested to fill an identification form with description of the protocol/methodology (i.e., software, equipment, orientation process, landmarks, assessment criteria) employed. For each case, a final identification decision (either positive or negative) should be 
Table 7.1 Summary of the characteristics of the datasets employed for the study

\begin{tabular}{|c|c|c|c|c|c|c|}
\hline \multirow[b]{2}{*}{ Case } & \multirow[b]{2}{*}{ \# Skulls } & \multirow[b]{2}{*}{ \# Photographs } & \multirow[b]{2}{*}{ \# Candidates } & \multirow[b]{2}{*}{ \# SFO'S } & \multicolumn{2}{|c|}{ \# Positive cases } \\
\hline & & & & & Male set & Female set \\
\hline N1 & 1 & 3 & 3 & 3 & 1 & 0 \\
\hline $\mathrm{N} 2$ & 1 & 3 & 3 & 3 & 1 & 1 \\
\hline N3 & 1 & 3 & 3 & 3 & 0 & 1 \\
\hline N4 & 1 & 3 & 3 & 3 & 0 & 0 \\
\hline N5 & 4 & 4 & 4 & 16 & 2 & 2 \\
\hline $\mathrm{N} 6^{\mathrm{a}}$ & 1 & 2 & 1 & 2 & 0 & 0 \\
\hline $\mathrm{N} 7^{\mathrm{a}}$ & 1 & 2 & 1 & 2 & $2(1)^{\mathrm{a}}$ & $2(1)^{\mathrm{a}}$ \\
\hline TOTAL & 7 & 20 & 18 & $32(30)^{\mathrm{a}}$ & $6(5)^{\mathrm{a}}$ & $6(5)^{\mathrm{a}}$ \\
\hline
\end{tabular}

${ }^{a}$ Although cases 6 and 7 are composed of two photographs, that is, they involve two SFOs, these two cases result in just one identification result, considering the matching of the skull over the two photographs

reported along with the rationale supporting the decision and at least one image illustrating the overlay/superimposition outcome.

The dataset used in this reliability test consisted of two sets, divided by sex, of seven CFS case studies each of them. These 14 CFS cases involve a total number of 60 SFO problems as given in Table 7.1. The dataset was collected at the University of Tennessee after obtaining informed consent from the responsible party for the deceased, and provided to the MEPROCS project as data share protocol established through the University of Dundee.

The dataset consisted generically of a set of ante-mortem photos, photos of the skull (with scales), and a set of 3D models of the skull acquired by laser scanning technology (Fastscan Polhemus Scorpion scanner). Physical 1:1 replicas of the skull 3D models were provided to those participants performing video-superimposition. Each set of case studies had the following structure: cases 1-4 mimic a scenario with one skull and three possible candidates, where only one ante-mortem photo of each candidate is available. In case 5, a more complex scenario is simulated, including four skulls and four possible candidates, with only one available ante-mortem photo of each candidate. In cases 6 and 7, the scenario simulated includes one skull and only one possible candidate, with several photos of the candidate available for analysis (see Table 7.1 for the case studies detailed explanation).

The performance of each participant was measured by computing true-positive, false-positive, true- and false-negative rates, and overall accuracy. All indicators were calculated for each sex and all case studies pooled together. Experience and familiarity with craniofacial identification techniques was also taken into account and level of experience of the participants was classified according to the following scheme:

- No previous experience and no CFS-related training.

- No previous experience but CFS-related training.

- Short previous research experience and CFS-related training.

- Moderate previous experience with CFS real cases and CFS-related training.

- Broad experience with CFS real cases. 
The study was carried out by 26 participants from the following institutions: University of Granada (Spain), University of Dundee (Scotland), Legal Medicine and Forensic Sciences Institute (Peru), North Carolina State University (USA), Complutense University of Madrid (Spain), University of Melbourne (Australia), Azienda Ospadaliera-Universitaria di Trieste (Italy), Russian Academy of Sciences (Russia), Portuguese Judiciary Police (Portugal), Moscow Region State Bureau of Forensic Examination (Russia), Spanish Civil Guard (Spain), Turkish Council of Forensic Medicine (Turkey), National Research Institute of Police Science (Japan), University of Milan (Italy), South African Police Service (South Africa), University of Vilnius (Lithuania), and University Sains Malaysia (Malaysia). In Table 7.2 all the participants (numbered from 1 to 26) are listed in the study with the corresponding level of experience. Since not all the participants completed the whole study, information of the dataset(s) tackled by each of them is provided as well.

Tables 7.3, 7.4, 7.5, and 7.6 summarize the methodologies employed by the participants grouped by the technological approach followed. They were classified following the taxonomy given in The Scientific Working Group for Forensic Anthropology (2012b), that is, computer-aided semi-automatic 3D-2D superimposition (Table 7.3), computer-aided manual 3D-2D superimposition (Table 7.4), computer-aided manual video superimposition (Table 7.5), and computer-aided manual photo superimposition (Table 7.6). The first column also indicates both the type of dataset used and the global performance. The datasets are either male, female, or both. The global performance of the participant methodology refers to the percentage of correct decisions. Significant details of each of them are briefly explained according to software and equipment employed, how the SFO process is tackled, and the kind of skull-face relationship assessment made (decision making).

\subsubsection{Results}

A total number of 1152 CFS problems have been tackled within this study. While previous Tables 7.3, 7.4, 7.5, and 7.6 reported on the global performance (correct decisions) of each participant-methodology, the following three tables report the results obtained by each participant, considering separately the two different datasets independently (Tables 7.7 and 7.8, male and female respectively) and both together (Table 7.9). Detailed performance indicators such as true positive (TP), false positive (FP), true negative (TN), and false negative (FN) are given in any case.

Considering only the global performance, participants P2, P3, and P4 achieved the higher rates surpassing $90.00 \%$ up to $94.29 \%$ achieved by P4 (Tables 7.3 and 7.4). They share a similar SFO approach (computer-aided 3D-2D), although P2 made use of a semiautomatic software. During the decision-making stage, they all employed the morphological criteria in Wilkinson (2004), and two of them also analyzed the criteria introduced in Austin-Smith and Maples (1994) and Yoshino (2012). However, only P2 tackled both female and male datasets. Similar 


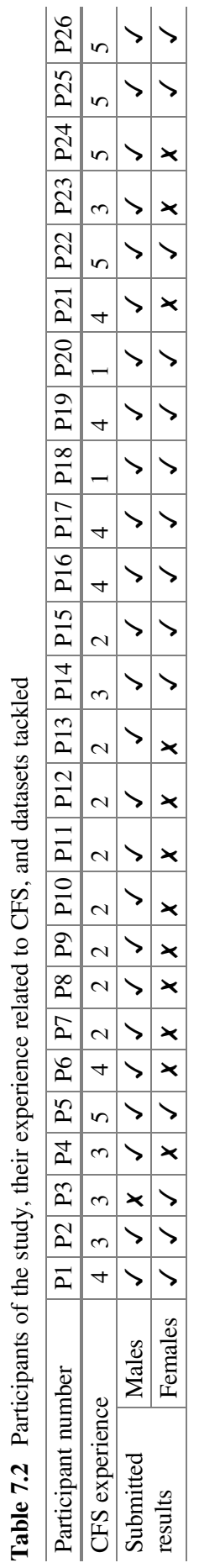


Table 7.3 Summarization of computer-aided semiautomatic 3D-2D superimposition (CAs3DS) approaches that participated in the study

\begin{tabular}{l|l|l|l}
\hline $\begin{array}{l}\text { Participant } \\
\text { number and } \\
\text { global } \\
\text { performance }\end{array}$ & $\begin{array}{l}\text { Software and } \\
\text { equipment }\end{array}$ & Skull-face overlay & Decision making \\
\hline $\begin{array}{l}\text { P2 } \\
\text { Both datasets }\end{array}$ & Face2Skul1TM & $\begin{array}{l}\text { Automatic SFO by matching } \\
\text { cranial and facial landmarks } \\
\text { (manually located). Manual } \\
\text { refinement of the overlay when } \\
\text { needed. }\end{array}$ & $\begin{array}{l}\text { Followed guideline and } \\
\text { criteria proposed in Austin- } \\
\text { Smith and Maples (1994), } \\
\text { Yoshino (2012), Wilkinson } \\
\text { (2004). }\end{array}$ \\
\hline $\begin{array}{l}\text { P19 } \\
\text { Both datasets }\end{array}$ & 3D-TADD & $\begin{array}{l}\text { Used 3D-TADDsoftware to } \\
\text { scale the photograph and posi- } \\
\text { tion the 3D model. }\end{array}$ & $\begin{array}{l}\text { Morphological and landmark } \\
\text { assessment. } \\
\text { Anatomical points and con- } \\
\text { tours of the head, the middle } \\
\text { and lower part of the face, } \\
\text { eyebrows, ears lobes, the line } \\
\text { between the lips, the wings of } \\
\text { the nose and supramental } \\
\text { furrow are automatically } \\
\text { detected. Manual refinement } \\
\text { of points and contours when } \\
\text { needed. }\end{array}$ \\
\hline
\end{tabular}

performances were obtained by P26 (88.30\%) and P18 (87.69\%). While the first followed video superimposition approach, the second employed computer 3D-2D software. Again, a morphological approach was the key aspect, leading their skull-face relationship assessment. From these rates, participants' performance decreases almost linearly until the worst results by P23, who based both the SFO and decision making in a landmark comparison.

Looking deeply at the individual performance, it is quite obvious that higher rates of true negatives were achieved in comparison to true positives. Just focusing on those participants who carried out the study over both male and females datasets (Table 7.9), we observe that four of them achieved true negative rates equal or higher than $90.00 \%$ (P2, P14, P18, P26). However, the same four participants achieved $80.00 \%, 50.00 \%, 62.50 \%$, and $66.67 \%$ of true positive, respectively. According to the average behavior considering the two datasets, the mean true positive rate is $52.63 \%$, while the mean true negative rate is $84.20 \%$. Consequently, the falsepositive rate is significantly lower than the false-negative rate. It is important to remark that the number of negative cases (50) is five times the number of positive cases (10).

Table 7.10 reports performance indicator of the different participants - methodologies grouped by the level of experience of the participant. There are not significant differences related to the level of experience of the participants. There is not a correlation between the performance and the level of experience of the practitioners. 
Table 7.4 Summarization of computer-aided manual 3D-2D superimposition (CAm3DS) approaches that participated in the study

\begin{tabular}{|c|c|c|c|c|}
\hline $\begin{array}{l}\text { Participant } \\
\text { number and } \\
\text { global } \\
\text { performance }\end{array}$ & $\begin{array}{l}\text { Software and } \\
\text { equipment }\end{array}$ & Skull-face overlay & $\begin{array}{l}\text { Anatomical } \\
\text { consistency } \\
\text { assessment criteria }\end{array}$ & Observation \\
\hline $\begin{array}{l}\text { P4 } \\
\text { Male dataset } \\
94.29 \%\end{array}$ & $\begin{array}{l}\text { Freeform Model- } \\
\text { ling Plus } \\
\text { Phantom }{ }^{\circledR} \text { Desk- } \\
\text { top }{ }^{\mathrm{TM}} \text { Haptic } \\
\text { Device } \\
\text { Adobe } \\
\text { Photoshop } \\
\text { Wacom tablet }\end{array}$ & $\begin{array}{l}\text { The cranium was } \\
\text { orientated first in a } \\
\text { trial and error } \\
\text { manner, by means } \\
\text { of moving and } \\
\text { rotating the stylus } \\
\text { of the haptic } \\
\text { device. Starting } \\
\text { points for the } \\
\text { alignment were } \\
\text { eyes/orbits in con- } \\
\text { junction with } \\
\text { either the maxil- } \\
\text { lary teeth, if visi- } \\
\text { ble, or the nasal } \\
\text { bridge. } \\
\text { Follow "fuzzy } \\
\text { landmarks" and } \\
\text { morphology for } \\
\text { orientation. The } \\
\text { mandible was ori- } \\
\text { entated in compli- } \\
\text { ance with the } \\
\text { facial expression } \\
\text { and the limits of a } \\
\text { physiologically } \\
\text { natural position. }\end{array}$ & $\begin{array}{l}\text { The resulting } \\
\text { images were then } \\
\text { imported into } \\
\text { Adobe Photoshop } \\
\text { and outline trac- } \\
\text { ings of the skull } \\
\text { and face were pro- } \\
\text { duced using } \\
\text { Wacom tablet. } \\
\text { Morphological } \\
\text { assessment based } \\
\text { on Austin-Smith } \\
\text { and Maples (1994), } \\
\text { Yoshino (2012), } \\
\text { Wilkinson (2004). }\end{array}$ & $\begin{array}{l}\text { The software has } \\
\text { two variables to } \\
\text { "play" with the } \\
\text { camera } \\
\text { projection. }\end{array}$ \\
\hline $\begin{array}{l}\text { P3 } \\
\text { Female } \\
\text { dataset } \\
91.43 \%\end{array}$ & $\begin{array}{l}\text { Freeform Model- } \\
\text { ling Plus } \\
\text { Phantom }{ }^{\circledR} \text { Desk- } \\
\text { top }{ }^{\mathrm{TM}} \text { Haptic } \\
\text { Device } \\
\text { Adobe } \\
\text { Photoshop } \\
\text { TM }\end{array}$ & $\begin{array}{l}\text { Manual orienta- } \\
\text { tion with software } \\
\text { and haptic device. } \\
\text { Anatomical } \\
\text { criteria of mor- } \\
\text { phological assess- } \\
\text { ment taken into } \\
\text { account during } \\
\text { this process. }\end{array}$ & $\begin{array}{l}\text { Morphological } \\
\text { assessment based } \\
\text { on (Wilkinson } \\
\text { 2006). }\end{array}$ & $\begin{array}{l}\text { Haptic device } \\
\text { used for moving } \\
\text { the mandible. }\end{array}$ \\
\hline $\begin{array}{l}\text { P18 } \\
\text { Both } \\
\text { datasets } \\
87.69 \%\end{array}$ & $\begin{array}{l}\text { Blender } \\
\text { Adobe } \\
\text { Photoshop }\end{array}$ & $\begin{array}{l}\text { Manual orienta- } \\
\text { tion using Blender } \\
\text { and Photoshop. }\end{array}$ & $\begin{array}{l}\text { Morphological } \\
\text { assessment. }\end{array}$ & \\
\hline $\begin{array}{l}\text { P14 } \\
\text { Both } \\
\text { datasets } \\
85.71 \%\end{array}$ & $\begin{array}{l}\text { Geomagic Stu- } \\
\text { dio10 } \\
\text { (3D software) } \\
\text { Adobe } \\
\text { Photoshop } \\
\text { CS6 }\end{array}$ & $\begin{array}{l}\text { Geomagic Studio } \\
\text { used to articulate } \\
\text { cranium and man- } \\
\text { dible. } \\
\text { Orientation of the } \\
\text { skull by trial and }\end{array}$ & $\begin{array}{l}\text { Landmark and } \\
\text { morphological } \\
\text { consistency } \\
\text { analysis. }\end{array}$ & $\begin{array}{l}\text { Consider first } \\
\text { biological profile, } \\
\text { asymmetries, and } \\
\text { pathologies. Give } \\
\text { special }\end{array}$ \\
\hline
\end{tabular}


Table 7.4 (continued)

\begin{tabular}{|c|c|c|c|c|}
\hline $\begin{array}{l}\text { Participant } \\
\text { number and } \\
\text { global } \\
\text { performance }\end{array}$ & $\begin{array}{l}\text { Software and } \\
\text { equipment }\end{array}$ & Skull-face overlay & $\begin{array}{l}\text { Anatomical } \\
\text { consistency } \\
\text { assessment criteria }\end{array}$ & Observation \\
\hline & & $\begin{array}{l}\text { error manipulation } \\
\text { of the 3D skull } \\
\text { model using } \\
\text { Photoshop }\end{array}$ & & $\begin{array}{l}\text { consideration to } \\
\text { teeth comparison. }\end{array}$ \\
\hline $\begin{array}{l}\text { P20 } \\
\text { Male dataset } \\
81.66 \%\end{array}$ & $\begin{array}{l}\text { Autodesk 3D } \\
\text { Studio MAX } \\
\text { Photoshop } \\
\text { CS6 }\end{array}$ & $\begin{array}{l}\text { Orientation (yaw, } \\
\text { pitch and roll) set- } \\
\text { ting in the same } \\
\text { plane porion, tra- } \\
\text { gus, Whitnall's } \\
\text { tubercle, and } \\
\text { ectocanthion } \\
\text { (Fenton et al. } \\
\text { 2008). }\end{array}$ & $\begin{array}{l}\text { Morphological } \\
\text { (outlines) and } \\
\text { landmark matching } \\
\text { assessment. }\end{array}$ & $\begin{array}{l}\text { Asymmetries are } \\
\text { key signs for } \\
\text { individualization. }\end{array}$ \\
\hline $\begin{array}{l}\text { P21 } \\
\text { Male dataset } \\
81.82 \%\end{array}$ & $\begin{array}{l}\text { Adobe } \\
\text { Photoshop }\end{array}$ & $\begin{array}{l}\text { Both 3D model } \\
\text { and AM photo } \\
\text { oriented and } \\
\text { resized in } \\
\text { Photoshop. } \\
\text { Separate use of } \\
\text { cranium and } \\
\text { mandible. }\end{array}$ & $\begin{array}{l}\text { Morphological and } \\
\text { landmark } \\
\text { assessment. }\end{array}$ & \\
\hline $\begin{array}{l}\text { P5 } \\
\text { Both } \\
\text { datasets } \\
80.88 \%\end{array}$ & $\begin{array}{l}\text { Adobe } \\
\text { Photoshop TM } \\
\text { CS3. } \\
\text { 3D Max Studio } \\
2011\end{array}$ & $\begin{array}{l}\text { Orientation and } \\
\text { overlay achieved } \\
\text { using software } \\
\text { tools. Process } \\
\text { guided by recom- } \\
\text { mendations pro- } \\
\text { posed in Lan and } \\
\text { Cai (1993). Use of } \\
\text { morphometric } \\
\text { planes, and land- } \\
\text { marks from Mar- } \\
\text { tin and } \\
\text { Saller (1966). }\end{array}$ & $\begin{array}{l}\text { Recommendations } \\
\text { by Lan and Cai } \\
\text { (1993). Morpho- } \\
\text { logical assessment. }\end{array}$ & \\
\hline $\begin{array}{l}\text { P1 } \\
\text { Both } \\
\text { datasets } \\
79.10 \%\end{array}$ & $\begin{array}{l}\text { RapidForm } 2006 \\
\text { Adobe } \\
\text { Photoshop }^{\mathrm{TM}}\end{array}$ & $\begin{array}{l}\text { 3D skull model } \\
\text { oriented by simul- } \\
\text { taneous view of } \\
\text { the model and the } \\
\text { AM photo. } \\
\text { Resize of the } \\
\text { image according } \\
\text { to cranial and } \\
\text { facial landmarks. }\end{array}$ & $\begin{array}{l}\text { Followed criteria } \\
\text { described in } \\
\text { Navarro- } \\
\text { Merino (2011). }\end{array}$ & \\
\hline $\begin{array}{l}\text { P17 } \\
\text { Both }\end{array}$ & $\begin{array}{l}\text { Craniofacial cor- } \\
\text { respondence } \\
\text { analysis program }\end{array}$ & $\begin{array}{l}\text { The program rep- } \\
\text { resents the algo- } \\
\text { rithm of }\end{array}$ & \multicolumn{2}{|c|}{$\begin{array}{l}\text { The program of craniofacial correspon- } \\
\text { dence based on the data on soft facial } \\
\text { tissue thickness and on the analysis of }\end{array}$} \\
\hline
\end{tabular}


Table 7.4 (continued)

\begin{tabular}{|c|c|c|c|c|}
\hline $\begin{array}{l}\text { Participant } \\
\text { number and } \\
\text { global } \\
\text { performance }\end{array}$ & $\begin{array}{l}\text { Software and } \\
\text { equipment }\end{array}$ & Skull-face overlay & $\begin{array}{l}\text { Anatomical } \\
\text { consistency } \\
\text { assessment criteria }\end{array}$ & Observation \\
\hline $\begin{array}{l}\text { datasets } \\
77.19 \%\end{array}$ & $\begin{array}{l}\text { (in-house } \\
\text { software) }\end{array}$ & $\begin{array}{l}\text { transformations } \\
\text { from dimensional } \\
\text { and descriptive } \\
\text { traits of a skull } \\
\text { into the } \\
\text { corresponding } \\
\text { parameters of } \\
\text { the face. }\end{array}$ & \multicolumn{2}{|c|}{$\begin{array}{l}\text { relationships between facial and skull } \\
\text { features, correlative and regression } \\
\text { analysis of the facial and skull features, } \\
\text { as well as a descriptive analysis of } \\
\text { indexes and variations of categorical } \\
\text { and quantitative characteristics. }\end{array}$} \\
\hline $\begin{array}{l}\text { P15 } \\
\text { Both } \\
\text { datasets } \\
76.81 \%\end{array}$ & $\begin{array}{l}\text { Geomagic Studio } \\
\text { software 3D } \\
\text { Rugle }\end{array}$ & $\begin{array}{l}\text { The 3Dscan is } \\
\text { rotated manually } \\
\text { (using 3D Rugle) } \\
\text { through all possi- } \\
\text { ble axes (X, } \\
\text { YandZ) to Frank- } \\
\text { fort horizontal } \\
\text { plane. The orien- } \\
\text { tation of the skull } \\
\text { is then electroni- } \\
\text { cally realigned so } \\
\text { that the anatomi- } \\
\text { cal position } \\
\text { becomes the } \\
\text { starting position. }\end{array}$ & $\begin{array}{l}\text { Morphological and } \\
\text { landmark } \\
\text { assessment. }\end{array}$ & $\begin{array}{l}\text { Geomagic is also } \\
\text { used to complete } \\
\text { the mandible } \\
\text { articulation. } \\
\text { Each photograph } \\
\text { is cropped and } \\
\text { resized to maxi- } \\
\text { mize the dimen- } \\
\text { sions of the face } \\
\text { in the frame. }\end{array}$ \\
\hline $\begin{array}{l}\text { P22 } \\
\text { Both } \\
\text { datasets } \\
71.43 \%\end{array}$ & $\begin{array}{l}\text { Claytools } \\
\text { Geomagic, Inc. } \\
\text { 3D Rugle } \\
\text { Adobe } \\
\text { Photoshop } \\
\text { Elements }\end{array}$ & $\begin{array}{l}\text { The obj 3D data } \\
\text { both of "cranium" } \\
\text { and "mandible" } \\
\text { were imported to a } \\
\text { 3D modeling tool, } \\
\text { Claytools } \\
\text { (Geomagic, Inc.). } \\
\text { A craniofacial } \\
\text { superimposition } \\
\text { was performed } \\
\text { with "3D Rugle" } \\
\text { software. These } \\
\text { are imported to an } \\
\text { Adobe Photoshop } \\
\text { Elements software } \\
\text { and superimposed } \\
\text { again. }\end{array}$ & $\begin{array}{l}\text { Morphological and } \\
\text { landmark assess- } \\
\text { ment (measure dis- } \\
\text { tances between } \\
\text { landmarks). }\end{array}$ & $\begin{array}{l}\text { A perspective } \\
\text { effect can be vir- } \\
\text { tually applied to } \\
\text { the 3D skull data } \\
\text { using this soft- } \\
\text { ware (3D Rugle). }\end{array}$ \\
\hline $\begin{array}{l}\text { P16 } \\
\text { Both } \\
\text { datasets } \\
67.24 \%\end{array}$ & $\begin{array}{l}\text { Rhinoceros } \bigcirc \text { or } \\
\text { Autodesk 3D } \\
\text { Studio@ software } \\
\text { Adobe } \\
\text { Photoshop } \\
\text { software }\end{array}$ & $\begin{array}{l}\text { Right size is } \\
\text { established from } \\
\text { inter-Whitnall's } \\
\text { malar tubercular } \\
\text { distance and/or } \\
\text { glabella-gnathion }\end{array}$ & $\begin{array}{l}\text { Morphological and } \\
\text { landmark } \\
\text { assessment. }\end{array}$ & $\begin{array}{l}\text { Generally do not } \\
\text { use 3D laser scan, } \\
\text { because partici- } \\
\text { pants have access } \\
\text { to a CT-scan with } \\
0.5 \mathrm{~mm} \text { isotropic }\end{array}$ \\
\hline
\end{tabular}


Table 7.4 (continued)

\begin{tabular}{l|l|l|l|l}
\hline $\begin{array}{l}\text { Participant } \\
\text { number and } \\
\text { global } \\
\text { performance }\end{array}$ & $\begin{array}{l}\text { Software and } \\
\text { equipment }\end{array}$ & Skull-face overlay & $\begin{array}{l}\text { Anatomical } \\
\text { consistency } \\
\text { assessment criteria }\end{array}$ & Observation \\
\hline & & $\begin{array}{l}\text { distance. } \\
\text { Orientation is } \\
\text { established } \\
\text { matching } \\
\text { Whitnall's malar } \\
\text { tubercles-porion, } \\
\text { where possible. } \\
\text { Superimposition } \\
\text { based on shapes. } \\
\text { Landmarks help } \\
\text { guiding the } \\
\text { process }\end{array}$ & $\begin{array}{l}\text { voxel that helps } \\
\text { in obtaining a } \\
\text { very anatomi- } \\
\text { cally detailed 3D } \\
\text { image. }\end{array}$ \\
\hline $\begin{array}{l}\text { P23 } \\
\text { Male dataset }\end{array}$ & $\begin{array}{l}\text { Geomagic Studio } \\
\text { software } \\
\text { 3D Studio Max } \\
\text { software }\end{array}$ & $\begin{array}{l}\text { Landmark-based } \\
\text { orientation fol- } \\
\text { lowing Gordon } \\
\text { and Steyn (2012). } \\
\text { sam }\end{array}$ & $\begin{array}{l}\text { Landmark-based } \\
\text { consistency analy- } \\
\text { sis following } \\
\text { Gordon and } \\
\text { Steyn (2012). }\end{array}$ & $\begin{array}{l}\text { 0, } \\
\text { agreements of } \\
\text { landmarks are } \\
\text { considered a pos- } \\
\text { itive match. 3 or } \\
\text { more a consid- } \\
\text { ered a negative } \\
\text { match. }\end{array}$ \\
\hline
\end{tabular}

While the participants who achieve higher rates of correct decisions are in category 3 (84.68\%), those generating lower results are, surprisingly, category four, together with category two grouped participants with the lowest performance $(75.00 \%$ and $74.32 \%$, respectively).

Finally, Table 7.11 depicts the overall accuracy according to the technological approach used by each participant. In overall, the approach followed by Participants 2, 3 (CAm3DS approach) and 24, 25, and 26 (CAmVS approach) is the most accurate $(88.49 \%$ and $84.56 \%$, respectively). These technological approaches represent the past and the future of the CFS technological development.

\subsubsection{Set of Criteria for Assessing the Skull-Face Overlay Relationship}

With all the data generated, some of the most representative experts in craniofacial identification joined in a discussion intended to identify and agree on the most important issues that have to be considered to properly employ the CFS technique. Tables 7.12, 7.13, 7.14, and 7.15 depict the identification of a set of common criteria for assessing the skull-face correspondence. 
Table 7.5 Summarization of computer-aided manual video superimposition (CAmVS) approaches that participated in the study

\begin{tabular}{|c|c|c|c|}
\hline $\begin{array}{l}\text { Participant } \\
\text { number and } \\
\text { global } \\
\text { performance }\end{array}$ & $\begin{array}{l}\text { Software and } \\
\text { equipment }\end{array}$ & Skull-face overlay & Decision making \\
\hline $\begin{array}{l}\text { P24 } \\
\text { Mala dataset } \\
80.00 \%\end{array}$ & $\begin{array}{l}\text { Digital video } \\
\text { mixer, digital } \\
\text { video camera, and } \\
\text { screen monitor }\end{array}$ & $\begin{array}{l}\text { The orientation was done by } \\
\text { aligning: Whitnall's tubercle } \\
\text { with ectocanthions; external } \\
\text { auditory meatus with the tra- } \\
\text { gus; vertical midline of the } \\
\text { face using the glabella, } \\
\text { nasion, anterior nasal spine, } \\
\text { prosthion, menton, and } \\
\text { pogonion. } \\
\text { The size was adjusted taking } \\
\text { soft tissue depth into } \\
\text { consideration. }\end{array}$ & $\begin{array}{l}\text { First, the correlation of the } \\
\text { shape characteristics } \\
\text { between facial skeleton and } \\
\text { face in the photograph was } \\
\text { compared. } \\
\text { Then, morphological } \\
\text { assessment was performed. }\end{array}$ \\
\hline $\begin{array}{l}\text { P25 } \\
\text { Both } \\
\text { datasets } \\
83.33 \%\end{array}$ & $\begin{array}{l}\text { Digital video } \\
\text { mixer, digital } \\
\text { video camera, and } \\
\text { screen monitor } \\
\text { AVerMedia TV } \\
\text { Series Product }\end{array}$ & $\begin{array}{l}\text { Skull: (1) orientated on an } \\
\text { own-made support enabling } \\
\text { rotation in three planes; } \\
\text { (2) zoomed in/out manually } \\
\text { by video camera to obtain } \\
\text { corresponding size; } \\
\text { (3) rotated manually to } \\
\text { obtain best position } \\
\text { according to vertical (gla- } \\
\text { bella-nasion-prosthion), hor- } \\
\text { izontal (ectocanthion- } \\
\text { ectocanthion and porion- } \\
\text { porion, when available) and } \\
\text { anteroposterior (prosthion- } \\
\text { porion) planes. }\end{array}$ & $\begin{array}{l}\text { Morphological assessment } \\
\text { of landmarks and outlines. }\end{array}$ \\
\hline $\begin{array}{l}\text { P26 } \\
\text { Both } \\
\text { datasets } \\
88.13 \%\end{array}$ & $\begin{array}{l}\text { Adobe } \\
\text { Photoshop }{ }^{\mathrm{TM}} \text { CS3 } \\
\text { Video system } \\
\text { (Wilkinson 2004) }\end{array}$ & $\begin{array}{l}\text { Follow the procedure } \\
\text { described in Jayaprakash } \\
\text { et al. (2001) }\end{array}$ & $\begin{array}{l}\text { Asses traits indicated in } \\
\text { Jayaprakash et al. (2001). }\end{array}$ \\
\hline
\end{tabular}

Table 7.6 Summarization of computer-aided manual photo superimposition (CAm3PS) approaches that participated in the study

\begin{tabular}{|c|c|c|c|c|}
\hline $\begin{array}{l}\text { Participant } \\
\text { number and } \\
\text { global } \\
\text { performance }\end{array}$ & $\begin{array}{l}\text { Software and } \\
\text { equipment }\end{array}$ & Skull-face overlay & Decision making & Observation \\
\hline $\begin{array}{l}\text { P6-P13 } \\
68.57- \\
82.35 \% \\
\text { Male dataset }\end{array}$ & $\begin{array}{l}\text { Adobe } \\
\text { Photoshop } \\
\text { or } \\
\text { GNU GIMP. } \\
\text { Dennis } \\
\text { Slice's } \\
\text { PhotoMatch }\end{array}$ & $\begin{array}{l}\text { Photoshop to resize images. } \\
\text { Then, PhotoMatch to } \\
\text { manipulate transparency, } \\
\text { scaling, and rotation to } \\
\text { match as many points as } \\
\text { possible. }\end{array}$ & $\begin{array}{l}\text { Special signs: } \\
\text { crowding, bro- } \\
\text { ken nasal bones, } \\
\text { asymmetry, etc. }\end{array}$ & $\begin{array}{l}\text { Do not use the } \\
\text { 3D data but } \\
\text { just the PM } \\
\text { skull photos. } \\
\text { Limited ori- } \\
\text { entation and } \\
\text { alignment } \\
\text { capabilities. }\end{array}$ \\
\hline
\end{tabular}

Eight different participants but all of them following the same methodology 
z

Z

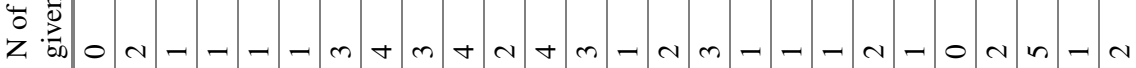

4

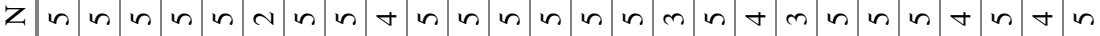

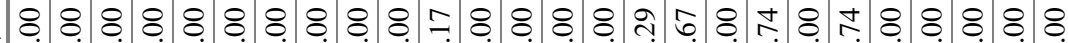
在

ฮี

$\vec{b}_{00}$

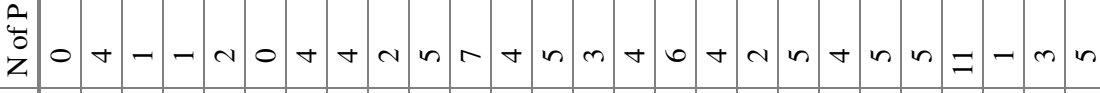

$\mathrm{z}$

药

\& \& \& \& \& \& \& \& \& \& Z

Z

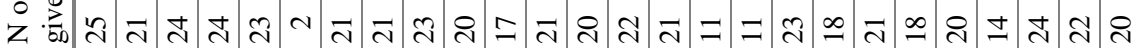

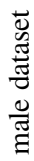

$z$

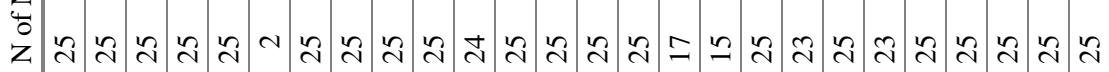
8.8.8.8.8.8.8.8.8.8.

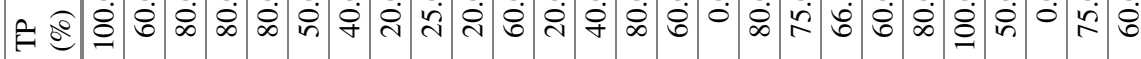

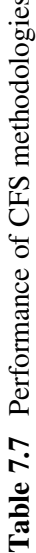

ขี

कू

कै

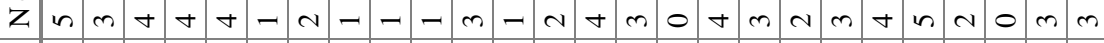

范

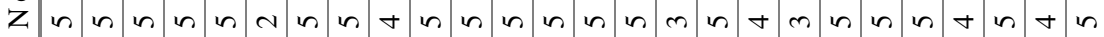
Z 유 శ్లిశ్లిల్లి 

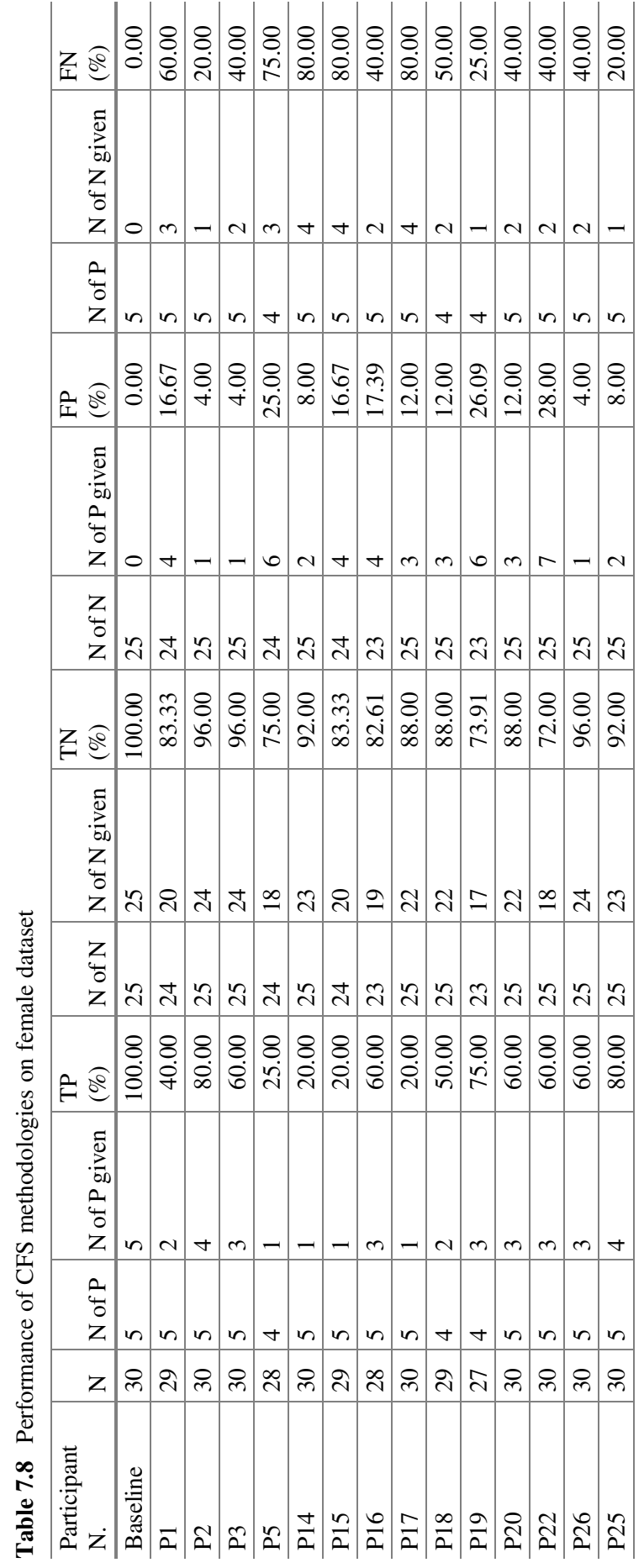


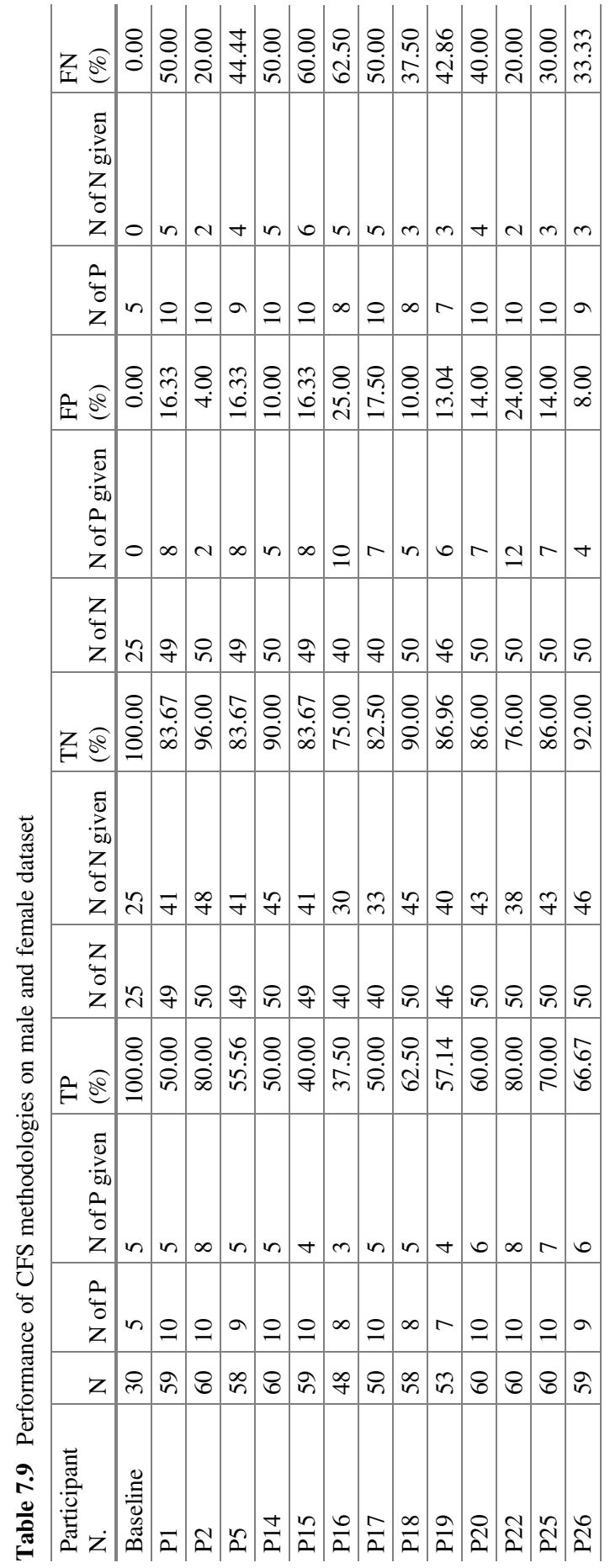


Table 7.10 Overall accuracy of CFS grouped by level of experience of the participant

\begin{tabular}{|c|c|c|c|c|c|c|c|}
\hline \multirow[b]{2}{*}{ Participants } & \multirow[b]{2}{*}{ Sample } & \multirow{2}{*}{$\begin{array}{l}\text { Correct } \\
\text { decisions }\end{array}$} & \multirow{2}{*}{$\begin{array}{l}\text { Ground } \\
\text { truth }\end{array}$} & \multicolumn{2}{|c|}{ Decision } & \multicolumn{2}{|c|}{ Decision (\%) } \\
\hline & & & & Positive & Negative & Positive & Negative \\
\hline \multirow[t]{2}{*}{ All } & \multirow[t]{2}{*}{ Global } & \multirow[t]{2}{*}{$78.99 \%$} & Positive & 100 & 90 & 52.63 & 47.37 \\
\hline & & & Negative & 152 & 810 & 15.80 & 84.20 \\
\hline \multirow[t]{2}{*}{1} & \multirow[t]{2}{*}{ Global } & \multirow[t]{2}{*}{$81.88 \%$} & Positive & 14 & 9 & 60.87 & 39.13 \\
\hline & & & Negative & 16 & 99 & 13.91 & 86.09 \\
\hline \multirow[t]{2}{*}{2} & \multirow[t]{2}{*}{ Global } & \multirow[t]{2}{*}{$74.32 \%$} & Positive & 15 & 33 & 31.25 & 68.75 \\
\hline & & & Negative & 43 & 205 & 17.34 & 82.66 \\
\hline \multirow[t]{2}{*}{3} & \multirow[t]{2}{*}{ Global } & \multirow[t]{2}{*}{$84.68 \%$} & Positive & 22 & 12 & 64.71 & 35.29 \\
\hline & & & Negative & 20 & 155 & 11.43 & 88.57 \\
\hline \multirow[t]{2}{*}{4} & \multirow[t]{2}{*}{ Global } & \multirow[t]{2}{*}{$75.00 \%$} & Positive & 18 & 14 & 56.25 & 43.75 \\
\hline & & & Negative & 34 & 126 & 21.25 & 78.75 \\
\hline \multirow[t]{2}{*}{5} & \multirow[t]{2}{*}{ Global } & \multirow[t]{2}{*}{$80.75 \%$} & Positive & 31 & 22 & 58.49 & 41.51 \\
\hline & & & Negative & 39 & 225 & 14.77 & 85.23 \\
\hline
\end{tabular}

Table 7.11 Overall accuracy of CFS grouped by technological approach employed

\begin{tabular}{|c|c|c|c|c|c|c|c|}
\hline \multirow[b]{2}{*}{ Participants N. } & \multirow{2}{*}{$\begin{array}{l}\text { Tech. } \\
\text { approach }\end{array}$} & \multirow{2}{*}{$\begin{array}{l}\text { Correct } \\
\text { decision }\end{array}$} & \multirow{2}{*}{$\begin{array}{l}\text { Ground } \\
\text { truth }\end{array}$} & \multicolumn{2}{|l|}{ Decision } & \multicolumn{2}{|c|}{ Decision $(\%)$} \\
\hline & & & & Positive & Negative & Positive & Negative \\
\hline \multirow[t]{2}{*}{ P2, P19 } & \multirow[t]{2}{*}{ CAs3DS } & \multirow[t]{2}{*}{$88.49 \%$} & Positive & 12 & 5 & 70.59 & 29.41 \\
\hline & & & Negative & 8 & 88 & 8.33 & 91.67 \\
\hline \multirow{2}{*}{$\begin{array}{l}\mathrm{P} 1, \mathrm{P} 3, \mathrm{P} 4, \mathrm{P} 5 \\
\mathrm{P} 14, \mathrm{P} 15, \mathrm{P} 16, \\
\mathrm{P} 17, \mathrm{P} 18, \mathrm{P} 20 \\
\mathrm{P} 21, \mathrm{P} 22, \mathrm{P} 23\end{array}$} & \multirow[t]{2}{*}{ CAm3DS } & \multirow[t]{2}{*}{$78.90 \%$} & Positive & 62 & 47 & 56.88 & 43.12 \\
\hline & & & Negative & 92 & 458 & 16.73 & 83.27 \\
\hline \multirow[t]{2}{*}{$\mathrm{P} 24, \mathrm{P} 25, \mathrm{P} 26$} & \multirow[t]{2}{*}{ CAmVS } & \multirow[t]{2}{*}{$84.56 \%$} & Positive & 13 & 11 & 54.17 & 45.83 \\
\hline & & & Negative & 12 & 133 & 8.28 & 91.72 \\
\hline \multirow{2}{*}{$\begin{array}{l}\text { P6, P7, P8, P9, } \\
\text { P10, P11, P12, } \\
\text { P13 }\end{array}$} & \multirow[t]{2}{*}{ CAmPS } & \multirow[t]{2}{*}{$74.06 \%$} & Positive & 12 & 24 & 33.33 & 66.67 \\
\hline & & & Negative & 31 & 145 & 17.61 & 82.39 \\
\hline
\end{tabular}

\subsection{Study on the Criteria Assessing Skull-Face Correspondence in Craniofacial Superimposition}

The MEPROCS consortium designed the current study, which aims to analyze the subjectivity and discriminative power of the different criteria (defined in the previous section of this chapter) for assessing the skull-face correspondence either proposed in the literature or by any of the MEPROCS partners.

\subsubsection{Experimental Study}

The dataset used in this study consisted of 18 different CFS problems, some of them composed of more than one image of the same subject, 24 SFOs in total. 
Table 7.12 Marking lines used to analyze anatomical consistency

\begin{tabular}{|c|c|c|c|}
\hline No. & Criteria & View & $\begin{array}{l}\text { Do you } \\
\text { employ } \\
\text { it? }\end{array}$ \\
\hline $\begin{array}{l}\text { Group } \\
1\end{array}$ & Superimposition of the following marking lines (face-skull): & $\begin{array}{l}\text { Frontal } \\
\text { (F) }\end{array}$ & - \\
\hline 1.1 & $\begin{array}{l}\text { excanthion-excanthion }(\mathrm{A}) \text { - ectocanthion-ectoconchion }\left(\mathrm{A}^{\prime}\right) \\
\text { Ectocanthion line }\end{array}$ & $\mathrm{F}$ & \\
\hline 1.2 & $\begin{array}{l}\text { glabella-gnathion }(\mathrm{B}) \text { - glabella-gnathion }\left(\mathrm{B}^{\prime}\right) \\
\text { Frontal central line }\end{array}$ & $\mathrm{F}$ & \\
\hline 1.3 & $\begin{array}{l}\text { superciliary-superciliary }(C) \text { - superciliary-superciliary }\left(C^{\prime}\right) \\
\text { Supraciliary line }\end{array}$ & $\mathrm{F}$ & \\
\hline 1.4 & $\begin{array}{l}\text { horizontal line at subnasal }(\mathrm{D}) \text { - horizontal line at nasospinal } \\
\left(\mathrm{D}^{\prime}\right) \\
\text { Subnasal line }\end{array}$ & $\mathrm{F}$ & \\
\hline 1.5 & $\begin{array}{l}\text { cheilion-cheilion }(\mathrm{E}) \text { - occusal line/horizontal line at } \\
\text { stomion }\left(\mathrm{E}^{\prime}\right) \\
\text { Cheilion line }\end{array}$ & $\mathrm{F}$ & \\
\hline 1.6 & $\begin{array}{l}\text { horizontal line at gnathion }(\mathrm{H})-\text { horizontal line at } \\
\text { gnathion }\left(\mathrm{H}^{\prime}\right) \\
\text { Gnathion line }\end{array}$ & $\mathrm{F}$ & \\
\hline 1.7 & $\begin{array}{l}\text { endocanthion-cheilion }(\mathrm{G}) \text { - entocanthion-caninion }\left(\mathrm{G}^{\prime}\right) \\
\text { [right] } \\
\text { Entocanthion vertical line }\end{array}$ & $\mathrm{F}$ & \\
\hline 1.8 & $\begin{array}{l}\text { endocanthion-cheilion }(G) \text { - entocanthion-caninion }\left(G^{\prime}\right)[\text { left }] \\
\text { Entocanthion vertical line }\end{array}$ & $\mathrm{F}$ & \\
\hline
\end{tabular}

Skull 3D models were obtained from patients whose head has been scanned with a cone beam computed tomography (CBCT).

The skull 3D models employed suffer from two different problems. Firstly, we only have part of the whole skull, from the jaw to the upper orbits, without including parietal, occipital, and part of the temporal areas. Secondly, the 3D model is, to a greater or lesser extent, noisy and may not be accurately represented. All those problems have the same origin: the use of CBCTs instead of CTs. High-resolution CTs together with photographs of the patient/volunteer were not accessible. However, one benefit of the CBCT data is that the volunteer was upright rather than supine, as commonly recorded for CT scanning.

Frontal and lateral photographs were taken of the same patients to create a set of positive cases, while other people with similar facial geometry were photographed in order to compose a set of negative cases. Nine of eighteen cases were positives and the other nine were negatives. Twelve of the photographs were lateral and twelve were frontal, half of them belonging to positive cases and the other half to negative cases.

The participants were provided the same 24 SFOs as a single image with four different layers: facial photograph with and without landmarks and skull projection with and without landmarks. 
Table 7.13 Landmarks used to evaluate soft tissue thickness

\begin{tabular}{|c|c|c|c|}
\hline No. & Criteria & View & $\begin{array}{l}\text { Do you } \\
\text { employ } \\
\text { it? }\end{array}$ \\
\hline $\begin{array}{l}\text { Group } \\
2\end{array}$ & $\begin{array}{l}\text { Overall consistency of the facial outline and facial soft } \\
\text { tissue thickness at the following pair of homologous } \\
\text { points (skull-face): }\end{array}$ & $\begin{array}{l}\text { Frontal }(\mathrm{F}) / \\
\text { Lateral-Oblique } \\
(\mathrm{L}-\mathrm{O})\end{array}$ & - \\
\hline 2.1 & gnathion - menton & $\mathrm{F}$ & \\
\hline 2.2 & gnathion - menton & $\mathrm{L}-\mathrm{O}$ & \\
\hline 2.3 & nasion - nasion & $\mathrm{L}-\mathrm{O}$ & \\
\hline 2.4 & glabella - glabella & $\mathrm{L}-\mathrm{O}$ & \\
\hline 2.5 & subespinale - subnasale & $\mathrm{L}-\mathrm{O}$ & \\
\hline 2.6 & pogonion - pogonion & $\mathrm{L}-\mathrm{O}$ & \\
\hline 2.7 & rhinion - rhinion & $\mathrm{L}-\mathrm{O}$ & \\
\hline 2.8 & gonion - gonion & $\mathrm{F}$ & \\
\hline 2.9 & zygion - zygion & $\mathrm{F}$ & \\
\hline 2.10 & trichion - trichion & $\mathrm{L}-\mathrm{O}$ & \\
\hline 2.11 & $\begin{array}{l}\text { The minimal tissue thickness all along the contour is } \\
\text { considered from the point of view of its symmetry by } \\
\text { side for evaluating the match as acceptable. }\end{array}$ & & \\
\hline 2.12 & Ant lacrimal crest - medial canthus & $\mathrm{F} / \mathrm{O}$ & \\
\hline 2.13 & Prosthion - supra-labiale & F/L-O & \\
\hline 2.14 & Alare - Alare & $\mathrm{F} / \mathrm{L}-\mathrm{O}$ & \\
\hline 2.15 & Gonion - gonion & $\mathrm{L}$ & \\
\hline 2.16 & Zygomaxilare - malare & $\mathrm{L}$ & \\
\hline 2.17 & Whitnall's tubercle - lateral canthus & $\mathrm{F} / \mathrm{L}-\mathrm{O}$ & \\
\hline 2.18 & occlusion mid-incisors - stomion & F/L-O & \\
\hline 2.19 & porion - tragion & $\mathrm{L}-\mathrm{O}$ & \\
\hline 2.20 & crista conchalis - supra-alare & $\mathrm{F} / \mathrm{L}-\mathrm{O}$ & \\
\hline 2.21 & intercanine distance $(75 \%)$ - chelion & $\mathrm{F}$ & \\
\hline 2.22 & eyeball position - pupilare & $\mathrm{F}$ & \\
\hline 2.23 & supraorbitale - sag eyebrow & $\mathrm{F}$ & \\
\hline 2.24 & two tangents nasal - pronasale & $\mathrm{F} / \mathrm{L}-\mathrm{O}$ & \\
\hline 2.25 & 1st premolar/canine radiating line - chelion & F/L-O & \\
\hline 2.26 & mastoidale - subaurale & $\mathrm{L}-\mathrm{O}$ & \\
\hline 2.27 & infraorbital foramen - chelion & $\mathrm{F} / \mathrm{L}-\mathrm{O}$ & \\
\hline
\end{tabular}

For the sake of an objective analysis, it was important to focus the attention of the participants on the criteria for analyzing the skull and the face relationship only. This study should include both positive and negative SFOs. The procedure to obtain each type of SFO was different.

For positive cases, optimal SFOs were achieved using the following procedure. The DICOM images resulting from the CBCT machine were automatically processed to obtain the corresponding 3D face and 3D skull models. After positioning homologous points in both the 3D face model and the photograph, the former 
Table 7.14 Consistency of the bony and facial outlines/morphological curves

\begin{tabular}{|c|c|c|c|}
\hline No. & Criteria & View & $\begin{array}{l}\text { Do you } \\
\text { employ } \\
\text { it? }\end{array}$ \\
\hline $\begin{array}{l}\text { Group } \\
3\end{array}$ & $\begin{array}{l}\text { Overall consistency of the bony and facial outlines/ } \\
\text { morphological curves: }\end{array}$ & $\begin{array}{l}\text { Frontal(F)/ } \\
\text { Lateral-Oblique } \\
\text { (L-O) }\end{array}$ & - \\
\hline 3.1 & $\begin{array}{l}\text { The outline of the frontal bone follows the forehead } \\
\text { outline. }\end{array}$ & $\mathrm{L}-\mathrm{O}$ & \\
\hline 3.2 & $\begin{array}{l}\text { The skull and head height is similar (account for vari- } \\
\text { ation in soft tissue and distortion in the perception } \\
\text { created by presence of hair). }\end{array}$ & L-O & \\
\hline 3.3 & The width of the cranium fills forehead area of the face. & $\mathrm{F}$ & \\
\hline 3.4 & $\begin{array}{l}\text { The length of the skull from menton to bregma fits } \\
\text { within the face. }\end{array}$ & $\mathrm{F}$ & \\
\hline 3.5 & $\begin{array}{l}\text { The lateral line of the zygomatic bone matches the } \\
\text { outline of cheek. }\end{array}$ & $\mathrm{F}$ & \\
\hline 3.6 & The chin outline is consistent with the mental outline. & $\mathrm{L}-\mathrm{O}$ & \\
\hline 3.7 & The gonial outline follows the outline of jaw angle. & $\mathrm{L}-\mathrm{O}$ & \\
\hline 3.8 & $\begin{array}{l}\text { The outline of frontal process of the zygomatic bone } \\
\text { can be aligned with the process seen in the face. The } \\
\text { outline of the zygomatic arch can be fitted between the } \\
\text { skull and the face. (This criterion is more easily appre- } \\
\text { ciated in individuals with minimal soft tissue } \\
\text { thickness). }\end{array}$ & L-O & \\
\hline 3.9 & The arcus supraciliariaris follows supraorbital margin. & $\mathrm{L}-\mathrm{O}$ & \\
\hline 3.10 & $\begin{array}{l}\text { The temporal line is consistent with the outline of the } \\
\text { forehead (Sometimes the temporal line cannot be } \\
\text { distinguished). }\end{array}$ & $\mathrm{F}$ & \\
\hline 3.11 & $\begin{array}{l}\text { The outline of the face and the outline of the skull all } \\
\text { along the contour follow each other maintaining sym- } \\
\text { metrical flow by side. }\end{array}$ & F & \\
\hline 3.12 & $\begin{array}{l}\text { The outline of the nose in the face represented by shade } \\
\text { distribution follows the outline of the nasal bone in the } \\
\text { skull maintaining symmetrical flow by side. }\end{array}$ & F & \\
\hline 3.13 & $\begin{array}{l}\text { The asymmetries in the facial organs especially the nose } \\
\text { reveal consistency with the asymmetries in the organs } \\
\text { of the skull including the nasal structures. These include } \\
\text { 1. Asymmetries in the nasal area including the nasal } \\
\text { bone, piriform aperture, and nasal spine } \\
\text { 2. Asymmetries in the zygomatic area, especially the } \\
\text { extent of protrusion of the arch } \\
\text { 3. Asymmetries in the occlusal line caused by protrud- } \\
\text { ing or overriding anterior dentition reflected as } \\
\text { asymmetries in the corresponding part of the lip closure } \\
\text { line } \\
\text { 4. Asymmetries in the gonia }\end{array}$ & F & \\
\hline 3.14 & The arcus supraciliariaris follows supraorbital margin. & $\mathrm{F}$ & \\
\hline
\end{tabular}


Table 7.14 (continued)

\begin{tabular}{|c|c|c|c|}
\hline No. & Criteria & View & $\begin{array}{l}\text { Do you } \\
\text { employ } \\
\text { it? }\end{array}$ \\
\hline $\begin{array}{l}\text { Group } \\
3\end{array}$ & $\begin{array}{l}\text { Overall consistency of the bony and facial outlines/ } \\
\text { morphological curves: }\end{array}$ & $\begin{array}{l}\text { Frontal(F)/ } \\
\text { Lateral-Oblique } \\
\text { (L-O) }\end{array}$ & - \\
\hline 3.15 & $\begin{array}{l}\text { The outline of the of the nasal bones follows the outline } \\
\text { of the nose in the skull with minimal tissue thickness } \\
\text { allowance }\end{array}$ & $\mathrm{L}$ & \\
\hline 3.16 & $\begin{array}{l}\text { The sagittal outline of the nasal cartilage is the mirror } \\
\text { image of the contour of the pyriform aperture, relative } \\
\text { to Line №1 passing through the rhinion point (1) and } \\
\text { parallel to Line №2 joining the nasion(2) and the } \\
\text { prostion (3) anthropometric points. Line№1 splits the } \\
\text { entire nasal cartilage into two symmetric mirrored } \\
\text { halves: the protruding part of the nose cartilage is the } \\
\text { mirror image of the cartilage filling the pyriform aper- } \\
\text { ture of the cranium. }\end{array}$ & & \\
\hline 3.17 & Lateral nasal bulges. & $\mathrm{F}$ & \\
\hline 3.18 & Oblique line of the mandible. & $\mathrm{F}$ & \\
\hline 3.19 & Dental information (bony to bony consistency). & $\mathrm{F} / \mathrm{L}-\mathrm{O}$ & \\
\hline
\end{tabular}

was automatically projected onto the latter so as to obtain an ideal match. Then, the parameters originating from that match between the 3D face model and the photograph were applied to the 3D skull model, resulting in an objective and accurate SFO. The latter superimposition is considered a ground-truth SFO.

Figure 7.1 shows an overview of the whole ground-truth data creation process.

For negative cases, the SFOs were performed using Face2Skull ${ }^{\mathrm{TM}}$ software. An expert was asked to obtain the best possible SFO and to judge the skull-face relationship without being informed of the actual negative relationship to avoid biasing the SFO process.

For the criteria assessment study, 37 forensic experts were asked to indicate which specific criteria they are going to use for evaluating the 24 skull-face relationships. The criteria are organized in four groups according to the family criteria: lines (group 1), landmarks-soft tissue (group 2), outlines (group 3), and positional relationship (group 4). Group 1 is composed of 28 criteria, group 2 has 27 criteria, group 3 is a set of 19 criteria, and group 4 is made up of 21 criteria.

Forensic experts were asked to evaluate the skull-face correspondence following a systematic approach. For each SFO, the degree of consistency of all the criteria previously selected was indicated using the following values: 0 : not evaluable, 1: not match, 2: poor match, 3: doubtful match, 4: good match and 5: perfect match.

In order to avoid personal interpretations, MEPROCS partners assigned in advance (before giving the instructions to the participants) the value 0 to those criteria they considered unable to be visually checked due to the noisy nature of the image, the absence of the bony part, or the pose of the photograph. That was carried out for each single SFO case. 
Table 7.15 Positional relationship analyzed to assess anatomical consistency

\begin{tabular}{|c|c|c|c|}
\hline No. & Criteria & View & $\begin{array}{l}\text { Do you } \\
\text { employ } \\
\text { it? }\end{array}$ \\
\hline $\begin{array}{l}\text { Group } \\
4\end{array}$ & $\begin{array}{l}\text { Overall consistency positional relationships between } \\
\text { the skull and face: }\end{array}$ & $\begin{array}{l}\text { Frontal }(\mathrm{F}) / \\
\text { Lateral-Oblique } \\
(\mathrm{L}-\mathrm{O})\end{array}$ & - \\
\hline 4.1 & $\begin{array}{l}\text { The prosthion lies posterior to the anterior edge of the } \\
\text { upper lip. The occlusal and the lip closure line are } \\
\text { consistent. }\end{array}$ & $\mathrm{F}$ & \\
\hline 4.2 & $\begin{array}{l}\text { The lateral angle of the eye lies within the lateral wall } \\
\text { of the orbit. }\end{array}$ & L-O & \\
\hline 4.3 & $\begin{array}{l}\text { The lateral orbital margin at the Whinall's turbercle } \\
\text { matches or approximates the of the ectocathionposition }\end{array}$ & L-O & \\
\hline 4.4 & $\begin{array}{l}\text { The width and height of piriform aperture lie within the } \\
\text { borders of the nose. }\end{array}$ & $\mathrm{F}$ & \\
\hline 4.5 & $\begin{array}{l}\text { The stomion lies at the central incisors (at the } \\
\text { occusal line). }\end{array}$ & L-O & \\
\hline 4.6 & $\begin{array}{l}\text { The lateral margin of the piriform aperture matches or } \\
\text { approximates the alare. }\end{array}$ & L-O & \\
\hline 4.7 & $\begin{array}{l}\text { The stomion lies at the central incisors (incisal margin } \\
\text { of the upper incisors). }\end{array}$ & $\mathrm{F}$ & \\
\hline 4.8 & The nasion is higher than the nasal root. & L-O & \\
\hline 4.9 & $\begin{array}{l}\text { The prosthion lies posterior to the anterior edge of the } \\
\text { upper lip. The occlusal and the lip closure line are } \\
\text { consistent. }\end{array}$ & L-O & \\
\hline 4.10 & $\begin{array}{l}\text { The medial margin of orbit aligns and superimposes } \\
\text { with the endocanthion. }\end{array}$ & $\mathrm{F}$ & \\
\hline 4.11 & The nasion is higher than the nasal root. & $\mathrm{F}$ & \\
\hline 4.12 & $\begin{array}{l}\text { The Whitnall's tubercle aligns with the ectochantus on } \\
\text { the horizontal plane and,vertically, the ectochantus lies } \\
\text { medial to the tubercle. The orbital width is consistent } \\
\text { with the eye-slit width. }\end{array}$ & $\mathrm{F}$ & \\
\hline 4.13 & $\begin{array}{l}\text { The chelion lies between the canine and the first pre- } \\
\text { molar (at the occusal line). }\end{array}$ & $\mathrm{F}$ & \\
\hline 4.14 & $\begin{array}{l}\text { The porion aligns just posterior to the tragus, slightly } \\
\text { inferior to the crus of the helix. }\end{array}$ & L-O & \\
\hline 4.15 & $\begin{array}{l}\text { The lower margin of piriform aperture matches the } \\
\text { subnasale. }\end{array}$ & L-O & \\
\hline 4.16 & $\begin{array}{l}\text { The eyebrow generally follows the upper edge of the } \\
\text { orbit over the medial two-thirds. At lateral superior } \\
\text { one-third of the orbit, the eyebrow continues horizon- } \\
\text { tally as the orbital rim begins to curve inferiorly. }\end{array}$ & $\mathrm{F}$ & \\
\hline 4.17 & $\begin{array}{l}\text { The external auditory meatus opening lies medial to the } \\
\text { tragus of the ear. (Place a projecting marker at the ear } \\
\text { canal to assess this criterion more easily). }\end{array}$ & $\mathrm{F}$ & \\
\hline 4.18 & $\begin{array}{l}\text { The chelion lies between the canine and the first pre- } \\
\text { molar (at the occusal line). }\end{array}$ & L-O & \\
\hline
\end{tabular}


Table 7.15 (continued)

\begin{tabular}{l|l|l|l}
\hline No. & Criteria & View & $\begin{array}{l}\text { Do you } \\
\text { employ } \\
\text { it? }\end{array}$ \\
\hline $\begin{array}{l}\text { Group } \\
4\end{array}$ & $\begin{array}{l}\text { Overall consistency positional relationships between } \\
\text { the skull and face: }\end{array}$ & $\begin{array}{l}\text { Frontal (F)/ } \\
\text { Lateral-Oblique } \\
\text { (L-O) }\end{array}$ & - \\
\hline 4.19 & $\begin{array}{l}\text { The anterior nasal spine lies posterior to the base of the } \\
\text { nose near the most posterior portion of the lateral septal } \\
\text { cartilage. }\end{array}$ & L-O & L-O \\
\hline 4.20 & $\begin{array}{l}\text { Gonial flare in the skull and the postero-lateral jaw } \\
\text { angle outline in the face. }\end{array}$ & L-O & \\
\hline 4.21 & $\begin{array}{l}\text { Gonial flare in the skull and the postero-lateral jaw } \\
\text { prominence in the face. }\end{array}$ & F & \\
\hline
\end{tabular}

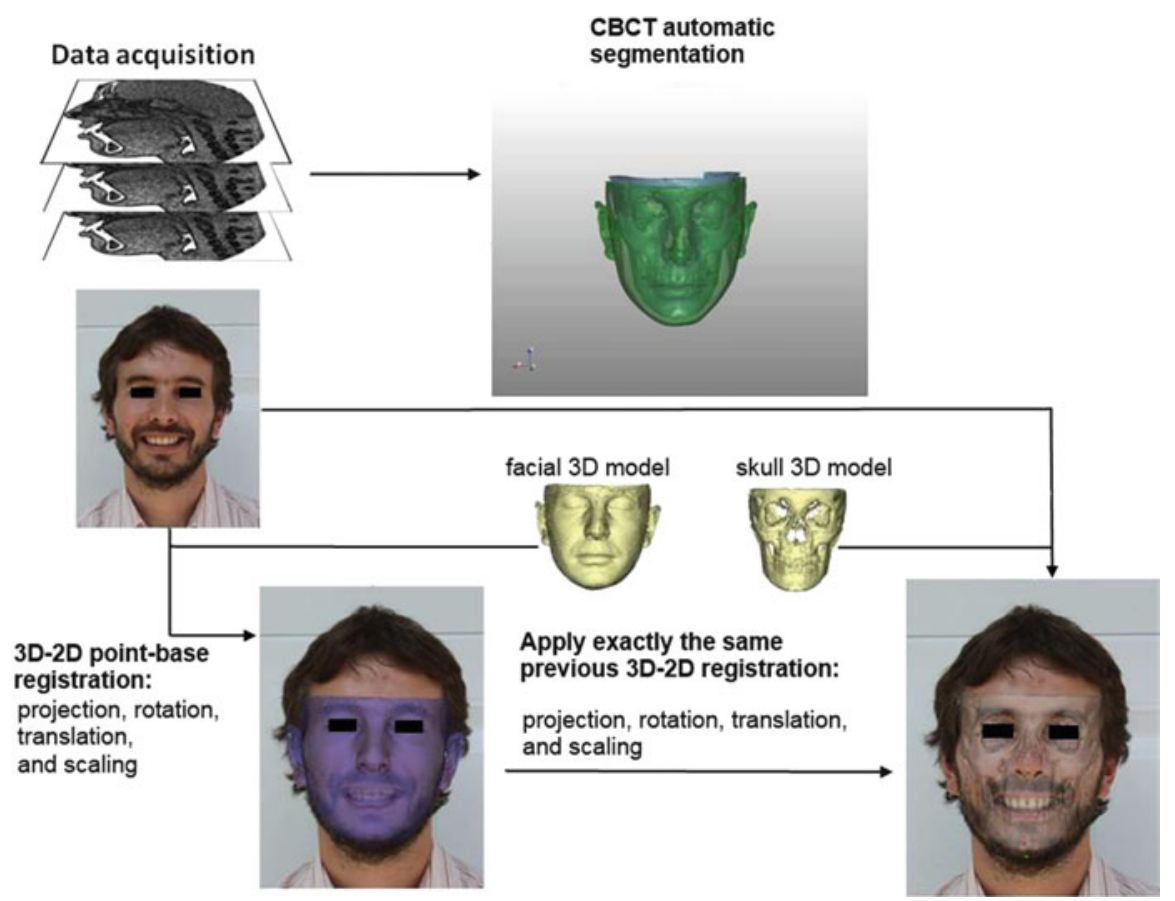

Fig. 7.1 Overview of the ground-truth data creation process

Finally, for each SFO case (and also for each CFS case when it implies more than one SFO), participants were asked to indicate the final identification decision according to the following scale: -3 : strong support of not being the same person, -2 : moderate support of not being the same person, -1 : limited support of not being the same person, 0 : not determined, +1 : limited support of being the same 
person, +2 : moderate support of being the same person, and +3 : strong support of being the same person. Therefore, the dataset is composed by:

The forensic expert, the specific SFO case and its state (positive or negative), the photograph of the SFO case (frontal or lateral pose), the criteria used by the expert in order to evaluate the corresponding SFO case, the family of the criteria, the degree of consistency of these latter criteria given by the expert ( 0 : not evaluable, 1 : not match, 2: poor match, 3: doubtful match, 4: good match and 5: perfect match), and the decision of the expert for the corresponding case ( -3 : strong support of not being the same person, -2 : moderate support of not being the same person, -1 : limited support of not being the same person, 0 : not determined, +1 : limited support of being the same person, +2 : moderate support of being the same person, and +3 : strong support of being the same person).

\subsubsection{Data Analysis}

We have developed three studies with the following characteristics:

1. According to the data employed:

(a) With all the data.

(b) Filtering (removing) the experts with a proficiency lower or equal than 0.5.

(c) Filtering (removing) the scenarios (SFO cases) with higher standard deviation (fourth quartile).

2. According to the view of the photographs: frontal versus lateral poses

3. According to the family of criteria: lines, landmarks-soft tissue, outlines, and positional relationship

The statistical analysis developed relied on several concepts that are introduced below together with an example:

- Cases with decision (CD): the cases in which the expert's decision is different from 0 (not undetermined)

- Expert proficiency: the proportion of cases with decision in which the expert evaluated the status of the case correctly

$$
\mathrm{EP}=\frac{\mathrm{TP}+\mathrm{TN}}{\mathrm{CD}}
$$

where TP is the number of positive cases with a positive decision and $\mathrm{TN}$ is the number of negative cases with a negative decision, and CD is the number of cases with decision

\subsubsection{Correlation Between Two Variables}

Before computing which are the most relevant criteria, we have calculated the correlation between the status of the identification case and the decision of the 
forensic expert (correlation-based expert proficiency). Furthermore, we have also estimated the correlation between the value of a criterion and the status of a case (criterion correlation with ground truth). That correlation assesses the tendency of a criterion to have higher values on positive cases and lower values on negative ones.

Correlation is a statistical technique that can show whether and how strongly pairs of variables are related. The Pearson correlation coefficient is the most widely used. It measures the strength of the linear relationship between normally distributed variables. When the variables are not normally distributed or the relationship between the variables is not linear, it may be more appropriate to use the Spearman rank correlation method. Spearman's coefficient, like any correlation calculation, is appropriate for both continuous and discrete variables, including ordinal variables (Wilkinson 2006). Due to the nature of our dataset, we have applied the Spearman rank correlation method.

The Spearman correlation coefficient is defined as the Pearson correlation coefficient $\rho$ between the ranked variables. For a sample of size $n$, the $n$ raw scores $X_{i}, Y_{i}$ are converted to ranks $x_{i}, y_{i}$, and $\rho$ is computed from

$$
\rho=1-\frac{6 \sum d_{i}^{2}}{n\left(n^{2}-1\right)},
$$

where $d_{i}=x_{i}-y_{i}$ is the difference between ranks. Identical values (rank ties or value duplicates) are assigned a rank equal to the average of their positions in the ascending order the values.

The sign of the Spearman correlation indicates the direction of association between $X$ (the independent variable) and $Y$ (the dependent variable). If $Y$ tends to increase when $X$ increases, the Spearman correlation coefficient is positive. If $Y$ tends to decrease when $X$ increases, the Spearman correlation coefficient is negative. A Spearman correlation of zero indicates that there is no tendency for $Y$ to either increase or decrease when $X$ increases. The Spearman correlation increases in magnitude as $X$ and $Y$ become closer to being perfect monotone functions of each other. When $X$ and $Y$ are perfectly monotonically related, the Spearman correlation coefficient becomes 1 .

We have performed the Spearman correlation with a statistical test in order to estimate the significance of the results. The considered level of statistical significance was 0.05 .

For the correlation-based expert proficiency, the specific aim was to test the null hypothesis $\left(\mathrm{H}_{0}\right)$ stating that the correlation between the decision of the expert and the status of the case are not correlated. In the case of the criterion correlation with the ground truth, the goal was to test the null hypothesis $\left(\mathrm{H}_{0}\right)$ stating that the correlation between the value of the criterion and the status of the case are not correlated.

As complementary studies, we have added the following analyses:

- Criterion weighted correlation with ground truth: same as the correlation with ground truth, except that the correlation coefficient associated with each expert is weighted according to his proficiency. 
- Criterion variability: it is computed as the mean standard deviation of the criterion evaluation over the same case. It aims to assess the subjectivity of a criterion.

\subsubsection{Linear Regression}

Correlation makes no a priori assumption as to whether one variable is dependent on the other(s) and is not concerned with the relationship between variables; instead, it gives an estimate as to the degree of association between the variables. In fact, correlation analysis tests for interdependence of the variables.

As regression attempts to describe the dependence of a variable on one (or more) explanatory variables, it implicitly assumes that there is a one-way causal effect from the explanatory variable(s) to the response variable, regardless of whether the path of effect is direct or indirect.

Therefore, we have complemented the latter correlation analysis with a linear regression test.

Linear regression attempts to model the relationship between two variables by fitting a linear equation to observed data. One variable is considered to be an explanatory variable, and the other is considered to be a dependent variable. This functional relationship may then be formally stated as an equation, with associated statistical values that describe how well this equation fits the data.

A linear regression line has an equation of the form $Y=a+b X$, where $X$ is the explanatory variable and $Y$ is the dependent variable. The slope of the line is $b$, and $a$ is the intercept (the value of $y$ when $x=0$ ).

The most common method for fitting a regression line is the method of leastsquares. This method calculates the best-fitting line for the observed data by minimizing the sum of the squares of the vertical deviations from each data point to the line (if a point lies on the fitted line exactly, then its vertical deviation is 0). Because the deviations are first squared, then summed, there are no cancellations between positive and negative values.

We have performed the linear regression test in order to estimate if the value of a criterion depends on the status of the case. The goal is to test the null hypothesis $\left(\mathrm{H}_{0}\right)$ stating that the value of a criterion has not an influence in the status of the case.

\subsubsection{Results}

With the aim of providing a feasible forum of discussion we have focused the analysis on only one scenario, the 1.a, that is, all the data (participants and CFS cases) are considered at the same time. Additionally, in some parts of the document, we also refer to the second scenario where the data was divided into two different sets according to the view of photograph: frontal and lateral.

Table 7.16 depicts the proportion of cases with decision in which the expert evaluates correctly status of the case (proficiency) and the number of cases given by 
Table 7.16 Cases with decision and simple expert proficiency

\begin{tabular}{l|l|l}
\hline Forensic expert & Proficiency & Cases with decision \\
\hline F1 & 0.62 & 0.96 \\
\hline F2 & 0.58 & 1.00 \\
\hline F3 & 0.58 & 0.83 \\
\hline F4 & 0.50 & 1.00 \\
\hline F5 & 0.54 & 0.79 \\
\hline F6 & 0.38 & 0.96 \\
\hline F7 & 0.62 & 1.00 \\
\hline F9 & 0.46 & 0.96 \\
\hline F10 & 0.42 & 0.96 \\
\hline F11 & 0.42 & 0.83 \\
\hline F12 & 0.48 & 0.96 \\
\hline F13 & 0.62 & 1.00 \\
\hline F14 & 0.54 & 0.83 \\
\hline F16 & 0.50 & 0.92 \\
\hline F17 & 0.58 & 1.00 \\
\hline F18 & 0.67 & 1.00 \\
\hline F19 & 0.67 & 1.00 \\
\hline F20 & 0.46 & 0.88 \\
\hline F21 & 0.54 & 1.00 \\
\hline F22 & 0.58 & 0.92 \\
\hline F23 & 0.67 & 0.96 \\
\hline F24 & 0.67 & 0.88 \\
\hline F25 & 0.75 & 1.00 \\
\hline F26 & 0.50 & 1.00 \\
\hline F28 & 0.50 & 0.88 \\
\hline F29 & 0.42 & 0.83 \\
\hline F30 & 0.67 & 1.00 \\
\hline F32 & 0.42 & 0.96 \\
\hline F33 & 0.50 & 1.00 \\
\hline & 0.62 & 1.00 \\
\hline & 0.75 & 0.96 \\
\hline & 0.46 & 1.00 \\
\hline & 0.54 & 1.00 \\
\hline & & 0.92 \\
\hline & & 0.75 \\
\hline
\end{tabular}

the expert with a decision different of the zero value. The average performance was poor. In the best case, the rate is just $75 \%$ (only two experts). A percentage of 37 (14 experts) of the participants did not overcome $50 \%$ of correct answers. The performance is thus worse than previous studies that also involved the SFO stage (Yoshino et al. 1995; Gordon and Steyn 2012; Jayaprakash et al. 2001; Martin and Saller 1957). Possible explanations for this low performance rates are 
- The absence of a complete cranium.

- The quality of some 3D models, which in some cases present noisy parts and artifacts.

- The materials given to the participants do not include the 3D skull models but just a projection on a $2 \mathrm{D}$ plane.

- The isolation of the decision-making stage given an SFO.

While the negative influence of the first three is quite evident, the fourth is not clear at all. It is the first time that such a study where SFOs are given at hand is developed. The process of overlaying the skull over the face also involves a continuous comparison of the skull-face relationship that is not performed within this study.

Table 7.17 shows the results of the Spearman test in order to calculate the correlation between the status of the identification case and the decision of the forensic expert. The proficiency in Table 7.16 corresponds to the Spearman correlation coefficient. We observe that seven experts achieve a significant correlation between their decision and the status of the case. F20, F21, F22, F23, F31, F34, and F36 have a Spearman positive correlation $>0$ with a $p$-value $<0.05$. In the rest of cases, we cannot reject the null hypothesis of correlation between the decision of the expert and the status of the case; that is, we cannot assert that the decision of the expert is correlated with the status of the case with a confidence level of $95 \%$.

Table 7.18 shows the number of times a criterion has been evaluated over the total number of evaluations (each participant for each SFO case), "Usage C." It also shows the percentage of participants that employed a criterion at least once, "Usage P." Both statistics are depicted for all the cases ("All"), only frontal cases ("Frontal"), and only lateral/oblique cases ("Lateral"). Those criteria that were employed in less than the $10 \%$ of the cases were removed from the corresponding study. In particular, criteria G2.10, G2.26, G3.2, and G3.4 do not reach the required $10 \%$ of usage irrespective of the dataset considered (all, only frontal, or only lateral). Criteria that were employed by less than $30 \%$ of the participants were also not considered in the corresponding study. The motivation for avoiding these criteria is related to the lack of significance of reduced samples of data.

Table 7.19 presents the results of the correlation between the value of a criterion and the status of the case with a p-value $\leq 0.05$, that is, statistically significant results. That correlation assesses the tendency of a criterion to have higher values on positive cases and lower values on negative ones.

Eight experts obtained a correlation between one or more criteria and the status of the case with a confidence level of $95 \%$. Hence, we can affirm that the use of some criteria is significantly correlated with the status of the case; that is, some criteria have higher values on positive cases and lower values in negative ones. In most cases, we obtain a positive correlation: when the degree of a criterion increases, the status of the case tends to a positive identification.

The performed regression analysis computes the independence between the value of a criterion and the status of the case. 
Table 7.17 Spearman tests, correlation-based expert proficiency, cases with p-values $<0.05$ in bold

\begin{tabular}{|c|c|c|}
\hline Forensic expert & Correlation coefficient & p-Value \\
\hline F1 & 0.29 & 0.17 \\
\hline $\mathrm{F} 2$ & 0.21 & 0.33 \\
\hline F3 & 0.32 & 0.13 \\
\hline F4 & 0.21 & 0.33 \\
\hline F5 & 0.33 & 0.11 \\
\hline F6 & -0.07 & 0.75 \\
\hline F7 & 0.03 & 0.91 \\
\hline F8 & -0.08 & 0.71 \\
\hline F9 & -0.10 & 0.64 \\
\hline F10 & 0.13 & 0.53 \\
\hline F11 & 0.24 & 0.27 \\
\hline F12 & 0.26 & 0.21 \\
\hline F13 & 0.26 & 0.21 \\
\hline F14 & 0.10 & 0.63 \\
\hline F15 & 0.30 & 0.15 \\
\hline F16 & 0.38 & 0.07 \\
\hline F17 & 0.34 & 0.11 \\
\hline F18 & 0.25 & 0.23 \\
\hline F19 & 0.22 & 0.31 \\
\hline F20 & 0.61 & 0.00 \\
\hline F21 & 0.45 & 0.03 \\
\hline F22 & 0.52 & 0.01 \\
\hline F23 & 0.49 & 0.01 \\
\hline F24 & 0.10 & 0.63 \\
\hline F25 & 0.23 & 0.29 \\
\hline F26 & -0.03 & 0.88 \\
\hline F27 & 0.21 & 0.33 \\
\hline F28 & -0.22 & 0.30 \\
\hline F29 & -0.05 & 0.81 \\
\hline F30 & 0.27 & 0.21 \\
\hline F31 & 0.54 & 0.01 \\
\hline F32 & -0.30 & 0.15 \\
\hline F33 & 0.29 & 0.17 \\
\hline F34 & 0.50 & 0.01 \\
\hline F35 & 0.30 & 0.16 \\
\hline F36 & 0.40 & 0.05 \\
\hline F37 & 0.13 & 0.54 \\
\hline
\end{tabular}

Table 7.20 depicts the results that have a p-value $\leq 0.05$, that is, those cases that reject the null hypothesis. Thus, shows the criteria that have significant influence on the status of the case.

Nine experts obtain a dependency between one or more criteria and the status of the case with a confidence level of $95 \%$. Hence, we can affirm that the use of some 


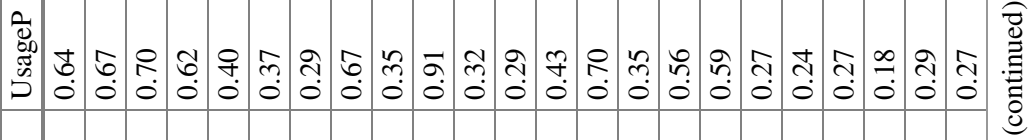

푼

矛

के

กึ่

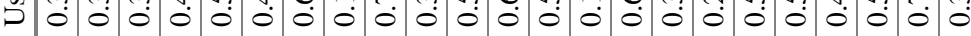

폴

莣

के

焉

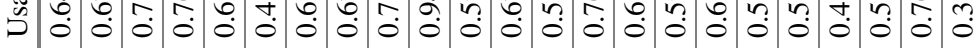

$\cup$

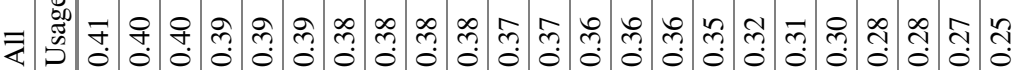

.

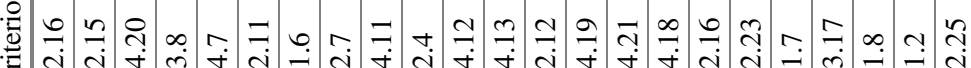
Ü

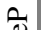

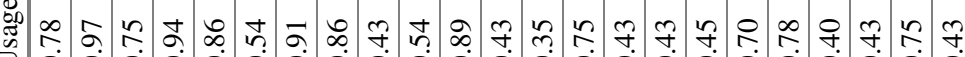

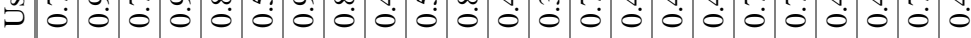

苞

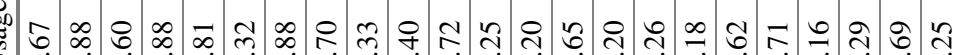
J

矛

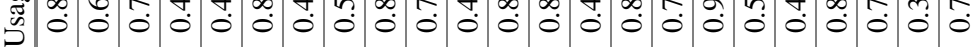

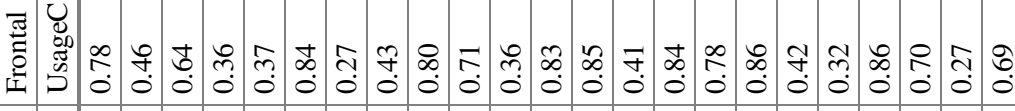

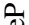

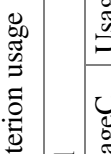

అ

ن

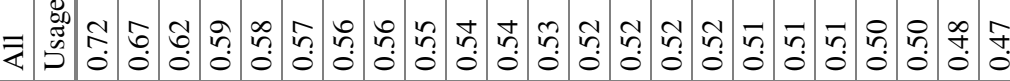

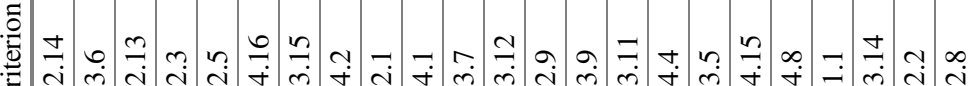

$\frac{\infty}{\frac{1}{0}}$

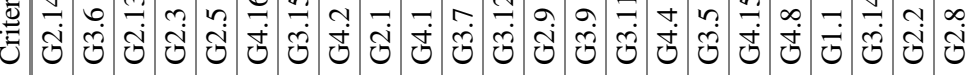




\begin{tabular}{|c|c|c|c|c|c|c|c|c|c|c|c|c|c|c|}
\hline & 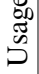 & & $\begin{array}{l}0 \\
\vdots \\
0\end{array}$ & & $\begin{array}{l}0 \\
\stackrel{0}{0}\end{array}$ & సે & ?ె. & $\stackrel{\infty}{+}$ & $\stackrel{n}{\stackrel{0}{0}}$ & & $\vec{n}$ & 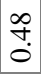 & $\hat{n}$ & \\
\hline 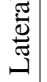 & 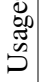 & & $\begin{array}{l}\tilde{0} \\
0\end{array}$ & & $\stackrel{2}{2}$ & ปั & $\stackrel{8}{8}$ & $\stackrel{5}{0}$ & in & & ป̀ & ָ̃ & $\frac{n}{0}$ & \\
\hline & $\begin{array}{l}\mathscr{E} \\
\mathscr{D} \\
\mathscr{D}\end{array}$ & & $\stackrel{?}{\stackrel{2}{0}}$ & & ஸ̊. & $\stackrel{0}{\circ}$ & in & $\stackrel{\infty}{+}$ & $\stackrel{m}{0}$ & & $\begin{array}{l}\infty \\
0 \\
0\end{array}$ & $\begin{array}{l}\stackrel{0}{\circ} \\
0\end{array}$ & & \\
\hline 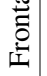 & 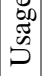 & & $\begin{array}{l}7 \\
0\end{array}$ & & mి & $\stackrel{I}{\circ}$ & 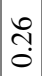 & $\stackrel{\infty}{0}$ & o. & & $\begin{array}{l}0 \\
0 \\
0\end{array}$ & $\begin{array}{l}\stackrel{d}{0} \\
\stackrel{0}{0}\end{array}$ & & \\
\hline & $\stackrel{\mathscr{D}}{\mathscr{D}}$ & ָิ & 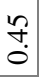 & ָิ & ஸ̊? & ڤి & 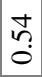 & $\stackrel{\infty}{+}$ & $\stackrel{n}{\circ}$ & 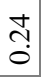 & $\bar{n}$ & 京 & & \\
\hline $\bar{\psi}$ & $\begin{array}{l}\mathscr{\varpi} \\
\mathscr{W} \\
\mathscr{D}\end{array}$ & 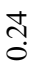 & 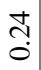 & $\stackrel{\text { I }}{0}$ & స઼ & $\frac{9}{0}$ & $\frac{\infty}{0}$ & $\frac{\infty}{0}$ & $\frac{\infty}{0}$ & $\frac{1}{0}$ & $\begin{array}{c}0 \\
0 \\
0\end{array}$ & $\frac{m}{0}$ & & \\
\hline & : & $\begin{array}{l}\hat{~} \\
\text { ป̂ }\end{array}$ & $\begin{array}{l}\tilde{N} \\
\mathrm{v} \\
\mathrm{v}\end{array}$ & $\begin{array}{l}\underset{\mathrm{J}}{\mathrm{U}} \\
\text { U. }\end{array}$ & $\begin{array}{l}\vec{N} \\
\mathcal{U}\end{array}$ & $\frac{\bullet}{0}$ & $\frac{0}{\dot{v}}$ & $\frac{9}{0}$ & $\overrightarrow{0}$ & $\begin{array}{l}\text { तે } \\
\text { ปิ }\end{array}$ & $\begin{array}{l} \pm \\
\dot{J}\end{array}$ & $\frac{9}{\vec{v}}$ & 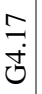 & \\
\hline & $\stackrel{\mathscr{n}}{\mathscr{D}}$ & "ूt & ڤ్ & $\begin{array}{l}\text { t) } \\
\stackrel{0}{0}\end{array}$ & 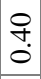 & $\stackrel{n}{\stackrel{n}{0}}$ & 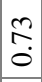 & ڤึ? & $\tilde{n}$ & ָे. & $\stackrel{q}{\mathfrak{s}}$ & $\stackrel{n}{\tilde{s}}$ & ָे & $\stackrel{m}{\circ}$ \\
\hline 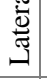 & 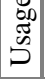 & $\stackrel{0}{0}$ & $\begin{array}{l}0 \\
\vdots \\
0\end{array}$ & ñ? & $\stackrel{m}{0}$ & $\begin{array}{l}n \\
0 \\
0\end{array}$ & 苞 & กิ & $\frac{\infty}{0}$ & $\frac{m}{0}$ & $\hat{\mathfrak{o}}$ & $\stackrel{ \pm}{\overrightarrow{0}}$ & $\stackrel{\theta}{\dot{\theta}}$ & ָ̊. \\
\hline & $\stackrel{\tilde{n}}{\omega}$ & tro & $\stackrel{\infty}{\stackrel{0}{0}}$ & 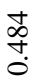 & $\frac{\infty}{2}$ & సે & 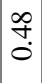 & $\stackrel{5}{\circ}$ & $\stackrel{m}{\stackrel{0}{0}}$ & $\stackrel{\Re}{0}$ & $\stackrel{n}{\stackrel{f}{0}}$ & $\stackrel{m}{0}$ & $\begin{array}{c}-\infty \\
0 \\
0\end{array}$ & $\begin{array}{l}\widetilde{\sigma} \\
\stackrel{0}{\circ}\end{array}$ \\
\hline $\begin{array}{l}\text { 苛 } \\
\text { 离 }\end{array}$ & 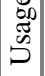 & $\stackrel{f}{0}$ & 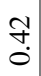 & $\stackrel{m}{?}$ & $\frac{n}{0}$ & กิ & $\stackrel{m}{m}$ & $\stackrel{\text { ț }}{0}$ & $\begin{array}{l}0 \\
0 \\
0\end{array}$ & $\stackrel{?}{i}$ & $\stackrel{n}{\stackrel{n}{0}}$ & $\begin{array}{l}\infty \\
\stackrel{0}{0} \\
0\end{array}$ & $\frac{m}{0}$ & ?ִ? \\
\hline & 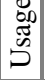 & ?ִ & $\begin{array}{l}? \\
\dot{0}\end{array}$ & $\stackrel{m}{o}$ & $\frac{\infty}{0}$ & $\frac{\infty}{6}$ & $\frac{m}{0}$ & i্ & $\stackrel{m}{0}$ & $\stackrel{m}{\stackrel{0}{0}}$ & 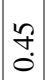 & $\frac{n}{\stackrel{2}{o}}$ & $\begin{array}{l}\bar{\infty} \\
0 \\
0\end{array}$ & ర్ర. \\
\hline $\bar{Z}$ & 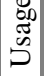 & $\stackrel{0}{+}$ & $\begin{array}{l}0 \\
+ \\
0\end{array}$ & $\stackrel{0}{+}$ & $\stackrel{f}{\stackrel{f}{0}}$ & $\stackrel{\text { 巳 }}{0}$ & 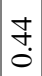 & $\stackrel{?}{\stackrel{f}{0}}$ & $\stackrel{\mathfrak{T}}{\stackrel{5}{0}}$ & 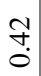 & $\vec{t}$ & $\underset{0}{\tau}$ & $\underset{\dot{O}}{\overrightarrow{0}}$ & $\underset{\sigma}{\nexists}$ \\
\hline & 莺 & 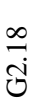 & $m$ & $\stackrel{0}{\circ}$ & $\stackrel{0}{\stackrel{0}{+}}$ & $\stackrel{\vartheta}{0}$ & $\stackrel{n}{\square}$ & $\stackrel{+}{\vec{U}}$ & 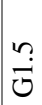 & $\overrightarrow{0}$ & $\frac{\bar{v}}{\mathrm{v}}$ & $\frac{m}{\tilde{U}}$ & $\tilde{O}$ & $\overrightarrow{\mathcal{U}}$ \\
\hline
\end{tabular}


Table 7.19 Spearman test, correlation statistically significant between criterion and the status of the case

\begin{tabular}{l|l|l|l}
\hline Forensic expert & Criterion & Correlation coefficient & p-Value \\
\hline F3 & G2.9 & 0.48 & 0.02 \\
\hline F3 & G2.14 & 0.51 & 0.01 \\
\hline F4 & G1.4 & 0.43 & 0.03 \\
\hline F4 & G3.18 & 0.49 & 0.01 \\
\hline F7 & G2.18 & 0.41 & 0.04 \\
\hline F11 & G3.12 & 0.47 & 0.02 \\
\hline F11 & G3.13 & 0.44 & 0.03 \\
\hline F11 & G3.15 & 0.65 & 0.00 \\
\hline F16 & G1.2 & 0.42 & 0.03 \\
\hline F16 & G1.5 & 0.41 & 0.04 \\
\hline F16 & G1.8 & 0.52 & 0.00 \\
\hline F16 & G2.3 & 0.49 & 0.01 \\
\hline F16 & G2.6 & 0.52 & 0.00 \\
\hline F16 & G2.14 & 0.56 & 0.00 \\
\hline F16 & G3.6 & 0.46 & 0.02 \\
\hline F16 & G4.14 & 0.50 & 0.01 \\
\hline F19 & G2.8 & 0.47 & 0.02 \\
\hline F19 & G3.7 & 0.43 & 0.03 \\
\hline F19 & G4.15 & 0.50 & 0.01 \\
\hline F21 & G3.19 & 0.41 & 0.04 \\
\hline F30 & G3.18 & 0.48 & 0.01 \\
\hline & & &
\end{tabular}

criteria is significantly dependent on the status of the case; that is, some criteria have higher values on positive cases and lower values in negative ones.

It is important to note that we have achieved similar results in the correlation and regression tests (Tables 7.19 and 7.20). The criteria that present the most influence in the status of the case are G2.14, G2.17, G2.18, and G3.12.

A boxplot with the expert's assessment across the scenarios is depicted in Fig. 7.2. This boxplot shows the significant variability within each of the expert's responses. In general, both negative and positive cases have similar performance rates although a lower variability resulted in the evaluation of the positive ones. While there are only two negative cases (4-2 and 11-1) where most of the participants $(\geq 75 \%)$ made a correct evaluation, there are four positive cases with a similar successful evaluation (3-1, 7-1, 13-1, and 18-1). Looking at the median values (black horizontal line inside the boxes), there are three negative cases that were incorrectly assessed by most of the participants: SFO cases 4-1, 15-1, and 16-1. The median values of the other three cases (8-1, 10-1, and 17-1) fall in the undetermined category (value 0). Similarly, there are three positive cases that were incorrectly evaluated by most of the participants: SFO cases 5-1, 5-2, and 12-1. For all these cases, 75\% of the participants did not make the correct identification. Differences were not observed between the evaluations of lateral versus frontal views. 
Table 7.20 Linear regression test, influence statistically significant between criterion and the status of the case

\begin{tabular}{l|l|l|l}
\hline Forensic expert & Criterion & F value & p-Value \\
\hline F3 & G2.9 & 5.97 & 0.02 \\
\hline F3 & G2.14 & 7.53 & 0.01 \\
\hline F4 & G1.4 & 5.00 & 0.03 \\
\hline F4 & G3.18 & 6.66 & 0.01 \\
\hline F7 & G2.18 & 5.96 & 0.02 \\
\hline F11 & G3.12 & 4.62 & 0.04 \\
\hline F11 & G3.15 & 11.56 & 0.00 \\
\hline F11 & G4.7 & 4.10 & 0.05 \\
\hline F16 & G1.5 & 4.66 & 0.04 \\
\hline F16 & G1.8 & 7.97 & 0.00 \\
\hline F16 & G2.3 & 6.82 & 0.01 \\
\hline F16 & G2.6 & 7.97 & 0.00 \\
\hline F16 & G2.14 & 8.00 & 0.00 \\
\hline F16 & G3.6 & 4.23 & 0.05 \\
\hline F16 & G3.12 & 4.45 & 0.04 \\
\hline F18 & G4.14 & 7.61 & 0.01 \\
\hline F19 & G4.3 & 4.22 & 0.05 \\
\hline F19 & G2.8 & 5.03 & 0.03 \\
\hline F19 & G2.17 & 4.50 & 0.04 \\
\hline F19 & G2.18 & 4.14 & 0.05 \\
\hline F21 & G4.15 & 5.76 & 0.02 \\
\hline F23 & G3.19 & 5.55 & 0.02 \\
\hline F30 & G2.11 & 4.00 & 0.05 \\
\hline & G3.18 & 7.48 & 0.01 \\
\hline & & & \\
\hline
\end{tabular}

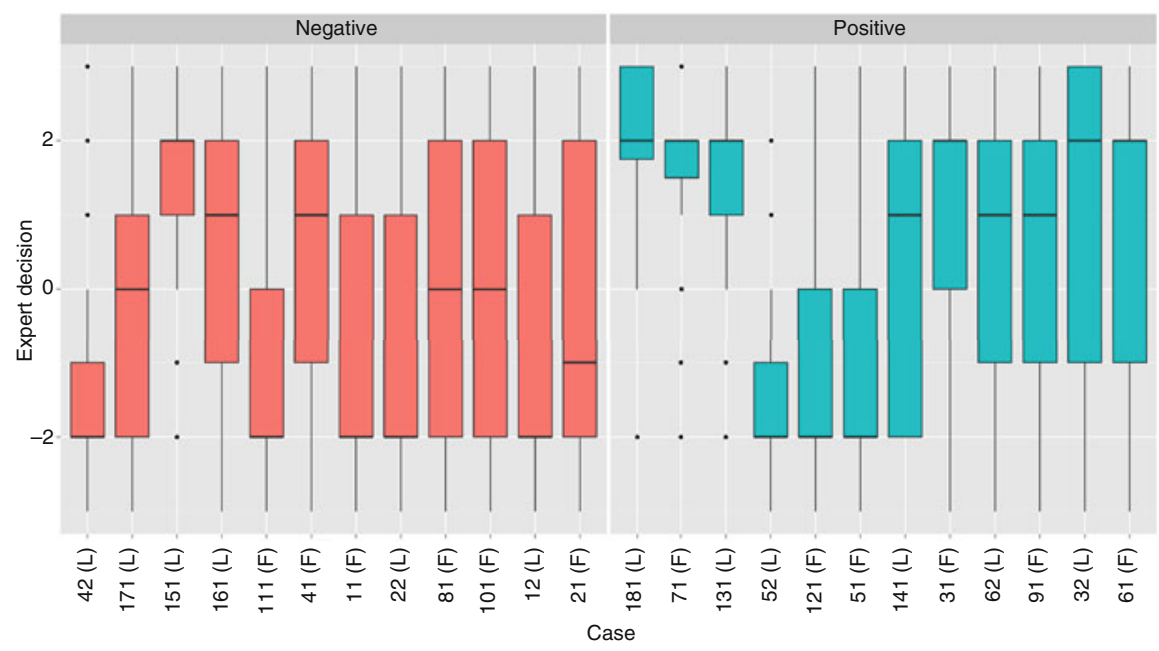

Fig. 7.2 Statistical representation of the expert's assessment for each (negative and positive) SFO case. Expert decisions (between -3 and +3 ) on the $y$-axis and SFO cases on the $\mathrm{x}$-axis. F and $\mathrm{L}$, in brackets after the number of the case, indicate frontal and lateral view cases, respectively 
The subjectivity was measured as the standard deviation of the evaluations (Table 7.21). The standard deviation was computed on each case, and then the values were averaged. The ranges of values for the criteria are within the interval $[1,5]$ and thus can conclude that there is a significant distribution in the evaluations by the different participants with standard deviations ranging from 0.85 to 1.31 .

A primary goal for the current study is to provide forensic anthropologists with the means (objective data) to select a set of criteria, or to establish a ranked order of

Table 7.21 Criterion subjectivity

\begin{tabular}{|c|c|c|c|}
\hline Criterion & Mean standard deviation & Criterion & Mean standard deviation \\
\hline $\mathrm{G} 2.20$ & 0.85 & G3.16 & 1.12 \\
\hline G3.10 & 0.87 & G2.12 & 1.12 \\
\hline G3.1 & 0.92 & G2.17 & 1.12 \\
\hline G1.5 & 0.92 & G2.14 & 1.12 \\
\hline G1.8 & 0.93 & G3.11 & 1.14 \\
\hline G3.18 & 0.97 & G3.9 & 1.14 \\
\hline G1.3 & 0.97 & G4.12 & 1.14 \\
\hline G2.19 & 0.97 & G2.3 & 1.14 \\
\hline G2.24 & 1.01 & G3.14 & 1.14 \\
\hline G1.2 & 1.02 & G2.15 & 1.14 \\
\hline $\mathrm{G} 2.16$ & 1.02 & G4.20 & 1.14 \\
\hline G2.23 & 1.03 & G3.6 & 1.15 \\
\hline G4.19 & 1.03 & G2.22 & 1.15 \\
\hline G1.7 & 1.04 & G3.8 & 1.15 \\
\hline $\mathrm{G} 2.25$ & 1.05 & G4.4 & 1.15 \\
\hline G4.10 & 1.06 & G4.6 & 1.15 \\
\hline G1.6 & 1.07 & G1.1 & 1.17 \\
\hline G2.21 & 1.07 & G2.11 & 1.17 \\
\hline G2.9 & 1.07 & G2.5 & 1.18 \\
\hline G2.27 & 1.08 & G4.15 & 1.19 \\
\hline G4.13 & 1.10 & G4.8 & 1.19 \\
\hline G2.7 & 1.10 & G3.5 & 1.19 \\
\hline G2.18 & 1.10 & G4.3 & 1.19 \\
\hline G2.8 & 1.10 & G4.16 & 1.19 \\
\hline G3.7 & 1.10 & G4.2 & 1.20 \\
\hline G1.4 & 1.10 & G2.1 & 1.20 \\
\hline G4.5 & 1.10 & G4.18 & 1.21 \\
\hline G4.14 & 1.10 & G3.19 & 1.21 \\
\hline G2.4 & 1.11 & G4.11 & 1.21 \\
\hline G4.1 & 1.11 & G3.13 & 1.21 \\
\hline G3.3 & 1.11 & G32.2 & 1.23 \\
\hline G4.21 & 1.11 & G3.12 & 1.23 \\
\hline G2.13 & 1.11 & G3.15 & 1.26 \\
\hline G4.9 & 1.11 & G2.6 & 1.31 \\
\hline
\end{tabular}




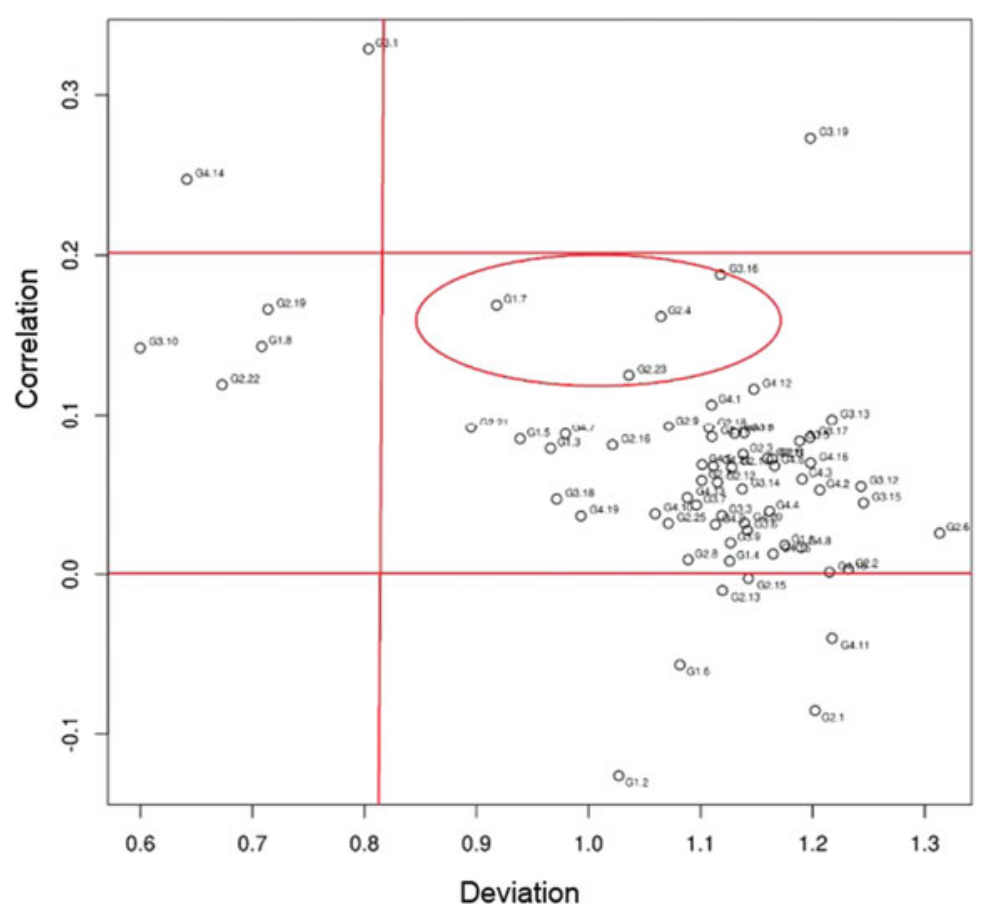

Fig. 7.3 Scatter plot including all the criteria under study spatially distributed according to their subjectivity (x-axis) and discriminative power (y-axis)

preference, with the most discriminative power and easy to evaluate traits. Figure 7.4 visualizes the standard deviation (related to the ease of objective assessment) and the correlation (related to the discriminatory power criterion).

Three red lines split five groups of criteria with one group split into two separate groups with have six groups in total, which represent the best criteria and the highest discriminatory power with the lowest variability in the top left corner (G3.1 and G4.14). Below this region, the criteria that can be considered easy to evaluate, which are important criteria in terms of discriminative power with high correlation values (G3.10, G2.19, G1.8, and G2.22). In the top right corner, the criteria with almost the highest discriminative power with highest variance are grouped (G3.19).The largest area, more or less in the center of the Fig. 7.3, shows the majority of the criteria that in general are not significantly different (G4.12, G4.1, G2.9, G2.16, G4.7, G1.3, G1.5, and G2.21).Within this region, surrounded by a red-colored circle, we have identified a fifth group composed by criteria with a good trade-off between subjectivity and discriminative power (G3.16, G1.7,G2.4, andG2.23).Finally, the right bottom corner groups the least useful criteria with regards to their subjectivity and do not discriminate between face and skull (G1.2, G2.1, G4.11, G1.6, G2.15, and G2.13).

Figure 7.4 depicts the differences between the frontal views that cluster specific criteria according to the pose of the person's face within the photograph.

For the frontal cases, five groups can be differentiated. At the top scatter plot, the criteria with highest discriminative power (G3.19) are observed. Below this group, 


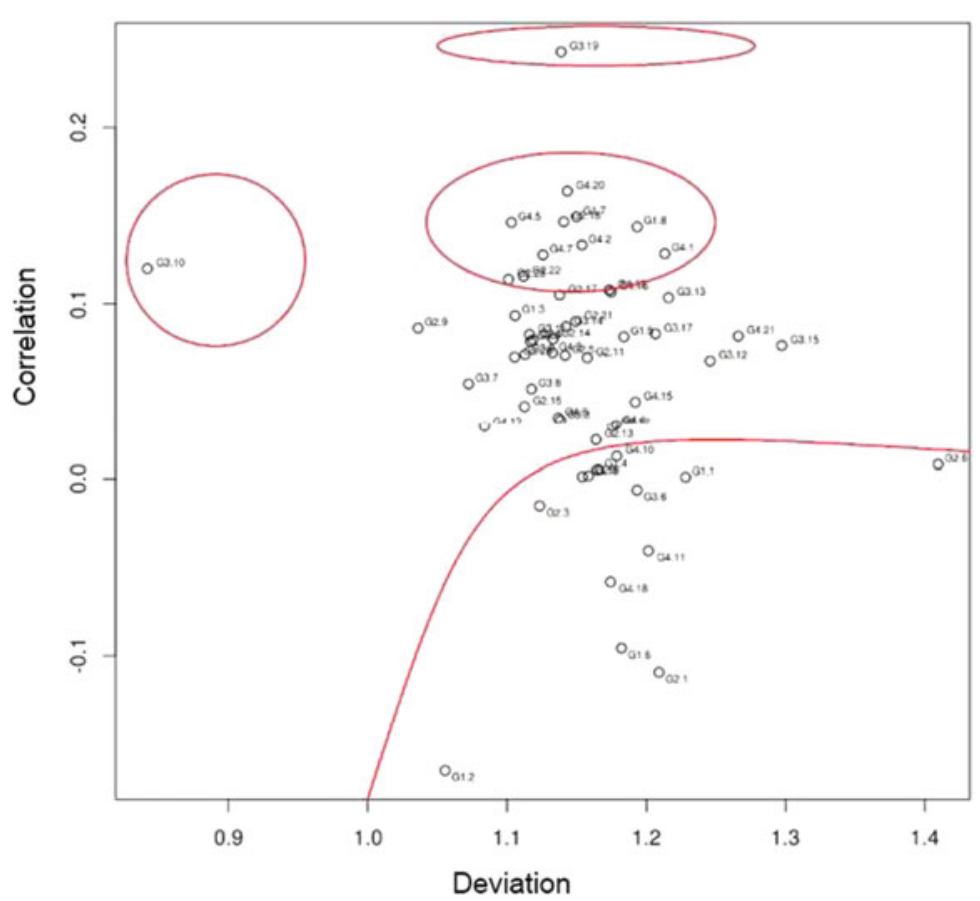

Fig. 7.4 Criterion according to the frontal pose of the person's face in the photograph

the group with the criteria with a good trade-off between subjectivity and discriminative power is observed (G4.20, G4.5, G1.7, G2.18, G1.8, G4.2, G4.7, G4.1, G2.22, and G2.23). On the left side of the scatter plot, easy to evaluate criterion is depicted (G3.10) with the least amount of variability. In addition, it is an important criterion in terms of discriminative power with high correlation values. In the center of the scatter plot, the majority of the criteria are found showing the least amount of difference among them. Finally, the right bottom region groups the least useful criteria with the highest subjectivity and that cannot be used to discriminate between face and skull (G1.2, G2.1, G1.6, G4.18, G4.11, G2.3, G3.6, G1.1, G2.8, G3.18, G1.4, G2.6, and G4.10).

Figure 7.5 depicts the differences between the lateral views that cluster specific criteria according to the pose of the person's face within the photograph.

For the lateral cases, although they can be grouped into eight separate groups, the two groups in the center part (between correlation values of 0 and 1.2) are considered as part of the same group of criteria with almost no discriminatory power. On the top left corner, the best criteria are represented (G3.1and G4.17), which also have the greatest discriminatory power and least variability. At the top right corner, encloses the group with the greatest discriminatory power and the greatest variability $(\mathrm{G} 4.14$ and G3.19). Below group, a group identified (criteria G2.4, G3.11, G2.9, G1.1, G4.10, G2.12, and G2.19) as still important correlation with the identification decisions and a significant variability is shown. Similarly, criterion G3.18 holds important discriminatory power but has a significantly lower variability. As in the 


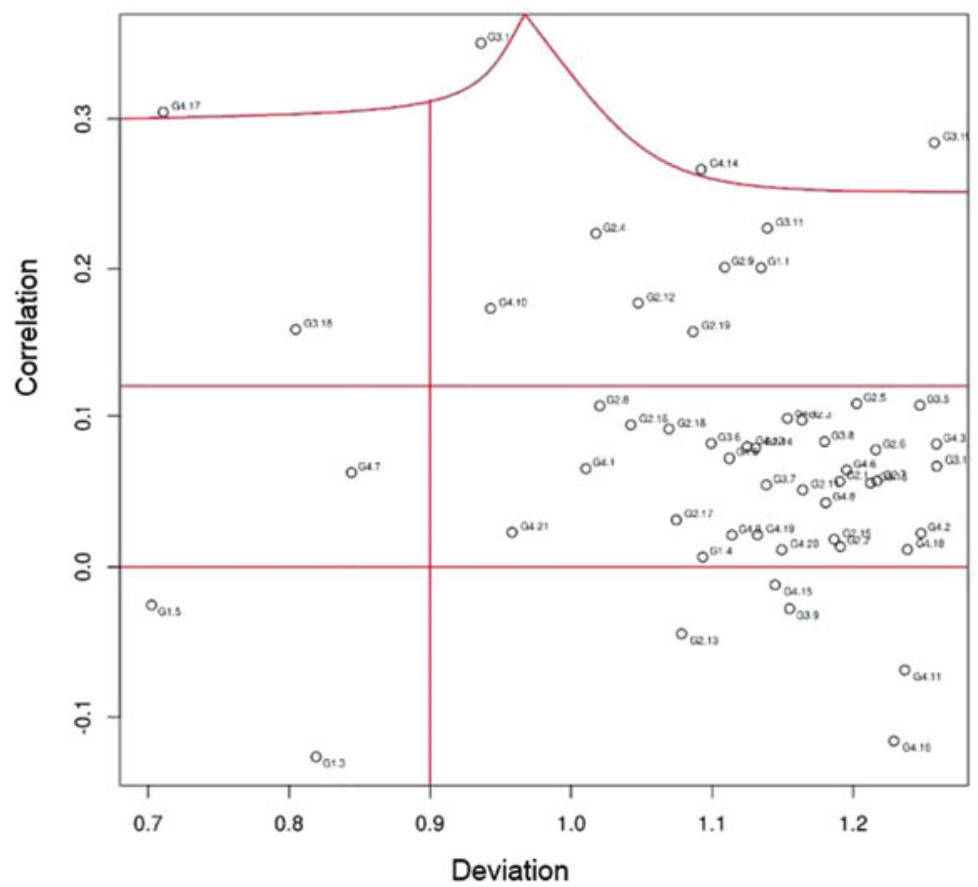

Fig. 7.5 Criteria according to the lateral pose of the person's face in the photograph

other two sections, the central part of the scatter plot contains the majority of the criteria, which do not hold significant correlation values. Finally, the bottom right part of the scatter plot contains the criteria with the greatest subjectivity and that cannot discriminate between face and skull (G4.15, G3.9, G2.13, G4.11, and G4.16). Note that G3.14 refers to the same anatomical correspondence criterion as G3.9 but analyzed on different image views.

Open Access This chapter is licensed under the terms of the Creative Commons AttributionNonCommercial 2.5 International License (http://creativecommons.org/licenses/by-nc/2.5/), which permits any noncommercial use, sharing, adaptation, distribution and reproduction in any medium or format, as long as you give appropriate credit to the original author(s) and the source, provide a link to the Creative Commons license and indicate if changes were made.

The images or other third party material in this chapter are included in the chapter's Creative Commons license, unless indicated otherwise in a credit line to the material. If material is not included in the chapter's Creative Commons license and your intended use is not permitted by statutory regulation or exceeds the permitted use, you will need to obtain permission directly from the copyright holder.

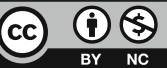




\section{Chapter 8 \\ MEPROCS Craniofacial Superimposition \\ Framework}

\subsection{Introduction}

Of the various tanatological identification techniques, CFS is considered a controversial technique within the scientific community. The lack of unified working protocols among practitioners as well as the absence of commonly accepted standards in the application of the technique have led to a lack of consensus regarding the reliability of CFS.

In general, experts in the field tend to apply their own approach to the problem, based on the technology available in their laboratory. For instance, when adjusting the scale of skull and face images, some investigators focus on a specific pair of homologous landmarks, others rely on a more global adjustment of the facial and skull contours or they look for a morphological consistency. Some experts have modeled the latter problem using a mathematical formulation that can be automatically solved using optimization methods.

Craniofacial superimposition evolved as new technology, available to practitioners, based on previously laid foundations (Wilkinson 2004; Austin-Smith and Maples 1994). The variety of supporting technological advances involved a large number of very diverse approaches, that is, photo CFS, video, computer-aided photo CFS, computer-aided video CFS, computer-aided 3D-2D CFS, as well as manual, semiautomatic, and automatic approaches, all of which can be found in the literature (Damas et al. 2011; Yoshino et al. 1995).

Furthermore, there are different anatomical criteria employed to assess goodness of fit: contours, lines, proportions, landmarks and soft tissue depth studies of points, morphology, asymmetries, positional relationships, etc. The differences are not only in the set of criteria used but also on the weight given to them, while evaluating the skull-face relationship. Finally, each expert has her/his own decision scale, with different numbers of labels, different names and meanings, and different criteria to move along the scale.

As stated in the introductory chapter of this book, the aim of the MEPROCS' project was to propose a common framework, avoiding particular assumptions that 
could bias the process, allowing the extensive application of the CFS technique in practical forensic identification scenarios.

To achieve this purpose, some of the most representative experts in craniofacial identification joined in a series of discussions intended to identify and agree on the most important issues to be considered in the proper implementation of the CFS technique. Three experimental studies, designed to obtain objective data that supports and guides these discussions, were carried out during the project.

\subsection{Study of the Most Important Issues for a Proper Implementation of the Craniofacial Superimposition Technique}

The first multiple-laboratory validation study on CFS included 26 participants from 17 different forensic and academic institutions from all over the world. The participants were asked to consider 14 identification scenarios, including a total of 60 CFS problems, of one-to-many and one-to-one cases, divided into female and male substudies. Each participant followed her/his own methodology, employing her/his particular technological means.

Once the study finished, all MEPROCS partners were provided with a detailed report summarizing the results of the study together with the individual results of each participant. This included a summary of the methodology followed by each participant, global performance together with false/true positive/negative rates, performance on male and female datasets separately and integrated, performance grouped by level of experience and by technological approach, and all superimposition images and skull-face relationship reports grouped by case (only in those cases with a higher variability and those with the worst performance).

A second reliability study, designed to analyze the subjectivity and discriminatory power of the different criteria for assessing the skull-face correspondence, was conducted. Thirty-seven participants with various levels of competency in CFS were asked to analyze $18 \mathrm{CFS}$ problems, some of them composed of more than one image of the same subject, totaling 24 superimpositions. For each pair of skull and face photographs, the investigator was provided with an optimal or near-optimal SFO, achieved by the superimposition of a 3D face model over the facial photograph of the subject. The data provided was obtained from CBCT of different subjects and face photographs of the subjects. Informed consent from the volunteers and confidentiality documents from the investigators were signed, prior to the study.

First of all, participants were asked to indicate which specific criteria they were going to use for evaluating the skull-face relationships (see the appendices for a detailed list of the criteria provided). Then, they were asked to evaluate the skull-face correspondence following a systematic approach. For each SFO, the degree of consistency of all the criteria previously selected were indicated using the following values: 0 -not evaluable, 1-no match, 2-poor match, 3-doubtful match, 4good match, 5-perfect match. 
In order to avoid personal interpretations, MEPROCS partners assigned in advance (before giving the instructions to the participants) the value 0 to those criteria they considered unable to be visually checked due to the noisy nature of the image, the absence of the bony part, or the pose of the photograph. This was carried out for each single SFO case.

Finally, for each SFO case (and also for each CFS case, which implies more than one SFO), participants were asked to indicate the final identification decision according to the following scale: -3 , strong support of not being the same person; -2 , moderate support of not being the same person; -1 , limited support of not being the same person; 0 , undetermined; +1 , limited support of being the same person; +2 , moderate support of being the same person; +3 , strong support of being the same person.

As in the first study, once this second study was completed, all partners were provided with an in-depth statistical analysis of the data. Three different areas of analysis were generated based on the following characteristics:

1. According to the data employed

2. According to the view of the photographs: frontal vs. lateral

3. According to the family of criteria: lines, landmarks-soft tissue, outlines, and positional relationship

Due to similar results and in order to narrow the discussion, the consortium decided to focus on the second statistical analysis.

Based on the conclusions of these discussions, and on validation studies over a significant number of cases (to get a solid picture of the reliability of CFS), the experts wrote up the current manuscript, which could be considered the first standard in the field, including good and bad practices, sources of error and uncertainties, technological requirements and desirable features, and finally a common scale for the craniofacial matching evaluation.

An in-depth analysis of all the resulting superimposition images in correlation with the respective analysis of the skull-face relationship identified the following main sources of errors.

\subsubsection{Main Sources of Error in Craniofacial Superimposition}

1. Skull-face overlay and, in particular, the adequate perspective of the skull. For example, most of the software programs employed for this task do not allow alteration of the projection, but "just" the orientation and scaling. In many cases, it involves an error-prone trial and error process. Orientation + scaling + perspective.

2. The digital articulation of the mandible and cranium after scanning can introduce errors. With no access to the occlusion as it was in life, the mandible may have been placed in an incorrect position with respect to the cranium.

3. The attachment of the mandible to the cranium.

4. The replication of the AM position of the mandible. 
5. The incomplete preservation and post-mortem reassembly of the skull. For example, the incorrect positioning of teeth in the sockets.

6. The inaccurate 3D skull acquisition (or segmentation in case of CT scanner), precision below $1 \mathrm{~mm}$, and/or specific features not properly scanned (or segmented). The latter was recorded at the nasal region, the teeth, and the orbits. Presence of artifacts.

7. The aspect ratio of the photograph.

8. The unknown origin of the AM photograph.

9. The post-mortem skull damage.

All the latter issues are considered sources of errors; thus, they should be considered in order to avoid accumulating and propagating errors during the CFS process. In addition, there are several issues that can negatively affect conclusions based on CFS, but, unlike sources of errors, they cannot be avoided. In contrast, they have to be considered an inherent part of the process, and thus, they have to be properly modeled and incorporated in the decision-making process. We have referred to these issues as sources of uncertainty, since, contrary to complete and precise knowledge, they represent partial, incomplete, imprecise, and/or vague information.

\subsubsection{Main Sources of Uncertainty in Craniofacial Superimposition}

1. Cephalometric landmark location uncertainty: this is related to the extremely difficult task of locating the points in a completely reproducible manner. The variability may arise for reasons such as

(a) Variation in the distribution of shadows that is dependent on the lighting conditions during photography.

(b) Unsuitable camera focusing, especially when the plane of focus is too shallow and hence the critical features are not sharp.

(c) Poor image quality, that is, low resolution.

(d) Face posture in the photograph, that is, facial expression and angle of view of the face (lateral, frontal, or oblique).

(e) Occlusion of part or all of a landmark.

(f) Imprecise definition of some anthropometric landmarks could be due to either ambiguous terminology or because it is poorly defined in an anatomical sense.

2. Landmark matching uncertainty: It refers to the imprecision that is involved in the matching of two sets of potentially corresponding landmarks derived from two different objects; a face and a skull.

(a) The correspondence between facial and cranial anthropometric landmarks is not always symmetrical and perpendicular to the skin surface and to the underlying bone.

(b) The facial soft tissue depth varies for each cephalometric landmark, as well as for different populations (based on age, race, and sex). 
(c) Considerations of how the distances between potentially corresponding landmarks are affected by the posture and facial expression in the image have to be taken into account.

(d) There are many studies describing the uncertainty related to differing soft tissue depths for different populations, but almost none of them considered the projection of those distances onto the AM photo used in the comparison.

3. Skull-face overlay uncertainty: There is no precisely quantifiable way of determining when an accurate superimposition has been achieved.

4. There are many unknown (and/or uncertain) parameters involved in the replication of the original photographic conditions used to produce the image employed in the comparison.

5. Morphological criteria are subjective or difficult to quantify.

6. The amount of morphological criteria that have to be satisfied for a positive identification.

7. The effects of dental changes detected from examination of the AM photographs used for comparison with the skull, as well as their accurate interpretation.

8. Age-related changes: The craniofacial morphology of children needs to be investigated and documented more comprehensively before comparisons between images taken at different times during childhood can be compared.

The following "best practices" and "practices that should be avoided" represent some guidelines to minimize or avoid the main sources of error, as well as, to deal with the sources of uncertainty that are concomitant to the application of CFS.

These steps should be viewed as recommendations and under no circumstances should they be perceived as requirements to accomplish a "valid" result. The authors are fully aware that the circumstances of each case are to be taken into consideration, when evaluating the results of identification based upon CFS.

\subsubsection{Best Practices in Craniofacial Superimposition}

1. Use the real skull to confirm correct fit of the mandible with the cranium.

2. Use the real skull and mandible to articulate the dentition and establish centric occlusion.

3. Reproduce the position of the mandible as displayed in the AM photograph.

4. Locate and mark landmarks on the skull before scanning.

5. Use multiple (more than one) AM photos or frames taken from video with the candidate in different poses, as far as they provide new information, for example, more anatomical information provided by additional viewpoints.

6. Use AM photographs of good quality. For optimal examination, in full frontal images, the resolution of the face image should be at least 180 pixels corresponding to the width of the head, or roughly 90 pixels between the pupils of the eyes. (ISO International Standard ISO/IECJTC 1/SC 37 N506).

7. Avoid images with obscuring objects. For example, spectacles and beards. 
8. During the growth period of children's lives, always use the most recent AM photos. For adults, use the most informative photos.

9. Perform CFS using the original AM images, avoiding as much as possible image manipulation.

10. Throughout the entire CFS process be careful to preserve the aspect ratio of the photograph.

11. Keep all the information contained within the original image (do not use cropped images, which can introduce error).

12. Extract as much information as possible from the photograph (digital and visual information) to infer original photographic conditions.

13. Analyze and describe separately both the skull and the face in the photograph(s) to be compared (this will include general morphology, specific dimensions, and any special, potentially individualizing, characteristics) prior to superimposition.

14. When multiple candidates are available, sort out AM photos to be compared by reference to the existing description of the skull and prioritize them in a sequence of most to least likely to correspond.

15. Use as many criteria as possible in order to study the relationship between the face and the skull.

16. Consider the discriminative "power" of each anatomical criterion.

17. Give an appropriate "weight" to each criterion according to the degree of uncertainty related to it, which will depend also on the AM view.

\subsubsection{Practices in Craniofacial Superimposition That Should Be Avoided}

1. Confirmation bias (e.g., coercive situations with investigating authorities, a misplaced enthusiasm to be a good citizen and be helpful etc.)

2. Attempting CFS on edentulous skulls (except in cases where skull morphology is highly individualizing with extreme malformations)

3. Using just one single, low-resolution, frontal passport-style photograph for comparison

4. Cases in which the subject is under the age of 5 years

\subsubsection{Recommended Landmarks to Guide Skull-Face Overlay}

Many CFS approaches make use of homologous craniometric and cephalometric landmarks to guide the SFO, that is, scaling, orientation, and projection of the skull over the facial photograph. Table 8.1 summarizes those pairs of homologous landmarks found by MEPROCS consortium to be the more reliable and effective for SFO. In addition, Table 8.2 depicts a second set of homologous landmarks, still useful for guiding purposes, but with the agreement of suffering from either difficulties to be precisely localized or lower orientation utility. Figures 8.1 and 8.2 show both sets of recommended and still useful landmarks for guiding SFO. 
Table 8.1 Recommended homologous landmarks for guiding SFO

\begin{tabular}{l|l}
\hline Craniometric & Cephalometric \\
\hline Whitnall's tubercle (wt) & lateral canthus (lc) \\
\hline subspinale (ss) & subnasale (sn) \\
\hline nasion (n) & nasion (n) \\
\hline occlusion mid-incisors (oc) & stomion (st) \\
\hline porion (po) & tragion (t) \\
\hline pogonion (pg) & pogonion (pg) \\
\hline glabella (g) & glabella (g) \\
\hline prosthion (pr) & supra-labiale (sl) \\
\hline alare (al) & alare (al) \\
\hline gnathion (gn) & menton (m) \\
\hline ant lacrimal crest (la) & medial canthus (mc) \\
\hline
\end{tabular}

Table 8.2 Other homologous landmarks still useful for guiding SFO

\begin{tabular}{l|l}
\hline Craniometric & Cephalometric \\
\hline zygion (zy) & zygion (zy) \\
\hline crista conchalis (cc) & supra-alare (sa) \\
\hline gonion (gn) & gonion $(\mathrm{g})$ \\
\hline intercanine distance (75\%) (id) & cheilion $(\mathrm{ch})$ \\
\hline supraorbitale (sa) & sag eyebrow (se) \\
\hline two tangents nasal & pronasale (prn) \\
\hline 1st premolar/canine radiating line & cheilion $(\mathrm{ch})$ \\
\hline mastoidale (ma) & subaurale (sba) \\
\hline infraorbital foramen (if) & cheilion $(\mathrm{ch})$ \\
\hline
\end{tabular}

In close relation to this, the technological means employed must also be considered. If these do not fulfill some basic requirements, they can be part of the problem, generating errors and/or introducing more uncertainty. In contrast, they can provide an invaluable support when they incorporate, together with those requirements, some desirable features that help to reduce errors, uncertainty, and the time employed. While the requirements list is intended to be a complete list of features that all the equipment has to fulfill, the desirable features should be considered an open list that can increase in line with the new research advances in the field. (Tables 8.3 and 8.4 are devoted to both the requirements and desirable features of the two main technological approaches that coexist in CFS: computer-aided and video superimposition.

\subsubsection{Protocol for Evaluation of Anatomical Consistency in Craniofacial Superimposition}

This protocol compiles criteria to be used in the assessment of consistency between the superimposed skull and photograph, analyzing anatomical criteria such as the concordance between the outlines of the face and the skull, soft tissue thickness, and the positional relationship of specific facial and skeletal features. 

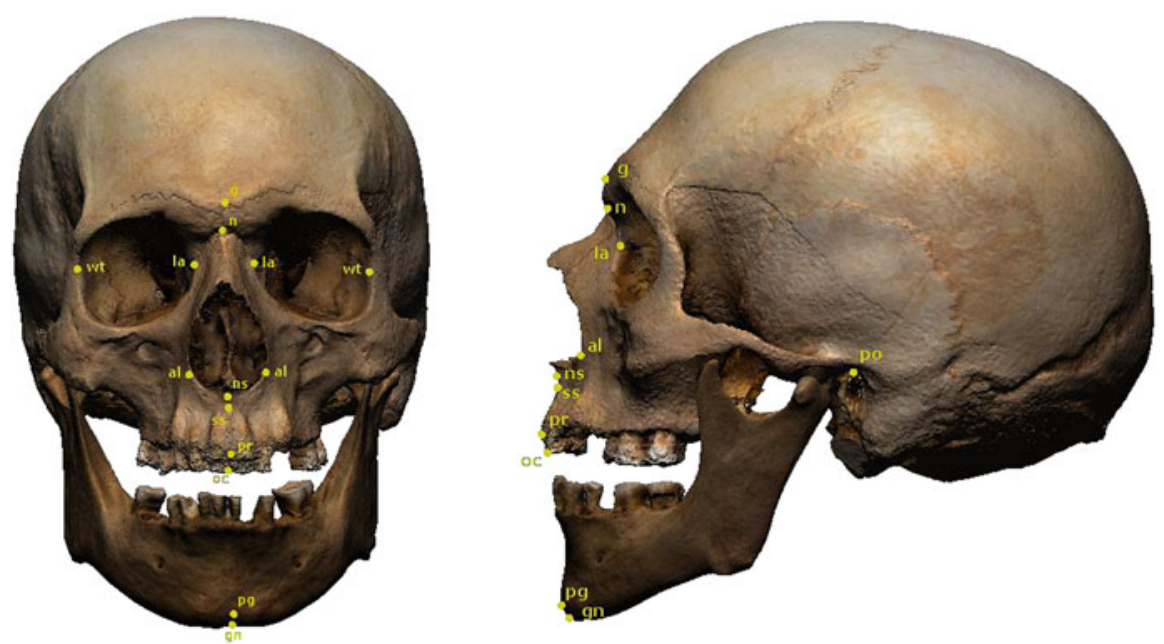

Fig. 8.1 In different colors, set of recommended craniometric landmarks for SFO (more reliable and effective) and set of still useful craniometric landmarks for guiding SFO, in frontal and lateral view
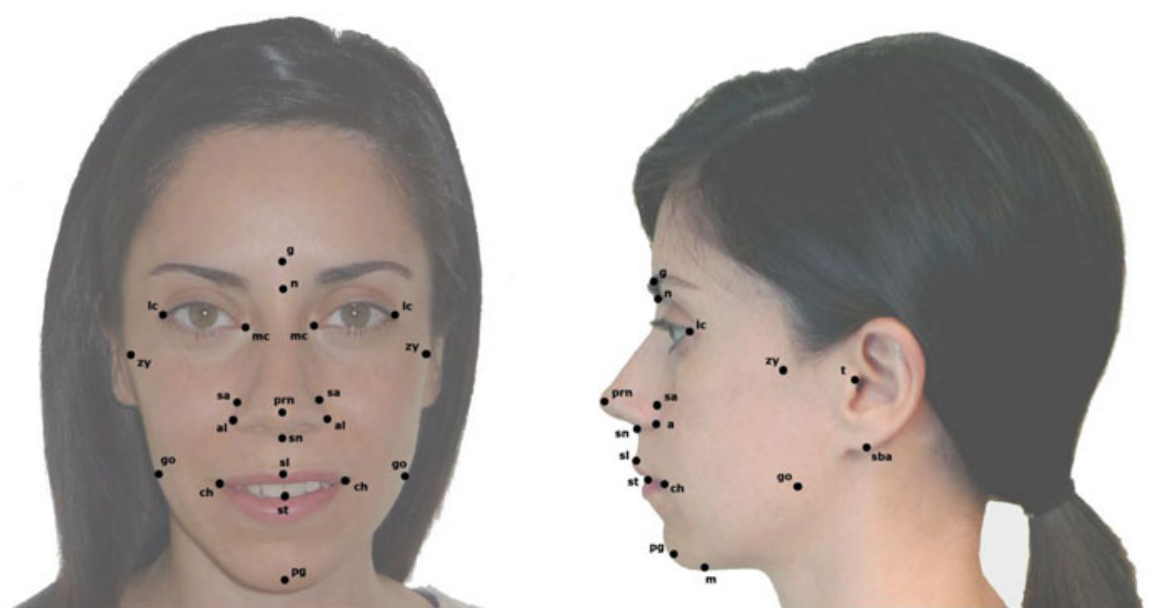

Fig. 8.2 In different colors, set of recommended cephalometric landmarks for SFO (more reliable and effective) and set of still useful cephalometric landmarks for guiding SFO, in frontal and lateral view

The examination criteria used in this protocol are based on previous works by Chai et al. (1989), Austin-Smith and Maples (1994), Lan (1995), Yoshino et al. (1997), Jayaprakash et al. (2001), and Yoshino (2012). The approach underlying this protocol requires a good knowledge of the anatomy of the skull and face.

This protocol offers a significant set of criteria extracted from a scientific study and international discussion on their discriminatory power and subjectivity. They can be seen as an effort in standardization of the criteria used by human-experts in evaluation of anatomical consistency in CFS. 
Table 8.3 CFS requirements and desirable features for computer-aided equipment

Tools for computer-aided craniofacial superimposition (3Dskull model - 2D face image)

\begin{tabular}{l|l|l}
\hline Type/name & Requirements & Desirable features \\
\hline $\begin{array}{l}\text { 3D scanner or CT } \\
\text { scanner }\end{array}$ & Precision $\leq 1 \mathrm{~mm}$ & Capture of texture information \\
\cline { 2 - 3 } $\begin{array}{l}\text { Software for landmark } \\
\text { location }\end{array}$ & $\begin{array}{l}\text { Tool to locate landmarks } \\
\text { in a single pixel }\end{array}$ & Tool to locate landmarks in a region \\
\hline $\begin{array}{l}\text { Software for performing } \\
\text { the skull-face overlay }\end{array}$ & $\begin{array}{l}\text { Show landmarks } \\
\text { Transparency mode } \\
\text { Tools to rotate, translate, } \\
\text { and scale the 3D skull } \\
\text { Tool to properly project } \\
\text { 3D skull onto 2D image }\end{array}$ & $\begin{array}{l}\text { Wipe mode } \\
\text { Simultaneous interaction with 3D skull } \\
\text { and the AM photograph }\end{array}$ \\
\hline $\begin{array}{l}\text { Software for assessing } \\
\text { the skull-face } \\
\text { relationship }\end{array}$ & Transparency mode & $\begin{array}{l}\text { Show landmarks and contours Wipe } \\
\text { mode } \\
\text { Tool for measuring Euclidean and surface } \\
\text { distances between points or perimeters } \\
\text { Tool for marking lines or contours }\end{array}$ \\
\hline
\end{tabular}

Table 8.4 CFS requirements and desirable features for video superimposition equipment

Tools for craniofacial video superimposition (physical skull-2Dface image)

\begin{tabular}{l|l|l}
\hline Type/name & Requirements & Desirable features \\
\hline $\begin{array}{l}\text { Two high-resolution CCD } \\
\text { video cameras each with a } \\
\text { TV Zoom lens }\end{array}$ & $\begin{array}{l}\text { Both of the same make and } \\
\text { specification }\end{array}$ & $\begin{array}{l}\text { Minimum resolution: } \\
600 \text { pixels. } \\
\text { Zoom lens: Manual, 1.2/ } \\
12.5-7.5 \text { with ability to } \\
\text { zoom in focus-locked state. }\end{array}$ \\
\hline Two high-quality tripods & $\begin{array}{l}\text { Sturdy and stable while manipulat- } \\
\text { ing camera movement }\end{array}$ & $\begin{array}{l}\text { Facilities to fine adjust the } \\
\text { focus maintaining stability. }\end{array}$ \\
\hline $\begin{array}{l}\text { A digital video vision } \\
\text { mixer }\end{array}$ & $\begin{array}{l}\text { Ability to capture analogue images } \\
\text { in real time as captured by the CCD } \\
\text { cameras }\end{array}$ & $\begin{array}{l}\text { Ability to mix (fade) as well } \\
\text { as wipe the images. } \\
\text { Mixing effect should include } \\
\text { all types of wipe facility. }\end{array}$ \\
\hline $\begin{array}{l}\text { A pan and tilt device to } \\
\text { which the universal skull } \\
\text { clamp can be fitted }\end{array}$ & $\begin{array}{l}\text { Capable of supporting the skull and } \\
\text { effecting the pan and tilt movements } \\
\text { as from a device with gears }\end{array}$ & $\begin{array}{l}\text { Stepwise movement is not } \\
\text { desirable. } \\
\text { A remote control unit to } \\
\text { operate the device is } \\
\text { desirable. }\end{array}$ \\
\hline A video cassette recorder & $\begin{array}{l}\text { Ability to record the real-time ana- } \\
\text { logue images generated during the } \\
\text { superimposition }\end{array}$ & $\begin{array}{l}\text { Enables demonstration of } \\
\text { superimposition in analogue } \\
\text { state. }\end{array}$ \\
\hline $\begin{array}{l}\text { Video capture software } \\
\text { To capture the superimposed images } \\
\text { both frame by frame and as video } \\
\text { strip }\end{array}$ & $\begin{array}{l}\text { Enables storage and easy } \\
\text { retrieval of images from } \\
\text { computer. }\end{array}$ \\
\hline $\begin{array}{l}\text { Illumination system: ver- } \\
\text { tical stands and lamps } \\
\text { Stands are to be provided with soft } \\
\text { dark blue velvet cloth to avoid } \\
\text { shadow }\end{array}$ & $\begin{array}{l}\text { Florescent lamps are desir- } \\
\text { able as the lighting is diffuse } \\
\text { and white. }\end{array}$ \\
\hline
\end{tabular}


Table 8.5 Recommended criteria for frontal view photographs

\begin{tabular}{|c|c|c|}
\hline Group properties & Criteria for frontal view & Verified? \\
\hline Highest discriminative power & $\begin{array}{l}\text { Dental information (hard tissue to hard tissue } \\
\text { consistency). }\end{array}$ & \\
\hline \multirow[t]{8}{*}{$\begin{array}{l}\text { Good trade-off between subjec- } \\
\text { tivity and discriminative power }\end{array}$} & $\begin{array}{l}\text { Gonial flare in the mandible and the postero-lateral } \\
\text { jaw angle outline in the face. }\end{array}$ & \\
\hline & $\begin{array}{l}\text { The lateral angle of the eye lies within the lateral } \\
\text { wall of the orbit. }\end{array}$ & \\
\hline & $\begin{array}{l}\text { The stomion lies at the central incisors (Incisal } \\
\text { margin of the upper incisors). }\end{array}$ & \\
\hline & The occlusal and the lip closure line are consistent. & \\
\hline & $\begin{array}{l}\text { Evaluate soft tissue thickness at occlussion } \\
\text { mid-incisors-stomion. }\end{array}$ & \\
\hline & $\begin{array}{l}\text { Evaluate consistency positional relationship } \\
\text { between the expected position of the Eye ball in } \\
\text { the skull and pupilare in the photographs. }\end{array}$ & \\
\hline & $\begin{array}{l}\text { The soft tissue position just beneath the eyebrow } \\
\text { should be more anterior than the orbital rim. }\end{array}$ & \\
\hline & $\begin{array}{l}\text { Marking line used to analyze anatomical consis- } \\
\text { tency: Entocanthion vertical line. Endocanthion- } \\
\text { cheilion-entocanthion-caninion [left and right]. It } \\
\text { is from entocanthion line to cheilion line, parallel } \\
\text { with the front central line, used to mark the rela- } \\
\text { tionship of entocanthion and maxillari teeth (Jacob } \\
\text { and Alt 1995). See Fig. 8.3. }\end{array}$ & \\
\hline $\begin{array}{l}\text { Easily to evaluate and important } \\
\text { discriminative power }\end{array}$ & $\begin{array}{l}\text { The temporal line is consistent with the outline of } \\
\text { the forehead (Sometimes the temporal line cannot } \\
\text { be distinguished). }\end{array}$ & \\
\hline
\end{tabular}

This step of the CFS procedure is crucial to the whole process. An incorrect assessment of the anatomical relationship between the skeletal remains and the subject depicted in the ante-mortem image can result in incorrect conclusions.

Considering that the available ante-mortem and post-mortem data vary from case to case, the assessment criteria were divided into those that are usable in frontal and lateral views, respectively. The different features and landmarks observed both on the skull and the superimposed image were classified into groups, depending on their objectiveness and discriminatory power.

The expert should note if the condition described for a specific criterion is verified or not with a certain degree between 1 (not verified at all) and 5 (perfectly verified). The verification of a criterion means the consistency between the skull and the face. The criteria that cannot be examined should be marked with a 0 (undetermined). The list with criteria is shown in Tables 8.5 and 8.6 according to the view of the photograph examined.

Table 8.7 also depicts those criteria that are not recommended due to their low discriminatory power and subjectivity.

The forensic expert should also list other criteria used that are not covered in this protocol, and make more detailed notes on the discrepancies observed with regard to a specific criterion or asymmetries observed in the face and the skull, which have a direct correlation that are directly correlated and enhance the likelihood of the skull being singular to the target person in the examination notes (Table 8.8). 
Table 8.6 Recommended criteria for lateral view photographs

\begin{tabular}{|c|c|c|}
\hline Group properties & Criteria for lateral/oblique view & Verified? \\
\hline Best criteria & $\begin{array}{l}\text { The outline of the frontal bone follows the fore- } \\
\text { head outline. }\end{array}$ & \\
\hline \multirow[t]{2}{*}{$\begin{array}{l}\text { Highest discriminative power } \\
\text { but also high variance }\end{array}$} & $\begin{array}{l}\text { The porion aligns just posterior to the tragus, } \\
\text { slightly inferior to the crus of the helix. }\end{array}$ & \\
\hline & $\begin{array}{l}\text { Dental information (hard tissue to hard tissue } \\
\text { consistency). }\end{array}$ & \\
\hline $\begin{array}{l}\text { Easily to evaluate and impor- } \\
\text { tant discriminative power }\end{array}$ & $\begin{array}{l}\text { Consistency of the bony and facial outlines/mor- } \\
\text { phological curves at the lower part of the face: } \\
\text { Oblique contour of the mandible follows the out- } \\
\text { line of the jaw. }\end{array}$ & \\
\hline \multirow{2}{*}{$\begin{array}{l}\text { Important discriminative power } \\
\text { and a significant variability }\end{array}$} & Evaluate soft tissue thickness at glabella-glabella. & \\
\hline & $\begin{array}{l}\text { The outline of the face and the outline of the skull } \\
\text { all along the contour follow each other. }\end{array}$ & \\
\hline
\end{tabular}

Table 8.7 Criteria not recommended due to low discriminative power and subjectivity

\begin{tabular}{|c|c|c|}
\hline \multirow[b]{2}{*}{ Not recommended criteria } & \multicolumn{2}{|l|}{ View } \\
\hline & Frontal & $\begin{array}{l}\text { Left/ } \\
\text { oblique }\end{array}$ \\
\hline Marking line used to analyze anatomical consistency: & $\mathrm{X}$ & \\
\hline \multicolumn{3}{|l|}{ Frontal central line. Glabella-gnathion-glabella-gnathion. } \\
\hline Soft tissue thickness at gnathion-menton. & $\mathrm{X}$ & \\
\hline $\begin{array}{l}\text { The chelion lies between the canine and the first premolar (at the } \\
\text { occusal line). }\end{array}$ & $\mathrm{X}$ & \\
\hline Evaluate soft tissue thickness at nasion-nasion. & $\mathrm{X}$ & \\
\hline $\begin{array}{l}\text { The chin outline (soft tissue) is consistent with the mental (hard tissue) } \\
\text { outline. }\end{array}$ & $\mathrm{X}$ & \\
\hline Evaluate soft tissue thickness at Gonion-gonion. & $\mathrm{X}$ & \\
\hline $\begin{array}{l}\text { Consistency of the bony and facial outlines/morphological curves: oblique } \\
\text { line of the mandible. }\end{array}$ & $\mathrm{X}$ & \\
\hline Evaluate soft tissue thickness at pogonion-pogonion. & $\mathrm{X}$ & \\
\hline The medial margin of orbit aligns and superimposes with the endocanthion. & $\mathrm{X}$ & \\
\hline The nasion is higher than the nasal root. & $\mathrm{X}$ & $\mathrm{X}$ \\
\hline The lower margin of the piriform aperture matches the subnasale. & & $\mathrm{X}$ \\
\hline $\begin{array}{l}\text { Consistency of the bony and facial outlines/morphological curves: the arcus } \\
\text { supraciliariaris follows the supraorbital margin. }\end{array}$ & & $\mathrm{X}$ \\
\hline Evaluate soft tissue thickness at prosthion-supralabiale. & & $\mathrm{X}$ \\
\hline $\begin{array}{l}\text { The eyebrow generally follows the upper edge of the orbit over the medial } \\
\text { two-thirds. At lateral superior one-third of the orbit, the eyebrow continues } \\
\text { horizontally as the orbital rim begins to curve inferiorly. }\end{array}$ & & $\mathrm{X}$ \\
\hline
\end{tabular}

" $\mathrm{X}$ " means not recommended for the corresponding view (either frontal or lateral/oblique)

Table 8.8 Examination notes
Examination notes

Other assessment criteria analyzed

Notes on particular discrepancies observed

Asymmetries on facial and cranial morphology 


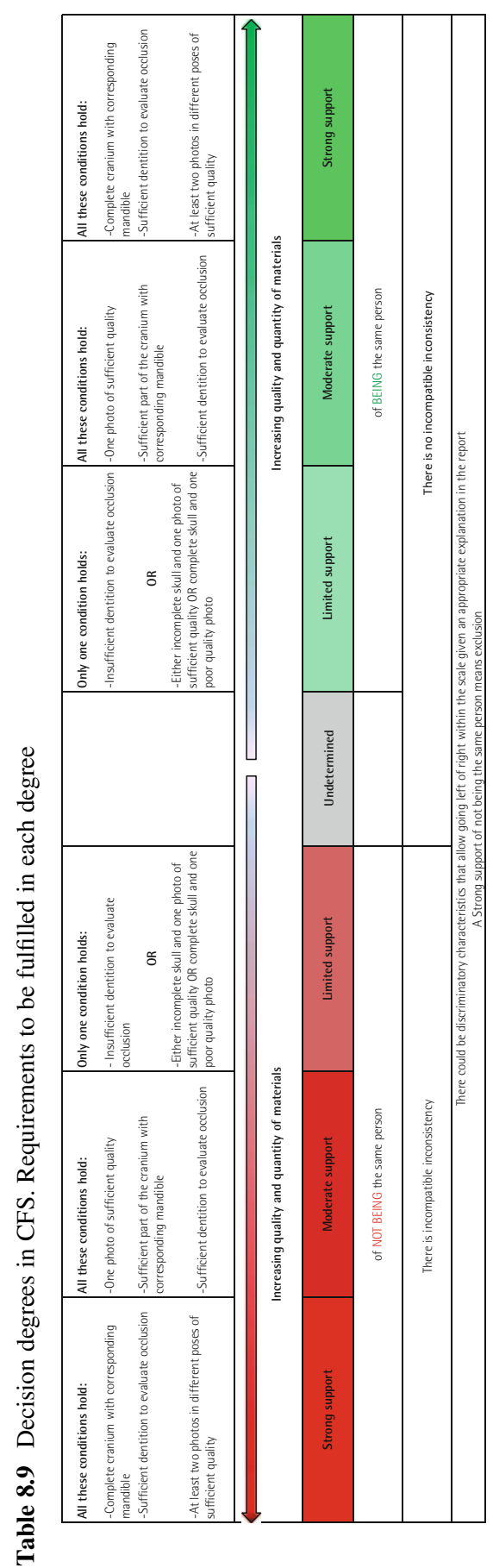




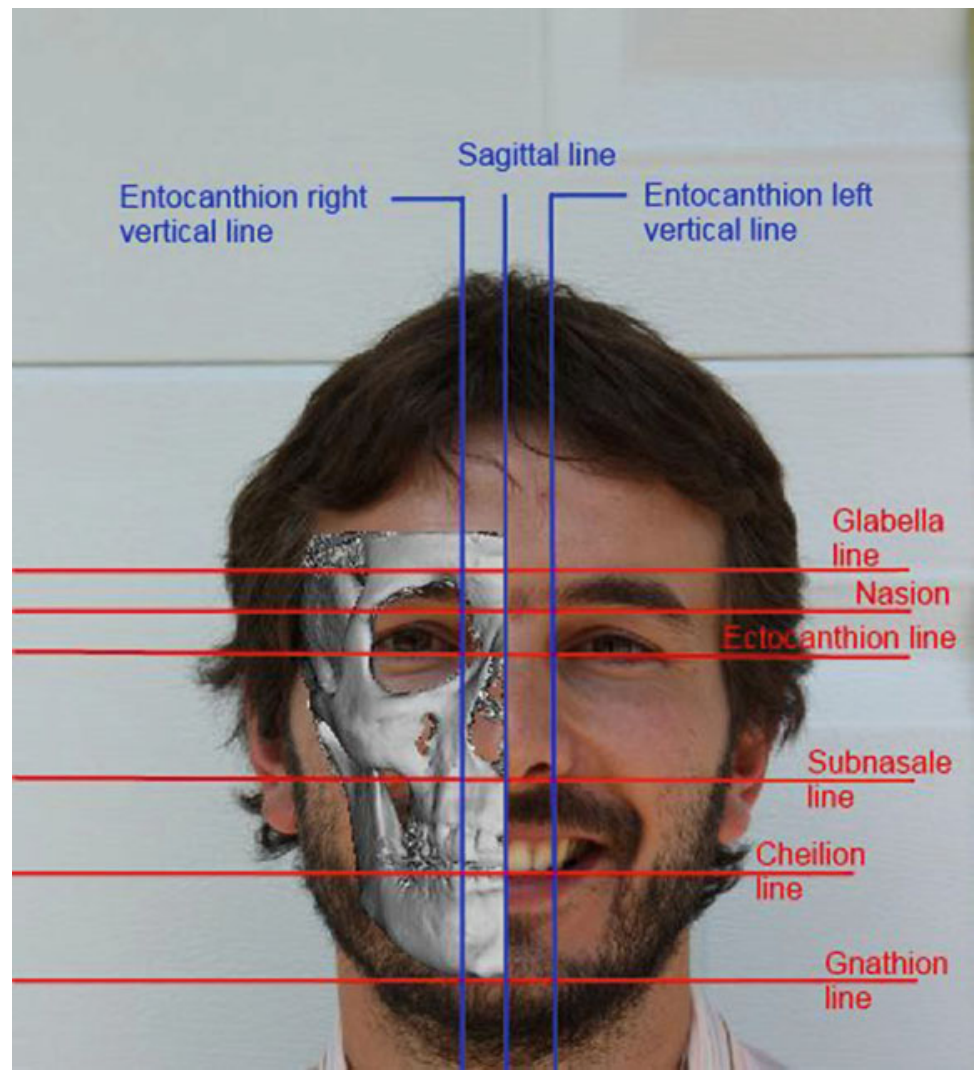

Fig. 8.3 Vertical and horizontal lines to analyze anatomical consistency in frontal photographs

\subsubsection{Final Decision Making}

Finally, Table 8.9 contains a gradual scale for decision making in CFS. The degree of support a specific CFS identification case can achieve must be in line with the quality and quantity of the materials (AM photographs, mandible, and cranium). Additionally, there could be discriminatory characteristics that allow modification of the latter degree of support given an appropriate explanation in the report. That is to say, Table 8.9 presents some guidelines to choose the most adequate degree of support. Considering the materials examined and the consistency of the matching between the face and the skull, a final decision should be provided in terms of strong, moderate, or limited support to the assertion that the skull and the facial image belong to the same person. 


\subsection{Conclusions}

The application of CFS differs greatly among experts worldwide. From the technological approach to the order and methodology implemented in each step of the procedure, including the process of adjusting the skull and face images and the criteria applied to assess the anatomical consistency between them as well as to achieve a decision based on the goodness of fit achieved.

Furthermore, each expert has a different scale designed to determine the final decision regarding the identification of the remains. In this chapter, the authors propose a series of practical recommendations, pitfalls to be avoided, and a decision scale that attempt to unify the application of CFS. These "best practice" suggestions are not to be deemed as all inclusive or legally binding, they are the fruit of in-depth discussions among practitioners from all over the world, based on the results of a series of studies conducted during the project.

Open Access This chapter is licensed under the terms of the Creative Commons AttributionNonCommercial 2.5 International License (http://creativecommons.org/licenses/by-nc/2.5/), which permits any noncommercial use, sharing, adaptation, distribution and reproduction in any medium or format, as long as you give appropriate credit to the original author(s) and the source, provide a link to the Creative Commons license and indicate if changes were made.

The images or other third party material in this chapter are included in the chapter's Creative Commons license, unless indicated otherwise in a credit line to the material. If material is not included in the chapter's Creative Commons license and your intended use is not permitted by statutory regulation or exceeds the permitted use, you will need to obtain permission directly from the copyright holder.

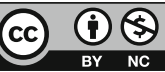




\section{Chapter 9 \\ MEPROCS Framework Validation}

\subsection{Introduction}

The purpose of this study is to validate the CFS framework developed during the last $2 \frac{1}{2}$ years and agreed by the MEPROCS consortium. Thus, all partners will be asked to deal with a variable (according to their availability and time constraints) number of CFS cases (positives and negatives) following all the recommendations collected within the framework referring to the procedure and the materials, the set of landmarks and criteria, the decision gradual system, and the requirements of the technical equipment. Individual and average performance will be compared with the performance achieved in Chap. 7 to check for a possible improvement as a consequence of following MEPROCS framework. Although a large number of cases have to be tackled within a significant reliability study, the current analysis will also serve to give an idea of the reliability of the methodology proposed. In addition, it can be also useful to study the influence of the technological means employed and the knowledge and experience of the practitioner performing the superimpositions.

The dataset used in this study consists of eight identification scenarios (S1-S8). Each of the first four scenarios (S1-S4) implies a comparison of one skull and four candidates with a variable number of AM photographs. Each of the last four scenarios (S5-S8) involves a comparison of only one candidate, with a variable number of AM photographs, and four different skulls. Thus, these eight scenarios correspond to a total number of 32 CFS cases, which at the same time involve up to 72 SFO problems as Table 9.1 details. The dataset was collected at two different institutions, the Laboratorio di Antropologia e Odontologia Forense (Italy) and the University of Vilnius (Lithuania), after obtaining informed consent from the responsible party for the deceased, and provided to the MEPROCS project following the data share protocol established by the project ethical committee.

The dataset provided for analysis consisted generically of a set of AM photos, photos of the skull (with scales), and a set of 3D models of the skull acquired by the structure light scanner Artec MHT. Each set of case studies had the following 
Table 9.1 Summary of the materials forming the dataset for the study

\begin{tabular}{l|l|l|l|l|l|l}
\hline Scenario & \# CFS & \# Skulls & \# Candidates & \# Photos & \# Max SFO & \# Positive/negative CFS \\
\hline S1 & 4 & 1 & 4 & $4-2-1-2$ & 10 & $1 / 3$ \\
\hline S2 & 4 & 1 & 4 & $1-3-2-2$ & 8 & $1 / 3$ \\
\hline S3 & 4 & 1 & 4 & $3-2-3-1$ & 9 & $1 / 3$ \\
\hline S4 & 4 & 1 & 4 & $3-1-3-2$ & 9 & $1 / 3$ \\
\hline S5 & 4 & 4 & 1 & 2 & 8 & $1 / 3$ \\
\hline S6 & 4 & 4 & 1 & 1 & 4 & $1 / 3$ \\
\hline S7 & 4 & 4 & 1 & 3 & 12 & $0 / 4$ \\
\hline S8 & 4 & 4 & 1 & 3 & 12 & $1 / 3$ \\
\hline Total & 32 & 20 & 20 & 45 & 72 & $7 / 25$ \\
\hline
\end{tabular}

structure: cases 1-4 mimic a scenario with one skull and three possible candidates, where only one ante-mortem photo of each candidate is available. In case 5, a more complex scenario is simulated, including four skulls and four possible candidates, with only one available ante-mortem photo of each candidate. In cases 6 and 7, the scenario simulated includes one skull and only one possible candidate, with several photos of the candidate available for analysis. Participants were not asked to tackle neither all the cases nor all the superimpositions within each case.

All the participants had to follow MEPROCS CFS framework, that is, best practices and recommended assessment criteria (detailed in Chap. 7).

This framework includes:

- The sources of uncertainty that have to be considered during the whole process

- The sources of error that have be minimized as much as possible

- The best practices that must be followed

- The practices that should be avoided

- The most appropriate pairs of homologous landmarks for orientation and assessment

- The requirement and desirable features of the technical means employed

- The most important criteria that must be evaluated for assessing the anatomical skull-face relationship

- The degrees for the craniofacial correspondence evaluation and the requirements to achieve each degree

All these recommendations have to be followed by all the participants in the current study. As a result of having a common methodology, "only" the technical means (that have to fulfill some requirements as well) and the knowledge and the experience of the practitioner should make a significant difference among the process followed by all the participants.

There are some of the issues included in the best practices that cannot be fulfilled due to the multicenter nature of the study. In particular:

- Use the real skull to confirm correct fit of the mandible with the cranium.

- Use the real skull and mandible to articulate the dentition and establish centric occlusion.

- Locate and mark landmarks on the skull before scanning. 


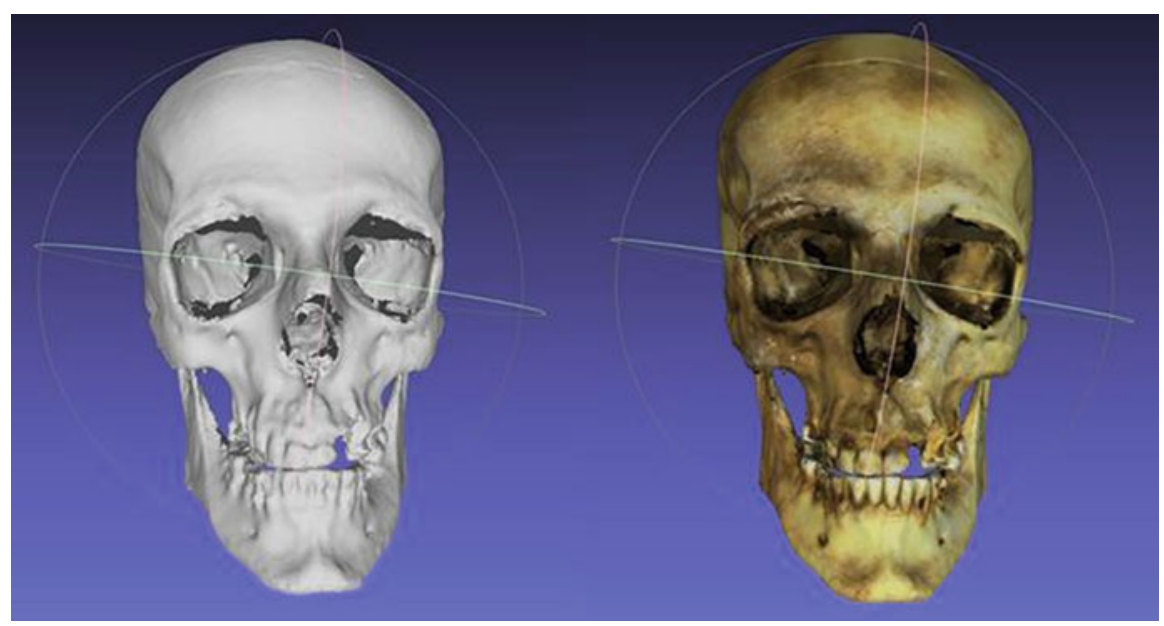

Fig. 9.1 Skull 3D model without texture information (on the left) and with texture information (on the right)

To minimize these shortcomings, we have obtained a digital replica of all the skulls with a precise 3D scanner device, which provided both accurate and realistic 3D models according to the original geometry and texture of the physical skull (see Fig.9.1).

Cranium and mandible are provided as separate 3D objects, so the participants can reproduce the position of the mandible as displayed in the AM photograph. In addition, they are also provided articulated as a single $3 \mathrm{D}$ object to better display the mandible articulation to minimize the effect of the second point. Landmarks were not located before scanning to avoid bias in the study since this point is already an issue that creates difference among different experts.

The fulfillment of the rest of the points included in the best practices is not always possible. The participants are limited by the quantity and quality of the materials and thus, according to the decision degrees in CFS, the confidence on their decision has to be adapted. Tables 9.2, 9.3, 9.4, and 9.5 summarize all these information. For each case study, it details the quantity and quality of the material of the corresponding CFS problems (for CFS problems for each identification case study). Each SFO implies the comparison of a single AM photograph with a skull 3D model. Thus, the following columns give information about the quality of both the image and the skull. In particular, the view of face of the subject within the photograph, if the photograph is the original or has been modified (mainly cropped from a larger photograph), if it is digital photograph or it is scanned, if the quality (mainly resolution) of the image fulfills MEPROCS guidelines, if the teeth of the subject are visible, and if there is any obscuring object or phenomena complicating the identification. Some remarks are given also to indicate other difficulties; in this study in particular, the perspective of some of the photograph could be difficult to achieve 


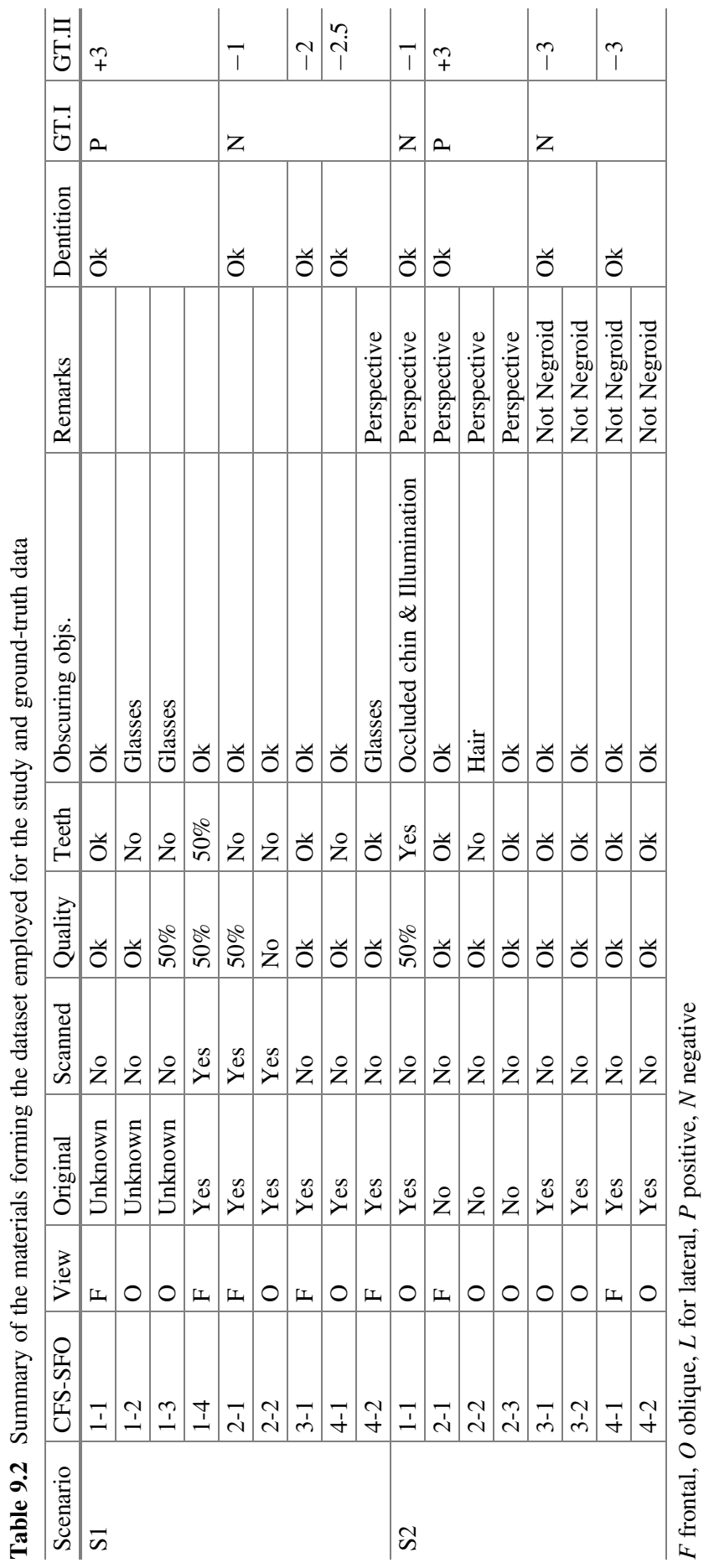




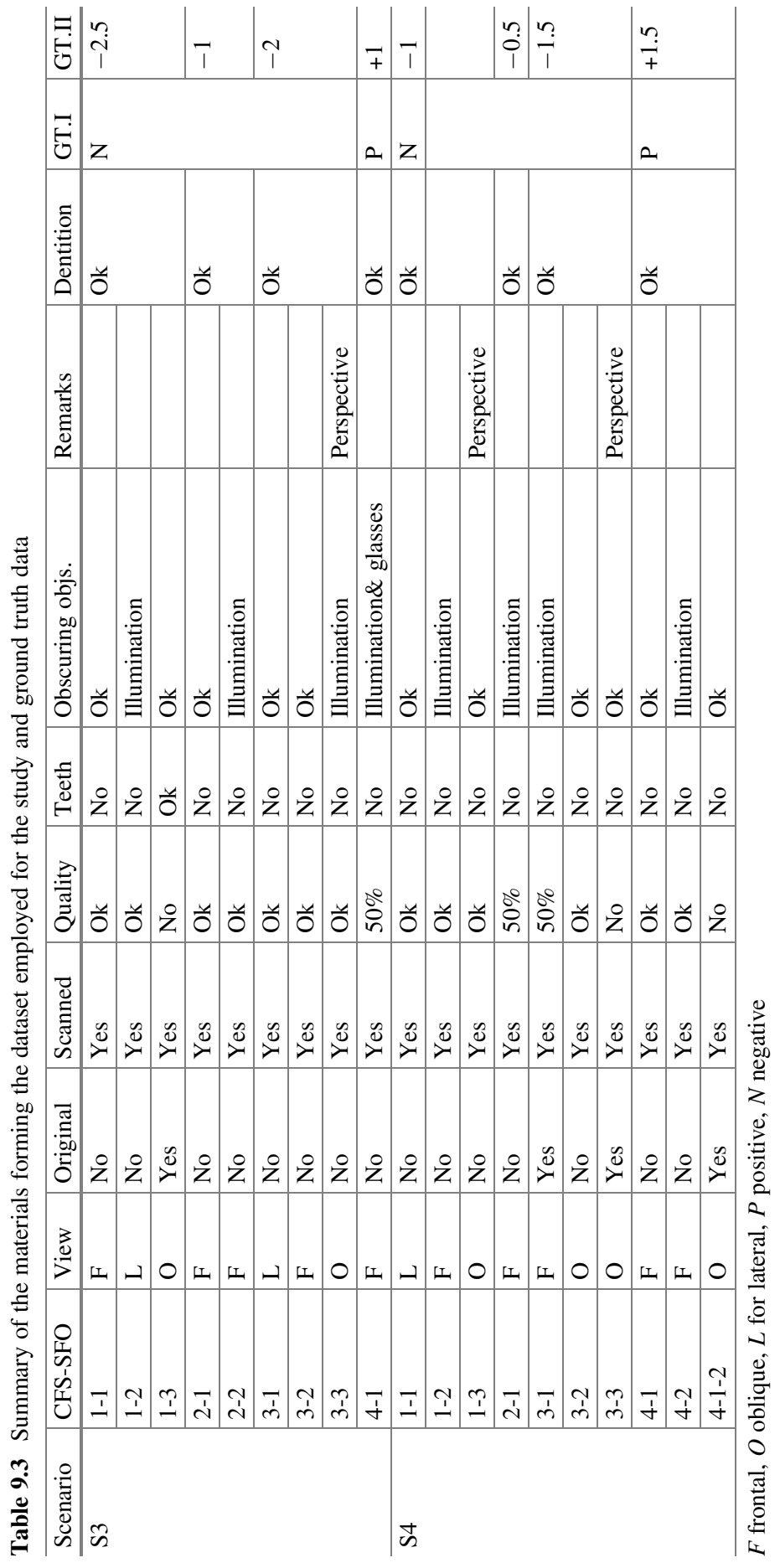




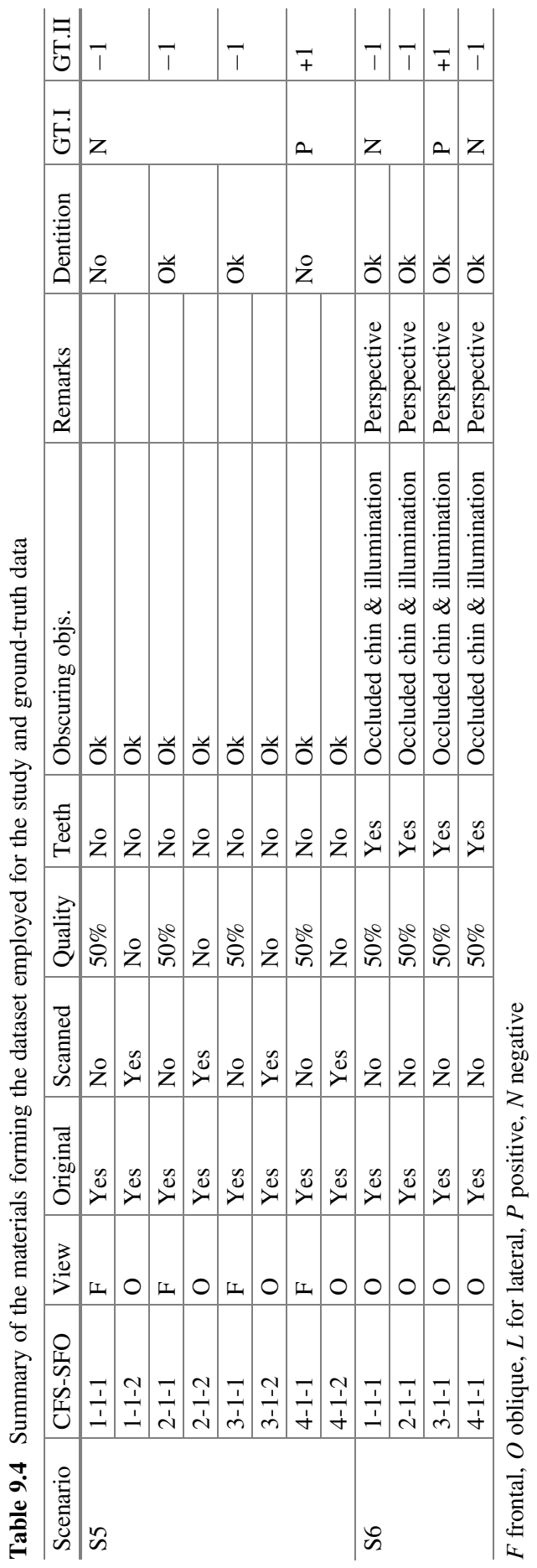




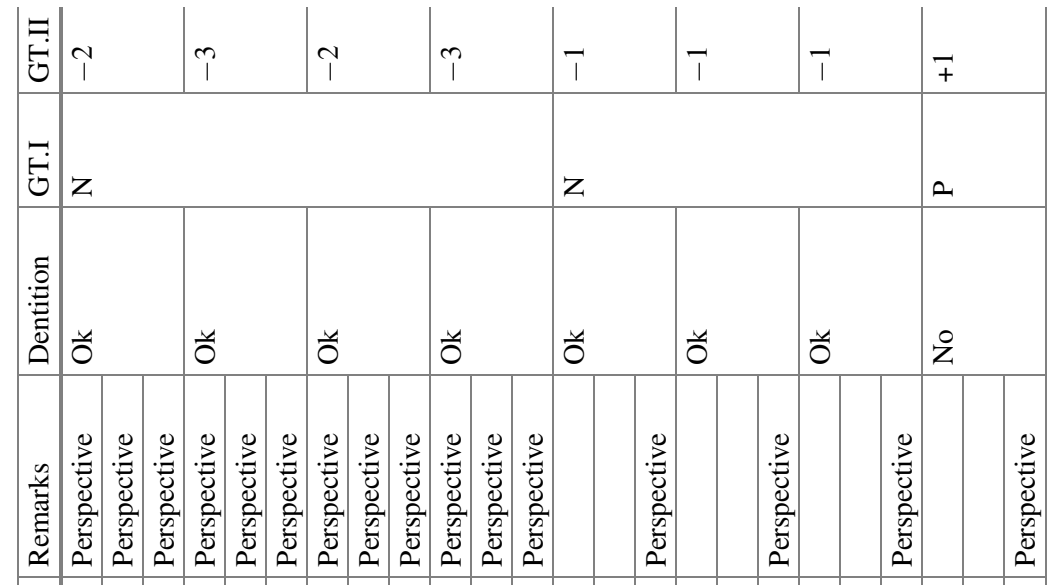

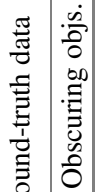
อิ

宅

至 $\stackrel{0}{=}$

苞

莺 음

宅 ఫ్ષ

离 $\stackrel{5}{ \pm}$

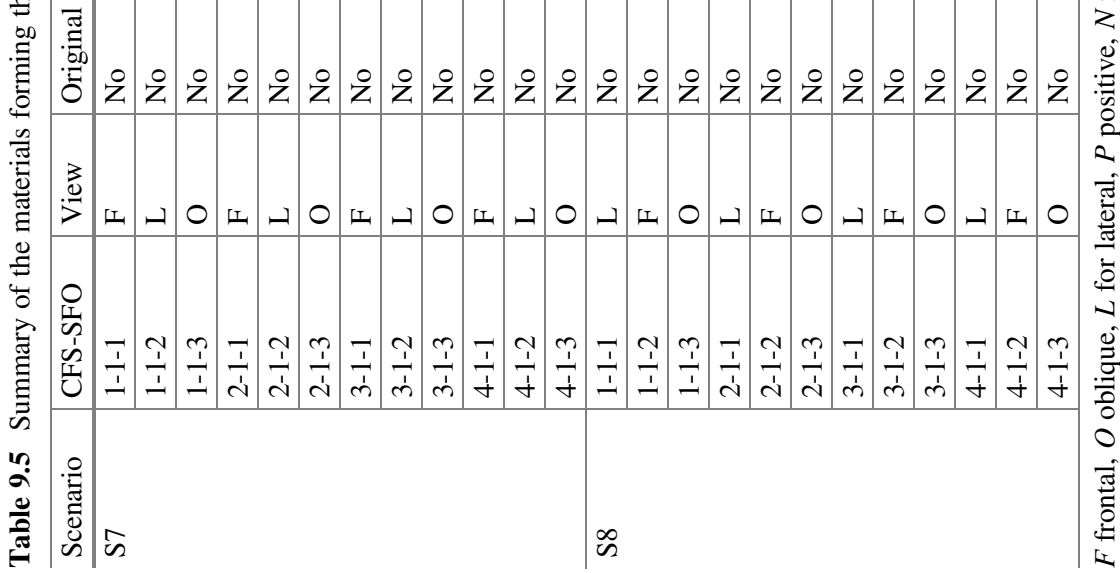


during the skull superimposition. Finally, it should be included information about the dentition of the skull, a "NO" means that the skull does not have enough dentition for teeth comparison purposes.

The last two columns refer to the real skull-face relationship, that is, the ground truth data (GT). The first of these two columns, "GT.I indicates whether the result of the CFS problem should be positive (P) or negative (N). The last column, "GT.II", refers to a ground-truth value different from the binary positive and negative real correspondence. It is a value established "manually" according to the scale defined in the decision degree table of MEPROCS framework and the quality and quantity of the materials described in Table 9.1. However, there is one important issue that could not be considered while establishing this second ground truth. As the decision degree table asserts: "There could be discriminatory characteristics that allow going left of right within the scale given an appropriate explanation in the report." This is not possible to model a priory, because it belongs to the anatomical correspondence interpretation by the participant. We have only modified "GT.II" in CFS cases 3 and 4 in the identification case study 2 , since the AM photographs clearly belong to Caucasian women while the cranium belongs to a Negroid.

Experience and familiarity with craniofacial identification techniques was also taken into account and level of experience of the participants was classified according to the following scheme:

1. No previous experience and no CFS-related training

2. No previous experience but CFS-related training

3. Short previous research experience and CFS-related training

4. Moderate previous experience with CFS real cases and CFS-related training

5. Broad experience with CFS real cases

The study was carried out by 12 participants from the following institutions: University of Granada (Spain), Legal Medicine and Forensic Sciences Institute (Peru), Complutense University of Madrid (Spain), University of Melbourne (Australia), Azienda Ospadaliera-Universitaria di Trieste (Italy), Russian Academy of Sciences (Russia), National Research Institute of Police Science (Japan), University of Milan (Italy), and Portuguese Judiciary Police (Portugal). Table 9.6 lists all the participants (numbered from 1 to 12) with their corresponding level of experience. Since not all the participants completed the whole study, information on the number of CFS addressed is provided as well. Finally, the last column depicts an approximate degree (linguistic scale) of the fulfillment of the guidelines suggested in the framework. Differently to the first study, there were no participants following neither a computer-aided manual video superimposition approach nor a computeraided manual photo superimposition approach. They all followed a computer-aided 3D-2D superimposition approach, manual in every case but participant 1 who employed a semiautomatic software.

After finishing every superimposition, participants were asked about the fulfillment of each point within the best practices and the practices that should be avoided 
Table 9.6 Participants of the study, their experience related to CFS, and number of CFS cases addressed

\begin{tabular}{l|l|l|l}
\hline Participant ID & CFS experience & CFS addressed & MEPROCS framework fulfillment \\
\hline 1 & 3 & 32 & High-moderate \\
\hline 2 & 4 & 12 & Moderate-high \\
\hline 3 & 5 & 32 & Moderate \\
\hline 4 & 5 & 32 & High \\
\hline 5 & 2 & 9 & Moderate-low \\
\hline 6 & 3 & 30 & Low \\
\hline 7 & 4 & 31 & Moderate-high \\
\hline 8 & 1 & 7 & Low \\
\hline 9 & 2 & 8 & Low \\
\hline 10 & 1 & 7 & Low \\
\hline 11 & 4 & 32 & Moderate-high \\
\hline 12 & 1 & 12 & Low \\
\hline
\end{tabular}

in order to obtain a degree of fulfillment of the framework. They were also asked if the computer tools employed are in line with the requirements and desirable features established along the framework. Additionally, we double checked the same points through the examination of the CFS image results provided by the participants. As a result, a few contradictions were found in some cases while absence of evidence supporting participants' answers in others. Thus, we finally arrived at Tables 9.7 and 9.8, which in most of the cases collect participants' answers (Wp: Whenever it was possible; "N": No; "Y": Yes) but sometimes the values were changed when it was clear that the participant does not apply a particular point of the framework. Additionally, when no evidences were provided, despite participant response, we indicate "Ne," that is, participants answered "Yes," but there is no evidence that they fulfilled this point.

Concerning the practices that should be avoided all of them answer "Yes" to the first point (confirmation bias), whenever it was possible to the second and third points (edentulous skulls and one single low-resolution image).

Apart from the 17 methodological points included in Table 9.7, MEPROCS framework also defines some requirements (7) and desirable features (8) concerning the computerized tools employed for acquiring, visualizing, and superimposing the skull 3D models over the AM photographs. Table 9.8 depicts which of these characteristics are provided by the systems they employed and which ones not.

Finally, participants were asked to fulfill a table with the corresponding degree of consistency of MEPROCS recommended criteria for each SFO addressed to include at least one image showing the superimposition obtained, indicating the time employed (see the last column of Table 9.8). At the end, for each CFS they were asked to provide a numeric decision according to the defined degrees of decisions (Damas et al. 2014). That numeric decision had to be supported by a decision report summarizing the main significant anatomical similarities and/or inconsistencies. 


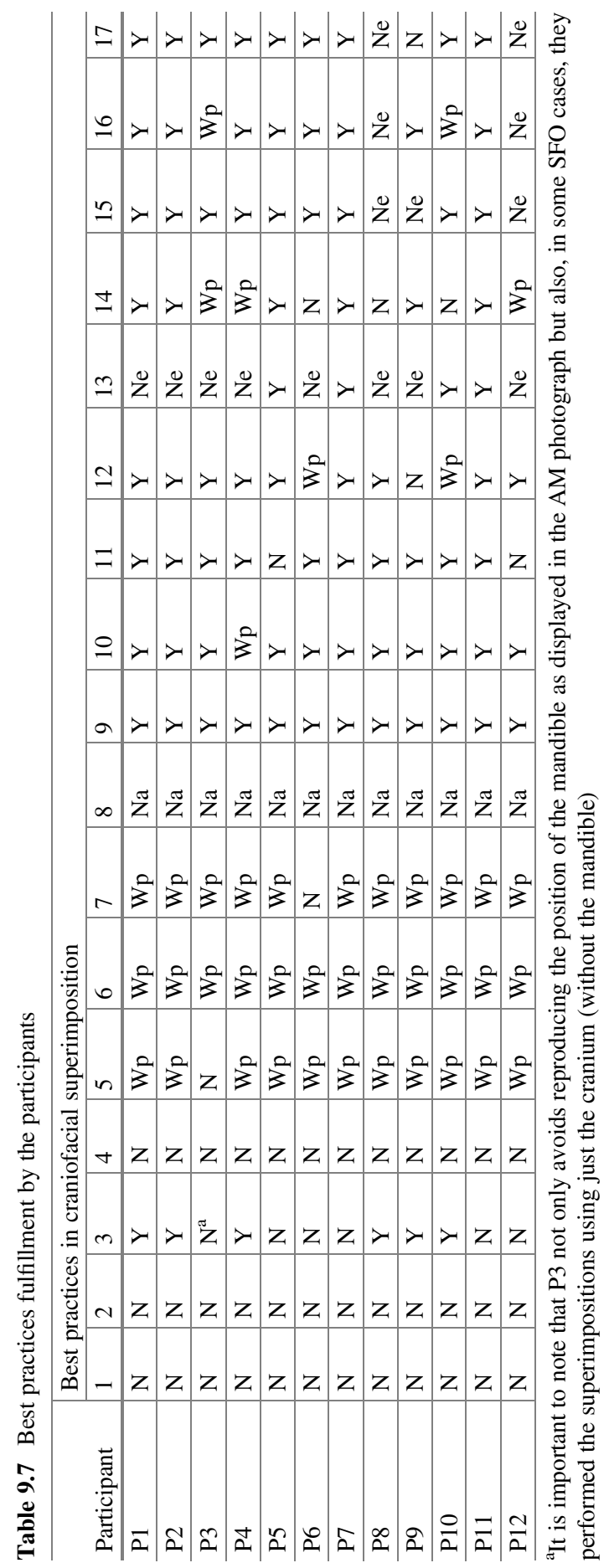


Table 9.8 Fulfillment of the requirements and desirable features of the computer-aided tools employed by the participants

\begin{tabular}{|c|c|c|c|c|c|c|c|c|c|c|c|c|c|c|c|}
\hline \multirow[b]{2}{*}{ Participant } & \multicolumn{7}{|c|}{ Requirements } & \multicolumn{8}{|c|}{ Desirable features } \\
\hline & 1 & 2 & 3 & 4 & 5 & $6^{\mathrm{a}}$ & 7 & 1 & 2 & 3 & 4 & 5 & 6 & 7 & 8 \\
\hline $\mathrm{P} 1$ & $\mathrm{Y}$ & $\mathrm{Y}$ & $\mathrm{Y}$ & $\mathrm{Y}$ & $\mathrm{Y}$ & $\mathrm{Y}$ & $\mathrm{Y}$ & $\mathrm{N}$ & $\mathrm{Y}$ & $\mathrm{Y}$ & $\mathrm{Y}$ & $\mathrm{Y}$ & $\mathrm{Y}$ & $\mathrm{N}$ & $\mathrm{N}$ \\
\hline $\mathrm{P} 2$ & $\mathrm{Y}$ & $\mathrm{N}$ & $\mathrm{Y}$ & $\mathrm{Y}$ & $\mathrm{Y}$ & $\mathrm{Y}$ & $\mathrm{Y}$ & $\mathrm{Y}$ & $\mathrm{Y}$ & $\mathrm{N}$ & $\mathrm{N}$ & $\mathrm{N}$ & $\mathrm{N}$ & $\mathrm{N}$ & $\mathrm{N}$ \\
\hline $\mathrm{P} 3$ & $\mathrm{Y}$ & $\mathrm{Y}$ & $\mathrm{Y}$ & $\mathrm{Y}$ & $\mathrm{Y}$ & $\mathrm{Y}$ & $\mathrm{Y}$ & $\mathrm{Y}$ & $\mathrm{Y}$ & $\mathrm{N}$ & $\mathrm{Y}$ & $\mathrm{Y}$ & $\mathrm{N}$ & $\mathrm{N}$ & $\mathrm{Y}$ \\
\hline $\mathrm{P} 4$ & $\mathrm{Y}$ & $\mathrm{Y}$ & $\mathrm{Y}$ & $\mathrm{Y}$ & $\mathrm{Y}$ & $\mathrm{Y}$ & $\mathrm{Y}$ & $\mathrm{Y}$ & $\mathrm{N}$ & $\mathrm{Y}$ & $\mathrm{N}$ & $\mathrm{Y}$ & $\mathrm{Y}$ & $\mathrm{Y}$ & $\mathrm{Y}$ \\
\hline P5 & $\mathrm{Y}$ & $\mathrm{N}$ & $\mathrm{N}$ & $\mathrm{Y}$ & $\mathrm{Y}$ & $\mathrm{Y}$ & $\mathrm{N}$ & $\mathrm{N}$ & $\mathrm{N}$ & $\mathrm{Y}$ & $\mathrm{Y}$ & $\mathrm{N}$ & $\mathrm{N}$ & $\mathrm{N}$ & $\mathrm{N}$ \\
\hline P6 & $\mathrm{Y}$ & $\mathrm{N}$ & $\mathrm{N}$ & $\mathrm{Y}$ & $\mathrm{Y}$ & $\mathrm{N}$ & $\mathrm{N}$ & $Y$ & $\mathrm{~N}$ & $\mathrm{~N}$ & $\mathrm{~N}$ & $\mathrm{~N}$ & $\mathrm{~N}$ & $\mathrm{~N}$ & $\mathrm{~N}$ \\
\hline $\mathrm{P} 7$ & $\mathrm{Y}$ & Y & Y & $\mathrm{Y}$ & $\mathrm{Y}$ & Y & Y & $Y$ & Y & $\mathrm{Y}$ & $\mathrm{Y}$ & $\mathrm{Y}$ & Y & $\mathrm{Y}$ & $\mathrm{N}$ \\
\hline P8 & $\mathrm{Y}$ & $\mathrm{N}$ & $\mathrm{Y}$ & $\mathrm{Y}$ & $\mathrm{Y}$ & $\mathrm{N}$ & $\mathrm{Y}$ & $\mathrm{N}$ & $\mathrm{Y}$ & $\mathrm{N}$ & $Y$ & $\mathrm{Y}$ & $\mathrm{N}$ & $\mathrm{N}$ & $\mathrm{N}$ \\
\hline P9 & $\mathrm{Y}$ & $\mathrm{N}$ & $\mathrm{N}$ & $\mathrm{Y}$ & $\mathrm{Y}$ & $\mathrm{Y}$ & $\mathrm{Y}$ & $\mathrm{N}$ & $\mathrm{N}$ & $\mathrm{Y}$ & $\mathrm{Y}$ & $\mathrm{Y}$ & $\mathrm{N}$ & $\mathrm{N}$ & $\mathrm{N}$ \\
\hline $\mathrm{P} 10$ & $\mathrm{Y}$ & $\mathrm{N}$ & $\mathrm{N}$ & $\mathrm{Y}$ & $\mathrm{Y}$ & $\mathrm{Y}$ & $\mathrm{Y}$ & $\mathrm{N}$ & $\mathrm{N}$ & $\mathrm{Y}$ & $\mathrm{Y}$ & $\mathrm{Y}$ & $\mathrm{N}$ & $\mathrm{N}$ & $\mathrm{N}$ \\
\hline P11 & $\mathrm{Y}$ & $\mathrm{N}$ & $Y$ & $\mathrm{Y}$ & $\mathrm{Y}$ & $\mathrm{Y}$ & $\mathrm{N}$ & $Y$ & $\mathrm{~N}$ & $\mathrm{~N}$ & $\mathrm{Y}$ & $\mathrm{N}$ & $\mathrm{N}$ & $\mathrm{N}$ & $\mathrm{N}$ \\
\hline P12 & $\mathrm{Y}$ & $\mathrm{N}$ & $\mathrm{Y}$ & $\mathrm{Y}$ & $\mathrm{Y}$ & $\mathrm{Y}$ & $\mathrm{N}$ & $\mathrm{N}$ & $\mathrm{N}$ & $\mathrm{Y}$ & $\mathrm{Y}$ & $\mathrm{N}$ & $\mathrm{Y}$ & $\mathrm{N}$ & $\mathrm{N}$ \\
\hline
\end{tabular}

$N$ no, $Y$ yes

${ }^{\text {a } D e s p i t e ~ p a r t i c i p a n t ~ P 1, ~ i t ~ i s ~ n o t ~ c l e a r ~ i f ~ t h e ~ r e s t ~ o f ~ p a r t i c i p a n t s ~ t h a t ~ a s s e r t ~ u s i n g ~ s o f t w a r e ~ t h a t ~}$ properly projects the 3D skull employed this feature or there is not such a feature or is rather limited

\subsection{Results}

A total number of 244 CFS problems, involving 382 SFOs, have been tackled by the participants. Their performance was measured according to true positive (TP), false positive (FP), true negative (TN), and false negative (FN) rates, together with expert proficiency (EP). All the indicators were calculated as the mean performance of the participant according to the number of CFS addressed. Additionally, we have also calculated a correlation value $\rho_{1}$ and a similarity value $s$.

Expert proficiency is calculated as $\mathrm{EP}=\frac{\mathrm{TN}+\mathrm{TP}}{P+N}$, where $P$ and $N$ are the number of positive and negative cases, respectively.

The equation for the correlation coefficient $\rho_{1}$ is: $\frac{\sum_{i}\left(x_{i}-\bar{x}\right) \sum_{i}\left(y_{i}-\bar{y}\right)}{\sqrt{\sum_{i}\left(x_{i}-\bar{x}\right)^{2} \sum_{i}\left(y_{i}-\bar{y}\right)^{2}}}$.

The equation for the similarity coefficient $s$ is: $\left|1-\frac{\sum_{i}\left(\left|x_{i}\right|-\left|y_{i}\right|\right)}{N \times 3}\right|$.

where $X$ and $Y$ are two sets of samples, $\bar{x}$ and $\bar{y}$ their respective means, and $\left|x_{i}\right|$ and $\mid$ $y_{i}$ l the absolute values of a particular sample of sets $X$ and $Y$, respectively. $N$ is the total number of samples. In Tables 9.9, 9.10, and 9.11, the set of sample $X$ and $Y$ corresponds to "GT.II" values (Table 9.2) and the identification decisions made by a particular participant, respectively.

While $\rho_{1}$ measures the correlation between the participants' decision and the ground-truth value according to MEPROCS scale ("GT.II"), $s$ considers only the absolute values of the same variables. Thus, $\rho_{1}$ calculates a correlation value according to correct and incorrect decisions and how well correlated is the degree 


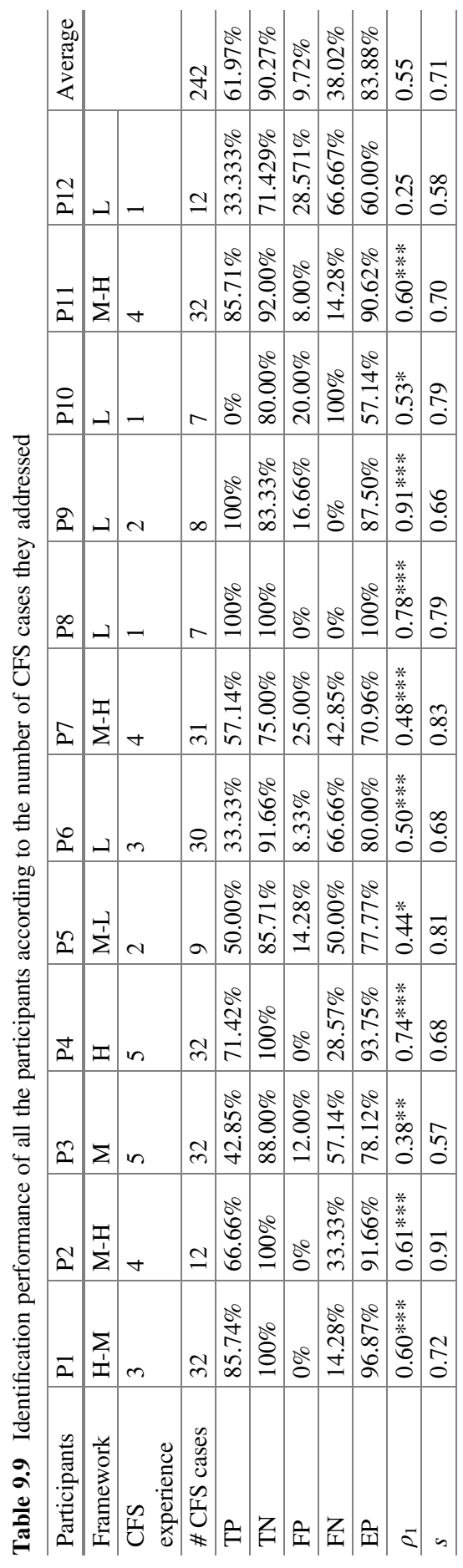


Table 9.10 Identification performance of different groups of participants according to the degree of fulfillment of the framework

\begin{tabular}{l|l|l|l|l}
\hline Average & All & Without L & Without M and M-L & Without M-H \\
\hline TP & $61.97 \%$ & $67.58 \%$ & $74.41 \%$ & $78.57 \%$ \\
\hline TN & $90.27 \%$ & $91.42 \%$ & $92.58 \%$ & $100.00 \%$ \\
\hline FP & $9.72 \%$ & $8.57 \%$ & $7.42 \%$ & $0.00 \%$ \\
\hline FN & $38.02 \%$ & $32.42 \%$ & $25.59 \%$ & $21.43 \%$ \\
\hline EP & $83.88 \%$ & $86.11 \%$ & $88.50 \%$ & $95.31 \%$ \\
\hline- & 0.51 & 0.52 & 0.58 & 0.67 \\
\hline- & 0.71 & 0.72 & 0.75 & 0.70 \\
\hline \# CFS cases & 242 & 180 & 139 & 64
\end{tabular}

Table 9.11 Identification performance of different groups of participants according to the participants' CFS experience

\begin{tabular}{l|l|l|l|l|l}
\hline Average & All & Experience $>1$ & Experience $>2$ & Experience $>3$ & Experience $>4$ \\
\hline TP & $61.97 \%$ & $64.05 \%$ & $63.25 \%$ & $64,543 \%$ & $57.14 \%$ \\
\hline TN & $90.27 \%$ & $91.16 \%$ & $91.71 \%$ & $89,820 \%$ & $94.00 \%$ \\
\hline FP & $9.72 \%$ & $8.83 \%$ & $8.28 \%$ & $10,180 \%$ & $6.00 \%$ \\
\hline FN & $38.02 \%$ & $35.94 \%$ & $36.74 \%$ & $35,457 \%$ & $42.85 \%$ \\
\hline EP & $83.88 \%$ & $85.32 \%$ & $85.57 \%$ & $84,173 \%$ & $85.93 \%$ \\
\hline- & 0.51 & 0.52 & 0.51 & 0.51 & 0.50 \\
\hline- & 0.71 & 071 & 0.71 & 0.71 & 0.62 \\
\hline \# CFS cases & 242 & 218 & 201 & 139 & 64 \\
\hline
\end{tabular}

of support of such decisions with the scale defined in MEPROCS framework. In contrast, $s$ is intended to isolate the measurement of the correlation in the degree of support (either positive or negative) of the decision.

Table 9.9 details participants' performance together with the degree of fulfillment of the framework according to the following scale: High ("H"), Moderate ("M"), Low ("L"), and their possible combinations.

Considering only the global performance ("EP"), 5 of the 12 participants carried out more than $90 \%$ of correct identification decisions. In particular, P8 managed to achieve a $100 \%$ of correct decisions although he/she only addressed 7 out of the 32 CFS cases. Contrary, P1 with a $96.87 \%$, P4with $93.75 \%$, and P11 with $90.62 \%$ of correct decisions tackled all the CFS cases (32). The worst results were achieved by participant 10 with only $57.14 \%$ of correct decisions over the seven CFS cases faced. The average performance is $83.88 \%$. With a similar tendency as the previous study developed (deliverable D4.4), "TN" and "FP" rates are clearly better than "TP" and "FN." In fact, four participants (P1, P2, P4, and P8) perfectly addressed negative cases, and the average "TN" rate is $90.27 \%$. Additionally, looking at the correlation values $\left(\rho_{1}\right)$, we can conclude that the decisions of the participants are well correlated with those expected within the scale given by MEPROCS framework. Table 9.9 also includes the significance ( $p$-values) for the following null hypothesis "There is no linear correlation between the participants' decisions and GT.II" with different 
degrees $(* p<0.05, * * p<0.01$ and $* * * p<0.001)$. Thus, according to the achieved p-values (super-index attached to each particular correlation value), all the participants' decisions except that of P12 are correlated with the expected decisions. Finally, higher values are obtained in the case of the similarity coefficient $s$. Such values increase because only the degree of support is considered.

The same average values are depicted in the first column of Table 9.10. However, we also include different average rates corresponding to different groups of participants with an increasing degree of fulfillment of the framework (see Table 9.10). In this sense, the second column refers to those participants who obtained at least a medium degree, the third includes only those participants who obtained at least medium-high degree, and finally, the last column includes participants with highmedium and high degree of fulfillment of the framework. From this figures, we can appreciate a significant improvement in participants' performance in line with the degree of fulfillment. Expert proficiency varies from an average value of $83.88 \%$ to $95.31 \%$ of the last group. Similarly, "TN" rates go from $90.27 \%$ to an outstanding $100.00 \%$.Although correlation follows the same increasing tendency, values slightly increase within the first groups and decrease in the last one.

Previous experience in CFS appears to not be a relevant factor in the identification performance (see Table 9.11). Only slightly differences are found when not considering participants that asserted to not have previous experience and CFS-related training.

Finally, Table 9.12 compares the performance of those participants that accomplished the two experimental studies designed by MEPROCS with the aim of testing CFS methodologies, tools, and practitioner's experience. While in the first one, the participants followed their own methodology, in the current study, they were forced to stick to MEPROCS framework, which also established some requirements and desirable features for the tools employed. The first important issue is the number of participants that performed the both studies, nine in total, addressing 520 CFS cases in the first study and 222 in the second. The average performance values are better in the second study for the percentage of correct decisions $(84.09 \%$ against $79.75 \%)$, "TN" (90.54\% against $83.33 \%)$ and "FP" (9.54\% against 16.66\%) rates. "TP" $(61.35 \%$ against $62.77 \%)$ and "FN" (38.64\% against $37.22 \%)$ rates are slightly worse in the second study. However, such percentages are really similar in both studies.

Finally, we computed some statistics using the values given by the participants to each particular criterion in each particular SFO case. First, the average standard deviation is used to numerically examine the differences while assessing (values from 0 to 5) the same criterion in all the SFO cases by the different participants. These values range from 0.87 (criterion 3.19 in frontal view, dental information) to 1.61 (criterion 1.7 in frontal view, entocanthion vertical line right).

Differently to $\rho_{1}$, we have calculated the correlation between the SFO binary (either positive or negative) ground truth ("GT.I") and the values given by the participants to each particular criterion in each particular SFO case. The equation for this correlation coefficient $\rho_{2}$ is the same as $\rho_{1}$ but $X$ sample refers now to binary ground truth of the SFOcase, "GT.I"(Tables 9.2-9.5) and $Y$ sample refers to the 


\begin{tabular}{|c|c|c|c|c|c|c|c|c|c|c|c|c|}
\hline & & & 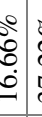 & 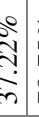 & $\begin{array}{l}0 \\
2 \\
2 \\
2 \\
2\end{array}$ & ते & $\begin{array}{l}0 \\
n \\
n \\
0 \\
0\end{array}$ & 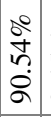 & 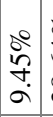 & 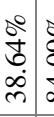 & 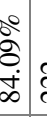 & ปิ \\
\hline & 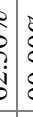 & مُ & 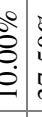 & 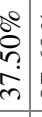 & $\begin{array}{l}0 \\
0 \\
0 \\
\infty \\
\infty\end{array}$ & $\stackrel{\infty}{n}$ & $\begin{array}{l}0 ̊ \\
m \\
m \\
m\end{array}$ & 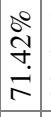 & $\begin{array}{c}0 \\
0 \\
n \\
\infty \\
\infty \\
i\end{array}$ & \begin{tabular}{l|l}
8 & \\
8 & \\
$\dot{0}$ & \\
0 &
\end{tabular} & $\begin{array}{l}8 \\
8 \\
8 \\
8 \\
8\end{array}$ & $\simeq$ \\
\hline & $\begin{array}{l}0 \\
0 \\
\vdots \\
\vdots \\
\vdots \\
\vdots\end{array}$ & $\begin{array}{l}0 \\
0 \\
0 \\
0 \\
0 \\
0\end{array}$ & 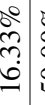 & $\begin{array}{l}8 \\
8 \\
8 \\
\dot{8} \\
n\end{array}$ & $\begin{array}{l}\stackrel{0}{0} \\
0 \\
2 \\
2\end{array}$ & in & $\begin{array}{c}0 \\
2 \\
\dot{2} \\
\infty\end{array}$ & $\begin{array}{c}0 \\
8 \\
\text { ja } \\
\alpha\end{array}$ & $\begin{array}{c}0 \\
\stackrel{0}{0} \\
0 \\
\infty \\
\infty\end{array}$ & \begin{tabular}{l|l}
$\stackrel{0}{0}$ & \\
0 & \\
$\dot{J}$ &
\end{tabular} & 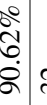 & ते \\
\hline & & & \begin{tabular}{l|l}
$\infty$ & \\
$\infty$ & \\
$\infty$ & \\
$\infty$ &
\end{tabular} & $\begin{array}{l}0 \\
0 \\
0 \\
+ \\
\infty \\
m\end{array}$ & 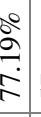 & in & $\begin{array}{l}0 \\
\pm \\
\text { in } \\
\text { in }\end{array}$ & $\begin{array}{c}0 \\
8 \\
0 \\
i \\
i \\
\end{array}$ & $\begin{array}{l}0 \\
8 \\
0 \\
\\
1\end{array}$ & 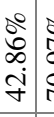 & : & $\bar{m}$ \\
\hline & $\begin{array}{l}0 \\
t \\
t \\
f\end{array}$ & | & 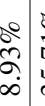 & $\begin{array}{l}\frac{0}{7} \\
\frac{1}{n} \\
m\end{array}$ & $\begin{array}{c}\frac{0}{7} \\
\frac{8}{\infty}\end{array}$ & 8 & $\begin{array}{c}0 \\
m \\
m \\
m\end{array}$ & $\begin{array}{l}\frac{0}{0} \\
\dot{b} \\
\dot{a}\end{array}$ & $\begin{array}{c}0 \\
\stackrel{0}{2} \\
m \\
\infty \\
\infty\end{array}$ & 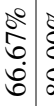 & $\begin{array}{l}\stackrel{0}{0} \\
8 \\
8 \\
\infty \\
\infty\end{array}$ & ల్ల \\
\hline & & $\begin{array}{l}0 \\
0 \\
0 \\
0 \\
0 \\
0\end{array}$ & $\begin{array}{c}\stackrel{0}{\infty} \\
\infty \\
\infty \\
\infty\end{array}$ & $\begin{array}{l}0 \\
0 \\
0 \\
\vdots \\
j \\
f\end{array}$ & $\begin{array}{l}00 \\
\infty \\
0 \\
0 \\
\end{array}$ & in & $\begin{array}{l}80 \\
8 \\
0 \\
0 \\
n\end{array}$ & $\mid \begin{array}{c}0 \\
\frac{0}{2} \\
n \\
\infty\end{array}$ & $\begin{array}{l}\stackrel{0}{\circ} \\
\stackrel{2}{ \pm} \\
\dot{ \pm}\end{array}$ & 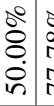 & 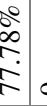 & $a$ \\
\hline & $\dot{0}$ & $\begin{array}{l}0 \\
0 \\
0 \\
0 \\
0\end{array}$ & 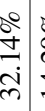 & $\begin{array}{l}0 \\
\stackrel{0}{ } \\
\grave{ \pm} \\
\dot{ \pm}\end{array}$ & $\frac{\stackrel{0}{0}}{\stackrel{+}{+}}$ & 8 & $\begin{array}{c}\stackrel{0}{f} \\
\stackrel{\sim}{*}\end{array}$ & $\begin{array}{l}0 \\
0 \\
0 \\
8 \\
0\end{array}$ & $\begin{array}{l}0 \\
8 \\
0 \\
0\end{array}$ & 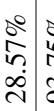 & 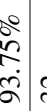 & ल) \\
\hline & 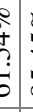 & 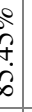 & 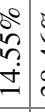 & $\begin{array}{l}0 \\
0 \\
0 \\
\vdots \\
\infty \\
m\end{array}$ & $\begin{array}{l}0 \\
\infty \\
\infty \\
0 \\
\infty \\
\infty\end{array}$ & in & $\begin{array}{l}0 \\
0 \\
0 \\
j \\
j \\
\mathcal{J}\end{array}$ & $\begin{array}{l}0 \\
8 \\
0 \\
\infty \\
\infty\end{array}$ & $\begin{array}{l}0 \\
8 \\
0 \\
\mathrm{j}\end{array}$ & 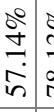 & $\begin{array}{c}0 \\
\substack{0 \\
\infty \\
\infty} \\
\end{array}$ & ले \\
\hline & & 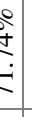 & 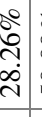 & $\begin{array}{l}8 \\
8 \\
8 \\
\vdots \\
i n \\
\end{array}$ & 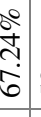 & $\stackrel{\infty}{n}$ & $\begin{array}{l}00 \\
6 \\
\dot{0} \\
0\end{array}$ & $\begin{array}{l}0 \\
0 \\
0 \\
8 \\
8 \\
-\end{array}$ & $\begin{array}{l}0 \\
8 \\
8 \\
0 \\
0\end{array}$ & 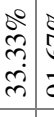 & 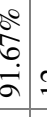 & $\simeq$ \\
\hline & 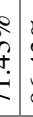 & $\begin{array}{l}0 \\
\vdots \\
0 \\
\vdots \\
0\end{array}$ & $\begin{array}{l}\stackrel{0}{2} \\
i n \\
m\end{array}$ & 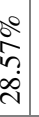 & $\begin{array}{l}\stackrel{0}{+} \\
\stackrel{+}{+} \\
\dot{a}\end{array}$ & 8 & $\begin{array}{l}20 \\
\frac{2}{2} \\
\infty \\
\infty\end{array}$ & $\mid \begin{array}{l}8 \\
8 \\
8 \\
8 \\
0 \\
\end{array}$ & $\begin{array}{l}0 \\
8 \\
8 \\
0 \\
0\end{array}$ & 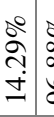 & 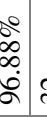 & ๗ิ \\
\hline & & Z & 空 & ZI & $\frac{0}{I I}$ & 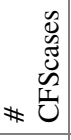 & 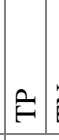 & Z & 足 & 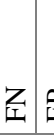 & 어 & 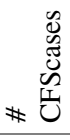 \\
\hline & & & & & & & 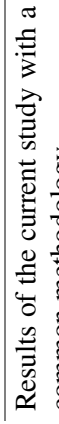 & 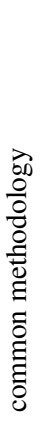 & & & & \\
\hline
\end{tabular}


values given to the different skull-face correspondence criteria by the different participants. Similar to Table 9.9, Table 9.13 also includes the significance ( $p$ values). According to them, the majority of the values given to the criteria by the participants are correlated with the CFS binary ground truth values ("GT.I"). Only criteria 1.70 and 2.22 (in frontal view), and 4.17 and 4.14) in lateral view resulted to be not correlated. The strongest correlation ( $p$-values lower than 0.0001 ) is achieved by criteria $3.19,4.20,4.50,4.10,2.23,3.10$ (in frontal view) and 3.19, 3.18, 2.40, 3.11 , and 2.90 (in lateral view). Exactly the same statistical results were achieved using Spearman correlation ("Sp") and regression ("r"), thus reinforcing the latter conclusions.

\subsection{Discussion and Conclusions}

The main goal of this experimental study is to validate the framework for CFS developed by MEPROCS consortium. Thus, a multiparametric analysis is discussed in this section according to framework understanding and fulfillment, participants' performance, and correlation between expected decisions and those given by the participants. While the latter two issues can be quantitatively validates, only a qualitative validation is possible for the former.

\subsubsection{Framework Understanding and Fulfillment}

Last column of Table 9.6 shows the degree of fulfillment of the framework by each participant. This degree was "manually" fixed following a quantitative approach with a certain degree of subjectivity. Degrees have been assigned according to the number and importance of practices and requirements not fulfilled. Even if all the participants were asked to fulfill every single point of the framework, the average degree of fulfillment is moderate. The main reasons for not following the recommendations could be summarized as follows:

- Impossibility due to limitations on the design of the study

- Impossibility due to limitations on the practitioner skills or tools

- Framework misunderstanding or resistance to change practitioner's normal procedure

As we explained, a few points were not possible to be fulfilled because of the remote nature of the study and the impossibility to share the actual skull, in particular points 1, 2, and 4. Point 8 , "During the growth and development stages use the most recent AM photos," was not applicable in the study, since there are no cases corresponding to juvenile people. Almost all the participants answered "whenever it was possible" for points 5,6 , and 7. These points refer to the use of multiple AM photos in different poses, AM photographs with a good quality and images without 


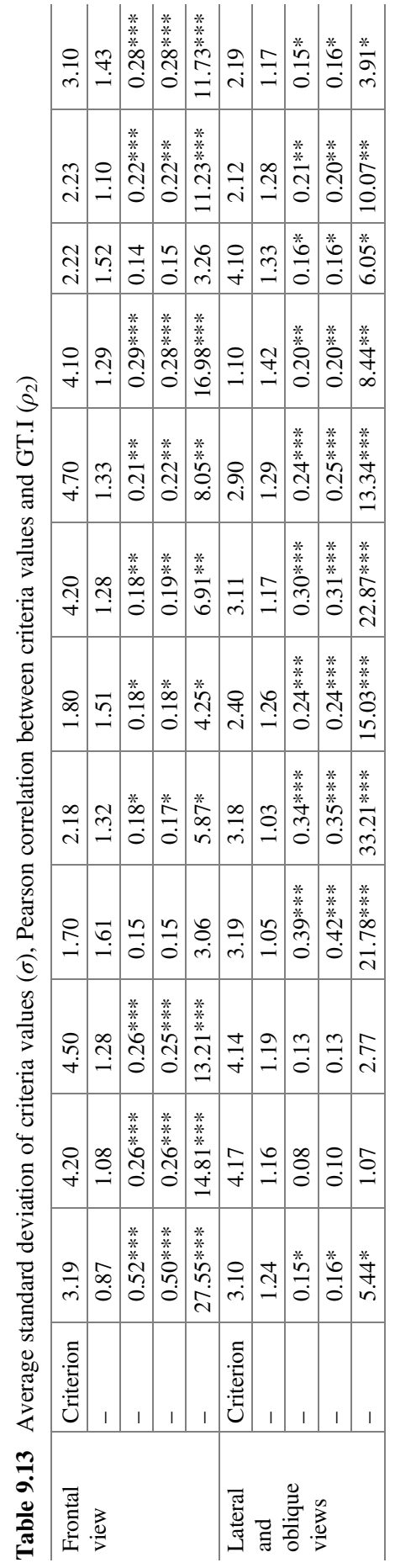


obscuring objects. Among them, as Table 9.5 shows, there are some cases where these conditions are not fulfilled; hence, most of the responses were Wp. Still referring to the AM pictures, most of the participants followed points 9, 10, 11, and 12. However, some authors decided to not articulate the mandible according to the AM photograph (point 3). This task was identified as an important source of error (approach CFS without a correct mandible position) but also a source of uncertainty (it is not possible to know exactly the precise articulation). The lack of proper skills or the absence of adequate tools could be the reasons to avoid mandible articulation, which has been identified as a difficult task.

The main limitations arose with the computer software employed. Eight of the participants noted that their software does not allow to locate or show landmarks, four participants recognized that the computer program employed does not allow transparency mode. Also in the requirement part, it is not clear if the participants that assert using a software that properly projects the 3D skull employed this feature or there is not such a feature or is rather limited. When analyzing the degree of fulfillment of the desirable features for CFS recommended in the MEPROCS framework, the situation is even worse. Six of them do not provide visualization capabilities of 3D models with texture information, eight of them do not allow wipe mode, three do not provide tools for the simultaneous interaction with 3D skull and the AM photograph, and only two of them provide tools for marking contours and lines and distance measurement.

Although all the participants reported to fulfill point 11, “. . do not use cropped images...", four participants provided cropped images as a result. They then recognized to crop the image before performing the SFO. This could have a negative effect depending on the software employed and the perspective of the particular photograph.

A majority of the participants did not give evidences of fulfilling point 13, "analyze and describe separately both the skull and the face in the photograph(s) to be compared...". A clear example is the identification scenario S2 where the skull belongs to a Negroid subject and three of the four possible candidates are clearly Caucasians. Just a few participants documented this issue and avoided to perform the corresponding SFO.

Opposite to point 15 , "use as many criteria as possible in order to study the relationship between the face and the skull," some of the participants only provided values for the framework criteria without further analysis of other criteria. It is not clear if they mentally or methodologically employed other criteria, but there is no evidence to consider that. Similarly, a few authors did not provide any evidence of following recommendations 16 and 17. "Consider the discriminative "power" of each anatomical criterion" and "Give an appropriate "weight" to each criterion ...", respectively. Behind the absence of evidences for points 13,15, 16, and 17 could be the nature of the task (experimental study against real identification scenario) and time constraints that make practitioners to be less precise and rigorous in their reports.

Similarity coefficient $s$ values are in general high, what denotes a good understanding and fulfillment of the decision degrees table of the framework. 
The main conclusion of the framework understanding and fulfillment is that, in general, the best practices and software requirements were understood. However, it was difficult to follow all the recommendations mainly due to design limitations and lack of specific software.

\subsubsection{Participants' Performance}

Results depicted in Tables 9.11 and 9.13 show a clear improvement in the performance linked with the fulfillment of the framework. This is quite obvious when considering incrementally those participants with at least a certain degree of fulfillment of the framework (Table 9.11). We can assert that for the given study, the relation between performance and framework fulfillment is almost linear. Even if the degree of fulfillment of the framework is not considered, there is still an objective improvement in the performance. This fact is demonstrated in Table 9.13. The results of the same group of participants in two similar studies were compared. In the first one, the participants followed their own methodology, while in the current study, they were required to follow MEPROCS framework. There is an improvement in the global performance and, in particular, in "TN" and "FP" rates. At this point, it is important to note one important difference between the types of identification scenarios presented in both studies. While in the current study, there are at least two AM photographs in 27 of the 32 CFS problems, in the study subject for comparison (Ibáñez et al. 2014b), only 4 of a total of 60 CFS problems involve the comparison of more than one AM photograph.

\subsubsection{Correlation}

Together with the analysis presented in Tables 9.7 and 9.8, the correlation values obtained reinforce the assumption that the introduction of framework improves participants' performance. Although not directly related with "EP," $\rho_{1}$ correlation is in general higher for those participants performing better (see Table 9.10). In addition, $p$-values demonstrated a strong correlation between the expected decision and the performance. Similarity coefficient $s$ values are even higher than correlation ones. This closer relation could be expected, since $s$ coefficient does not link participants' decisions with correct decisions by just with the expected degree of support.

One important factor that could not be considered when we established the ground-truth values of each CFS case ("GT.II" in Tables 9.1-9.5) refers to the inability to model in advance discriminatory characteristics of either the skull or the face in the AM photograph that allow, as indicated in the definition of the decision degrees table of the framework, going left of right within the scale given an appropriate explanation. This fact presumably has an influence in the correlation 
values as ground-truth values did not consider discriminatory characteristics but just quality and quantity of the materials.

The assessment of the skull-face relationship criteria made by the participants resulted in its being correlated with the CFS cases ground truth ("GT.I") in the majority of the cases. However, criteria 1.70 and 2.22 (in frontal view), and 4.17 and 4.14(in lateral view) are not correlated. We find two possible explanations of the lack of correlation for these criteria.

Although the proposed methodologies for achieving an optimal and unbiased SFO (Ibáñez et al. 2015) and for the analysis of the criteria for assessing skull-face correspondence in craniofacial superimposition (Ibáñez et al. 2014a) were themselves a great achievement, the conclusions drawn in the criteria study, as pointed out by the authors, were influenced by the materials employed (i.e., cone-beam CTs that lacked the upper part of the skull and presented additional inconveniences), and more thorough studies have to be developed. The low correlation values could be also explained through the different SFO obtained by the participants. As pointed out in the first study (Ibáñez et al. 2014b), that of course had a clear influence on the analysis of the morphological relationship. A common problem that still affects MEPROCS framework is the absence of an objective evaluation of the resulting SFO. Each participant followed a different approach, and it is not possible to say which one is better without the ground-truth data.

Open Access This chapter is licensed under the terms of the Creative Commons AttributionNonCommercial 2.5 International License (http://creativecommons.org/licenses/by-nc/2.5/), which permits any noncommercial use, sharing, adaptation, distribution and reproduction in any medium or format, as long as you give appropriate credit to the original author(s) and the source, provide a link to the Creative Commons license and indicate if changes were made.

The images or other third party material in this chapter are included in the chapter's Creative Commons license, unless indicated otherwise in a credit line to the material. If material is not included in the chapter's Creative Commons license and your intended use is not permitted by statutory regulation or exceeds the permitted use, you will need to obtain permission directly from the copyright holder.

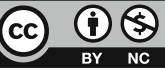




\section{Chapter 10 \\ Conclusions}

\subsection{Introduction}

The conclusions of this handbook cannot be separated from the MEPROCS project where the manuscript was first conceived and then progressively developed by the team through a wide variety of tasks contributing to the final document.

It is not a trivial task to summarize the main points resulting from 30 months of difficult work at an international level. Beyond the particular conclusions that are detailed below, the main global achievement of the MEPROCS project is the focus toward an international standard in craniofacial superimposition. To the best of our knowledge, such standardization has never been attempted before in the field of forensic anthropology. Furthermore, the particular standardization approach followed in MEPROCS and described in this handbook can be easily replicated in some other forensic disciplines where similar initiatives are demanded.

The absence of similar joint efforts in the past or at least the lack of public documentation represented a real challenge for MEPROCS. This handbook is a first attempt to resolve the situation and facilitate similar works in the future.

In this chapter, the main achievements of the MEPROCS project are presented in Sect. 10.2. Sect. 10.3 describes the problems encountered during the project and the way they were solved. Section 10.4 is devoted to present some future works and research proposals. Finally, some concluding remarks are included in Sect. 10.5.

\subsection{Main Achievements}

When compared to what the state of the art was before MEPROCS, there are plenty of important achievements that are directly related to the tasks performed in the project. Some of the most representative are enumerated as follows: 
- The handbook. This represents one of the most important achievements of the project. From the very beginning, when the MEPROCS proposal was formulated and submitted for evaluation to the European Commission, it was our intention to achieve an international agreement with practical use. This was a twofold challenge: the contents and its distribution. The former was a challenge, because the standardization task had not been tried before in the field. The distribution was also challenging as we wanted to facilitate as much as possible global access to the handbook. The publication in an open-access format by Springer (one of the leading publishing companies in the world) solved this issue.

- Global effort. One of the most important MEPROCS characteristics was the aim to be a global initiative. It was global because for the first time there was a collective, interdisciplinary, and international effort focusing on craniofacial superimposition. Furthermore, it was open and inclusive so that new institutions interested in this technique could join the project at any time. The conclusions of the project would be more important for the evolution of the technique and the profession in general, if the final number of participants was greater than the initial consortium. In particular, the number of institutions involved in MEPROCS evolved from the starting 7 institutions up to more than 30 . At the moment, most of the participant institutions are willing to continue in collaboration to achieve the pending MEPROCS objectives together with any other task that could contribute to the evolution of the technique beyond the time constraints imposed by the commitments related to a project using public funds.

- Global analysis. For the first time, the technique was analyzed considering the different tasks involved along the whole process of craniofacial superimposition, that is, from the very first steps to study the skull found (once cleaned) to the final report. This type of analysis may be considered global in its approach.

- Global participants. MEPROCS attracted the attention of a broad variety of end-users, that is, professionals who have important responsibilities in forensic identification. In particular, both researchers and practitioners were crucial to achieve the MEPROCS objectives. Among them, we emphasize the collaboration of the police forces of four different countries. Furthermore, the role of the technical institutions that joined MEPROCS was equally important and the need for a multidisciplinary team to properly approach the CFS technique was demonstrated.

- Common data. In order to achieve international agreements that lead to standards on CFS, it was vital to avoid the bias induced by the subjective evaluations of the results. That was only possible with a purely objective approach to all the MEPROCS tasks based on the study of the same data. Important legal and ethical issues were analyzed and addressed in order to share the data among the MEPROCS participants worldwide. Finally, we would like to thank the data providers for their altruistic and crucial contribution to the success of the project. In particular, Prof. Caroline Wilkinson (University of Dundee) who provided the data with the permission of the University of Tennessee, Dr. Fabio Cavalli (Azienda Ospedaliero-Universitaria di Trieste) who provided clinical data, 
Dr. Cristina Cattaneo (University of Milan), and Dr. Rimantas Jankaukas (Vilnius University) who provided data from their own laboratories.

- Ground truth. Unlike some other more established forensic techniques, there was a lack of ground-truth data in craniofacial superimposition, that is, a procedure that could provide a perfect skull-face overlay in an objective and unquestionable manner. This information is fundamental for the appropriate validation of any technique. MEPROCS provided the first ground-truth dataset for craniofacial superimposition. Only with the availability of such ground-truth data, the most relevant criteria to analyze a particular superimposition could be recommended.

- Specialized training. The International Conference on Craniofacial Superimposition (ICCFS-2014) took place in Dundee in July 2014. It was the final and most important MEPROCS event and the first international conference specifically devoted to craniofacial superimposition. The ICCFS-2014 technical program was rich and varied, including two keynote speakers renowned worldwide. During the last 3 days of the conference, the delegates (more than 100) had a unique opportunity to receive a diverse and high-quality training on craniofacial superimposition based on the MEPROCS recommendations and including the approaches of different laboratories from all around the world.

- First standard in the field. The aim of the first technical study performed in MEPROCS was to assess the reliability of different craniofacial superimposition methodologies and the corresponding technical approaches to this type of identification. With all the data generated, some of the most representative experts in craniofacial identification joined in a discussion intended to identify and agree on the most important issues to be considered for craniofacial superimposition. As a consequence, the consortium produced the first standards in the field, including best and worst practices, sources of error and uncertainties, technological requirements and desirable features, and, finally, a common scale for the craniofacial matching.

- Set of evaluation criteria. The purpose of the second technical study was to analyze the subjectivity and discriminative power of the different criteria for assessing the skull-face correspondence as proposed in the literature or by any of the MEPROCS partners. This novel study provided important insights to better understand: (1) which are the most and less discriminative criteria; (2) which criterion depends more on the expert who is evaluating it and which criteria are more independent, that is, less subjective. Even though the conclusions drawn in the study were influenced by the materials employed (i.e., cone-beam CTs [CBCTs] that lacked the upper part of the skull and presented additional inconveniences), the proposed methodology was itself a great achievement that may lead to further and more thorough studies.

- MEPROCS framework. According to the conclusions of the two technical studies, the MEPROCS consortium defined the MEPROCS framework to aid in the application of craniofacial superimposition. The framework consists of best and worst practices, sources of error and uncertainties, technological requirements and desirable features, a common scale for the craniofacial matching evaluation, 
and finally a set of evaluation criteria. See Chap. 8 for a detailed description of the framework.

- Performance evolution analysis. Once the craniofacial superimposition framework was proposed, a third technical study was performed. All partners were asked to deal with a variable number of CFS cases (positives and negatives) following all the recommendations collected within the framework. Individual and average performance was compared with the performance achieved during the first study in order to analyze its evolution (either positive or negative) when considering the MEPROCS framework. Though the number of participants was limited, the performance of the majority improved when they followed the MEPROCS recommendations.

- International awareness. Craniofacial superimposition, although existing for at least a century, is still a controversial technique within the scientific community. That is demonstrated by the small number of recent publications. The evolution of the use of craniofacial superimposition strongly depended on the specific country and the frequency of potential cases as well as the available means to apply alternative identification techniques. In developed countries, the small number of cases and the recent advances in alternative and more expensive techniques for identification led to a progressive reduction in the application of craniofacial superimposition. In contrast, the large number of cases in developing countries is typically related to high criminal rates or humanitarian issues such as crimes against humanity or identification following mass disasters. Also, the funds for identification are usually limited in these regions. This situation leads to a very frequent application of the technique in such countries. MEPROCS faced this duality and the need to awaken interest on the international consolidation of the technique. In particular, different labs have shown a new interest in craniofacial superimposition. MEPROCS has also laid the foundations for a more reliable technique. Definitely, the advances in the reliability of the technique will involve a broad number of new stakeholders.

- From experts' opinions to studies of metadata. In craniofacial superimposition, as in forensic identification in general, both legal authorities and the scientific community are insisting upon real science in forensic identification, that requires the successful demonstration of individualization (i.e., an expert's confirmation of a particular set of characteristics unique to the deceased (Holobinko 2012). The core assumptions that underpin conventional forensic craniofacial superimposition rely more on experience and faith than on empirical evidence. Perception and judgment may be affected by bias, expectations, beliefs, and motivations. Many forensic disciplines, including identification sciences like anthropology, involve some degree of subjectivity. Disciplines like forensic anthropology may be problematic to the courts since they may sometimes employ a combination of traditional scientific methodologies and less rigorous observational methodologies coupled with case study evaluations or casework experience. Since the 1993 US Daubert ruling, many forensic disciplines including anthropology have determined that there is a need to critically reevaluate some of the techniques and methods used in their examinations, as well as the validity of the underlying 
scientific theories (Christensen and Crowder 2009; Saks 2010). It is therefore imperative to minimize the risk of error through quality assurance (i.e., proper training, method validation, accreditation, and certification). Quality assurance in forensic anthropology can be established through validation studies of analytical methods in order to determine method reliability (precision and accuracy) and through the development of professional standards in the form of best practice protocols. Subjectivity is not necessarily equal to unreliability (Christensen and Crowder 2009); thus, nothing is preventing at least some types of anthropological testimony from being admitted as technical expert testimony under the Kumho standard, as the court acknowledges that science is too complex to evaluate with a single set of standards (Grivas and Komar 2008). The potential users of practical guidelines, other recommendations, and protocols need to know how much confidence they can place in such recommendations. Protocols must be systematically developed by panels of experts with access to the available evidence, an understanding of the problem and research methods, and sufficient time for reflection (Grade-Working-Group 2004) that the MEPROCS project provided. Some of the key elements of the methodology discussed in these guidelines are the fact that they were developed by a multidisciplinary group; they were based on a systematic review of the scientific evidence; and recommendations were linked to the supporting evidence and graded according to the strength of that evidence.

\subsection{Problems Encountered}

It is important to highlight that the achievements were reached after solving some problems encountered. The problems presented threats for the success of the project, but they were addressed in the following ways:

- Ethical and legal issues to share data. Important legal and ethical issues were analyzed and addressed in order to share the data among the MEPROCS participants world-wide. In particular, two different forms were distributed to every data provider and data user. In the first form, the data provider certified the data release for scientific purposes, according to his national laws and ethical regulations/ethical committee/etc. This included a number of cases consisting of either ante-mortem photographs, laser-scans of the skull, $x$-rays of the skull, CTs of the skull, or any other. The data provider also certified that for the cases provided, the person had been positively identified via DNA/dental records/other. In the second form, the user was informed about the kind of material provided and the particular terms of use of such material. The user certified that he was the scientific lead from his institution for the MEPROCS project. Also, he certified that he could receive the scientific material for scientific purposes and accepted the previous terms of use and all the applicable regulations according to his national laws and 
ethical regulations, ethical committees, etc. The particular templates of both forms can be found in Appendix C.

- Technical issues to obtain ground-truth data. The precise projection of the skull onto a photograph of the same person is not a trivial task. After thorough analysis of the problem, the MEPROCS participants determined that the only chance to achieve it was using clinical data (which also involved an informed consent that the patient should sign to facilitate the data use). The particular procedure to obtain the ground truth included images resulting from orthostatic Cone-Beam CT processed to obtain the corresponding 3D face and 3D skull models. After positioning homologous points in both the $3 \mathrm{D}$ face model and the photograph of the patient, the former was automatically projected onto the latter to produce a perfect match. Then, the parameters were applied to the 3D skull model, resulting in a perfect SFO. The latter superimposition is considered a ground-truth skull-face overlay. A detailed explanation is given in Ibáñez et al. (2015).

- Coordination difficulties. It was challenging to coordinate a large group of very renowned experts, researchers, and practitioners with different experiences and interests. The use of the technique is marginal in some countries, while it plays a crucial role in others. In order to overcome these difficulties, MEPROCS was always guided by the global aim to perform a scientific and objective approach to every single task of the project. In this sense, the role of the technical studies was essential. Also, the tireless efforts to reach global agreements that were only possible in face-to-face meetings should be emphasized.

- Economic limitations. Initially, the MEPROCS consortium consisted of seven partners. The project activities and their corresponding budget were scaled according to this size. Though one of the objectives of the project was to involve new institutions, we did not expect the positive and proactive attitude of so many additional participants. This represented a great opportunity for international collaboration (which was the main aim of the project), but, at the same time, we had to properly manage our limited funds. We requested some modifications in the budget from the project officer in Brussels in order to respond to this new situation. The total amount of funds remained the same, but we proposed some changes among different items of the budget. Once approved by the European authorities, we could use the funds to organize six meetings (attended by 20 persons, average), one international workshop (attended by 30 delegates), and the final conference that supported the travel and accommodation expenses (together with bursaries for students) of more than 80 delegates.

- Time constraints. Initially, the MEPROCS duration was 24 months. The appropriate use of the original MEPROCS grant to support the activities of many more new institutions was not easy. Beyond that economical challenge, the involvement and active collaboration of an important number of new participants had an important impact on the MEPROCS schedule as well. The project became more ambitious because it was a great opportunity to launch new technical studies that were not originally planned. This situation was explained to the European authorities who approved the extension of the project for six additional months, considering the same funds initially granted for the project. Throughout this 
period of time (30 months) and until the very last day, there was continuous work in the numerous tasks of the project with a special effort on the handbook.

\subsection{Future Trends and Research Propositions}

The diverse support received by the forensic community, together with the different interests and uses of the technique in different countries, and the significant differences obtained in the reliability studies developed so far lead us to identify three main challenges in craniofacial superimposition for the future:

- The need of a broader study on the evaluation criteria. MEPROCS suffered a limitation as far as the resources and materials employed to analyze the subjectivity and discriminative power of the different criteria for assessing the skull-face correspondence are concerned. This is a crucial aspect that deserves important attention in the future. The methodology followed in MEPROCS should lead to further studies involving significant numbers of participants evaluating a relevant number of cases. Some of the aims of such studies should be the selection of the more significant criteria and the connection of the criteria with the decision degrees included in the MEPROCS framework, that is, the estimation of the criteria that should be satisfied to support every decision degree.

- The need of objective assessment and automation. Knowledge exchange and the possibility to improve existing approaches and propose new methods to solve problems are the main forces behind the evolution of science. The guarantee of objective procedures to evaluate the performance of those proposals is essential.

To compare the performance of newly developed CFS methods, a common forensic dataset of known case studies should be available. In this way, the validation of the methods proposed could be applied to solved cases and thus comparison of the results with the identification previously determined by forensic anthropologists.

The absence of a common repository of solved CFS cases has limited the development of automatic methods that could solve some of the most tedious CFS tasks in a fast, accurate, reproducible, and objective way. To date, few automatic CFS tasks are used in practical applications despite the high number of cases examined and the large amount of time that the forensic expert spends in performing the examination. In particular, skull-face overlay was as a very challenging and timeconsuming part of the craniofacial superimposition technique. Despite the existence of promising works in this direction, automatic techniques have not been implemented on a large scale due to the inability to test their performance in an objective manner.

It is thus essential to obtain ground-truth data and there are a number of open problems related to use of Cone-Beam CTs (CBCTs). Since CBCTs are employed for maxillofacial treatments, the images' acquisition field generally lacks the upper part of the head because it is useless for those purposes. Moreover, the inclusion of 
the upper part of the head would represent a needless additional radiation of the patient. Nevertheless, that lack of information is a clear limitation for many craniofacial superimposition tasks. In particular, this is an important shortcoming for the appropriate evaluation of the results. Furthermore, the segmentation of the available CBCT data to obtain only the bonny part of the whole medical image is another real challenge. There are plenty of artifacts typically from tooth fillings that really complicate this task. Also, CBCTs' resolution is not as good as conventional CTs, which were discarded in MEPROCS ground-truth studies (Ibáñez et al. 2015), because the gravity could have an impact on the flesh that would invalidate the potential conclusions drawn from such data.

- The need of a significantly large reliability study. Such a reliability study should take into consideration the two previous points. On the one hand, this crucial task was not faced in MEPROCS due to the lack of time. Therefore, the statistical basis for the use of the technique has not been produced by the studies conducted in MEPROCS. On the other hand, the reliability studies reported in the literature are fraught with limitations. The absence of an objective measure of the skull face overlay match, technical limitations of the equipment, disregard for accurate landmarks location while performing landmark based methods, absence of soft tissue data for the tested population, insufficient quality of the 3D cranial models, postmortem photographs, reduced samples, absence of appropriate statistical analysis, and the absence of inter- and intraobserver studies are just a few of such shortcomings. Statistically significant reliability studies that tackle the challenges identified in this manuscript are required to obtain a more solid picture on the reliability of craniofacial superimposition and its potential complementary role with other forensic sciences techniques.

\subsection{Concluding Remarks}

Most of the aforementioned future trends and research propositions can only be properly faced by a multidisciplinary team. After MEPROCS, we can conclude that many of the achievements were only possible thanks to the diverse consortium that consisted of forensic laboratories, police forces, and technical institutions. In particular, the application of craniofacial superimposition requires an awareness of the technical implications related to imagery, discipline that is in continuous and fast technological development, especially with regard to three-dimensional images and interactivity. This technological trend may lead, in the near future, to new and more sophisticated imaging tools. These new tools will need to be carefully evaluated from time to time for their potential use in craniofacial superimposition.

Objective and unbiased validation studies over a significant number of cases are required to get a more solid picture on craniofacial superimposition reliability. It will not be possible to compare the performance of existing and upcoming methods for craniofacial superimposition without a common forensic database available for the 
research community. Skull-face overlay is a key task within craniofacial superimposition that has a direct influence on the subsequent task devoted to evaluate the skull-face relationships. Once legal and ethical issues are overcome to facilitate the public use, the creation of a database of skull-face overlay cases is a real need.

Besides, new statistical and computational techniques should be devised based on the available data. Soft computing and computer vision should play an irreplaceable role in the evolution of the technique.

In general, we can't confirm that the current state of the technique is mature enough to be used as sole evidence for positive identification; however, we can confirm that those who follow the MEPROCS recommendations greatly improve their performance and have a better scientific basis.

Open Access This chapter is licensed under the terms of the Creative Commons AttributionNonCommercial 2.5 International License (http://creativecommons.org/licenses/by-nc/2.5/), which permits any noncommercial use, sharing, adaptation, distribution and reproduction in any medium or format, as long as you give appropriate credit to the original author(s) and the source, provide a link to the Creative Commons license and indicate if changes were made.

The images or other third party material in this chapter are included in the chapter's Creative Commons license, unless indicated otherwise in a credit line to the material. If material is not included in the chapter's Creative Commons license and your intended use is not permitted by statutory regulation or exceeds the permitted use, you will need to obtain permission directly from the copyright holder.

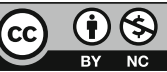




\section{Appendix A. Informed Consent Template Relating to Human Remains}

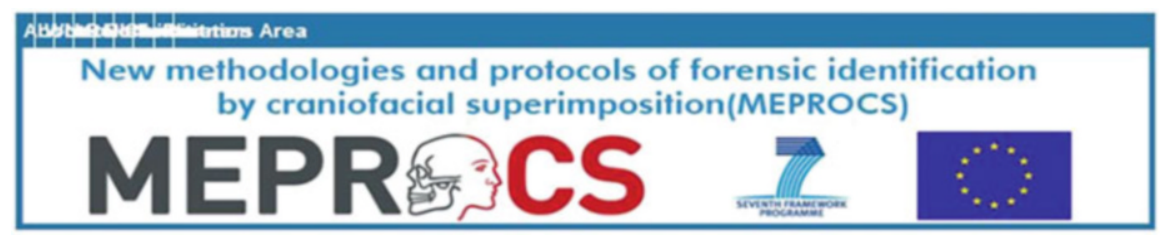

\section{INFORMED CONSENT TEMPLATE INSTRUCTIONS}

- Model Text is in bold and is generally required

- Instructions are in italics

- Indicates that the investigator should fill in the appropriate information.

- If the template is downloaded, ensure all instructional comments are deleted or revised as appropriate.

DELETE THIS BOX WHEN SUBMITTING CONSENT FORM

NAME OF THE CENTRE WHERE THE STUDY IS GOING TO BE CARRIED OUT:

\section{CONSENT BY SUBJECT FOR PARTICIPATION IN A STUDY}

Identification Case Number:

Name of Subject:

Local Identification Number:

STUDY TITLE: Semi-automatic Craniofacial Superimposition Results Validation

Person Directing Study:

Address:

Telephone Number: 
As the responsible party for the deceased, you are being asked to participate in a study involving the corpse. A member of the MEPROCS project team will explain what is involved in this study and how it will affect the remains of the deceased. This consent form describes the study procedures, the implications and benefits of participation, as well as how the deceased's confidentiality will be maintained. Please take your time to ask questions and feel comfortable making a decision whether to participate or not. This process is called informed consent. If you decide to participate in this study, you will be asked to sign this form.

\section{WHY IS THIS STUDY BEING DONE?}

The purpose of this study is to provide a specific reliability index to the semiautomatic CFS method. This method is very useful for both the forensic anthropology community and Police Forces for the identification of unknown persons, together with other techniques or, on its own when there is not enough (ante- or post-mortem) information available to apply them. Craniofacial superimposition has been used for more than one century, contributing to the process of identification in many cases, especially in scenarios like mass disasters, terrorism, missing persons identification, and common grave investigation. However, there is lack of protocols and standards in the application of the technique and contradictory information concerning its reliability. The MEPROCS project aims to propose a common EU framework to allow the extensive application of the CFS technique in practical forensic identification scenarios commonly tackled by the European scientific police units, providing an objective evaluation of the forensic identification results achieved by CFS, avoiding particular assumptions that could bias the process.

\section{HOW MANY PEOPLE WILL TAKE PART IN THE STUDY}

About X people will take part in this study at the Name of the Centre and if applicable add and about Y people throughout the European Union.

\section{WHAT IS INVOLVED IN THE STUDY?}

The semi-automatic CFS system needs a 3D model of the skull of the deceased and one or more face photographs of the same person when he/she was alive. In order to obtain a reliable $3 D$ model of the skull, flesh and hair have to be removed from the skull. Whenever a forensic anthropologist or scientific police involved in the project considers that a deceased individual could be useful for the project he/she will follow the informed consent process.

During this study, [insert name] and [his/her] team will collect information about the deceased for the purposes of this research. Only medical images from the skull of the deceased and alive photographs of the face are required for carrying out this study. In addition information about race, sex and age will be needed in order to contextualize each study case. No more personal data is required.

\section{HOW LONG WILL I BE IN THE STUDY?}

The time required for the $3 \mathrm{D}$ digitisation process varies depending on the particular conditions of the body (ranging from some minutes to a few hours). Then, the body 
of the deceased is not used any more. A 3D model of the skull will be filed in the deceased's record and a codified copy will be used for the purposes of the study. This data will be used for the duration of the project and could also be useful for future research at a national or international level.

[If applicable, include:]

[Insert PI name] may decide to take the deceased off the study without your consent if:

\section{[Include all that are applicable]}

- Other relatives do not agree with it.

- If the study is stopped.

\section{WHAT ARE THE RISKS OF THE STUDY?}

The only risks derived from participation in the project are those related to the managing of personal information, but as it will be explained below confidentiality and privacy will be maintained as established in the Directive 95/46/EC.

\section{ARE THERE ANY BENEFITS TO TAKING PART IN THE STUDY?}

If you agree to take part in this study, there may not be a direct benefit to you. However, we hope the information learned from this study will benefit the global standardization of the technique, making the identification of deceased persons a faster and more reliable process.

\section{WHAT OTHER OPTIONS ARE THERE?}

Instead of being in this study, you have the option of not participating. MEPROCS members understand and respect your decision.

\section{WHAT ARE THE COSTS?}

There will be no costs to you or the deceased's insurance company resulting from your participation in this study.

\section{WILL I BE PAID FOR MY PARTICIPATION?}

"You will not be paid to participate"

\section{WHAT ABOUT CONFIDENTIALITY?}

Study records that identify the deceased will be kept confidential. Skull and face images acquired from the deceased will be filed with the rest of the protected information in his/her personal record. Only authorized personnel can access this data. A copy of the skull and face images will be codified with a random number that does not allow their identification. A database will be created with files of the codified images that will not contain personal data that could lead to any person's identification. These files will only include information about race, sex and age in order to carry out statistical studies. The data collected in this study will be used for the purpose described in the form. By signing this form, you are allowing the MEPROCS team of the corresponding Centre to access the codified images of the 
deceased and to data related to his/her sex, race and age, but, they never could access any another personal data that allows his/her identification. The MEPROCS team includes the individuals listed on this consent form and other personnel involved in this study.

As part of the study, [insert PI name] and [his/her] team will report the results of your study, related procedures and tests explained above to the European Centre for Soft Computing. These only include codified images under the right numeration and data related to race, age and sex.

The project will be reviewed by regional or national Ethical Committees whose responsibility is to protect human subjects in research.

Data from this study may be used in specialized publications or presentations. The deceased's name and other identifying information will be removed before the data is used.

\section{WHAT ARE MY RIGHTS AS A PARTICIPANT?}

Taking part in this study is voluntary.

If you choose to no longer be in the study and you do not want any of the deceased's information to be used, you must inform [insert PI name] in writing at the address on the first page.

\section{[Include for all studies]}

You will be given a signed copy of this document. This consent form document does not have an expiration date.

\section{WHOM DO I CALL IF I HAVE QUESTIONS OR PROBLEMS?}

You have talked to (insert name of person conducting consent process) about this study and you have had the opportunity to ask questions concerning any and all aspects of the research. If you have further questions about the study, you may call (insert PI name and phone number).

If you have any questions concerning your rights in this research study you may contact a MEPROCS ethical committee representative at this institution.

\section{SUBJECT}

The study and the procedures associated with it have been explained to me. I will receive a signed copy of this consent form for my records.

As a person responsible for the deceased I agree that the MEPROCS team may use the skull and information of the deceased that I am responsible for in their study. I made this decision freely and I do not have to sign this form if I do not want to be part of this study.

Signature of Responsible:

Date:

Time: $\mathrm{AM} / \mathrm{PM}$ (circle) 


\section{PERSON OBTAINING CONSENT}

I have explained to insert name of subject/parent/guardian the nature and purpose of the study and the risks involved. I have answered and will answer all questions to the best of my ability. I will give a signed copy of the consent form to the subject [and if appropriate add] and family.

Signature of Person Obtaining Consent:

Date:

Time: $\mathrm{AM} / \mathrm{PM}$ (circle)

\section{FORENSIC ANTHROPOLOGIST/SCIENTIFIC POLICE:}

Signature of Forensic Anthropologist/Scientific Police:

Date: Time: $\mathrm{AM} / \mathrm{PM}$ (circle)

\section{PROXY/SURROGATE CONSENT:}

The subject on whose behalf I consent has no legally authorized representative or that person is unavailable despite efforts to contact him/her. I believe my proxy decision on behalf of the subject conforms as closely as possible to what the subject would have done or intended under the circumstances. This decision takes into account what I believe are the subjects' personal, philosophical, religious and/or moral beliefs and ethical values relative to the purpose of life, sickness, medical procedures, suffering and death. These issues have been discussed by the doctors directing this research and myself.

Signature of Individual Providing Surrogate consent:

Relationship to Subject:

Date:

Time: AM/PM (circle) 


\section{Appendix B. Informed Consent Template Regarding Data Collection from Living Individuals}

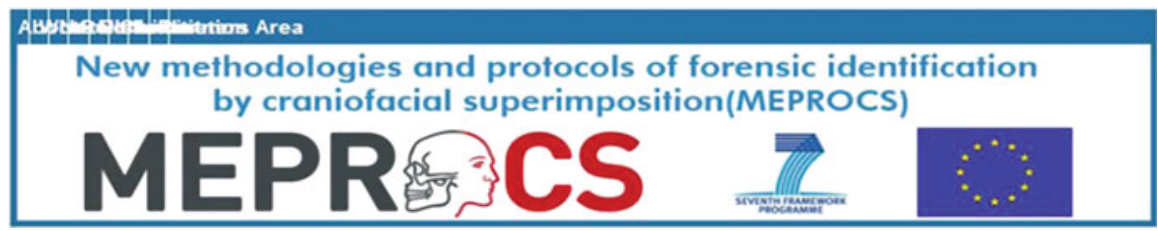

\section{INFORMED CONSENT TEMPLATE INSTRUCTIONS}

- Model Text is in bold and is generally required

- Instructions are in italics

- Indicates that the investigator should fill in the appropriate information.

- If template is downloaded, ensure all instructional comments are deleted or revised as appropriate.

DELETE THIS BOX WHEN SUBMITTING CONSENT FORM

NAME OF THE CENTRE WHERE THE STUDY IS GOING TO BE CARRIED OUT

CONSENT BY SUBJECT FOR PARTICIPATION IN A STUDY

Identification Case Number:

Name of Subject:

Local Identification Number:

STUDY TITLE: Semi-automatic Craniofacial Superimposition Results Validation

Personal Directing Study:

Address:

Telephone Number: 
You are being asked to participate in a research project. A member of the MEPROCS project team will explain what is involved in this study. This consent form describes the study procedures, the implications and benefits of participation, as well as how confidentiality will be maintained. Please take your time to ask questions and feel comfortable in making a decision whether to participate or not. This process is called informed consent. If you decide to participate in this study, you will be asked to sign this form.

\section{WHY IS THIS STUDY BEING DONE?}

The purpose of this study is to provide a specific reliability index to the semiautomatic CFS method. This method is very useful for both the forensic anthropology community and Police Forces for the identification of unknown persons, together with other techniques or, on its own when there is not enough (ante- or post-mortem) information available to apply them. CFS has been used for more than one century, contributing to the process of identification in many cases, especially in scenarios like mass disasters, terrorism, missing persons identification, and common grave investigation. However, there is lack of protocols and standards in the application of the technique and contradictory information concerning its reliability. The MEPROCS project aims to propose a common EU framework to allow the extensive application of the CFS technique in practical forensic identification scenarios commonly tackled by the European scientific police units, providing an objective evaluation of the forensic identification results achieved by CFS, avoiding particular assumptions that could bias the process.

\section{HOW MANY PEOPLE WILL TAKE PART IN THE STUDY?}

About X people will take part in this study at the Name of the Centre and if applicable add and about Y people throughout the European Union.

\section{WHAT IS INVOLVED IN THE STUDY?}

The semi-automatic CFS system needs a 3D model of the skull of the individual and one or more face photographs of the same living person. Whenever a forensic anthropologist or scientific police involved in the project considers that an individual could be useful for the project he/she will follow the informed consent process.

During this study, [insert name] and [his/her] team will collect information about the individual for the purposes of this study. Only medical images of the skull and living photographs of the face are required for carrying out this study. In addition, information about race, sex and age will be needed in order to contextualize each study case. No more personal data is required.

\section{HOW LONG WILL I BE IN THE STUDY?}

The time required for the 3D digitisation varies, but could range from 5-30 minutes. A $3 D$ model of the skull will be filed in the participant's record and a codified copy will be used for the study purpose. This data will be used for the duration of the project and could be also useful for future research at a national or international level. 
[If applicable, include:]

[Insert PI name] may decide not to use this data without your consent if the study is stopped.

\section{WHAT ARE THE RISKS OF THE STUDY?}

The only risks derived from the participation in the project are those related to the managing of personal information, but as it will be explained below confidentiality and privacy will be maintained as established in the Directive 95/46/EC.

\section{ARE THERE ANY BENEFITS TO TAKING PART IN THE STUDY?}

If you agree to take part in this study, there may not be a direct benefit to you. But, we hope the information learned from this study will benefit the global standardization of the technique, making identifications of the deceased a faster and more reliable process.

\section{WHAT OTHER OPTIONS ARE THERE?}

Instead of being in this study, you have the option of not participating. MEPROCS members understand and respect your decision.

\section{WHAT ARE THE COSTS?}

There will be no costs to you resulting from your participation in this study.

\section{WILL I BE PAID FOR MY PARTICIPATION?}

"You will not be paid to participate"

\section{WHAT ABOUT CONFIDENTIALITY?}

Study records that identify the individual will be kept confidential. Skull and face images acquired from the individual will be filed with the rest of the protected information in his/her personal record. Only authorized personnel can access this data. A copy of the skull and face images will be codified with a random number that does not allow their identification. A database will be created with files of the codified images that will not contain personal data that could lead to any person's identification. These files will only include information about race, sex and age in order to carry out statistical studies. The data collected in this study will be used for the purpose described in the form. By signing this form, you are allowing the MEPROCS team of the corresponding Centre to access your codified images and to data related with your sex, race and age, but they never could access other personal data that allows your identification. The MEPROCS team includes the individuals listed on this consent form and other personnel involved in this study.

As part of the study, [insert PI name] and [his/her] team will report the results of your study, related procedures and tests explained above to the European Centre for Soft Computing. These only include codified images under the right numeration and data related to race, age and sex. The project will be reviewed by regional or national Ethical Committees whose responsibility is to protect human subjects in research. Data from this study may be used in specialized publications or presentations. The 
individual's name and other identifying information will be removed before this data is used.

\section{WHAT ARE MY RIGHTS AS A PARTICIPANT?}

Taking part in this study is voluntary. If you choose to no longer be in the study and you do not want any of your information to be used, you must inform [insert PI name] in writing at the address on the first page.

\section{[Include for all studies]}

You will be given a signed copy of this document. This consent form document does not have an expiration date.

\section{WHOM DO I CALL IF I HAVE QUESTIONS OR PROBLEMS?}

You have talked to (insert name of person conducting consent process) about this study and you have had the opportunity to ask questions concerning any and all aspects of the research. If you have any further questions about the study, you may call (insert PI name and phone number).

If you have any questions concerning your rights in this research study you may contact a MEPROCS ethical committee representative at this institution.

\section{SUBJECT}

The study and the procedures associated with it have been explained to me. I will receive a signed copy of this consent form for my records.

I agree that the MEPROCS team may use my images and information in their study. I made this decision freely and I do not have to sign this form if I do not want to be part of this study.

Signature of Responsible:

Date:

Time: $\mathrm{AM} / \mathrm{PM}$ (circle)

\section{PERSON OBTAINING CONSENT}

I have explained to insert name of subject/parent/guardian the nature and purpose of the study and the risks involved. I have answered and will answer all questions to the best of my ability. I will give a signed copy of the consent form to the subject [and if appropriate add] and family.

Signature of Person Obtaining Consent:

Date:

Time: AM/PM (circle)

FORENSIC ANTHROPOLOGIST/SCIENTIFIC POLICE:

Signature of Forensic Anthropologist/Scientific Police:

Date:

Time: $\mathrm{AM} / \mathrm{PM}$ (circle) 


\section{Appendix C. Informed Consent Form for Scientific Material Sharing}

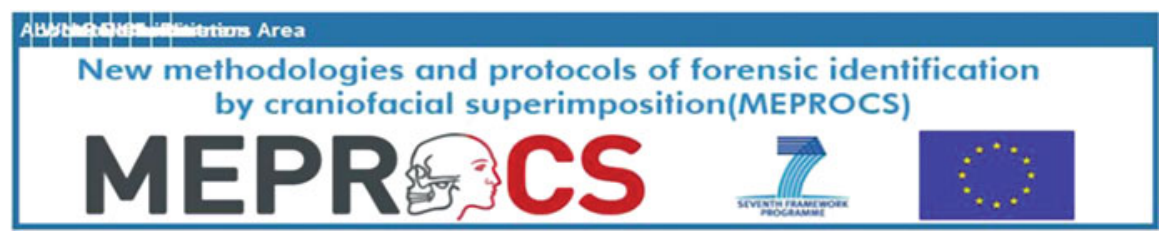

Name:

Affiliation:

Qualification:

Country:

STUDY TITLE: Semi-automatic Craniofacial Superimposition Results Validation

\section{WHY IS THIS STUDY BEING DONE?}

The purpose of this study is to provide a specific reliability index to the semiautomatic CFS method. This method is very useful for both the forensic anthropology community and Police Forces for the identification of unknown persons, together with other techniques or, on its own when there is not enough (ante- or post-mortem) information available to apply them. CFS has been used for more than one century, contributing to the process of identification in many cases, especially in scenarios like mass disasters, terrorism, missing persons identification, and common grave investigation. However, there is a lack of protocols and standards in the application of the technique and contradictory information concerning its reliability. The MEPROCS project aims to propose a common EU framework to allow the extensive application of the CFS technique in practical forensic identification scenarios commonly tackled by the European scientific police units, providing an objective evaluation of the forensic identification results achieved by CFS, avoiding particular assumptions that could bias the process. 
This study material includes:

1. Human remains, collected after obtaining informed consent from the responsible party for the deceased;

2. Data collecting from living individuals, who decide to participate in this study, after being properly informed and giving their consent;

3. Human remains shared by institutions in which they have been stored for more than 15 years, and whose national laws allow their use after this period of time. This informed consent is addressed specifically to this third group.

I hereby certify that I can release for scientific purposes, according to our national laws and ethical regulations/ethical committee/etc., information and images concerning case/process number

of our series, consisting of:

- ante-mortem photos

- pictures of the skull, number

- laser scans of the skull

- $\mathrm{X}$ rays

- ct scans

- other:

I also certify that for case/process number

the person the skull belongs to, has been positively identified via DNA/dental records/other, and therefore that the ante-mortem images do belong to the case.

Sincerely

Date: Signature: 


\section{References}

(1964) Declaration of Helsinki: ethical principles for medical research involving human subjects. In: Association WM (ed)

(1997) Convention on human rights and biomedicine. Convention for the Protection of Human Rights and Dignity of the Human Being with regard to the Application of Biology and Medicine (2005) Universal declaration on bioethics and human rights 2005. In: UNESCO (ed)

(2012) Interpol 2009 guide [Online]. http://www.interpol.int/content/download/9158/68001/ version/5/file/Guide.pdf

Al-Amad S, McCullough M, Graham J, Clement JG, Hill A (2006) Craniofacial identification by computer-mediated superimposition. J Forensic Odonto-Stomatol 24:47-52

Alemán I, Botella MC, Ruiz L (1997) Determinación del sexo en el esqueleto postcraneal. Estudio de una población mediterránea actual. Archivo Español de Morfología 2:7-17

Anastassov GE, van Damme PA (1996) Evaluation of the anatomical position of the lateral canthal ligament: clinical implications and guidelines. J Craniofac Surg 7:429-436

Angel JL (1978) Restoration of head and face for identification. Proceedings of Meetings of American Academy of Forensic Science

Asananer T (1972) News from Thailand. Scandanavian Soc Forensic Odontology Newsl 6:13

Aulsebrook WA, İşcan MY, Slabbert JH, Becker P (1995) Superimposition and reconstruction in forensic facial identification: a survey. Forensic Sci Int 75:101-120

Aulsebrook WA, Becker PJ, İşcan MY (1996) Facial soft-tissue thicknesses in the adult male Zulu. Forensic Sci Int 79:83-102

Austin D (1999) Video superimposition at the C.A. Pound Laboratory 1987 to 1992 . J Forensic Sci 44:695-699

Austin-Smith D, Maples WR (1994) The reliability of skull/photograph superimposition in individual identification. J Forensic Sci 39:446-455

Bäck T, Fogel DB, Michalewics Z (1997) Handbook of evolutionary computation. Oxford University Press, Bristol

Bajnóczky I, Királyfalvi L (1995) A new approach to computer-aided comparison of skull and photograph. Int J Leg Med 108:157-161

Ballerini L, Cordón O, Santamaria J, Damas S, Alemán I, Botella M (2007) Craniofacial superimposition in forensic identification using genetic algorithms. In: Third international symposium on information assurance and security. IEEE, pp 429-434

Ballerini L, Cordón O, Damas S, Santamaría J (2009) Automatic 3D modeling of skulls by scatter search and heuristic features. Appl Soft Comput 52:149-158

Balueva T, Veselovskaya E (2004) New developments in facial reconstruction. Archael Ethnol Anthropol Eurasia 30:9 
Balueva T, Veselovskaya E, Valencia-Caballero L, et al. (2009) Nuevos estudios en el area de reconstruccion facial a partir de datos craneologicos. Rev Esp de Antropol Fis 11-22

Balueva T, Veselovskaya EV, Rasskazova AV (2010) A comparison of the medieval and modern populations of the Novgorod region, based on facial reconstruction. Archael Ethnol Anthropol Eurasia 38:135-144

Bankowski IM (1958) Die Bedeutung der Unterkieferform und—stellung für die photographische Schädelidentifizierung

Basauri C (1967) A body identified by forensic odontology and superimposed photographs. Int Crim Police Rev 204:37-43

Bastiaan RJ, Dalitz GD, Woodward C (1986) Video superimposition of skulls and photographic portraits-a new aid to identification. J Forensic Sci 31:1373-1379

Benazzi S, Fantini M, de Crescenzio F, Mallegni G, Mallegni F, Persiani F, Gruppioni G (2009) The face of the poet Dante Alighieri reconstructed by virtual modelling and forensic anthropology techniques. J Archaeol Sci 36:278-283

Berger D (1965) Untersuchungen über die Weichteildickenmasse des Gesichts

Bernardini F, Rushmeier H (2002) The 3D model acquisition pipeline. In: Computer graphics forum, 2002. Wiley Online Library, pp 149-172

Berner ES (2007) Clinical decision support systems: theory and practice. Springer

Besl PJ, McKay ND (1992) Method for registration of 3-D shapes. In: Robotics-DL tentative. International Society for Optics and Photonics, pp 586-606

Bilge Y, Kedici PS, Alakoç YD, Ülküer KÜ, Ilkyaz YY (2003) The identification of a dismembered human body: a multidisciplinary approach. Forensic Sci Int 137:141-146

Birkner F (1905) Beitrage zur Rassenanatomie der chinesen. Korrespondenz Deutsches Gesicht Antropologie Ethnologie Urgeschte 35:4

Birngruber CG, Kreutz K, Ramsthaler F, Krähahn J, Verhoff MA (2010) Superimposition technique for skull identification with Afloat ${ }^{\circledR}$ software. Int J Legal Med 124:471-475

Biwasaka H, Saigusa K, Aoki Y (2005) The applicability of holography in forensic identification: a fusion of the traditional optical technique and digital technique. J Forensic Sci 50:393-399

Board IR (2012) General guidance: investigator responsibilities

Brocklebank L, Holmgren C (1989) Development of equipment for the standardization of skull photographs in personal identifications by photographic superimposition. J Forensic Sci 34:1214-1221

Bronkhorst D (2006) Truth and justice: a guide to truth commissions and transitional justice. Amnesty International Dutch Section

Brown KA (1982) The identification of Linda Agostini: the significance of dental evidence in the Albury Pyjama Girl case. Am J Forensic Med Pathol 3:131-142

Burns K (2007) Forensic anthropology training manual. Prentice-Hall

Cattaneo C (2007) Forensic anthropology: developments of a classical discipline in the new millennium. Forensic Sci Int 165:185-193

Cavanagh D, Steyn M (2011) Facial reconstruction: soft tissue thickness values for South Africa black females. Forensic Sci Int 208:215.e1-215.e7

Chai D, Lan Y, Tao C, Gui R, Mu Y, Feng J, Wang W, Zhu J (1989) A study on the standard for forensic anthropologic identification of skull-image superimposition. J Forensic Sci 34:1343-1356

Chee L, Cheng C (1989) Skull and photographic superimposition: a new approach using a second party's interpupil distance to extrapolate the magnification factor. J Forensic Sci 34:708-713

Christensen AM, Crowder CM (2009) Evidentiary standards for forensic anthropology. J Forensic Sci 54:1211-1216

Claes P, Vandermeulen D, de Greef S, Willems G, Clement JG, Suetens P (2010) Computerized craniofacial reconstruction: conceptual framework and review. Forensic Sci Int 201:138-145

Clement JG, Ranson D (1998) Craniofacial identification in forensic medicine. Arnold/Oxford University Press, London/New York

Cocks F (1971) Barkly highway murder. Criminologist 6:41-53 
Codinha S, Fialho C (2010) Facing the dead: prediction of facial soft tissue depths from craniometric dimensions for forensic craniofacial identification. Universidade de Coimbra

Couly G, Hureau J, Tessier P (1976) The anatomy of the external palpebral ligament in man. J Maxillofac Surg 4:195-197

Czekanowski J (1907) Untersuchungen uber das Verhaltnis der Kopfmafse zu den Schadelmafsen. Archiv fur Anthropologie 6:42-89

Damas S, Cordón O, Ibáñez O, Santamaría J, Alemán I, Botella M, Navarro F (2011) Forensic identification by computer-aided craniofacial superimposition: a survey. ACM Comput Surv 43:27

Damas S, Wilkinson C, Kahana T, Veselovskaya E, Abramov A, Jankauskas R, Jayaprakash PT, Ruiz E, Navarro F, Huete MI, Cunha E, Cavalli F, Clemen JG, Lestón P, Molinero F, Briers TM, Viegas F, Imaizumi K, Humpire D, Ibáñez O (2014) Study on the performance of different craniofacial superimposition approaches (II): best practices proposal. Forensic Sci Int 257:504-508

Davy-Jow SL, Decker SJ, Ford JM (2012) A simple method of nose tip shape validation for facial approximation. Forensic Sci Int 214:208.e1-208.e3

de Greef S, Claes P, Vandermeulen D, Mollemans W, Suetens P, Willems G (2006) Large-scale in-vivo Caucasian facial soft tissue thickness database for craniofacial reconstruction. Forensic Sci Int 159:S126-S146

Denis L, Speidel T (1987) Comparison of three methods of profile change prediction in the adult orthodontic patient. Am J Orthod Dentofac Orthop 92:6

Domaracki M, Stephan CN (2006) Facial soft tissue thicknesses in Australian adult cadavers. J Forensic Sci 51:5-10

Dorion RB (1983) Photographic superimposition. J Forensic Sci 28:724-734

Dumont ER (1986) Mid-facial tissue depths of white children: an aid in facial feature reconstruction. J Forensic Sci 31:1463-1469

El-Mehallawi IH, Soliman EM (2001) Ultrasonic assessment of facial soft tissue thicknesses in adult Egyptians. Forensic Sci Int 117:99-107

Enciso R, Memon A, Mah J (2003) Three-dimensional visualization of the craniofacial patient: volume segmentation, data integration and animation. Orthod Craniofacial Res 6:66-71

Fantini M, de Crescenzio F, Persiani F, Benazzi S, Gruppioni G (2008) 3D restitution, restoration and prototyping of a medieval damaged skull. Rapid Prototyp J 14:318-324

Farkas LG (1981) Anthropometry of the head and face in medicine. Elsevier North Holland, New York

Farkas LG, Munro IR (1987) Anthropometric facial proportions in medicine. Springfield, Thomas

Fedosyutkin BA, Nainys JV (1993) The relationship of skull morphology to facial features. In: Forensic analysis of the skull. Wiley-Liss

Fenton TW, Heard AN, Sauer NJ (2008) Skull-photo superimposition and border deaths: identification through exclusion and the failure to exclude. J Forensic Sci 53:34-40

Fernándes CM, Serra-Mda C, da Silva JV, Noritomi PY, Pereira FD, Melani RF (2012) Tests of one Brazilian facial reconstruction method using three soft tissue depth sets and familiar assessors. Forensic Sci Int 214:211

Fischer E (1905) Anatomische Untersuchungen an den Kopfweichteilen zweier Papua. Corr BL Anthrop Ges Jhg 36:118-122

Galantucci LM, Percoco G, Angelelli G, Lopez C, Introna F, Liuzzi C, de Donno A (2006) Reverse engineering techniques applied to a human skull, for CAD 3D reconstruction and physical replication by rapid prototyping. J Med Eng Technol 30:102-111

Galdames IS, Cantín López M, Zavando Matamala DA, Perez Rojas FJ, Torres Muñoz SR (2008) Comparisons in soft-tissue thicknesses on the human face in fresh and embalmed corpses using needle puncture method. Int J Morphol 26:4

Gatliff BP (1984) Facial sculpture on the skull for identification. Am J Forensic Med Pathol $5: 327-332$ 
Gejvall NG (1974) Superimposition plus SEM-comparison of hair cuticle for identification purpose. Int J Skelet Res 1:99-103

George RM (1987) The lateral craniographic method of facial reconstruction. J Forensic Sci 32:25

George RM (1993) Anatomical and artistic guidelines for forensic facial reconstruction. In: Forensic analysis of the skull, pp 215-227

Gerasimov MM (1955) The reconstruction of the face from the basic structure of the skull. Russia

Ghosh AK, Sinha P (2001) An economised craniofacial identification system. Forensic Sci Int 117:109-119

Ghosh AK, Sinha P (2005) An unusual case of cranial image recognition. Forensic Sci Int 148:93-100

Glaister J, Brash JC (1937) Medico-legal aspects of the Ruxton case. Livingstone

Glanville EV (1969) Nasal shape, prognathism and adaptation in man. Am J Phys Anthropol 30:29-37

Gonzalez RC, Woods RE (2008) Digital image processing. Addison-Wesley, Boston, MA

Gonzalez-Colmenares G, Botella-Lopez M, Moreno-Rueda G, Fernández-Cardenete J (2007) Age estimation by a dental method: a comparison of Lamedin's and Prince Ubelaker's technique. J Forensic Sci 52:1156-1160

Gordon I, Drennan MR (1948) Medico-legal aspects of the Wolkersdorfer case. S Afr Med J 22:543-549

Gordon GM, Steyn M (2012) An investigation into the accuracy and reliability of skull-photo superimposition in a South African sample. Forensic Sci Int 216:198.e1-198.e6

Grade-Working-Group (2004) Grading quality of evidence and strength of recommendations. BMJ $328: 1-8$

Gray L (1965) The deviated nasal septum I. Aetiology. J Laryngol Otol 79:567-575

Grivas CR, Komar DA (2008) Kumho, Daubert, and the nature of scientific inquiry: implications for forensic anthropology. J Forensic Sci 53:771-776

Grüner O (1993) Identification of skulls: a historical review and practical applications. In: Forensic analysis of the skull. Wiley Liss, New York

Gruner O, Reinhard R (1959) A photographical procedure for cranial identification. Dtsch Z Gesamte Gerichtl 48:247-256

Guyomarc'h P, Stephan CN (2012) The validity of ear prediction guidelines used in facial approximation. J Forensic Sci 57:1427-1441

Hansen N, Ostermeier A (2001) Completely derandomized self-adaptation in evolution strategies. Evolut Comput 9(2):159-195

Helmer RP (1984) Schädelidentifizierung durch Elektronische Bildmischung. Kriminalstik-Verlag

Helmer RP (1987) Identification of the cadaver remains of Josef. Zeitschrift für Rechtsmedizin 102:451-459

Helmer RP, Grüner O (1977a) Schädelidentifizierung durch Superprojektion nach dem Verfahren der elektronischen Bildmischung, modifiziert zum Trickbild-Differenz-Verfahren. Zeitschrift für Rechtsmedizin 80:189-190

Helmer RP, Grüner O (1977b) Vereinfachte Schädelidentifizierung nach dem Superprojektionsverfahren mit Hilfe einer Video-Anlage. Zeitschrift für Rechtsmedizin 80:183-187

Helmer RP, Schimmler J, Rieger J (1989) Value of skull identification as evidence using a superimposed video image technic with reference to individual craniometric differences in the human skull. Zeitschrift für Rechtsmedizin 102:451-459

His W (1895) Johann Sebastian Bach's Gebeine and Antiltz nebst Bemerkungen uber Dessen Bilder. Abhandlung durch Mathematic and Physic 22:380

Hodson G, Lieberman LS, Wright P (1985) In vivo measurements of facial soft tissue thickness in American Caucasoid children. J Forensic Sci 30:1110-1112

Holdaway R (1983) A soft tissue cephalometric analysis and its use in orthodontic treatment planning. Part I. Am J Orthod 84:28 
Holobinko A (2012) Forensic human identification in the United States and Canada: a review of the law, admissible techniques, and the legal implications of their application in forensic cases. Forensic Sci Int 222:394.e1-394.e13

Hwang HS, Park MK, Lee WJ, Cho JH, Kim BK, Wilkinson CM (2012) Facial soft tissue thickness database for craniofacial reconstruction in Korean adults. J Forensic Sci 57:1442-1447

Ibáñez O, Ballerini L, Cordón O, Damas S, Santamaría J (2009a) An experimental study on the applicability of evolutionary algorithms to craniofacial superimposition in forensic identification. Inf Sci 179:3998-4028

Ibáñez O, Cordón O, Damas S, Santamaría J (2009b) Multimodal genetic algorithms for craniofacial superimposition. In: Nature-inspired informatics for intelligent applications and knowledge discovery: implications in business, science, and engineering, p 119

Ibáñez O, Cordón O, Damas S, Santamaria J (2011) Modeling the skull-face overlay uncertainty using fuzzy sets. IEEE Trans Fuzzy Syst 19:946-959

Ibáñez O, Cordón O, Damas S (2012a) A cooperative coevolutionary approach dealing with the skull-face overlay uncertainty in forensic identification by craniofacial superimposition. Soft Comput 16:797-808

Ibáñez O, Cordón O, Damas S, Santamaría J (2012b) An advanced scatter search design for skullface overlay in craniofacial superimposition. Expert Syst Appl 39:1459-1473

Ibáñez O, Valsecchi A, Cavalli F, Huete MI, Campomanes-Álvarez BR, Campomanes-Álvarez C, Vicente R, Navega DS, Ross AH, Wilkinson C, Jankauskas R, Imaizumi K, Hardiman R, Ruiz E, Molinero F, Lestón P, Veselovskaya E, Abramov A, Steyn M, Cardoso J, Humpire D, Lusnig L, Gibelli DM, Mazzarelli D, Gaudio D, Collini F, Damas S (2014a) Study on the criteria for assessing skull-face correspondence in craniofacial superimposition. Technical Report AFE 19. European Centre for Soft Computing, Spain

Ibáñez O, Vicente R, Navega DS, Wilkinson C, Jayaprakash PT, Huete MI, Briers TM, Hardiman R, Navarro F, Ruiz E, Cavalli F, Imaizumi K, Jankauskas R, Veselovskaya E, Abramov A, Lestón P, Molinero F, Cardoso J, Cagdir J, Humpire D, Nakanishi Y, Zeuner A, Ross AH, Gaudio D, Damas S (2014b) Study on the performance of different craniofacial superimposition approaches (I). Technical Report AFE 18. European Centre for Soft Computing, Spain

Ibáñez O, Cavalli F, Campomanes-Álvarez BR, Campomanes-Álvarez C, Valsecchi A, Huete MI (2015) Ground truth data generation for skull-face overlay. Int J Legal Med 129:569-581

Ichikawa K (1975) Morphological relationships between nose breadth and aperture piriformis on the view point of face type. Rep Natl Inst Police Sci 28:133-136

Ikeuchi K, Sato Y (2001) Modeling from reality. In: Springer (ed). The Kluwer International Series, US

Inada E, Saitah I, Hayasaki H, Iwase Y, Kubota N, Tokemoto Y, Yamada C, Yamasaki Y (2009) Relationship of nasal and skeletal landmarks in lateral cephalograms of preschool children. Forensic Sci Int 191:111.e1-111.e4

Indriati E (2009) Historical perspectives on forensic anthropology in Indonesia. In: Blau S, Ubelaker DH (eds) Handbook of forensic anthropology and archaeology. Left Coast Press

Ishii M, Yayama K, Motani H et al (2011) Application of superimposition based personal identification using skull computed tomography images. J Forensic Sci 56:960-966

İşcan MY (1993) Introduction of techniques for photographic comparison: potential and problems. In: Iscan MY, Helmer R (eds) Forensic analysis of the skull. Wiley, New York

İşcan MY (2005) Forensic anthropology of sex and body size. Forensic Sci Int 147:107-112

İşcan MY, Solla HE, McCabe BQ (2005) Victim of a dictatorial regime: identification of Mr. Roberto Gomensoro Josman. Forensic Sci Int 151:213-220

Iten P (1987) Identification of skulls by video superimposition. J Forensic Sci 32:173-188

Jacob B, Alt KW (1995) Advances in forensic sciences: forensic odontology and anthropology, vol 7, in cooperation with K. W. Alt, P. Pieper. Köster, Berlin

Janssens PA, Hansch CF, Voorhamme LL (1978) Identity determination by superimposition with anthropological cranium adjustment. Int J Skelet Res 5:109-122 
Jayaprakash PT, Srinivasan GJ, Amravaneswaran MG (2001) Cranio-facial morphanalysis: a new method for enhancing reliability while identifying skulls by photo superimposition. Forensic Sci Int 117:121-143

Jayaprakash P, Singhb B, Yusopc RAA, Susilawati H (2010) Skull-photo superimposition: a remedy to the problem of unidentified dead in Malaysia. Malays J Forensic Sci 1:35-42

Keen PG, Morton MS (1978) Decision support systems: an organizational perspective. AddisonWesley, Reading, MA

Klonaris NS, Furue T (1980) Photographic superimposition in dental identification - is a picture worth 1000 words. J Forensic Sci 25:859-865

Knußmann RE (1988) Anthropologie I. Stuttgart

Koch R, Gonzales A, Witt E (1979) Profile and soft tissue changes during and after orthodontic treatment. Eur J Orthod 1:6

Koelmeyer TD (1982) Videocamera superimposition and facial reconstruction as an aid to identification. Am J Forensic Med Pathol 3:45-48

Kollmann J, Buchly W (1898) Die Persistenz der Rassen und die Reconstruction der Physiognomie prahistorischer Schadel. Archives fur Anthropologie 25:329-359

Krogman WM, İşcan MY (1986) The human skeleton in forensic medicine. Charles C. Thomas, Springfield

Kumari T, Chandra Sekharan P (1992) Remote control skull positioning device for superimposition studies. Forensic Sci Int 54:127-133

Laguna M, Martí R (2003) Scatter search: methodology and implementations in C. Springer

Lan Y (1990) Research report on model TLGA-213 image superimposition identification system. Special issue on criminal technology supplement. The Fifth Bureau of the National Public Security Department, Beijing, China, 13

Lan Y (1992) Development and current status of skull image superimposition methodology and instrumentation. Forensic Sci Rev 4:126-136

Lan Y (1995) A study on national differences in identification standards for Chinese skull-image superimposition. Forensic Sci Int 74:135-153

Lan Y, Cai D (1985) Study on model TLGA-1 skull identification apparatus. Special issue on criminal technology supplement. The Fifth Bureau of the National Public Security Department, 3

Lan Y, Cai D (1988) A new technology in skull identification. In: Helmet R (ed) Advances in skull identification via video superimposition. Kiel

Lan Y, Cai D (1993) Technical advances in skull-to photo superimposition. In: Iscan MY, Helmer RP (eds) Forensic analysis of the skull. Wiley-Liss, New York

Landa MI, Garamendi PM, Botella MC, Alemán I (2009) Application of the method of Kvaal et al. to digital orthopantomograms. Int J Legal Med 123:123-128

Leopold IH (1968) Trends in ocular therapy. Am J Ophthalmol 65:297-317

Maat G (1989) The positioning and magnification of faces and skulls for photographic superimposition. Forensic Sci Int 41:225-235

Macho GA (1986) An appraisal of plastic reconstruction of the external nose. J Forensic Sci 31:1391-1403

Manhein MH, Listi GA (2000) In vivo facial tissue depth measurements for children and adults. J Forensic Sci 45:48-60

Martin R (1914) Lehrbuch der Anthropologie in sistematischer Darstellung. Gustav Fischer, Jena

Martin R, Saller K (1957) Lehrbuch der Anthropologie in systematischer Darstellung mit besonderer Berücksichtigung der anthropologischen Methoden. Gustav Fischer, Jena

Martin R, Saller K (1966) Lehrbuch der Anthropologie in Sistematischer Darstellung (in German). Gustav Fischer Verlag, Stuttgart

McClintock Robinson J, Rinchose D, Zullo TG (1986) Relationship of skeletal pattern and nasal form. Am J Orthod Dentofac Orthop 89:7

McKenna J (1988) A method of orientation of skull and camera for use in forensic photographic investigation. J Forensic Sci 33:751-755 
McKenna J, Jablonski NG, Fearnhead R (1984) A method of matching skulls with photographic portraits using landmarks and measurements of the dentition. J Forensic Sci 29:787-797

Menezes M, Rosati R, Allievi C, Sforza C (2009) A photographic system for the three-dimensional study of facial morphology. The Angle Orthodontist 79:1070-1077

Merkel F (1886) Der musculus superciliaris. Anat Anz:11

Mitchell T (1997) Machine learning. McGraw Hill, New York

Miyasaka S (1987) Progress in facial reconstruction technology. J Forensic Sci 32:1305-1330

Nakasima A, Terajima M, Mori N, Hoshino Y, Tokumori K, Aoki Y, Hashimoto S (2005) Threedimensional computer-generated head model reconstructed from cephalograms, facial photographs, and dental cast models. Am J Orthod Dentofac Orthop 127:282-292

Nanda RS, Meng H (1990) Growth changes in the soft tissue facial profile. The Angle Orthodontist 60:177-190

Navarro-Merino FJ (2011) Superposición craneofacial para identificación humana. Un estudio en población mediterránea. University of Granada

Nickerson B, Fitzhorn P, Koch S, Charney M (1991) A methodology for near-optimal computational superimposition of two-dimensional digital facial photographs and three-dimensional cranial surface meshes. J Forensic Sci 36:480-500

Ogawa H (1960) Anatomical study on the Japanese head by X-ray cephalometry. J Tokyo Dental College Soc 60:17-34

Panenková P (2007) Face approximation and information about facial soft tissue thickness. In: Association EA (ed) Summer School of the European Anthropological Association, Prague, pp 233-239

Paredis J (1995) Coevolutionary computation. Artif Life 2:355-375

Pearson K, Morant GM (1934) The Wilkinson head of Oliver Cromwell and its relationship to busts, masks and painted portraits. Biometrika 26:1-116

Pesce Delfino V, Colonna M, Vacca E, Potente F, Introna F (1986) Computer-aided skull/face superimposition. Am J Forensic Med Pathol 7:201-212

Pesce Delfino V, Vacca E, Potente F, Lettini T, Colonna M (1993) Shape analytical morphometry in computer-aided skull identification via video superimposition. Wiley, New York

Phillips V, Smuts N (1996) Facial reconstruction: utilization of computerized tomography to measure facial tissue thickness in a mixed racial population. Forensic Sci Int 83:51-59

Pickering RB, Bachman DC (2012) The use of forensic anthropology. CRC Press, Boca Raton, FL

Powell N, Humphreys B (1984) Proportions of the aesthetic face. Thieme-Stratton, New York

Preedy VR (2012) Handbook of anthropometry: physical measures of human form in health and disease. Springer

Prinsloo I (1953) The identification of skeletal remains in Regina versus K and another: the Howick Falls murder case. J Forensic Med 1:11-17

Prokopec M, Ubelaker D (2002) Reconstructing the shape of the nose according to the skull. Forensic Sci Commun:4

Puech PF, Puech B, Tichy G (1989) Identification of the cranium of WA Mozart. Forensic Sci Int 41:101-110

Pushparani C, Ravichandran C, Sivakumari K (2012) Radiography superimposition in personal identification-a case study involving surgical implants. J Forensic Res 3(2)

Ranson DL (2009) Legal aspects of identification. In: Blau S, Ubelaker DH (eds) Handbook of forensic anthropology and archaeology. Left Coast Press

Rathbun TA (1984) Personal identification: facial reproductions. In: Rathbun T, Buikstra J (eds) Human identification: case studies in forensic anthropology. Springfield, IL, Charles C Thomas

Reddy K (1973) Identification of dismembered parts: the medicolegal aspects of the Nagaraju case. Forensic Sci 2:351-374

Renwick N (2012) Ear lobe morphology and its relationship to the mastoid process. Centre for Anatomy and Human Identification, University of Dundee, Dundee. AXIS: The Online Journal of CAHId, 12

Rhine S (1983) Tissue thickness for South-western Indians. New Mexico 
Rhine JS, Campbell HR (1980) Thickness of facial tissues in American blacks. J Forensic Sci 25:847-858

Rhine JS, Moore CE, Weston JT (1982) Facial reproduction: tables of facial tissue thickness of American caucasoids in forensic anthropology. Albuquerque University of New Mexico

Ricci A, Marella GL, Apostol MA (2006) A new experimental approach to computer-aided face/ skull identification in forensic anthropology. Am J Forensic Med Pathol 27:46-49

Richtsmeier JT, Paik CH, Elfert PC, Cole TM III, Dahlman HR (1995) Precision, repeatability, and validation of the localization of cranial landmarks using computed tomography scans. Cleft Palate Craniofac J 32:217-227

Roos N (1977) Soft-tissue profile changes in class II treatment. Am J Orthod Dentofac Orthop 72:165-175

Rosenstein T, Talebzadeh N, Pogrel MA (2000) Anatomy of the lateral canthal tendon. Oral Surg Oral Med Oral Pathol Oral Radiol Endodontol 89:24-28

Ross AH (2004) Use of digital imaging in the identification of fragmentary human skeletal remains: a case from the Republic of Panama. Forensic Sci Commun 6

Rudee D (1964) Proportional profile changes concurrent with orthodontic therapy. Am J Orthod Dentofac Orthop 50:13

Rumelhart DE, McClelland D (1986) Parallel distributed processing: explorations in the microstructure of cognition. MIT Press, Cambridge, MA

Rynn C (2006) Craniofacial approximation and reconstruction: tissue depth patterning and the prediction of the nose. Dundee

Rynn C, Wilkinson CM (2006) Appraisal of traditional and recently proposed relationships between the hard and soft dimensions of the nose in profile. Am J Phys Anthropol 130(3):364-373

Rynn C, Wilkinson CM, Peters HL (2010) Prediction of nasal morphology from the skull. Forensic Sci Med Pathol 6:20-34

Rynn C, Balueva T, Veselovskaya E (2012) Relationships between the skull and face. In: Wilkinson C, Rynn C (eds) Craniofacial identification. Cambridge University Press, Cambridge

Sahni D (2002) Preliminary study on facial soft tissue thickness by magnetic resonance imaging in Northwest Indians. Forensic Sci Commun 4

Sahni D, Sanjeev D, Singh I, Singh P (2008) Facial soft tissue thickness in northwest Indian adults. Forensic Sci Int 176:137-146

Saks MJ (2010) Forensic identification: from a faith-based "Science" to a scientific science. Forensic Sci Int 20:14-17

Santamaría J, Cordón O, Damas S (2007a) Evolutionary approaches for automatic 3D modeling of skulls in forensic identification. Applications of evolutionary computing. Springer

Santamaría J, Cordón O, Damas S, Alemán I, Botella M (2007b) A scatter search-based technique for pair-wise 3D range image registration in forensic anthropology. Soft Comput 11:819-828

Santamaría J, Cordón O, Damas S, García-Torres JM, Quirin A (2009a) Performance evaluation of memetic approaches in 3D reconstruction of forensic objects. Soft Comput 13:883-904

Santamaría J, Cordón O, Damas S, Ibáñez O (2009b) Tackling the coplanarity problem in 3D camera calibration by means of fuzzy landmarks: a performance study in forensic craniofacial superimposition. In: IEEE 12th International Conference on Computer Vision Workshops, pp 1686-1693

Saxena T, Ramchandra P, Sangamesh NC, Choudhary A, Aggarwal A, Yadav N (2012) Facial soft tissue thickness in North Indian adult population. J Ind Acad Oral Med Radiol 24:121-125

Schuliar Y, Knudsen PJ (2012) Role of forensic pathologists in mass disasters. Forensic Sci Med Pathol 8:164-173

Schultz AH (2005) The metopic fontanelle, fissure, and suture. Am J Anat 44:24

Scully B, Nambiar P (2002) Determining the validity of Furue's method of craniofacial superimposition for identification. Malays J Comput Sci 9:17-22

Sekharan PC (1971) Revised superimposition technique for identification of the individual from the skull and photograph. J Crim Law Criminol Police Sci 62:107 
Sekharan PC (1988) Video superimposition technology practised. In: Helmet R (ed) Advances in skull identification via video superimposition. Kiel

Sekharan PC (1993) Positioning the skull for superimposition. In: Iscan MY, Helmer RP (eds) Forensic analysis of the skull. Willey-Liss, New York, pp 105-118

Selzter A (1944) The nasal septum: plastic repair of the deviated septum associated with a deflected tip. Arch Otolaryngol 40:10

Sen N (1962) Identification by superimposed photographs. Int Crim Police Rev 162:284-286

Seta S, Yoshino M (1993) A combined apparatus for photographic and video superimposition. In: Iscan MY, Helmer RP (eds) Forensic analysis of the skull. Wiley-Liss, New York

Shahrom A, Vanezis P, Chapman R, Gonzales A, Blenkinsop C, Rossi M (1996) Techniques in facial identification: computer-aided facial reconstruction using a laser scanner and video superimposition. Int J Legal Med 108:194-200

Sills F (2004) Craniosacral biodynamics: the primal midline and the organization of the body. North Atlantic Books, USA

Simpson K (1943) Rex v. Dobkin: the baptist church cellar murder. Medico-Legal Soc Trans 11:132-145

Simpson E, Henneberg M (2002) Variation in soft-tissue thicknesses on the human face and their relation to craniometric dimensions. Am J Phys Anthropol 118:121-133

Singare S, Lian Q, Wang WP, Wang J, Liu Y, Li D, Lu B (2009) Rapid prototyping assisted surgery planning and custom implant design. Rapid Prototyp J 15:19-23

Sinha P (1998) A symmetry perceiving adaptive neural network and facial image recognition. Forensic Sci Int 98:67-89

Sivaram S, Wadhera CK (1975) Identity from skeleton-A case study. Forensic Sci 5:166

Smeets D, Claes P, Vandermeulen D, Clement J (2010) Objective 3D face recognition: evolution, approaches and challenges. Forensic Sci Int 201:7

Sognnaes RF (1980) Hitler and Bormann identifications compared by postmortem craniofacial and dental characteristics. Am J Forensic Med Pathol 1:105-115

Solla HE, Iscan MY (2001) Skeletal remains of Dr. Eugenio Antonio Berrìos Sagredo. Forensic Sci Int 116:201-211

Stadtmuller F (1925) Zur Beurteilung der Plastischen Rekonstruktions-Methods der Physiognomie auf dem Schadel. Zeitschrift Fur Morphologic und antropologie 22:35

Stephan CN (2002) Facial approximation: globe projection guideline falsified by exophthalmometry literature. J Forensic Sci 47:730-735

Stephan CN (2009) Craniofacial identification: techniques of facial approximation and craniofacial superimposition. In: Blau S, Ubelaker DH (eds) Handbook of forensic anthropogy and archeaology. Left Coast Press, Walnut Creek, CA

Stephan CN, Davidson PL (2008) The placement of the human eyeball and canthi in craniofacial identification. J Forensic Sci 53:612-619

Stephan CN, Murphy SJ (2008) Mouth width prediction in craniofacial identification: cadaver tests of four recent methods, including two techniques for edentulous skulls. J Forensic OdontoStomatol 26:2-7

Stephan CN, Simpson EK (2008) Facial soft tissue depths in craniofacial identification (part I): an analytical review of the published adult data. J Forensic Sci 53:1257-1272

Stephan CN, Henneberg M, Sampson W (2003) Predicting nose projection and pronasale position in facial approximation: a test of published methods and proposal of new guidelines. Am J Phys Anthropol 122:240-250

Stewart TD (1983) The points of attachment of the palpebral ligaments: their use in facial reconstructions on the skull. J Forensic Sci 28:5

Stratmann H (1998) Excuses for the truth [Online]. http://home.wxs.nl/ loz/maneng.htm

Subtelny JD (1959) Intelligibility and associated physiological factors of cleft palate speakers. J Speech Lang Hear Res 2:353-360

Sutton PR (1969) Fissured fractures: 2,501 transverse crack lines in permanent incisors. Aust Dent J 14:18-21 
Suzuki K (1948) On the thickness of soft part of the Japanese face. J Anthropol Soc Nippon 60:4 Takač Š, Pilija V (2012) Exclusion of identification by negative superposition. Glasnik Antropološkog društva Srbije:311-316

Talass MF, Talass L, Baker RC (1987) Soft-tissue profile changes resulting from retraction of maxillary incisors. Am J Orthod Dentofac Orthop 91:385-394

Tandler J (1909) Über den Schädel Haydns. Mitteilungen der Anthropologie Gesellschaft Wien 39:20

Tao C (1986) Report on computer programming for model TLGA-1 skull identification. Special issue on criminal technology supplement. The Fifth Bureau of the National Public Security Department. Beijing, China, 41

Taylor JA, Brown KA (1998) Superimposition techniques. In: Clement JG, Ranson DL (eds) Craniofacial identification in forensic medicine. Hodder Arnold, London

Tedeschi-Oliveira SV, Melani RF, Hadded de Almeida N, Saavedra de Paiva LA (2009) Facial soft tissue thickness of Brazillian adults. Forensic Sci Int 193:127.e1-127.e7

Teixeira WR (1985) The Mengele report. Am J Forensic Med Pathol 6:279-283

The Scientific Working Group for Forensic Anthropology, S (2012a) Code of ethics and conduct

The Scientific Working Group for Forensic Anthropology, S (2012b) Personal identification

The Scientific Working Group for Forensic Anthropology, S (2012c) Facial approximation

Ubelaker DH, Bubniak E, O’Donnell G (1992) Computer-assisted photographic superimposition. J Forensic Sci 37:750-762

Ullrich H, Stephan CN (2011) On Gerasimov's plastic facial reconstruction technique: new insights to facilitate repeatability. J Forensic Sci 56:470-474

Urquiza M, Botella M, Ciges M (2005) Study of a temporal bone of homo heidelbergensis. Acta Otolaryngol 125:457-463

Utsuno H, Kageyama T (2005) Facial soft tissue thickness in Japanese female children. Forensic Sci Int 152:101-107

van der Pluym J, Shan WW, Taher Z, Beaulieu C, Plewes C (2007) Use of magnetic resonance imaging to measure facial soft tissue depth. Cleft Palate Craniofac J 44:52-57

Virchow H (1912) Die anthropologische Untersuchung der Nase. Zeitschrift fur Ethnologie 44:48

Vogel G (1968) Zur Identifizierung unbekannter Toter. Kriminalistik 4:187-189

von Eggeling H (1909) Anatomische untersuchungenan den Kopfen con cier Hereros, einem Herero- und einem Hottentottenkind. In: Schultze L (ed) Forschungsreise im westrichen und zentraien Sudafrika. Denkschriften, Jena

Waldman BH (1982) Change in lip contour with maxillary incisor retraction. Angle Orthod $52: 129-134$

Weaver DF, Bellinger DH (1946) Bifid nose associated with midline cleft of the upper lip. Arch Otolaryngol Head Neck Surg 44:480-482

Webster G (1955) Photography as an aid identification: the plumbago Pit case. Police J 28:185-191

Webster W, Murray W, Brinkhous W, Hudson P (1986) Identification of human remains using photographic reconstruction. In: Kathleen JR (ed) Forensic osteology: advances in the identification of humans remains. Charles C Thomas, Springfield, IL

Weinig E (1958) Die Nachweisbarkeit von Giften in exhumierten Leichen. Deutsche Zeitschrift für die gesamte gerichtliche Medizin 47:19

Welcker H (1883) Schiller's Schadel und Todtenmaske, nebst Mittheilungen uber Schadel und Todtenmaske Kant's. Viehweg F and Son, Braunschweig

Whitnall SE (1921) Anatomy of the eye and orbit. Oxford Medical Publication, Oxford

Wilkinson C (2002) In vivo facial tissue depth measurements for white British children. J Forensic Sci 47:459-465

Wilkinson C (2004) Facial approximation: comments on Stephan (2003). Am J Phys Anthropol 125:329-330

Wilkinson C (2006) Facial anthropology and reconstruction. In: Thompson T, Black S (eds) Forensic human identification. CRC Press, Boca Ratón 
Wilkinson C (2009) 13th Meeting of international association of craniofacial identification. Forensic Sci Med Pathol 5:1-1

Wilkinson C, Mautner SA (2003) Measurement of eyeball protrusion and its application in facial reconstruction. J Forensic Sci 48:12-16

Williamson MA, Nawrocki SP (2002) Variation in midfacial tissue thickness of African-American children. J Forensic Sci 47:25-31

Wolff E (1976) Eugene Wolff's anatomy of the eye and orbit: including the central connexions, development, and comparative anatomy of the visual apparatus. Saunders, London

Yoshino M (2012) Craniofacial superimposition. In: Wilkinson CM, Rynn C (eds) Craniofacial identification. Cambridge University Press, Cambridge, pp 238-253

Yoshino M, Seta S (1989) Personal identification of the human skull: superimposition and radiographic techniques. Forensic Sci Rev I:19

Yoshino M, Seta S (2000) Skull-photo superimposition. Encyclopedia Forensic Sci 2:807-815

Yoshino M, Imaizumi K, Miyasaka S, Seta S (1995) Evaluation of anatomical consistency in craniofacial superimposition images. Forensic Sci Int 74:125-134

Yoshino M, Matsuda H, Kubota S, Imaizumi K, Miyasaka S, Seta S (1997) Computer-assisted skull identification system using video superimposition. Forensic Sci Int 90:231-244

Zadeh LA (1965) Fuzzy sets. Inf Cont 8:338-353

Zitova B, Flusser J (2003) Image registration methods: a survey. Image Vis Comput 21:977-1000 